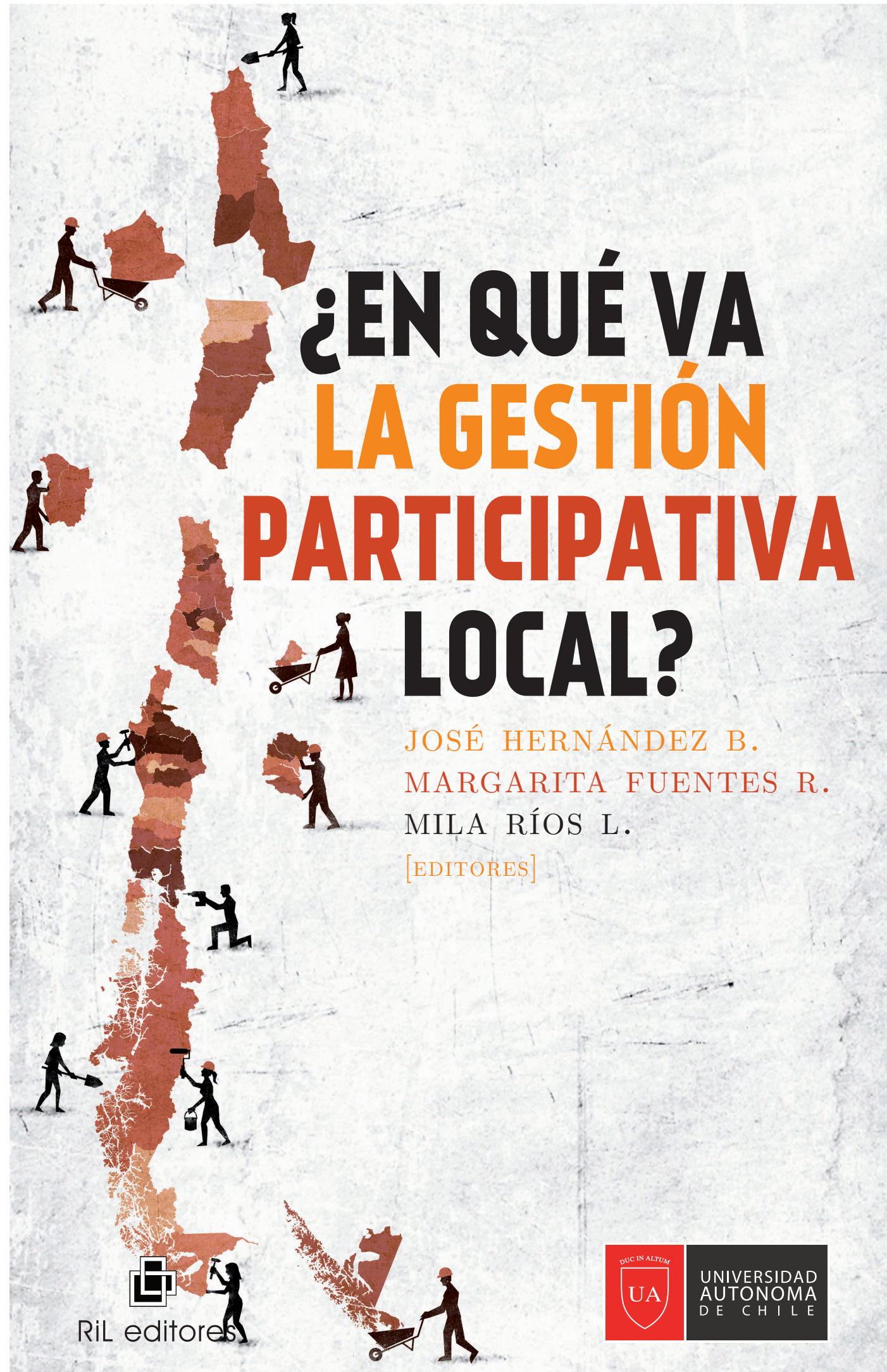




¿En Qué va la Gestión Participativa Local? 



\author{
José Hernández Bonivento \\ Margarita Fuentes Romero \\ Mila Ríos Lemus \\ (EDITORES)
}

\title{
¿EN QUÉ VA LA \\ Gestión Participativa \\ LOCAL?
}

\author{
Análisis e implementación \\ de mecanismos de participación ciudadana \\ en la gestión pública local chilena
}


352.I4 Hernández Bonivento, José

$\mathrm{H} \quad ¿$ En qué va la Gestión Participativa Local? Análisis e implementación de mecanismos de participación ciudadana en la gestión pública local chilena / José Hernández Bonivento, Margarita Fuentes Romero, Mila Ríos Lemus, editores. - - Santiago : RIL editores

- Universidad Autónoma de Chile, 2019.

258 p. ; $23 \mathrm{~cm}$.

ISBN: 978-956-OI-0673-5

1 GOBIERNO LOCAL-CHILE. 2. GOBIERNO LOCAL-CHILEPARTICIPACIÓN CIUDADANA.

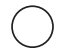

¿EN Qué VA La Gestión Participativa Local?

ANÁlisis E IMPLEMENTACIÓN DE MECANISMOS DE PARTICIPACIÓN CIUDADANA EN LA GESTIÓN PÚBLICA LOCAL CHILENA

Primera edición: mayo de 2019

(C) J. Hernández B., M. Fuentes R., M. Ríos L., 2019

Registro de Propiedad Intelectual

$\mathrm{N}^{\mathrm{o}} 30 \mathrm{I} .228$

(C) RIL® editores, 2019

Sede Santiago:

Los Leones 2258

CP 75 I I055 Providencia

Santiago de Chile

(j) (56) 222238 I00

ril@rileditores.com • www.rileditores.com

Sede Valparaíso:

Cochrane 639, of. 92

CP 236I80I Valparaíso

(D) (56)322746203

valparaiso@rileditores.com

Sede España:

europa@rileditores.com • Barcelona

(C) Centro de Comunicación de las Ciencias, 2019

Universidad Autónoma de Chile

https://ciencias.uautonoma.cl I ciencias@uautonoma.cl

ISBN Universidad Autónoma 978-956-8454-28-9

Composición e impresión: RIL® editores

Diseño de portada: Matías González Pereira

Impreso en Chile $\bullet$ Printed in Chile

ISBN 978-956-OI-0673-5

Derechos reservados. 


\section{ÍNDICE}

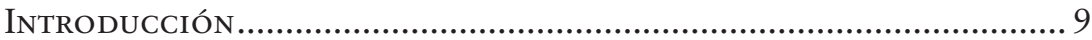

PRIMERA PARTE:

Visiones SOBRE LA PARTICIPACIÓN CIUDADANA EN CHILE

Descentralización y participación ciudadana

¿Es determinante la descentralización para el fortalecimiento

democrático a escala regional? El caso de la Región de Los Ríos

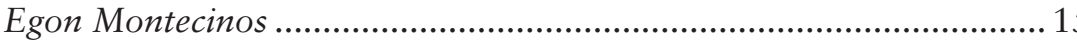

La participación ciudadana en Chile

Francis Elizabeth Valverde Mosquera .............................................. 37

Propuesta de modelo de gobierno

abierto municipal para Chile

Consejo para la Transparencia............................................................... 53

\section{Segunda PARTE: \\ Mecanismos de Participación Ciudadana en Chile}

Los presupuestos participativos

Bernardo Navarrete Yáñez

Consejo comunal de organizaciones de la sociedad civil

COSOC... ¿Real promotor de la participación

ciudadana en el espacio local?

Mila Ríos Lemus

Cartas de servicio. Una herramienta de participación ciudadana para la mejora de los servicios municipales en Chile.

Experiencia de la Subdere

Marcelo Rojas Belmar 
Avances y desafíos de los fondos

de desarrollo vecinal FONDEVE

Margarita Fuentes

\author{
TERCERA PARTE: \\ Buenas prácticas de Gestión Participativa Municipal
}

Municipalidad de Nacimiento.

Experiencia presupuestos participativos 2017-2018

Mariela Muñoz.

Directorio urbano de Coyhaique:

hacia una participación eficiente

Juan Carmona.

Escuela abierta:

una herramienta transformadora

Gianinna Repetti Lara, Alejandra Placencia Cabello 163

Programa Congreso Infantil.

Municipalidad de Temuco

Departamento Comunitario y Vecinal.....

CUARTA PARTE:

EXPERIENCIAS DESDE LA SOCIEDAD Civil PARA

la Participación Ciudadana

Promoción de la participación ciudadana a nivel local desde las bibliotecas públicas en Chile: aprendizajes del programa

Biblioacción Ciudadana

Juan Fernández Labbé.

ABRE: la colaboración en el centro de la gestión municipal Manuel Barros Riveros.

Gestión municipal y empresas:

hacia un nuevo modelo de gobernanza

Rodrigo Soto Cuevas, Gonzalo Vial Luarte. 


\section{INTRODUCCIÓN}

Han pasado décadas desde que la idea de un gobierno más centrado en la ciudadanía tomara vuelo en la región, transformando instituciones, generando marcos legales y consolidando incentivos para fomentar el involucramiento ciudadano en la toma de decisiones. De la mano con los procesos de democratización y descentralización, la participación ciudadana se empezó a considerar un punto esencial y fundamental de nuestra vida republicana, y en toda América Latina se empezaron a evidenciar avances importantes, que contrastaron con nuestra historia llena de autoritarismos.

Pero esta llamada "revolución silenciosa» de los gobiernos locales de la región no se encuentra libre de problemas. Por una parte, las expectativas creadas han sido muy altas, generando no poca frustración en las personas: recordemos que no hace mucho tiempo, y gracias al «efecto Porto Alegre» y sus presupuestos participativos, algunos académicos llegaron a señalar la caída de la democracia representativa y el ascenso de un nuevo Contrato Social, basado en la democracia participativa. Aunque este tipo de mecanismos participativos han alcanzado fama internacional, son pocos los que siguen pensando que la participación es algo más que un complemento a los sistemas tradicionales de gobierno.

Otro punto que suele surgir en los debates sobre la participación ciudadana es el excesivo formalismo y la poca incidencia de los participantes en la toma de decisiones. En efecto, el desarrollo de mecanismos de participación institucionales se ha realizado, en su totalidad, en una lógica de "arriba hacia abajo», donde se le exige al ciudadano asumir los costos de la participación, pero sin comprometerse a que su opinión sea tomada en cuenta a la hora de decidir.

El caso chileno nos es explicativo tanto del ascenso de la idea participativa como de la frustración originada por las falsas 
expectativas. Luego de años de debate y discusión, en 2011 surgió la Ley de Asociaciones y Participación Ciudadana en la Gestión Pública (Ley 20.500), la cual buscaba ser la piedra angular para la construcción de una sociedad participativa y una administración abierta a los ciudadanos. Pero sin haber cumplido una década desde su promulgación, ya existen discusiones de reforma y hasta conceptos establecidos por comisiones presidenciales para cambiar y mejorar dicho marco legal.

Con el ánimo de aportar en esta discusión, cada vez más importante para Chile en un contexto de desafección política e institucional, presentamos en este libro los resultados de un arduo trabajo colectivo entre académicos, funcionarios públicos y actores de la sociedad civil, que busca analizar y dar cuenta tanto de vacíos como de avances en materia de participación ciudadana en la gestión pública local.

El libro cuenta de cuatro partes. En la primera, compuesta por tres capítulos, se presentan tres visiones sobre la participación ciudadana y los niveles locales de gobierno en Chile. El primero de ellos es un trabajo realizado por Egon Montecinos (UACH), quien desde su experiencia académica y práctica de gestión como intendente de la Región de Los Ríos nos presenta un breve acercamiento a la temática, además de relatarnos una experiencia de presupuestos participativos a nivel regional, tan importante en estos tiempos de cambios institucionales a dicho nivel de gobierno. A punto seguido contamos con una visión más crítica, otorgada por Francis Valverde desde las organizaciones de la sociedad civil, sobre la situación actual de la participación ciudadana en Chile, aspecto que debiera ser parte de cualquier debate sobre el tema en el país. Termina esta sección con una nueva iniciativa, propuesta por el Consejo para la Transparencia, que busca complementar no solo el área de participación ciudadana, sino su articulación con los temas de transparencia y acceso a la información para consolidar un modelo de gobierno abierto a nivel municipal en Chile, poniendo de manifiesto la importancia de la innovación para el mejoramiento de la interacción entre ciudadanos y administraciones locales. 
La segunda parte del libro se dedica a revisar los mecanismos de participación ciudadana con mayor relevancia en la legislación actual chilena. Iniciamos con el capítulo que escribe Bernardo Navarrete (USACH) sobre los presupuestos participativos, elaborando un análisis profundo sobre estos mecanismos a nivel latinoamericano, y presentando algunos puntos interesantes para tener en cuenta al momento de generar dichas estrategias. Un segundo capítulo, elaborado por Mila Ríos (UC - Subdere), da cuenta de los Consejos Comunales de las Organizaciones de la Sociedad Civil (COSOC), un mecanismo central para la legislación actual pero que ha sido blanco de muchas críticas por su formalidad y sus alcances, buscando así poner en evidencia los desafíos de este central mecanismo. Sigue un tercer capítulo sobre las Cartas de Servicio, una nueva estrategia establecida por la Subsecretaría de Desarrollo Regional (Subdere) de la que da cuenta Luis Marcelo Rojas, profesional de dicha entidad en la sección de municipalidades, y que señala la posibilidad de generar acuerdos ciudadanos sobre servicios públicos a nivel municipal. Por último, se detalla el análisis sobre los Fondos de Desarrollo Vecinal (FONDEVE), estrategias de financiamiento y subsidio para organizaciones sociales territoriales, realizado por Margarita Fuentes (ICHEM - UA), donde se detallan tanto las fortalezas como los desafíos más grandes de este marcado vínculo entre las municipalidades, los concejos comunales y la ciudadanía.

Para la tercera parte hemos querido involucrar a funcionarios municipales, encargados y protagonistas de la implementación de la legislación en los territorios, para que sacaran un espacio de sus apretadas agendas y se animaran a contarnos, de primera mano, las experiencias que han desarrollado en sus comunas. Aquí se recogen las experiencias de presupuestos participativos de Nacimiento, la Mesa Urbana de Coyhaique, la Escuela Abierta de Recoleta y el Congreso Infantil de Temuco, todas ellas iniciativas propias que demuestran cómo la voluntad política puede ser la diferencia entre el cumplimiento formal y la implementación real de los espacios creados por la legislación nacional. 
Por último, presentamos tres iniciativas que han surgido de la sociedad civil, y que buscan establecer lazos de cooperación y colaboración para alcanzar metas de beneficio social y colectivo a nivel municipal. Recogemos aquí la iniciativa de acompañamiento y sistematización realizada por el Centro Latinoamericano para el Desarrollo Social, RIMISP, del proyecto Biblioacción Ciudadana, presentada por su investigador Juan Fernández Labbé, donde da cuenta de una necesidad manifiesta para la gestión participativa local: la creación de capacidades y la educación cívica para el desarrollo de los derechos sociales en las nuevas generaciones. Un segundo capítulo habla del proyecto ABRE, desarrollado por la Fundación Ciudadano Inteligente y presentado por Manuel Barros (FCI), donde se expone un modelo para la construcción de capacidades y la generación de programas de participación ciudadana vinculante a nivel municipal. Por último, el capítulo desarrollado por Gonzalo Vial presenta la experiencia de la Fundación Huella Local, organización social que busca generar lazos de colaboración entre municipalidades de bajos recursos y empresas privadas para alcanzar metas de desarrollo local que impacten a quienes más lo necesitan.

Todos estos capítulos buscan plantear puntos de vista que parten de la experiencia real, y que intentan dejar de lado tanto las altas expectativas como el excesivo optimismo que rodea la participación ciudadana, para centrarse en los avances y desafíos del marco institucional como de la implementación de estrategias de involucramiento ciudadano. Lejos de intentar con esto abarcar exhaustivamente el tema de la democratización de la gestión pública, nuestro interés ha sido renovar una discusión sobre las ventajas y desventajas de la participación ciudadana, donde se observen tanto las críticas como las potencialidades de una ley que, más que una finalidad en sí misma, debe ser concebida como una vía para alcanzar metas de beneficio colectivo por nuestras municipalidades y gobiernos regionales.

LOS EDITORES, Santiago, octubre de 2018 


\section{PRIMERA PARTE: \\ VISIONES SOBRE LA PARTICIPACIÓN CIUDADANA EN CHILE}





\title{
DESCENTRALIZACIÓN \\ Y PARTICIPACIÓN CIUDADANA \\ ¿ES DETERMINANTE LA DESCENTRALIZACIÓN \\ PARA EL FORTALECIMIENTO DEMOCRÁTICO \\ A ESCALA REGIONAL? \\ El caso de la Región de Los Ríos
}

\author{
Egon Montecinos \\ Universidad Austral de Chile
}

\section{INTRODUCCIÓN}

La discusión sobre la relación entre descentralización y democracia trae consigo diversas hipótesis. Una de ellas plantea que distribuir poder detonaría procesos democráticos a escala regional o local, es decir, traería consigo más participación ciudadana, más empoderamiento de territorios y mayor visibilidad de los sectores excluidos al interior de una región. En la literatura científica, no existe evidencia concluyente que sostenga dicho planteamiento, dado que la descentralización, sobre todo en su dimensión política, es un factor interviniente, mas no exclusivamente determinante para detonar procesos democráticos a escala local. En este artículo se explora esta relación tomando el caso de Chile, el cual es un país altamente centralizado y que hasta el año 2020 sus autoridades regionales serán designadas y no electas por la ciudadanía. Para desarrollar este argumento se toma como referencia el caso de la región de Los Ríos, en la cual se impulsó entre el año 2014 y 2017 una iniciativa de presupuesto participativo a escala regional. A partir del estudio de esta inédita 
iniciativa en Chile, se espera responder a la pregunta: ¿Cuáles son los factores más influyentes para detonar procesos democráticos y participativos en países con procesos restringidos de descentralización como Chile? Se espera responder y argumentar esta pregunta para identificar aquellos factores que podrían ser determinantes para el futuro proceso de descentralización que vivirá el país.

Se sostiene que ante niveles similares de centralismo/descentralización en regiones, además de la voluntad política regional para dar origen a la iniciativa, será el capital social y capital cívico existente en un territorio (sea este región, provincia o comuna), el determinante para que instrumentos y mecanismos democráticos se mantengan sin necesidad de ser detonados producto de mayores atribuciones o más descentralización desde el nivel central de gobierno hacia los gobiernos regionales.

El presupuesto participativo regional implementado en la región de Los Ríos es una iniciativa que no surge a raíz de una política pública nacional de participación ciudadana, ni producto de las políticas de descentralización impulsadas desde el gobierno, sino que surge el año 2014 como una iniciativa exclusivamente regional. De ahí entonces que permite evaluar las condicionantes fundamentales para su desarrollo, en contextos de elevado centralismo administrativo, político y fiscal como es el caso de Chile.

El capítulo se estructura de la siguiente manera. En una primera parte se entregan antecedentes teóricos sobre la relación descentralización y democracia, haciendo énfasis en el mecanismo presupuesto participativo en Chile. Posteriormente se describe el caso de presupuesto participativo desarrollado en la Región de Los Ríos, explicando sus principales características, reglamento y funcionamiento. En el apartado siguiente se hace un análisis de las condicionantes más relevantes que determinaron el origen y el desarrollo del caso en Chile. Finalmente se cierra el artículo con algunas conclusiones. 


\section{DESCENTRALIZACIÓN Y DEMOCRACIA: RELACIÓN VIRTUOSA PERO NO CAUSAL}

Diversos son los estudios sobre la descentralización que ponen énfasis en la incidencia que pueda tener en los procesos democráticos de los países de la región, como por ejemplo, en la recuperación de la participación ciudadana y en el fortalecimiento de la gobernabilidad democrática de la sociedad civil ${ }^{1}$. En esta misma línea, Mascareño (2009) señala que la descentralización acercaría el ciudadano a las estructuras de gobierno y a la toma de decisiones públicas, y que de tal forma contribuiría al desarrollo de las nacientes democracias o a la disminución de las crisis de legitimidad donde ya ella existía.

Como la participación ciudadana es una actividad colectiva que implica que los actores sociales tengan cierto poder de influencia en las decisiones que les conciernen, se parte del supuesto de que la vida local constituye el medio más natural para fortalecerla, especialmente otorgando poder a las autoridades y a la institucionalidad pública territorial. Por ello se parte del supuesto que dicho poder de incidencia se ve favorecido con los procesos de descentralización que estarían facilitando el acercamiento de los ciudadanos en la gestión de lo público. A su vez, estos procesos de descentralización también deberían estimular diversas formas de participación de la comunidad, que incluye -entre otras cosas- nuevas instancias de representación política y de desarrollo, como por ejemplo sistemas de decisión innovadores como presupuestos participativos, contraloría social, planificación participativa, consejos ciudadanos, entre otros.

Algunos estudios ponen una luz de alerta en tanto indican que descentralizar implica algunos riesgos, ya que al impulsar procesos de descentralización sin hacer coincidir sus objetivos con la capacidad humana, técnica y administrativa que poseen los gobiernos locales o regionales para cumplirlo, no solo no se provocarán procesos democráticos o participativos, sino que se pueden generar más problemas que beneficios: por ejemplo, que el poder caiga en manos de caciques

Para profundizar en esta materia ver (Cunill, 1991 y 1997; Rufián y Palma, 1993; Huerta et al., 2000; De la Maza. et al., 2004; Hernández, 2001; Herrero, G. R., \& Ajangiz, R. 2007; Schneider, C., \& Welp, Y. 2011). 
locales y/o que exista una mala utilización de los recursos fiscales (Montecinos, 2005). Esta condición se puede transformar en una situación altamente ineficiente en comparación con las características iniciales que se pretendía mejorar, y provocar situaciones clientelares que contribuirían a debilitar en vez de fortalecer los procesos democráticos locales (Carrillo, 2003; García-Guadilla, 2002).

Como consecuencia, existen posiciones que señalan que, a pesar de las múltiples ventajas de la descentralización, esta genera numerosos problemas de control e incentivos, como por ejemplo la ausencia de controles institucionalizados sobre la acción del gobierno, lo que da lugar a que muchos programas sean manipulados con fines políticos ${ }^{2}$.

Bajo estos argumentos se ponen en tela de juicio las bondades de la descentralización y sigue siendo una preocupación si es el mecanismo más idóneo para generar procesos de incorporación de la ciudadanía como un actor clave en la gestión pública, y de ser así, cómo se puede lograr un mayor control de la sociedad civil sobre el servicio público, y qué cambios se deben impulsar para que los organismos del Estado operen de manera más autónoma en lo administrativo y responsable en lo político (Bresser y otros, 2004). Uno de los mecanismos más revisados en la literatura de las ciencias sociales en los últimos 20 años ha sido el de los presupuestos participativos, dado que su aparición en casos distintos de Brasil está asociada a múltiples factores como la descentralización, factores políticos/electorales de carácter territorial, u otros. Lo cierto es que la mayoría de los estudios se han hecho a escala comunal o local, siendo los niveles regionales escasamente estudiados y abordados en las ciencias sociales.

2 Para profundizar en este punto ver (Cremer, Estache y Seabright, 1994; Penfold, 2000; Nickson 2003) 


\section{El Presupuesto participativo a escala Regional: El CASO DE LA Región de Los Ríos en Chile}

Chile cuenta con 345 municipios y 15 regiones. La región de Los Ríos es una de las quince regiones de Chile, ubicada 800 kilómetros al sur de Santiago; limita al norte con la región de La Araucanía, al este con Argentina, al sur con la Región de Los Lagos y al oeste con el océano Pacífico. Cuenta con una superficie de 18.429,5 km cuadrados y una población de 384.837 habitantes según el Censo 2017. La región está compuesta por las provincias de Valdivia y del Ranco, la capital regional es la ciudad de Valdivia. La Región de Los Ríos surgió a partir de la segregación de la provincia de Valdivia de la región de Los Lagos el 2 de octubre de 2007, precedida por un movimiento social de más de 30 años que demandaba ser región. Cuenta con 12 comunas: Valdivia, Corral, Máfil, Mariquina, Paillaco, Lanco, Panguipulli, Los Lagos, Río Bueno, Lago Ranco, Futrono y La Unión.

En el año 2014 se inicia en esta región un mecanismo de presupuesto participativo de escala regional. La iniciativa perseguía vincular directamente participación ciudadana con recursos regionales. Fue así como se incorporó la participación ciudadana en la distribución de los recursos asociados a una parte del Fondo Nacional de Desarrollo Regional (FNDR), el cual es el principal presupuesto que tienen las regiones para realizar inversión pública. En específico, dentro del FNDR existe una partida presupuestaria denominada Fondo Regional de Iniciativa Local (en adelante FRIL), a la cual se le aplicó una dimensión de «decisión participativa» por parte de la comunidad organizada. A esta modalidad se le llamó «FRIL Participativo».

\section{CONTEXTO INSTITUCIONAL EN GOBIERNOS SUBNACIONALES EN CHILE}

Chile se ha caracterizado históricamente por ser un país altamente centralizado. Las municipalidades han gozado de autonomía, con mayores o menores grados desde 1891, siendo el único nivel 
subnacional dirigido por autoridades electas de manera directa por la ciudadanía. Tras la dictadura militar, a partir de 1992 se procedió a elegir nuevamente a los alcaldes y concejales como representantes locales de manera directa. A pesar de ser efectivamente un caso de descentralización política y administrativa, la falta de autonomía fiscal que padecen las municipalidades se transforma en una importante barrera para hablar en propiedad de un modelo descentralizado efectivo (Montecinos, 2007). Esto se traduce en un importante constreñimiento para la inclusión de innovaciones institucionales que digan relación con mecanismos de participación ciudadana en la gestión, al no poder satisfacer las expectativas que el proceso pudiese generar, pudiendo inclusive transformarse en un elemento que juegue en contra de la posibilidad de reelección del incumbente.

Aun con este contexto institucional adverso, la primera experiencia municipal chilena en presupuesto participativo se desarrolló en la comuna de Cerro Navia en el año 2001. De ahí en adelante, el proceso ha avanzado lentamente, alcanzando en 2012 un total de 30 comunas que han desarrollado este mecanismo, equivalentes a menos del 10\% del total de municipalidades del país.

De acuerdo con la literatura y la experiencia comparada internacional (Goldfrank, 2006), la creación de estos mecanismos nace en cierta manera influenciada por la filiación política del alcalde, como también de su intensidad de preferencia para desarrollar este tipo de iniciativas. Para el caso chileno, y ya después de 30 años de experiencia de presupuestos participativos en América Latina, la «variable ideológica» en el origen de este mecanismo no es determinante. Existen casos documentados en Chile, Brasil, Argentina, República Dominicana y Perú, de que esta iniciativa se presenta en municipios de heterogeneidad ideológica (Montecinos, 2014).

El otro nivel subnacional en Chile es el de los Gobiernos Regionales, (en adelante GORE), creados en 1992 mediante la ley N¹9.175 Orgánica Constitucional sobre Gobierno y Administración Regional, cuya principal fuente de financiamiento de proyectos, tal como se indicó, es el FNDR. Los GORE fueron planteados en principio como una institución descentralizada, con personalidad 
jurídica y patrimonio propio. Están integrados por un ejecutivo regional representado por el intendente regional, quien es representante directo del presidente de la república en la región. Además, el gobierno regional está integrado por un consejo regional conformado por consejeros regionales, quienes hasta antes del año 2013 eran elegidos por los concejales de cada comuna, es decir de manera indirecta por la ciudadanía.

Desde el año 1992 y hasta 2013 los consejeros regionales no fueron elegidos por la ciudadanía, lo que traía como consecuencia que los gobiernos regionales se transformaban en un órgano de baja figuración ante el electorado, actuando en la práctica como financiador de proyectos y programas a través del FNDR que presentaban principalmente las municipalidades. En la práctica, con la creación de los gobiernos regionales el año 1992 se intentó realizar un ejercicio de descentralización administrativa y de cierta manera fiscal, ya que se le otorgó a los GORE la capacidad de decidir cerca del 10\% de los recursos públicos a invertir en la región. El $90 \%$ restante sigue siendo invertido en una región a través de ministerios o servicios públicos descentralizados, como el ministerio de obras públicas, vivienda, salud, educación, entre otros. Por ejemplo, solo el ministerio de obras públicas en la región de Los Ríos invierte el doble de recursos que el Gobierno Regional. Mientras el FNDR de Los Ríos en el año 2016 invirtió poco más de 52 mil millones de pesos, el ministerio de obras públicas superó los 107 mil millones.

A partir del año 2014 se provoca un cambio sustantivo en el nivel regional de Chile. Los consejeros regionales se eligieron de manera directa por la ciudadanía, lo cual significó un gran avance en democratización de este nivel de gobierno. En suma, a partir del año 1992 las regiones cuentan con recursos para hacer inversión pública y a partir del año 2014 tienen consejeros electos por la ciudadanía, pero aún cuentan con la figura del intendente regional designado por la presidencia de la república. Todo este contexto, hace que en esta unidad administrativa sean prácticamente nulas las innovaciones democráticas o participativas, como los presupuestos participativos u otras iniciativas. 


\section{El Fondo Regional de Iniciativa Local: FRIL}

Los gobiernos regionales tienen la capacidad de generar reglamentos regionales, abocados a asuntos que dicen relación con sus atribuciones, por ejemplo, normar los procedimientos vinculados a materias presupuestarias como la distribución de los recursos del FNDR, entre otros. Uno de los reglamentos que regula el gobierno regional es el de la implementación de los proyectos denominados FRIL.

¿Qué son los FRIL? Para el año 2008, la ley de presupuestos del sector público contempló la creación del FRIL para que se implementen a escala regional y financien proyectos presentados por las municipalidades de cada región, con una inversión máxima de hasta 2.000 unidades tributarias mensuales (92 millones de pesos aproximadamente, casi 140 mil dólares). Dos son las características principales de este fondo. La primera es que financia proyectos que no entran al sistema nacional de inversiones, por lo tanto no requieren de evaluación técnica sectorial por parte del ministerio de desarrollo social, el cual entrega una certificación a cada proyecto que busque financiamiento público. Segundo, son proyectos de rápida ejecución, sedes, plazoletas, canchas, veredas, estaciones médicas rurales, etc.

El FRIL es regulado a través de un reglamento regional, el cual debe ser autorizado por la contraloría regional de la república. El ejecutivo regional, o sea el intendente (a), le presenta al consejo regional CORE la propuesta de reglamento FRIL a través del cual se detallan los mecanismos de distribución de recursos, tipologías de proyectos a financiar, procedimientos administrativos para regular las inversiones, entre otros. El ejecutivo también plantea el monto a destinar, cuyo piso mínimo está determinado en la ley de presupuestos, pudiéndose aumentar la partida correspondiente en virtud del acuerdo al que pueden llegar el intendente con los consejeros regionales. Por ejemplo, el año 2014 en Los Ríos se destinaron 5 mil millones de pesos a FRIL, mientras que el año 2016 se aumentaron a 6 mil millones. Posterior a estas decisiones políticas se da el siguiente camino: 
- Aprobación de proyectos al interior de cada municipalidad para ser presentada como propuesta de proyectos al gobierno regional.

- Presentación de iniciativas por parte de las municipalidades al gobierno regional.

- Análisis técnico del GORE: las iniciativas son revisadas en cuanto a su factibilidad técnica.

- Aprobación de proyectos: los declarados factibles son presentados al consejo regional para su aprobación.

- Transferencia de recursos: cumplida la etapa anterior, se hace entrega de los fondos a las municipalidades para su ejecución.

Algunas de las críticas que se le hacen al FRIL es que eventualmente otorga una ventana de oportunidades para el desarrollo de vínculos clientelares, dado que los actores principales en torno a estos proyectos son el intendente, consejeros regionales y alcaldes, (en menor medida concejales) que se relacionan con la ciudadanía para financiar proyectos de la naturaleza antes mencionada. Gran parte de los proyectos que se financian por esta vía están focalizados en infraestructura que favorece a grupos considerados sensibles a prácticas clientelares, tales como la construcción y mejoramiento de sedes para organizaciones de la sociedad civil, como juntas de vecinos, mejoramiento de veredas o plazas, entre otros. Estas obras tienen un alto impacto ante la ciudadanía en su diario vivir, al ser parte de su entorno inmediato; es por ello que el valor de estos instrumentos, es que se transforman en un mecanismo rápido, barato y eficaz de relación entre gobernante y gobernado.

$\mathrm{Al}$ ser un fondo en el que los proyectos presentados por las municipalidades son aprobados por el consejo regional, los representantes de este cuerpo colegiado (hoy elegidos por la ciudadanía) se transforman en importantes jugadores de veto ante alcaldes y concejales, para así responder a sus electores. La diferencia sustantiva es que antes del año 2013, al ingresar las iniciativas al CORE, cada consejero se transformaba en jugador de veto para cumplir con los compromisos contraídos, pero ante los concejales de cada comuna, (también con los alcaldes). 


\section{LA INNOVACIÓN DEMOCRÁTICA:}

\section{LA PROPUESTA DEL FRIL PARTICIPATIVO}

A contar de marzo del año 2014 la estructura decisional del FRIL se vio alterada por esta innovación democrática que modificó el sistema de incentivos, pero en favor de la ciudadanía, y en desmedro de la estructura decisional tradicional. El año 2014, al asumir la gestión del gobierno regional en Los Ríos, el representante de la presidenta de la república en su calidad de intendente regional manifestó su interés en implementar un mecanismo de presupuestos participativos a escala regional, iniciativa inédita en todo el país dado que, como se ha señalado, estas solo habían sido desarrolladas a nivel comunal.

Fue en esta región y en este marco institucional que se implementaron una serie de etapas destinadas a la materialización de un mecanismo de estas características, cuyo objetivo principal fue distribuir el poder regional sobre los recursos fiscales incorporando a un nuevo actor decisional: la sociedad civil organizada.

Las etapas para incorporar un nuevo diseño institucional, que no tenía antecedentes y cuyo único sustento era la voluntad política, fueron las siguientes:

- Análisis de contexto institucional: se revisó las ventanas de oportunidades existentes en la institucionalidad vigente para los GORE. Es así que se llegó a la conclusión que la mejor alternativa era implementar la metodología del presupuesto participativo en el FRIL, dado que no consideraba una cantidad relevante de recursos como sí ocurría con los FNDR tradicionales, siendo así más fácil para lograr el pilotaje regional en un ítem de menor cuantía. Así surge el concepto de FRIL participativo.

- Presentación de la propuesta a la sociedad civil: se realizó una presentación de la iniciativa a los representantes de las organizaciones de la sociedad civil de la región. En esto se incorporó a representantes de las uniones comunales de las juntas de vecinos, de los consejos de la sociedad civil 
de cada comuna, y otros representantes sociales, gremiales, sectoriales y territoriales.

- Creación de la unidad de participación ciudadana y presupuestos participativos al interior del gobierno regional: mediante acto administrativo del intendente ${ }^{3}$, y con el objetivo de darle un diseño institucional a la iniciativa. Se incorporó la naciente unidad a la estructura burocrática tradicional. Se creó una nueva unidad destinada a abordar técnicamente el diseño, ejecución y evaluación de mecanismos de participación ciudadana en la toma de decisiones en el GORE, dentro de la cual se consideró los presupuestos participativos.

- Elaboración del reglamento: la unidad ya señalada elaboró una propuesta de reglamento del FRIL participativo.

- Presentación ante el consejo regional y aprobación de nuevo reglamento FRIL: se remitió la propuesta ante el órgano colegiado. Inicialmente la propuesta fue rechazada dado que los consejeros regionales consideraron que destinar un $50 \%$ de los recursos FRIL tradicional a FRIL participativo era demasiado para un mecanismo participativo. Luego de una negociación política y a raíz de la presencia en la sesión de los dirigentes sociales, quienes respaldaban dicha propuesta, se logró la aprobación del reglamento quedando finalmente en un $30 \%$ del total de recursos destinados a financiar proyectos bajo la modalidad FRIL participativo.

- Presentación a la contraloría regional del nuevo reglamento FRIL participativo: la toma de razón de la contraloría no resultaba fácil porque existía la posibilidad de que la respuesta fuera negativa, dado que se trataba de una innovación institucional sin precedentes a escala nacional. Por ello, se debió plantear que la decisión por parte de la ciudadanía tendría reglamentariamente el carácter de «consultiva»y

Resolución exenta, acto administrativo del Ejecutivo Regional que puede ser derogado o sustituido por otro mediante la mera decisión del mismo actor. La aprobación del organigrama del Gobierno Regional por parte del Consejo Regional en 2016 permitió otorgar a la Unidad el carácter de permanente, asegurando así su institucionalización, siendo modificable sólo mediante acuerdo del Consejo y el Ejecutivo Regional. 
que la «sanción vinculante» sería realizada por el concejo municipal, garantizando así la concordancia con el ordenamiento jurídico vigente.

- Puesta en vigencia: tras la toma de razón de contraloría, se siguió el trámite regular para un reglamento regional, siendo publicado en el diario oficial, entrando así en vigencia aproximadamente en agosto de 2014.

- Difusión del mecanismo: el equipo del GORE presentó el reglamento a los actores sociales relevantes, agrupados a través de las uniones comunales de juntas de vecinos, y de los consejos comunales de organizaciones de la sociedad

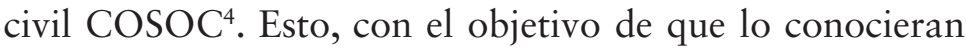
en profundidad y de este modo pudieran hacer uso de este de manera empoderada.

\section{DISEÑO DEL FRIL PARTICIPATIVO}

El nuevo reglamento aprobado consideró los elementos centrales del antiguo reglamento FRIL: tipología de proyectos, requisitos para admisibilidad, procedimientos administrativos para la transferencia de recursos, entre otros. Así, la innovación incorporada fue que la determinación del 30\% de los recursos estaría normada por un acápite especial nombrado como "anexo metodológico de participación ciudadana», manteniéndose el resto del articulado sin modificaciones.

Las etapas contempladas para el mecanismo participativo fueron las siguientes:

Los Consejos Comunales de Organizaciones de la Sociedad Civil COSOC fueron creados mediante la ley 20.500 de Participación Ciudadana en la Gestión Pública, destinados a representar a la sociedad civil organizada dentro de la estructura de la municipalidad. Cuentan con funciones principalmente de carácter consultivo y propositivo, en cuanto a materias como por ejemplo la formulación de observaciones al presupuesto comunal, a la cuenta pública del alcalde, la proposición de una consulta comunal, entre otros. 
- Definición de los recursos por comuna: con el objetivo de garantizar equidad territorial en la asignación de los recursos, se aplicó una fórmula mediante la cual se asignaban los recursos a cada municipio considerando ocho variables dispuestas como mecanismos compensatorios en torno a las condiciones de vulnerabilidad de las respectivas unidades territoriales. Las variables fueron: base común, participación en el fondo común municipal, índice de ruralidad, población de pueblos originarios, aislamiento comunal, número de habitantes, distancia de la capital comunal a la regional, eficacia del gasto FRIL en el año anterior. La consideración de este punto fue fundamental dado que es una región donde existen brechas importantes entre comunas en materias como ruralidad y población.

- Definición del cuerpo elector y territorio a considerar: El reglamento aprobado faculta al alcalde para que en conjunto con el concejo municipal puedan definir el territorio en el que se desarrollará el proceso participativo como también quiénes serán los que tomarán la decisión de los recursos FRIL participativo asignados a la comuna. En este marco, se podía considerar a la comuna como un distrito único o focalizarlo en una o varias localidades; al igual que definir un cuerpo elector representativo de la sociedad civil (pudiendo ser el consejo de la sociedad civil o la unión comunal de juntas de vecinos o ambas instancias las que decidían los recursos) o a la ciudadanía en general.

- Presentación de la cartera de proyectos: Las iniciativas podían provenir de requerimientos previos formuladas por la ciudadanía a las autoridades comunales, o de solicitudes que surgieran durante el proceso participativo mismo.

- Elección de iniciativas: El órgano elector podía ser las uniones comunales de juntas de vecinos, el consejo de la sociedad civil COSOC, ambas, o los proyectos se podrían seleccionar mediante votación directa en todo el territorio o en parte del territorio. 
- Certificación por parte del gobierno regional: Se determinó que la unidad de participación ciudadana del GORE deberá seguir el proceso, dando cuenta del cumplimiento de las disposiciones planteadas en el reglamento participativo. De ser así, emitirá un certificado, el cual es requisito esencial para el otorgamiento de los recursos.

- Sanción de iniciativas: el concejo municipal ratificará mediante un acuerdo la decisión de la ciudadanía en orden de prioridad de proyectos de inversión técnicamente viables para presentar al gobierno regional.

Transcurridas estas etapas, el proceso continúa en virtud de lo dispuesto para la tipología de proyectos FRIL tradicional. A pesar de que el reglamento hace un claro reconocimiento a la autonomía de las municipalidades, existe un condicionamiento a la entrega de los recursos, ya que, en caso de no implementarse procesos participativos, se niega la transferencia y son redestinados a otras comunas.

\section{EJECUCIÓN DEL FRIL PARTICIPATIVO}

El FRIL participativo debutó en el proceso de presentación de iniciativas del año 2014 para ser ejecutadas el año 2015 y el año 2016 tuvo su segunda versión. Tal como se aprecia en detalle en el cuadro a continuación, en los dos años de ejecución se aprobaron más de 3.319 millones de pesos chilenos (casi 5 millones de dólares). Con ello se financiaron 79 proyectos distribuidos en las 12 municipalidades. El costo promedio de cada proyecto aprobado en FRIL participativo es de 42 millones de pesos (equivalente a 63 mil dólares). 
NÚMERO DE PROYECTOS E INVERSIÓN EN FRIL PARTICIPATIVO

\begin{tabular}{|c|c|c|c|}
\hline & $\begin{array}{c}\text { Año presupuestario } \\
2015\end{array}$ & $\begin{array}{c}\text { Año presupuestario } \\
2016\end{array}$ & Totales \\
\hline $\begin{array}{c}\text { Número de } \\
\text { proyectos }\end{array}$ & 42 & 37 & 79 \\
\hline $\begin{array}{c}\text { Recursos } \\
\text { destinados }\end{array}$ & 1.564 .298 .126 & 1.754 .827 .247 & 3.319 .125 .373 \\
(US 2,3 millones) & (US 2,6 millones) & (US 4,9 millones ) \\
\hline
\end{tabular}

Fuente: elaboración propia con base en información del Gobierno Regional de Los Ríos.

Los proyectos decididos por la comunidad organizada de cada comuna, y aprobados por el consejo regional se pueden agrupar en sedes sociales para juntas de vecinos, adultos mayores, clubes deportivos, mejoramiento de alumbrado público, mejoramiento de red de agua potable, estación médico rural, mejoramiento de plazas y plazoletas, construcción de áreas verdes, entre otros. En el cuadro siguiente se detalla una síntesis en torno a la forma en que cada una de las municipalidades implementó la iniciativa.

IMPLEMENTACIÓN DEL PROCESO PARTICIPATIVO

\begin{tabular}{|c|c|c|c|c|c|c|}
\hline Comuna & $\begin{array}{c}\text { Coalición } \\
\text { política } \\
\text { alcalde }\end{array}$ & Año & $\begin{array}{c}\text { Origen } \\
\text { iniciativas }\end{array}$ & $\begin{array}{l}\text { Órgano } \\
\text { decisorio }\end{array}$ & $\begin{array}{c}\text { Tomadores } \\
\text { de decisión } \\
\text { no tradi- } \\
\text { cionales (ni } \\
\text { alcaldes ni } \\
\text { concejales) }\end{array}$ & Territorio \\
\hline \multirow[b]{2}{*}{ Corral } & \multirow[t]{2}{*}{$\begin{array}{l}\text { Chile } \\
\text { Vamos }\end{array}$} & 2014 & $\begin{array}{l}\text { Listado } \\
\text { SECPLAN }\end{array}$ & cosoc & 6 & Comunal \\
\hline & & 2015 & $\begin{array}{l}\text { Asamblea } \\
\text { territorial }\end{array}$ & $\begin{array}{l}\text { Sufragio } \\
\text { universal }\end{array}$ & 187 & $\begin{array}{l}\text { Dos loca- } \\
\text { lidades ru- } \\
\text { rales }\end{array}$ \\
\hline \multirow{2}{*}{ Futrono } & \multirow{2}{*}{$\begin{array}{l}\text { Nueva } \\
\text { Mayoría }\end{array}$} & 2014 & \multirow{2}{*}{$\begin{array}{l}\text { Listado } \\
\text { SECPLAN }\end{array}$} & \multirow{2}{*}{ cosoc } & 8 & \multirow{2}{*}{ Comunal } \\
\hline & & 2015 & & & 9 & \\
\hline \multirow{2}{*}{ La Unión } & \multirow{2}{*}{$\begin{array}{l}\text { Nueva } \\
\text { Mayoría }\end{array}$} & 2014 & \multirow{2}{*}{$\begin{array}{l}\text { Listado } \\
\text { SECPLAN }\end{array}$} & \multirow{2}{*}{ COSOC } & 12 & \multirow{2}{*}{ Comunal } \\
\hline & & 2015 & & & 8 & \\
\hline \multirow{2}{*}{ Lanco } & \multirow[t]{2}{*}{ Chile Vamos } & 2014 & \multirow{2}{*}{$\begin{array}{l}\text { Listado } \\
\text { SECPLAN }\end{array}$} & \multirow{2}{*}{ cosoc } & 10 & \multirow{2}{*}{ Comunal } \\
\hline & & 2015 & & & 11 & \\
\hline
\end{tabular}




\begin{tabular}{|c|c|c|c|c|c|c|}
\hline \multirow{2}{*}{$\begin{array}{l}\text { Lago } \\
\text { Ranco }\end{array}$} & \multirow{2}{*}{$\begin{array}{l}\text { Nueva } \\
\text { Mayoría }\end{array}$} & 2014 & \multirow{2}{*}{$\begin{array}{l}\text { Asamblea } \\
\text { territorial }\end{array}$} & \multirow{2}{*}{ UNCO } & 28 & \multirow{2}{*}{ Comunal } \\
\hline & & 2015 & & & 35 & \\
\hline \multirow{2}{*}{ Los Lagos } & \multirow{2}{*}{$\begin{array}{l}\text { Nueva } \\
\text { Mayoría }\end{array}$} & 2014 & \multirow{2}{*}{$\begin{array}{l}\text { Listado } \\
\text { SECPLAN }\end{array}$} & \multirow{2}{*}{ COSOC } & 11 & \multirow{2}{*}{ Comunal } \\
\hline & & 2015 & & & 9 & \\
\hline \multirow{2}{*}{ Máfil } & \multirow{2}{*}{$\begin{array}{l}\text { Nueva } \\
\text { Mayoría }\end{array}$} & 2014 & \multirow{2}{*}{$\begin{array}{l}\text { Listado } \\
\text { SECPLAN }\end{array}$} & \multirow{2}{*}{ cosoc } & 7 & \multirow{2}{*}{ Comunal } \\
\hline & & 2015 & & & 10 & \\
\hline \multirow[b]{2}{*}{ Mariquina } & \multirow{2}{*}{$\begin{array}{l}\text { Nueva } \\
\text { Mayoría }\end{array}$} & 2014 & \multirow{2}{*}{$\begin{array}{l}\text { Listado } \\
\text { SECPLAN }\end{array}$} & COSOC & 11 & Comunal \\
\hline & & 2015 & & $\begin{array}{l}\text { Sufragio } \\
\text { universal }\end{array}$ & 851 & $\begin{array}{l}\text { Dos } \\
\text { territorios }\end{array}$ \\
\hline \multirow{2}{*}{ Paillaco } & \multirow{2}{*}{$\begin{array}{l}\text { Nueva } \\
\text { Mayoría }\end{array}$} & 2014 & \multirow{2}{*}{$\begin{array}{l}\text { Listado } \\
\text { SECPLAN }\end{array}$} & \multirow{2}{*}{ cosoc } & 11 & \multirow{2}{*}{ Comunal } \\
\hline & & 2015 & & & 9 & \\
\hline \multirow{2}{*}{ Panguipulli } & \multirow[t]{2}{*}{ Chile Vamos } & 2014 & \multirow{2}{*}{$\begin{array}{l}\text { Listado } \\
\text { SECPLAN }\end{array}$} & \multirow{2}{*}{ cosoc } & 10 & \multirow{2}{*}{ Comunal } \\
\hline & & 2015 & & & 7 & \\
\hline \multirow{2}{*}{ Río Bueno } & \multirow[t]{2}{*}{ Chile Vamos } & 2014 & \multirow{2}{*}{\begin{tabular}{|l} 
Listado \\
SECPLAN \\
\end{tabular}} & \multirow{2}{*}{$\begin{array}{l}\text { UNCO + } \\
\text { COSOC }\end{array}$} & 14 & \multirow{2}{*}{ Comunal } \\
\hline & & 2015 & & & 12 & \\
\hline \multirow[b]{2}{*}{ Valdivia } & \multirow[t]{2}{*}{ Chile Vamos } & 2014 & \multirow[b]{2}{*}{$\begin{array}{l}\text { Listado } \\
\text { SECPLAN }\end{array}$} & COSOC & 17 & Comunal \\
\hline & & 2015 & & $\begin{array}{l}\text { Sufragio } \\
\text { universal }\end{array}$ & 220 & $\begin{array}{l}\text { Dos unida- } \\
\text { des vecina- } \\
\text { les }\end{array}$ \\
\hline
\end{tabular}

COSOC: consejo de la sociedad civil regido por la ley 20.500; UNCO: unión comunal de juntas de vecinos, regida por la ley 19.418 .

Fuente: elaboración propia.

Al revisar el cuadro anterior, se puede deducir que la coalición política a la cual pertenece el alcalde no ejerce influencia o no establece relación con la modalidad a elegir para decidir los recursos FRIL participativo. Por lo tanto, se puede afirmar que la variable ideológica no es la que explica las modalidades FRIL participativo que seleccionaron los alcaldes.

En cuanto al origen de los proyectos se puede señalar que en su gran mayoría (10 de las 12) las municipalidades utilizaron como propuesta un listado previo de proyectos elaborado por la secretaría de planificación comunal, en base a requerimientos formulados con anterioridad al alcalde por distintas organizaciones sociales.

En solo dos comunas se realizaron asambleas territoriales, explorando así una modalidad de carácter deliberativo. Dentro de 
ellas es necesario hacer la distinción en la comuna de Lago Ranco, la cual en los dos años facilitó los elementos logísticos necesarios para que la directiva de la unión comunal de juntas de vecinos pudiera recorrer cada una de las juntas de vecinos existentes en la comuna, levantando junto a sus directivas el requerimiento más urgente que pudiese ser cubierto mediante una iniciativa FRIL participativo (modalidad similar a la usada en Brasil, conocida como la caravana de prioridades). En el caso de la comuna de Corral, el segundo año el alcalde definió utilizar la asamblea territorial como mecanismo de levantamiento de requerimientos. Se trabajó en dos sectores de la comuna, en los cuales las organizaciones mayoritarias son clubes deportivos y juntas de vecinos.

La mayoría de los municipios optó por presentar a la comunidad un listado cerrado de iniciativas previamente existentes por dos razones. Por un lado, para no perder el control de la agenda política del proceso participativo, y por otro lado para ahorrar recursos tanto de tiempo, humanos, logísticos y monetarios en el levantamiento de iniciativas. Muchos municipios de la región, con la excepción de los más grandes (Valdivia, Panguipulli, Río Bueno y La Unión) no cuentan con personal suficiente para levantar y formular iniciativas en un mismo año calendario.

En cuanto al órgano decisorio, el año 2014 las municipalidades solicitaron colaboración al GORE para implementar la modalidad que permitiera una rápida toma de decisiones. En ese sentido, la recomendación fue recurrir al COSOC: instancia existente y garantizada por la ley de municipalidades y que estaba presente en prácticamente todas las comunas ${ }^{5}$, la cual es representativa de la sociedad civil pero cuya agenda es determinada por su presidente, el alcalde. De hecho, era esta autoridad la que dirigía el proceso de votación. Así, representaba el menor costo para la municipalidad, por lo que su uso fue el predominante.

En el caso de Lago Ranco en ambas ocasiones se recurrió a la Unión Comunal de Juntas de Vecinos, al no existir un COSOC

Lago Ranco fue la única comuna que durante ambos años no contó con COSOC, implementándolo a inicios de 2016. Así, Los Ríos pasó a ser la única región del país que cuenta con el $100 \%$ de sus comunas con COSOC en funciones. 
constituido, teniendo en la definición de las opciones un rol relevante el presidente de dicha organización, quien coordinaba la votación. De hecho, en 2015 el alcalde planteó la posibilidad de realizar un proceso de participación ciudadana mediante voto universal, pero el dirigente manifestó un rechazo categórico junto a su organización, por lo cual se mantuvo la modalidad inicial.

En el caso de Corral, el año 2015 el alcalde planteó su preferencia por el mecanismo universal, haciéndose presente durante las dos jornadas de votación mediante las cuales se desarrolló el proceso. Misma situación sucedió en la comuna de Valdivia donde el alcalde optó por realizar votación directa en solo un sector de la ciudad. En el caso de la municipalidad de Río Bueno, el alcalde decidió fusionar al consejo de la sociedad civil COSOC con la unión comunal de juntas de vecinos urbana y rural.

En cuanto al territorio donde implementar la decisión sobre el FRIL participativo, en la mayoría de los casos se optó por considerar a la comuna como una sola unidad. Dentro de las excepciones constatadas, se encuentran las comunas de Corral, Mariquina y Valdivia en 2015. En todos ellos fue el alcalde quien realizó la selección de las unidades territoriales en las cuales se implementó el mecanismo, que en el caso de Valdivia se decidieron los sectores por ser los que representaban mayor necesidad, en Corral se debía a una cercanía personal del alcalde con ambas zonas; en Mariquina se planteó como parte de una división geográfica consuetudinaria de la comuna: Valle y Costa, velándose por un mecanismo de compensación rural-urbano, mediante el cual existían tres alternativas de iniciativas, contando el elector con dos preferencias a marcar. Así, se aseguraba la ejecución de la propuesta rural (con menor población en el área de influencia), mientras que la competencia más ardua se desarrolló en el sector urbano. 


\section{Conclusiones}

A partir de la descripción y análisis del caso, se puede deducir que algunos procesos de profundización de la democracia pueden ser detonados por factores endógenos y no necesariamente dependen de procesos «nacionales» de descentralización, o de incentivos específicos como una ley nacional de presupuesto participativo o participación ciudadana.

Para el caso de la región de Los Ríos fue determinante una alta intensidad de preferencia o voluntad política por parte del tomador de decisión inicial, para que esta iniciativa se implemente a escala regional. No obstante, se observa que ha sido esencial la existencia de un capital social y particularmente la alta valoración del régimen democrático para que el proceso se implemente con un alto compromiso inicial de los dirigentes sociales. Sin embargo, llama la atención que ese «entusiasmo» de los dirigentes también ha servido para «vetar» que el proceso se amplíe por ejemplo a una votación directa de los proyectos por parte de los ciudadanos. Se deduce que la alta valoración de la democracia existente en la región es una valoración de la democracia representativa más que de una democracia participativa que le asigna un rol protagónico al ciudadano que no necesariamente ejerce un rol de responsabilidad dirigencial. El concepto de «democracia representativa comunitaria» que plantea Ives Cabannes, (2004: 6), es la idea que mejor explica el desarrollo que ha tenido la experiencia del FRIL participativo en el caso de la región de Los Ríos. Se distribuye poder e incidencia de decisión desde el representante político regional hacia los representantes de la sociedad civil, o niveles intermedios entre el representante político y los ciudadanos. Se trata de iniciativas en las cuales la mayoría de los involucrados constituyen cúpulas integradas por representantes de organizaciones de la sociedad civil, a los que se suman los alcaldes con cierto poder de veto y manejo de la agenda; como consecuencia se habilita la participación de solo un segmento de la población de la comuna (Delamaza y Ochsenius, 2010: 216).

Si bien es cierto en este capítulo se confirma la clásica hipótesis de que la voluntad política es vital para el origen de iniciativas de 
participación ciudadana y en particular de los presupuestos participativos, también se pueden confirmar dos hipótesis adicionales. La primera de ellas es que la capacidad de articulación de las organizaciones sociales, sumada a un alto protagonismo de sus dirigentes y a la valoración de la democracia como sistema de gobierno, facilitan la implementación de una iniciativa participativa impulsada desde el gobierno. Se asegura un contrapeso y también un correlato en los representantes de la sociedad civil.

La segunda hipótesis es que la descentralización por sí misma no necesariamente provoca procesos democráticos a escala regional y local. Múltiples experiencias municipales, ahora esta experiencia regional de Los Ríos y la incipiente experiencia en la región de Tarapacá ${ }^{6}$, confirman que, en un país centralizado como Chile, la variable «territorio» es determinante para profundizar la democracia. Es frecuente defender la descentralización apuntando a que una de sus bondades es que provocará más democracia y participación. La transferencia de poder, así como la presencia de aspectos legales que sostengan estas iniciativas es de vital relevancia, no obstante, el territorio y sus dinámicas políticas y sociales también importan, y muchas veces resultan más determinantes que aquellas variables nacionales o procesos globales que se plantean a escala país.

Cuando existe un territorio compuesto por ciudadanos y líderes sociales que ejercen una ciudadanía activa, involucrándose en los asuntos públicos, se contribuye a que la democracia se fortalezca de manera endógena, sin necesidad de esperar estímulos externos para que eso suceda. En consecuencia, la democracia sí se fortalece con más descentralización, pero su permanencia y pleno ejercicio depende de los ciudadanos y sus territorios. Esta iniciativa se encuentra en curso y su futuro depende de cuánto se haya empoderado la sociedad civil de la iniciativa.

6 El año 2016 comenzó a ser replicada la experiencia del FRIL participativo en la región de Tarapacá. 


\section{BiBLIOGRAFÍA}

Bland, G. (2004). Enclaves and Elections. The Decision to Decentralize in Chile. En Decentralization and Democracy in Latin America, editado por Alfred P. Montero y David J. Samuels. Notre Dame, IN: University of Notre Dame Press, 94-121.

Bresser, L., N. Cunill, L. Garnier, O. Oszlak y A. Przeworski (2004). Política y gestión pública. Buenos Aires: F.C.E.

Cabbanes, Y. (2004). Presupuestos participativos: marco conceptual y análisis de su contribución a la gobernanza urbana y los objetivos de desarrollo del milenio. ONU Hábitat, Quito, Ecuador.

Carrillo, J. (2003). Descentralización y buen gobierno en Colombia. Tesis para optar al grado de Doctor en Ciencias Políticas y Sociales, UNAM.Delamaza, G., y Ochsenius, C. (2010). Redes de participación institucional y gobernanza democrática local. El caso de los Presupuestos Participativos en Chile. Revista del CLAD Reforma y Democracia. Febrero, pp. 213-246.

García-Guadilla, M. (2002). Democracy, decentralization and clientelism: New relationships and old practices. Latin American Perspectives, $29,5$.

Goldfrank, B. (2006). Los procesos de presupuesto participativo en América Latina: éxito, fracaso y cambio, en Revista de Ciencia Política, 26(2), pp. 03-28.

Mardones, R. (2006). Descentralización y Transición en Chile, en Revista de Ciencia Política, 26(1), pp. 03-24.

Mascareño, C. (2009), Descentralización y Democracia en América Latina: ¿Una relación directa? Revisión conceptual del estado del arte. Revista Reforma y Democracia, CLAD, 45, pp.63-98.

Montecinos, E. (2005). Los estudios de descentralización en América Latina: una revisión sobre el estado actual de la temática. Revista EURE, 31(93), pp. 77-88.

Montecinos, E. (2007). Limitaciones del diseño institucional para una gestión municipal participativa. El caso chileno. En Economia, Sociedad $y$ Territorio, VI(23), pp. 725-743.

Montecinos, E. (2011). Democracia participativa y presupuesto participativo en Chile: ¿complemento o subordinación a las instituciones representativas locales?. En Revista de Ciencia Política, 31(1), pp. 73-99.

Montecinos, E. (2012). Democracia y presupuesto participativo en América Latina. La mutación del presupuesto participativo fuera de Brasil. Revista del CLAD Reforma y Democracia, 53. 
Montecinos, E. (2014). Diseño institucional y participación ciudadana en los presupuestos participativos: Los casos de Chile, Argentina, Perú, República Dominicana y Uruguay. Política y gobierno, 21(2), 351-378. 


\title{
LA PARTICIPACIÓN CIUDADANA EN CHILE
}

\author{
Francis Elizabeth Valverde Mosquera \\ Miembro Consejo Nacional de Participación Ciudadana \\ y Fortalecimiento de la Sociedad Civil
}

\section{INTRODUCCIÓN}

Hablar de participación ciudadana es hablar del poder de los y las habitantes del país para generar las transformaciones necesarias que aseguren una vida digna para todos y todas, en una sociedad justa y libre donde el reconocimiento y ejercicio de los derechos humanos de cada uno y cada una es el fundamento de la igual dignidad de todos los seres humanos, como señala el artículo 1 de la Declaración Universal de Derechos Humanos.

La realidad en Chile está lejos de esta aspiración ciudadana. Las condiciones que debe asegurar la estructura del Estado para promover la participación no están dadas. La participación requiere oportunidades y posibilidades que denominamos ambiente habilitante. La segregación socioeconómica y territorial, la inequidad y desigualdad, la corrupción y desconfianza en las instituciones, la falta de proyectos comunitarios, colectivos y sociales, el individualismo y consumismo, y la concentración del poder político y económico, atentan contra las necesarias condiciones básicas para promover la participación ciudadana.

Este artículo hace un recorrido por los principales hechos que fundamentaron y posibilitaron el estado actual de la participación ciudadana en nuestro país. 
Podemos decir que la participación ciudadana entendida como un derecho humano esencial es una aspiración por alcanzar, que requiere cambios estructurales, culturales, políticos y económicos para que sea una realidad.

\section{LA PARTICIPACIÓN EN LOS COMPROMISOS INTERNACIONALES DE DERECHOS HUMANOS}

La participación es un principio eje de los derechos humanos, a la vez que un derecho, lo que implica que esta es considerada un factor habilitante y facilitador para el pleno ejercicio del conjunto de los derechos humanos, y por ello está presente en la mayoría de estos instrumentos. Ya la Declaración Universal de Derechos Humanos, adoptada y proclamada por la Asamblea General de las Naciones Unidas en su resolución 217 A (III), del 10 de diciembre de 1948, señalaba en su Artículo 21:

1. Toda persona tiene derecho a participar en el gobierno de su país, directamente o por medio de representantes libremente escogidos; 2. Toda persona tiene el derecho de acceso, en condiciones de igualdad, a las funciones públicas de su país y 3. La voluntad del pueblo es la base de la autoridad del poder público; esta voluntad se expresará mediante elecciones auténticas que habrán de celebrarse periódicamente, por sufragio universal e igual y por voto secreto u otro procedimiento equivalente que garantice la libertad del voto.

Posteriormente, esto fue reafirmado en el Pacto Internacional de Derechos Civiles y Políticos, de 1966, donde se vincula el derecho a la participación con los derechos a reunión pacífica y asociarse libremente; en la Convención sobre la Eliminación de Todas las Formas de Discriminación contra la Mujer de 1979; la Convención sobre los Derechos de las Personas con Discapacidad del 2006; la Convención Internacional para la Protección de Todas las Personas contra las Desapariciones Forzadas de 2006; Convención Internacional sobre la Eliminación de todas las Formas de Discriminación Racial de 1965; Convención Internacional sobre la Protección de los Derechos de Todos los Trabajadores Migratorios y de sus Familiares de 1990; 
etc. A nivel del continente americano, también podemos encontrar instrumentos que dan cuenta de los compromisos asumidos por los Estados en relación con la participación. El primero de ellos es la Convención Americana sobre Derechos Humanos (Pacto de San José) que en su art. 23 consagra los Derechos Políticos.

Este cúmulo de instrumentos internacionales nos permite, en conjunto con la Carta Iberoamericana de Participación Ciudadana en la Gestión Pública, definir la participación ciudadana como un

proceso de construcción social de las políticas públicas, que conforme al interés general de la sociedad democrática, canaliza, da respuestas o amplía los derechos económicos, sociales, culturales, políticos y civiles de las personas y los derechos de las organizaciones o grupos en que se integran así como los de las comunidades y pueblos indígenas ${ }^{1}$,

\section{y agrega:}

3. La participación ciudadana en la gestión pública es consustancial a la democracia. Los principios democráticos de la representación política deben complementarse con mecanismos de participación de la ciudadanía en la gestión pública, que permitan expandir y profundizar la democracia y su gobernabilidad.

\section{La PARTICIPACIÓN EN Chile}

Se puede afirmar que la participación ciudadana en Chile ha sido uno de los aspectos no asumidos por el proceso de transición iniciado en 1990 con la asunción del gobierno de la Concertación de Partidos por la Democracia, encabezado por Patricio Aylwin. En este sentido fue política pública oficiosa y no reconocida, el desmantelamiento del amplio y activo movimiento social que abrió el camino hacia la derrota política-electoral de la dictadura cívico-militar que usurpó el poder durante 17 años (1973 -1989).

1 Cumbre Iberoamericana de Jefes de Estado y Presidentes (2009). Carta Iberoamericana de Participación Ciudadana en la Gestión Pública, Estoril, Portugal. Capítulo $1, \mathrm{~N}^{\circ} 2$. 
Dicho movimiento social fue protagonista de las grandes protestas que se desarrollaron desde el 11 de mayo de 1983 hasta el 1 y 2 de julio de 1986, que dan cuenta de un proceso de creciente organización de las personas en los niveles comunitarios y locales. Dichos eventos, más allá del enorme número de víctimas producto de la represión del régimen, fue el resultado de un largo proceso de rearticulación de la sociedad chilena que se había iniciado casi desde el mismo momento de producido el golpe de Estado. En primer lugar, los lugares de encuentro de los y las creyentes de diversas confesiones que asumieron la tarea de dar protección a quienes estaban siendo perseguidos y perseguidas por el nuevo régimen, proporcionaron el impulso de organización en torno al tema de los derechos humanos. En este punto es importante resaltar al CONAR (Comité Nacional de Ayuda a Refugiados), Comité Pro Paz y posteriormente la Vicaría de la Solidaridad, instituciones que desde sus comienzos -septiembre de 1973, 1974 y 1976 respectivamente- asumieron que la organización, producto de la participación, era vital para la defensa de la vida y los derechos humanos amenazados por la violencia represiva.

Pasado el primer momento de gobierno militar, donde se cometieron las más graves violaciones a los derechos humanos, se inició un período de constitución de organizaciones no gubernamentales que asumieron tareas en muy diversos ámbitos, pero íntimamente relacionadas con los derechos humanos ${ }^{2}$.

Todos y cada uno de estos organismos no gubernamentales propiciaron y trabajaron para reconstruir el tejido social generando condiciones para la creación de nuevas organizaciones y para el fortalecimiento de las existentes, proceso que constituyó un aspecto relevante de su quehacer. Unido a esto, también las organizaciones sindicales y políticas habían encontrado maneras de avanzar en su reconstitución adaptándose a las condiciones limitantes del contexto histórico existente. Baste para señalar esto las conmemoraciones del

Fundación de Ayuda Social de las Iglesias Cristianas (FASIC, 1975), Servicio Evangélico para el Desarrollo (SEPADE, 1975), Servicio Paz y Justicia (SERPAJ, 1976), Centro de Investigaciones Económicas para América Latina (CIEPLAN, 1976), Comisión Chilena de Derechos Humanos (CCHDH, 1978) y la Coordinadora de Comunidades Populares (1978), Corporación de Defensa de los Derechos del Pueblo (CODEPU, 1980) por nombrar algunas que aún perduran. 
Día del Trabajo, del 1 de mayo de 1978 y la del 1 de mayo de 1979 en Plaza Artesanos, con 365 detenidos. Con posteridad, el Día de la Mujer, 7 de marzo de 1980, una manifestación con 118 detenidos y el 19 de agosto de 1982, en los inicios de la crisis económica, se lleva a cabo una masiva Marcha del Hambre.

A partir de 1983, la crisis económica y las jornadas de protestas nacionales activan toda la capacidad organizativa del movimiento social construido a la sombra de la resistencia a la represión. Comedores Populares, Ollas Comunes, Comprando Juntos, Grupos de Salud, Comités de Base de Derechos Humanos, Comités de Vivienda, Comunidades Cristianas Populares, Centros Culturales, etc. Durante el período de protestas, estas organizaciones se mantienen y aparecen otras de carácter más político en la perspectiva de recuperar la democracia, las Mesas de Concertación, Comités Democráticos Populares, Coordinadoras de Organizaciones Poblacionales (Delamaza, 1985. pp.106-107) por nombrar algunas. Este gran despliegue organizacional enmarca el agotamiento de la capacidad de la dictadura cívico-militar para darle una gobernabilidad sustentable al país y la obliga a buscar espacios de negociación para defender su proyecto refundacional.

Asumido el gobierno civil en 1990 y dotado de la legitimidad democrática producto de las luchas del período dictatorial, este concentra en sí las más altas expectativas del movimiento social y popular en la esperanza de transformaciones profundas en todos los ámbitos de la vida. Por un lado, la lucha por la justicia y contra la impunidad demandaba acciones decididas como la derogación y/o anulación del Decreto Ley de Amnistía de 1978 y la reforma del Poder Judicial, por nombrar solo un par de ellas. Por otro lado, el desmantelamiento del modelo económico y la recuperación de los derechos sociales y políticos, eran demandas fuertemente sostenidas por el movimiento social popular. Sin embargo, la renuncia del nuevo gobierno a su programa democratizador en sus aspectos más estructurales generó una creciente decepción que ha puesto en cuestión la legitimidad democrática de lo obrado. 
Actualmente existe suficiente evidencia, a partir de declaraciones de Edgardo Boeninger (1997) y otros, de que existió una negociación entre la dictadura cívico-militar y el gobierno civil entrante para condicionar la entrega del poder a la mantención de aspectos centrales y relevantes del entramado institucional autoritario elaborado para la implantación del modelo neoliberal y de la impunidad de los ejecutores de los crímenes contra los derechos humanos.

Este condicionamiento a la entrega del poder por parte de la dictadura implicó la necesaria desmovilización del movimiento social que había provocado el término de esta. A lo menos se identifican dos mecanismos para lograr ese objetivo: el disciplinamiento de los actores sociales y políticos dentro de la institucionalidad heredada y, la clausura de las líneas de financiamiento de las organizaciones no gubernamentales que dotaban al movimiento social de capacidad formativa y de análisis político.

Uno de los efectos de esta situación se dejó sentir rápidamente en la participación electoral. De un máximo de $87 \%$ en 1989 , baja a $82 \%$ en 1993 -siguiente elección presidencial-, iniciando una curva descendente en participación electoral que ha llevado al país a tener la mayor pérdida de participación en el mundo, llegando a un 36\%. Esta situación de gran relevancia para la legitimidad democrática del país ha sido sistemáticamente ignorada por los actores políticos responsables de generar políticas públicas que resuelvan los problemas de la sociedad, y ponen en cuestión la legitimidad democrática y representatividad de las autoridades elegidas.

Los siguientes gráficos dan cuenta en términos cuantitativos de lo planteado: 
Gráfico 4. Países América Latina i990-20i 6: Porcentaje de votos emitiDOS EN ELECCIONES PARLAMENTARIAS EN RELACIÓN AL TOTAL DE LA POBLACIÓN EN EDAD DE VOTAR Y DIFERENCIA 2OI6-I990.
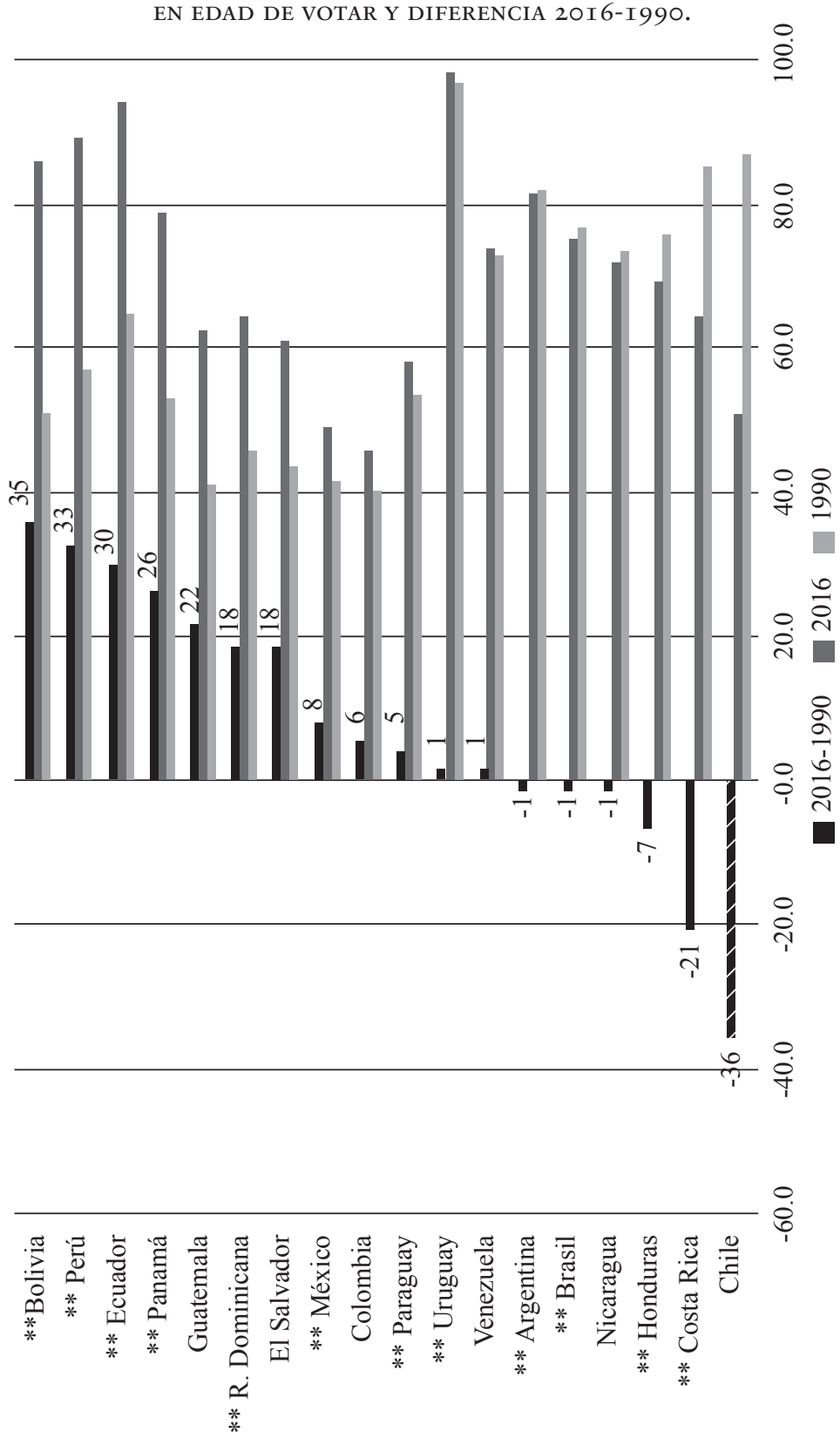

Fuente: Diagnóstico sobre la participación electoral en Chile, PNUD, octubre 2017, p.14. 
Gráfico 5. Chile I989-20I3: Porcentaje y nÚmero De PERSONAS QUe PARTicipa EN ELECCIONES EN RELACIÓN AL TOTAL DE LA POBLACIÓN EN EDAD DE VOTAR
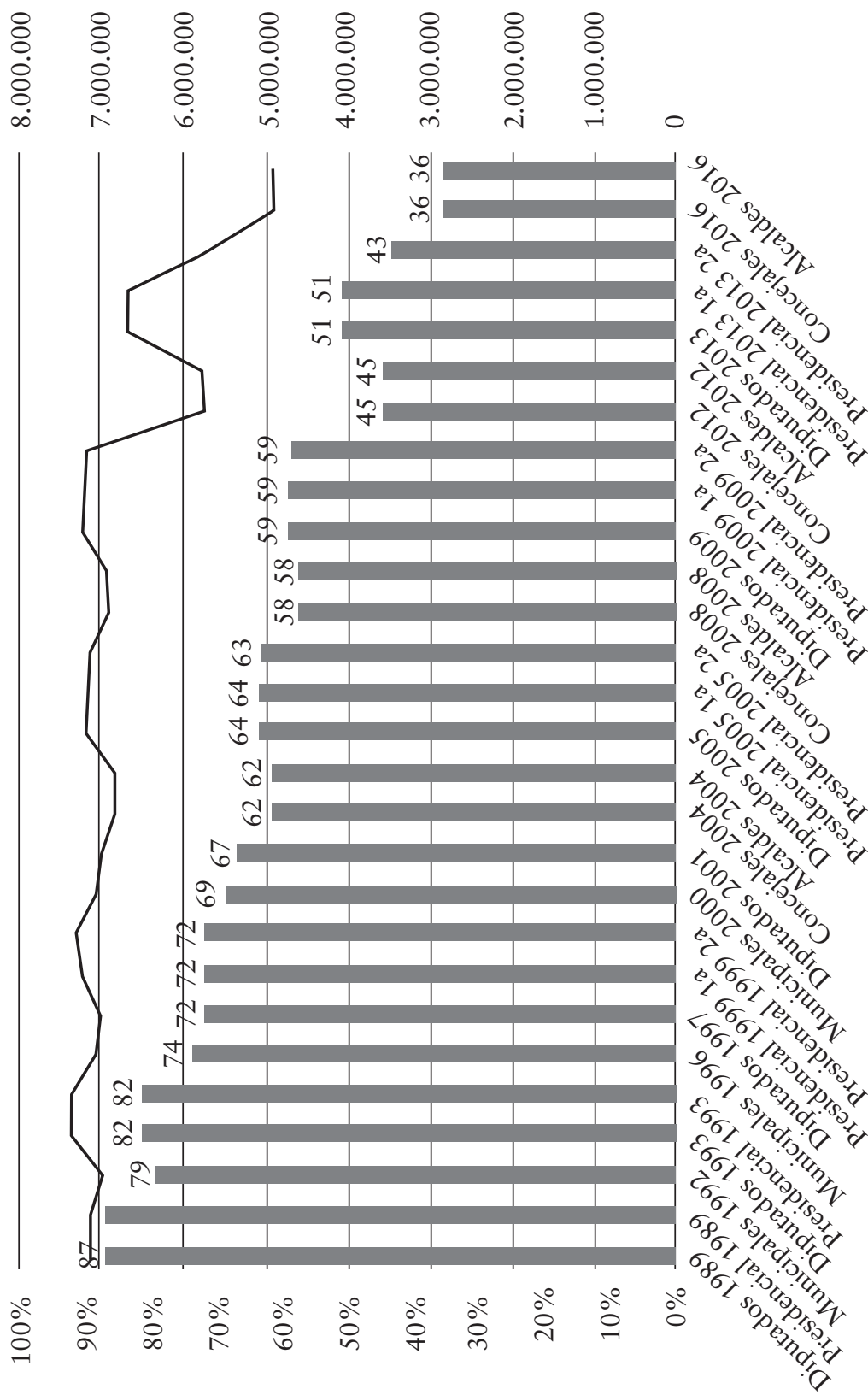

Fuente: Diagnóstico sobre la participación electoral en Chile, PNUD, octubre 2017, p.16. 
El debate sobre la participación electoral logra ver la luz solo en los momentos posteriores a las elecciones, y ha tenido como contraparte un sostenido aumento de la protesta social y la desconfianza hacia las instituciones de la sociedad y hacia la política y sus gestores. Por ello la preocupación por el estado de la participación en Chile ha movilizado a un conjunto de actores de la sociedad civil que entienden que el consenso con el sistema político es esencial para preservar las libertades fundamentales. En esta perspectiva encontramos que los informes sobre la situación de los derechos humanos en Chile han estado alertando sobre la profunda brecha que se ha extendido entre el funcionamiento de la democracia y las demandas de la sociedad.

Un claro ejemplo de esto son algunos de los capítulos del Informe Anual sobre los Derechos Humanos en Chile 2009 del Centro de Derechos Humanos de la Universidad Diego Portales. En el capítulo Protesta Social y Derechos Humanos señala:

Las protestas o movilizaciones sociales son manifestaciones del ejercicio de la libertad de expresión, y del derecho a reunión, todos reconocidos por la Constitución y los tratados internacionales que obligan a Chile. En ocasiones constituyen la única forma de que los sectores marginados puedan hacerse oír (Informe anual sobre DD. HH en Chile. 2009. Pág.45).

Y explica las razones de las movilizaciones porque esas conversaciones a las que es invitada la sociedad civil, por ejemplo, los estudiantes, operan sobre la base de decisiones que ya se han adoptado; las invitaciones buscan legitimar un proceso de consulta que finalmente carece de relevancia en las decisiones que se adopten (Informe anual sobre DD. HH en Chile. 2009. Pág.47).

En estos párrafos están contenidos dos de los elementos cruciales del estado de la participación ciudadana en Chile. Por un lado, la instalación de espacios aparentes de diálogo entre autoridades y sociedad civil y movimiento social que no tiene vinculación alguna con las decisiones que se toman, las que normalmente ya vienen 
acordadas y son antagónicas a las demandas de la sociedad. Y el segundo aspecto, es la criminalización de la protesta social como política de Estado de los gobiernos incluyendo el abuso policial como práctica habitual y generalizada:

Respecto de la criminalización de la protesta social, una de las denuncias que la sociedad civil ha hecho sentir con mayor fuerza apunta a los abusos en que incurren las fuerzas policiales, que van desde detenciones ilegales a violencia innecesaria, aun con casos de muerte (Informe anual sobre DD. HH en Chile. 2009. Pág.61).

La constante ineficacia o sistemática improductividad de los espacios de participación ciudadana (la mayor parte de lo planteado en estos espacios es de carácter consultivo, y no es tomado en cuenta en la elaboración de políticas públicas), con su consecuente pérdida de asociatividad, en contraste con el incremento de la protesta social y su subsecuente criminalización ha constituido la panorámica que recorre los capítulos de los informes de derechos humanos que año tras año se emiten en Chile.

El reconocer esta brecha de legitimidad construida a partir de la disminución de la confianza en las instituciones y la sostenida baja en la participación electoral permite cuestionar la falta de proactividad de los actores políticos para enfrentar este grave problema para la democracia chilena.

Al buscar las iniciativas políticas en el sentido de propiciar la participación ciudadana, a lo largo de los sucesivos gobiernos desde 1990, surgen muy pocas que merezcan ser mencionadas. Quizás la de mayor envergadura fue la reforma constitucional que bajo el gobierno de Ricardo Lagos pretendió eliminar los enclaves autoritarios y legitimar como democrática una constitución emanada de una dictadura.

La incomprensión del carácter estructural de la institucionalidad heredada y la incapacidad, de parte de los actores políticos, de dotarse de la voluntad política necesaria para derrumbar la férrea resistencia de los herederos de la dictadura cívico-militar a permitir transformaciones que desmantelen el sistema de privilegios 
establecidos en la constitución de 1980 (AFP, ISAPRES, el Mercado como regulador de las relaciones en la sociedad, privatizaciones de los bienes comunes, acumulación de la riqueza, etc.).

\section{EVOLUCIÓN DE LA CONFIANZA: INSTITUCIONES POLÍTICAS}

P: ¿Cuánta confianza tiene usted en las instituciones que voy a nombrar?

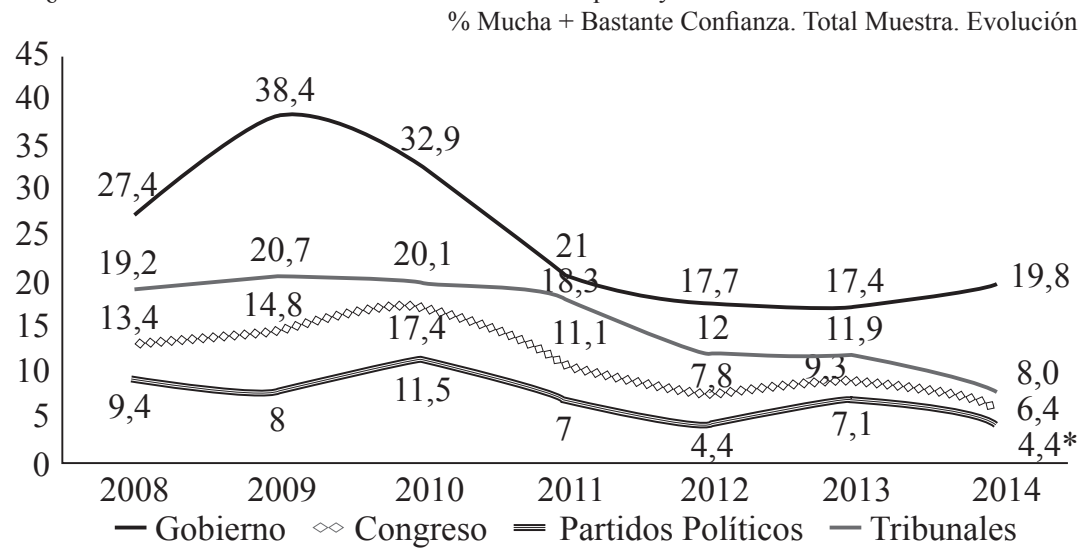

* Diferencia estadísticamente significativa de 2014 y 2013

Fuente: Encuesta Nacional UDP, 2008-2014

Este gráfico da cuenta de la baja continua de los niveles de confianza en las instituciones claves de una democracia.

Ciertamente que, con tan bajos niveles de confianza, la participación ciudadana no tiene espacio para desarrollarse ni un ambiente habilitante que permita revertir la falta de legitimidad democrática del sistema político.

Desde esta perspectiva, la participación electoral -esencial para la democracia representativa- fluye hacia la participación social. Sin embargo, las mismas dificultades de la participación ciudadana las tiene la participación social: la inexistencia de un ambiente habilitante, la ausencia de políticas públicas de fortalecimiento organizacional y falta de líneas de financiamiento. A pesar de esto, es evidente que estos últimos años, diversas temáticas han convocado masivamente a actores sociales, a saber, educación, seguridad social, conflicto del pueblo mapuche con el Estado chileno, entre otras. Pero ello no ha 
conllevado un desarrollo organizacional del espacio de la participación social, más bien se han canalizado hacia la participación informal y no estructurada.

De acuerdo con los Informes de Desarrollo Humano del PNUD en Chile, el 33\% de las personas declaró pertenecer a alguna organización en el año 2000, cifra que bajó levemente el año 2012 al $32 \%$, esto a pesar de que el año 2011 ha sido considerado de masiva participación y presencia de manifestantes en los espacios públicos.

A pesar de que las iniciativas promovidas para posibilitar y facilitar la participación ciudadana no han dado los resultados esperados, es necesario distinguirlas para poder identificar algunas propuestas que pudieran ayudar a avanzar hacia la construcción de un ambiente habilitante para la participación.

Un conjunto de iniciativas, de la mayor relevancia, fueron impulsadas por el gobierno de Ricardo Lagos, dentro de las medidas para resolver la crisis desatada por los sobresueldos de funcionarios del Estado (caso MOP-Gate). Estas fueron la convocatoria del Consejo Ciudadano para el Fortalecimiento de la Sociedad Civil, la elaboración de un proyecto de ley de participación y el Instructivo Presidencial de Participación Ciudadana. Posteriormente el gobierno de Michelle Bachelet formuló una agenda pro participación y un Instructivo Presidencial sobre Participación Ciudadana en la Gestión Pública que consideraba que los órganos de administración del Estado: 1) establecieran una Norma General de Participación; 2) dieran cuenta pública anual, directamente a la ciudadanía, de la gestión de sus políticas, programas, acciones y de su ejecución presupuestaria; 3) establecer Consejos de la Sociedad Civil, de carácter consultivo; y 4) poner en conocimiento público la información relevante de sus políticas, programas, acciones y presupuestos. Estas iniciativas no fueron implementadas durante el período presidencial correspondiente.

El año 2011, ya entrado el gobierno de Sebastián Piñera, se promulgó la Ley 20.500 sobre asociaciones y participación ciudadana en la gestión pública. Lo relevante de esta ley es la institucionalización de los Consejos de la Sociedad Civil en todas las instancias de administración del Estado, desde el nivel central hasta el nivel comunal, y la creación del Fondo de Fortalecimiento de las Organizaciones 
de Interés Público. Durante el período presidencial correspondiente se avanzó muy poco en su implementación.

Llegado el segundo mandato presidencial de Michelle Bachelet, vio la luz un nuevo instructivo presidencial que promovió la implementación de los Consejos de la Sociedad Civil y la convocatoria al Consejo Nacional de Participación Ciudadana y Fortalecimiento de la Sociedad Civil con el mandato de hacer un diagnóstico del estado de la participación ciudadana en Chile y hacer propuestas de modificación de la Ley 20.500. Sin embargo, entregado el informe final en enero de 2017, ninguna de las iniciativas legislativas propuestas fue impulsada por parte del gobierno convocante.

Estas recomendaciones tienen dos componentes:

1 Propuestas de marco constitucional para el derecho a la participación y mecanismos de democracia directa.

1.1 Incorporación de la participación como derecho humano exigible en la constitución política del Estado.

1.2 Fortalecimiento de la participación a través de la incorporación de nuevos mecanismos democráticos.

a) Reconocimiento de la participación como ejercicio de la soberanía.

b) Iniciativa Popular de Ley.

c) Referéndum Revocatorio de Proyecto de Ley.

d) Voto Programático.

e) Referéndum Revocatorio de Mandato.

1.3 Definición de ciudadano y ciudadana. Reconocimiento de todas las personas que habitan el país como ciudadanos y ciudadanas.

2. Modificaciones a la Ley 20.500 y demás cuerpos legales.

2.1 Crear una institucionalidad de participación.

2.1.1 Crear un Consejo Nacional de Participación Ciudadana y Fortalecimiento de la Sociedad Civil.

2.1.2 Crear la Subsecretaría de Participación Ciudadana. 2.2 Participación Ciudadana en la Gestión Pública.

2.2.1 Dictar un Reglamento de Participación Ciudadana en la Gestión Pública. 


\section{CONCLUSiOnes}

La participación ciudadana en Chile es una dimensión esencial de una sociedad democrática, sin embargo, esta relevancia no pareciera ser reconocida por los tomadores y las tomadoras de decisiones. Es claro también que no existe una cultura participativa en la totalidad de los niveles y sectores de la administración del Estado. Situación similar podemos observar en el Poder legislativo y el Poder Judicial.

Construir un ambiente habilitante para la participación requiere de transformaciones de muy diversa índole. Ciertamente hay cambios legales que alcanzan hasta la Constitución. También se requieren cambios culturales y políticos que le den sustentabilidad a las reformas que se emprendan.

$\mathrm{Al}$ reconocer que la participación es un derecho humano facilitador del ejercicio de todos los derechos humanos, ya en sus dimensiones política, social y ciudadana, se está reconociendo el poder que implica esta participación en la construcción y transformación de la sociedad. Este poder de los y las habitantes del país es el que le otorga legitimidad democrática a un Estado; la nuestra está altamente cuestionada y solo a través de la participación organizada de todos y todas los y las habitantes del país, sin distinción alguna, y en todos los niveles de la sociedad barrial, local, laboral, educacional, cultural, social y político se podrá avanzar hacia las transformaciones necesarias para sentirnos parte de un proyecto país democrático y garante de los derechos humanos.

\section{Bibliografía}

Araujo, K. (2017). Democracia y transformaciones sociales en Chile: ¿Qué significa actuar democráticamente? Fundación Friedrich Ebert en Chile.

Baño, R. (ed.) (2003). Unidad Popular, 30 años después. Santiago, Chile: LOM Ediciones.

Boeninger, E. (1997). Democracia en Chile, Lecciones para la gobernabilidad. Santiago, Chile: Editorial Andrés Bello.

CEJIL (2014). Los derechos humanos en el sistema interamericano. Compilación de instrumentos, Buenos Aires, Argentina. 
Consejo Nacional de Participación Ciudadana y Fortalecimiento de la Sociedad Civil. (2017). Informe final. Estado de la participación ciudadana en Chile y propuestas de reforma a la Ley 20.500 sobre Asociaciones y Participación Ciudadana en la Gestión Pública. Chile.

Dagnino, E., Olvera, A., Panfichi, Á. (coordinadores) (2006). La disputa por la construcción democrática en américa latina. México: Fondo de Cultura Económica, CIESAS, Universidad Veracruzana.

Delamaza, G. y Garcés, M. (1985). La Explosión de las Mayorías. Santiago, Chile: ECO Educación y Comunicaciones

Garretón, M. A. (coord.), Barozet, E., Martner, G., Delamaza, G.,Zarzuri, R., y Fuentes, C. (2016). La gran ruptura. Institucionalidad Política $y$ actores sociales en el Chile del siglo XXI. Santiago, Chile: LOM Ediciones

Garretón, M. A., Cavarozzi, M., Cleaves, P., Gereffi, G., y Hartlyn, J. (2004). América Latina en el siglo XXI. Hacia una nueva matriz sociopolitica. Santiago, Chile: LOM Ediciones.

Godoy Arcaya, O. (1999). La transición Chilena a la Democracia: Pactada. Estudios Públicos 74, Santiago, Chile.

Mayol, A. (2016). Autopsia ¿De qué murió la elite chilena? Santiago, Chile: Catalonia.

Moulian, Tomás (1997). Chile Actual. Anatomía de un mito. Santiago, Chile: Universidad Arcis, LOM Ediciones

Stern, S. (2013). Luchando por mentes y corazones. Las batallas de la memoria en el Chile de Pinochet. (Libro Dos de la trilogía La caja de la memoria del Chile de Pinochet). Santiago, Chile: Ediciones Universidad Diego Portales. 



\title{
Propuesta De MOdelo De GOBIERNo ABIERTO MUNICIPAL PARA CHILE
}

\author{
Consejo para la Transparencia"
}

\section{Presentación}

El Gobierno Abierto (GA) es un paradigma cultural que promueve y aspira a una forma de relacionamiento horizontal entre la ciudadanía y el sistema público. En ese sentido, para el Modelo la definición de Gobierno Abierto utilizada -y que se consideró más apropiada por parte de los participantes de la construcción- es la que se plantea en la Carta Iberoamericana de Gobierno Abierto ${ }^{1}$ en la que se entiende como

el conjunto de mecanismos y estrategias que contribuye a la gobernanza pública y al buen gobierno, basado en los pilares de la transparencia, participación ciudadana, rendición de cuentas, colaboración e innovación, centrando e incluyendo a la ciudadanía en el proceso de toma de decisiones, así como en la formulación e implementación de políticas públicas, para fortalecer la democracia, la legitimidad de la acción pública y el bienestar colectivo.

Francisca Gutiérrez Vielma; Diego González Labarca; Daniel Pefaur Dendal; Daniela Moreno Tacchi; Eduardo González Yáñez.

1 Aprobada por la XVII Conferencia Iberoamericana de Ministras y Ministros de Administración Pública y Reforma del Estado Bogotá, Colombia, 7 y 8 de julio de 2016. 
Por ende, le plantea un desafío a las instituciones públicas, cuyas lógicas orgánicas y de funcionamiento se han articulado tradicionalmente en torno a sistemas administrativos y de toma de decisiones más bien jerárquicas y cerradas, lo que evidencia la necesidad de abrirse hacia formas que incorporen la transparencia, la participación ciudadana y la rendición de cuentas.

A nivel internacional, el principal referente de GA es la Alianza por el Gobierno Abierto $^{2}$ (AGA u $\mathrm{OGP}^{3}$ en inglés), que busca promover los valores de transparencia y rendición de cuentas en los gobiernos, con el fin de mejorar la calidad de estos y de los servicios que son brindados a la ciudadanía. Chile es integrante pleno de esta Alianza y el Ejecutivo ha promovido los principios del Gobierno Abierto como una política de Estado ${ }^{4}$ desde el año 2011, implementando tres planes de acción: el primero fue ejecutado entre los años 2012-2013, el segundo entre 2014-2016, actualmente se desarrolla el tercer plan de acción 2016-2018 y, paralelo a ello, el país se encuentra elaborando su cuarto plan para el bienio 2019-2021.

Dado el importante aporte que el Consejo para la Transparencia (en adelante, Consejo o CPLT) tuvo en la implementación del primer y segundo plan -dentro de los que destaca la universalización del Modelo de Gestión en Transparencia Municipal y el Portal de Transparencia del Estado- así como su conocimiento y positiva experiencia en el trabajo con municipios, durante el proceso de elaboración del tercer plan de acción, representantes de municipios y de organizaciones no gubernamentales pidieron al Consejo que asumiera el desafío de generar, junto a ellos, un Modelo de Gobierno Abierto para el nivel municipal, como un compromiso de Chile ante la Alianza para el Gobierno Abierto.

El Consejo para la Transparencia tuvo interés en desarrollar este compromiso, puesto que se alinea con su objetivo de promover una

2 Es una iniciativa multilateral que busca asegurar compromisos concretos de los Gobiernos para promover la transparencia, capacitar a los ciudadanos, luchar contra la corrupción y aprovechar las nuevas tecnologías para fortalecer la gobernabilidad (https://www.opengovpartnership.org/about/about-ogp).

3 http://www.opengovpartnership.org/

4 Gobierno de Chile (2014) «Plan de Acción de Chile. Gobierno Abierto 2014 2016», Ministerio Secretaría General de la Presidencia, Santiago de Chile, p. 10. 
cultura de la transparencia en el sector público. Resulta además particularmente relevante que sea una iniciativa ascendente, que surge del interés y compromiso de los propios municipios, suponiendo una ruptura de las lógicas verticalistas con las que generalmente se diseñan las políticas públicas en el país. El desarrollo del Modelo de Gobierno Abierto Municipal es, además, una primera apertura de los planes nacionales a la esfera local-municipal, lo que se torna muy relevante al considerar que son los municipios la primera cara del Estado frente a sus comunidades, siendo responsables de la gestión de servicios sociales y comunitarios de alta sensibilidad social, por lo que la promoción de la transparencia y la apertura hacia más participación y colaboración ciudadana comienzan a volverse imperativos.

El compromiso quedó plasmado de la siguiente forma:

co-construir un Modelo de Gobierno Abierto a Nivel Subnacional en base a revisión de las mejores prácticas nacionales e internacionales en la materia y que sea implementado de forma piloto en, a lo menos, 5 municipios de la zona central del país (Plan de Acción 2016-2018, p. 10).

El principal responsable del mismo ante la AGA es el Consejo para la Transparencia, sin embargo, las acciones para su desarrollo han sido realizadas con la activa participación e involucramiento de los municipios de Cerro Navia, Peñalolén, Providencia, Recoleta, Santo Domingo, Talagante y Vitacura, así como con la colaboración de la Fundación Ciudadano Inteligente y Chile Transparente, desde la decisión de abordar el compromiso poniendo en la práctica los principios de gobierno abierto, promoviendo la ciudadanía, la integración y la discusión pública en la detección de problemas y diseño de soluciones, además de difundir la información para enriquecer el debate, promoviendo una visión compartida de los asuntos públicos.

El Modelo se articula como reflexión y aspiración a mejorar las formas en que se vive y se trabaja la política pública a nivel municipal, y pretende también convertirse en una guía práctica para orientar los pasos sobre cómo ir avanzando hacia dichas mejoras, orientadas a una mayor democratización de los municipios y su 
administración, así como un mecanismo para potenciar el control social y la colaboración en la construcción de territorios locales más integradores y amigables para sus comunidades.

En este documento se presenta el Modelo y se describe el proceso colaborativo de diseño y construcción que le dio origen, documentando y visibilizando el trabajo realizado en conjunto, de manera de socializarlo e invitar a más gobiernos locales a hacerlo propio.

\section{Metodología de Construcción del Modelo}

Para la construcción del Modelo y las dimensiones que se presentan a continuación, se realizaron las siguientes acciones:

- REVISIÓN DE EXPERIENCIAS NACIONALES E INTERNACIONALES: realizada a fines de 2016, su objetivo era sintetizar y presentar una visión panorámica de las principales dimensiones y herramientas que se habían abordado a la fecha en materia de Gobierno Abierto a nivel local, en el ámbito nacional e internacional, y recoger las mejores prácticas de diversas experiencias. Se realizó una síntesis conceptual del gobierno abierto, y de sus implicancias en el mundo municipal; se revisó la experiencia chilena a través del Índice Institucional para el Gobierno Abierto Municipal (IIGAM 2016) ${ }^{5}$, además de una revisión de experiencias internacionales de gobierno abierto a nivel subnacional, la cual abordó: el Modelo de Gobierno Abierto del Instituto Nacional de Transparencia, Acceso a Información y Protección de Datos Personales de México (INAI); las experiencias municipales de Miraflores, en Perú, y de Bahía Blanca en Argentina; el Modelo de la Junta de Castilla y León en España; el Modelo Irekia del País Vasco; el trabajo del Distrito Metropolitano de Quito, de la Municipalidad de Córdova y Junín en Argentina, de Recife en Brasil, así como los programas New York City

5 http://ichem.uautonoma.cl/ichem-entrega-resultados-del-primer-indice-institucional-para-el-gobierno-abierto-municipal/ 
Data y What Works Cities, ambos de los Estados Unidos. Esta revisión se puso a disposición de los participantes de los grupos de trabajo y expertos, de manera que sirviera de base para la definición de las principales dimensiones que podría considerar el Modelo.

- Talleres con expertos en gobierno abierto: se realizaron tres talleres, cuyo objetivo era identificar y recoger distintas visiones y experiencias en cuanto a la idea y práctica de Gobierno Abierto de los panelistas. Para ello, se convocó a diversos expertos del mundo académico, social, institucional y municipal. En el primer taller, realizado el 20 de diciembre de 2016, participaron Cristián Pliscoff ${ }^{6}$, Alejandro Barros ${ }^{7}$ y Álvaro Ramírez-Alujas ${ }^{8}$. En el segundo taller -realizado el 22 de diciembre de 2016-, participaron Juan Felipe López ${ }^{9}$, Andrés Bustamante ${ }^{10}$ y Cristián López ${ }^{11}$. Por último, en el tercer taller, realizado el 20 de marzo de 2017, participaron Manuel Aris ${ }^{12}$, Francisco Arellano ${ }^{13}$ y José Hernández Bonivento ${ }^{14}$. En los tres talleres se obtuvo información respecto a cómo incorporar los elementos del Gobierno Abierto, que consideraban claves, al modelo para la obtención de resultados.

- Talleres de discusión y diseño con representantes MUNICIPALES Y DE SOCIEDAD CIVIL PARA EL DESARROLLO DEl Modelo: se realizaron cinco sesiones de trabajo con representantes de los municipios participantes, así como con representantes de Chile Transparente y la Fundación Ciudadano Inteligente, con el objetivo de revisar los insumos

\footnotetext{
Académico de la Universidad de Chile y ex director de la Escuela de Gobierno y Gestión Pública del Instituto de Asuntos Públicos de esa casa de estudios.

7 Consultor en tecnologías e innovación pública.

8 Académico de la Universidad de Chile e investigador asociado del Grupo de Investigación en Gobierno, Administración y Políticas Públicas.

9 Ex director ejecutivo del Laboratorio de Gobierno.

10 ASIMOV Consultores.

11 De la Asociación de Municipalidades de Chile.

12 Ex director de incidencia (s) en Fundación Espacio Público.

13 Asesor jurídico de Fundación Datos Protegidos.

14 Investigador del Instituto Chileno de Estudios Municipales.
} 
de trabajo recabados a través de la revisión de experiencias internacionales y las jornadas con expertos. En estas sesiones se definieron y diseñaron el objetivo del Modelo de Gobierno Abierto Municipal, sus dimensiones, escalas e indicadores.

- Retroalimentación del Comité de Expertos para Realizar comentarios al Modelo: una vez desarrollado el Modelo en detalle, se presentó a los expertos para que lo revisaran y dieran su opinión sobre posibles modificaciones. Una vez revisado por ellos, el CPLT expuso las propuestas de cambio ante los representantes municipales y se sometieron a evaluación los cambios recomendados.

- Foros con Ciudadanos y con Funcionarios MunicipaLES: con el objetivo de recoger las opiniones, percepciones e impresiones acerca de un gobierno abierto municipal, así como la experiencia práctica respecto de cómo se podrían implementar y amalgamar en las estructuras y prácticas cotidianas del municipio, se presentó el Modelo aprobado por expertos a funcionarios y sociedad civil de los municipios. Para ello se realizaron seis foros con ciudadanos (en Cerro Navia, Peñalolén, Providencia, Talagante, Santo Domingo y Vitacura, en los cuales participaron en total 133 ciudadanos) y cinco con funcionarios municipales (en Cerro Navia, Peñalolén, Providencia, Talagante y Vitacura, en los cuales participaron en total 116 funcionarios municipales).

Luego de realizadas estas actividades, se trabajó nuevamente el Modelo de Gobierno Abierto Municipal y el Consejo realizó nuevas propuestas de cambio, las que fueron revisadas y aprobadas tanto por los municipios como por las organizaciones de sociedad civil, dando forma al Modelo que se presenta en este documento.

A modo de síntesis, se presenta el siguiente esquema del proceso: 
Propuesta de modelo de gobierno abierto municipal para Chile

Desarrollo del Modelo de Gobierno Abierto Municipal

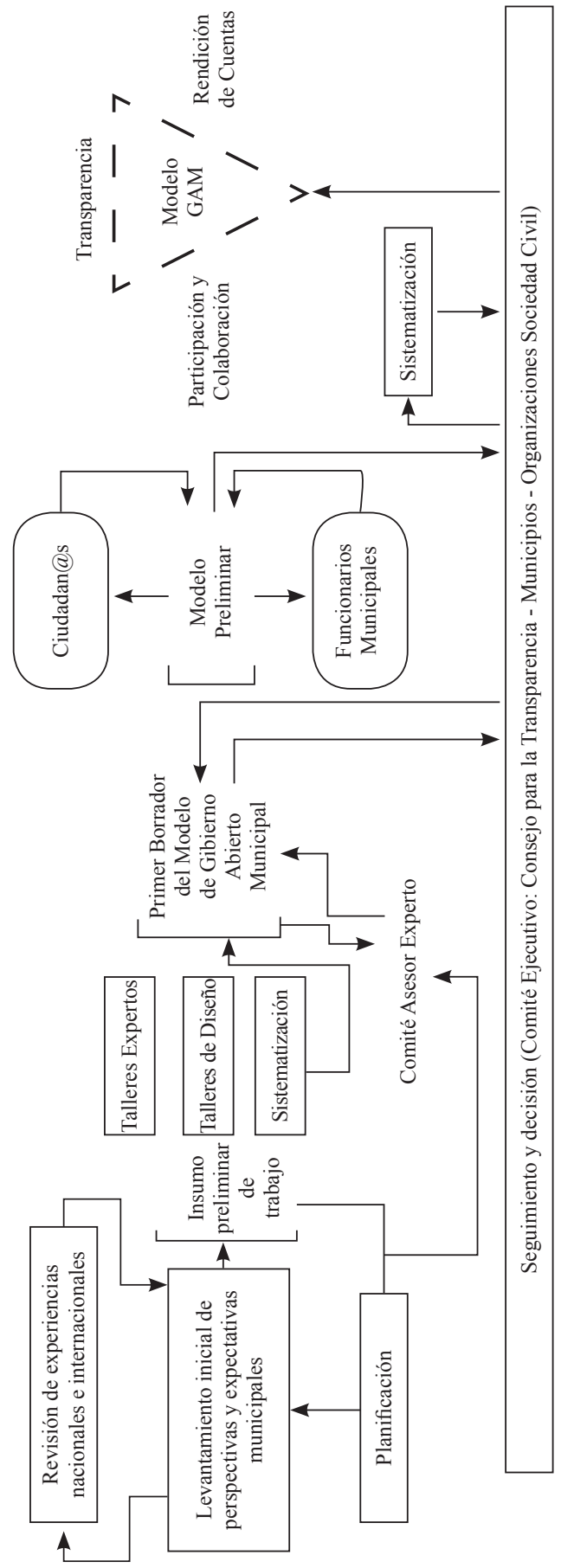




\section{Modelo de Gobierno Abierto Municipal (GAM)}

El Modelo se estructura a partir de tres dimensiones: 1) Transparencia, 2) Participación Ciudadana y Colaboración, y 3) Rendición de Cuentas. Cada una de estas se desagrega en una escala de cinco niveles. Para avanzar en cada una de las escalas, el Modelo sugiere ciertas herramientas que pueden ser utilizadas por las Municipalidades, según sus necesidades y características. Adicionalmente, el Modelo incorpora la innovación como elemento transversal a las tres dimensiones. Tanto las dimensiones como las escalas serán tratadas con detalle más adelante.

\section{Reglas básicas}

1. Respecto del Modelo:

a. El cumplimiento de cada una de las dimensiones que estructuran el Modelo se medirá de forma escalable, ajustándose a las condiciones y capacidades de los municipios.

b. Cada escala tiene como base parámetros mínimos de cumplimiento y cada nivel subsecuente supone mayor complejidad en las acciones comprometidas y dificultad en su ejecución. Por ello, la satisfacción de las actividades constitutivas de una escala es condición de posibilidad del desarrollo de las que constituyen el nivel escalar inmediatamente posterior.

c. Por cada dimensión del Modelo los municipios participantes deben presentar verificadores capaces de mostrar la ejecución de actividades.

d. Deben generarse mecanismos y/o instrumentos que permitan identificar los logros alcanzados en cada caso (incluyendo indicadores al desarrollo de cada acción, escala y dimensión).

e. Se requiere a los municipios iniciar la integración sistemática de los principios del Gobierno Abierto -y sus herramientas- a sus instrumentos de regulación, ordenamiento y planificación comunal/municipal. Se realizará un proceso de evaluación de los avances del Modelo que incluirá tres 
instancias: i) un compromiso de implementación por parte del municipio; ii) un proceso de diagnóstico municipal y, posteriormente, iii) un Cuestionario de Autoevaluación $\mathrm{Mu}$ nicipal, basado en el Mecanismo de Revisión Independiente de la AGA.

2. Respecto de la relación con la ciudadanía y del involucramiento funcionario en la instalación del GA a nivel municipal, es necesario:

a. Reconocer y considerar las demandas ciudadanas, estableciendo acciones de acuerdo con las condiciones propias de los municipios.

b. Involucrar a los funcionarios en la instauración y promoción de los valores del Gobierno Abierto; para ello se deben generar procesos de capacitación, tanto a directivos como a funcionarios, en materias y herramientas propias de Gobierno Abierto.

c. Generar canales de comunicación con la ciudadanía, así como ir midiendo su satisfacción con respecto al Gobierno Abierto municipal.

d. Utilizar un lenguaje claro, es decir, los procesos y la información deben incluir orientaciones con palabras sencillas y con un formato amigable.

3. Respecto de la interrelación de los municipios con otros organismos:

a. Generar instancias que promuevan la transferencia de prácticas entre municipios, así como de intercambio de aprendizajes (metodologías y herramientas) con otras instituciones del nivel central y/o intermedio.

b. Promover instancias de transferencia de prácticas con otros municipios u otras instancias locales de otros países.

\section{Criterios transversales}

A las reglas recién expuestas, se suman criterios transversales que se consideran relevantes para el Modelo, estos son: 
- Diagnóstico Municipal de las acciones que se están llevando a cabo y que podrían ser parte de prácticas de Gobierno Abierto, incluyendo un proceso de consulta pública para conocer los intereses de la comunidad sobre las posibles herramientas a implementar por parte del municipio.

- Estrategia comunicacional durante todo el proceso de implementación, tanto a nivel interno como externo.

- Compromiso de implementación, en el que se declaren ámbitos de trabajo, y en el que será obligatorio establecer acciones en todas las dimensiones del Modelo, sugiriéndose que su ejecución esté formalizada mediante resolución municipal, por ejemplo, decretos alcaldicios.

- Capacitación Permanente del municipio en temáticas DE Gobierno Abierto, tales como transparencia y acceso a información, probidad, participación ciudadana, modernización de la gestión pública, innovación.

- Proceso de evaluación y seguimiento continuo de aVANCES DE la implementación del Modelo.

\section{Recomendaciones de buenas prácticas}

Se recomiendan y se considerarán buenas prácticas en la implementación del Modelo, las siguientes acciones:

- Incorporar un Plan de Gestión del Cambio que acompañe el proceso de la implementación.

- La creación de un Comité Asesor, o Consultivo, en el que participen organizaciones sociales, universidades y sector privado, que entregue asesoría, seguimiento y recomendaciones respecto a la implementación. Se recomienda que este Comité sea el Consejo de Organizaciones de la Sociedad Civil (COSOC) en aquellos municipios donde esté conformado al momento de suscribirse al Modelo. 


\section{Dimensiones}

Como se adelantó anteriormente, las dimensiones del Modelo son tres: i) Transparencia; ii) Participación Ciudadana y Colaboración, y iii) Rendición de Cuentas. Para cada una de ellas, se ha establecido una escala con cinco niveles escalables de cumplimiento, de manera que las Municipalidades puedan incorporarse al Modelo a través de la implementación de acciones en línea con su propio desarrollo de actividades. Al adscribirse al Modelo, cada Municipalidad debe realizar un diagnóstico orientado a determinar en qué nivel se encuentra dentro de cada dimensión. Luego se proponen herramientas ad hoc para el cumplimiento de cada nivel (véanse tablas siguientes):

\section{Transparencia}

\begin{tabular}{|l|l|}
\hline DIMENSIÓN I & $\begin{array}{l}\text { TRANSPARENCIA }{ }^{5} \text { : SE DEBE GENERAR UNA APERTURA DE LA IN- } \\
\text { FORMACIÓN EN PODER DE LOS ORGANISMOS PÚBLICOS, PRO- } \\
\text { MOVIENDO QUE ESTA SEA SOCIALMENTE ÚTIL Y ADECUADA AL } \\
\text { INTERÉS CIUDADANO DE LA INFORMACIÓN PÚBLICA. }\end{array}$ \\
\hline Escala 1 & $\begin{array}{l}\text { Cumplimiento normativo en Transparencia Activa y Derecho } \\
\text { de Acceso a la Información. }\end{array}$ \\
\hline Herramientas & $\begin{array}{c}\text { Ley de transparencia y acceso a la información } \\
\text { 2. Instrucciones generales CPLT }\end{array}$ \\
& $\begin{array}{l}\text { Herramienta de Autoevaluación de Transparen- } \\
\text { cia Activa (TA) y Derecho de Acceso a Informa- } \\
\text { ción (DAI) }\end{array}$ \\
Escala 2 & $\begin{array}{l}\text { Portales de transparencia } \\
\text { Antegración completa de Buenas Prácticas en Transparencia } \\
\text { Activa yerecho de Acceso a la Información comprendidas } \\
\text { en las Instrucciones y Recomendaciones del CPLT. Incluyendo } \\
\text { la incorporación y promoción de buenas prácticas y mejoras } \\
\text { en Gestión Documental y/o Digitalización de procesos mu- } \\
\text { nicipales. }\end{array}$ \\
\hline
\end{tabular}

15 Entendida como la ponderación entre el derecho de acceso a información y el derecho a la protección de datos personales. 


\begin{tabular}{|c|c|c|}
\hline & 1. & Open data (datos abiertos) \\
\hline & 2 & Sistemas de contratación abierta \\
\hline Herramientas & 3 & Lenguaje claro \\
\hline & 4 & Buenas prácticas en transparencia \\
\hline & 5 & Modelo de Gestión Documental \\
\hline Escala 3 & $\begin{array}{l}\text { Diseño de } \\
\text { cas que ha } \\
\text { pativamen }\end{array}$ & $\begin{array}{l}\text { ramientas de información focalizada con temáti- } \\
\text { z sido definidas de manera cooperativa y partici- } \\
\text { on la ciudadanía. }\end{array}$ \\
\hline & 1. $\mathrm{N}$ & odologías de Foro con público objetivo \\
\hline & 2. $\mathrm{F}$ & s abiertos: Salas de exhibición y diálogo \\
\hline & 3. G $-a-1$ & pos focales (focus groups) \\
\hline & 4. $\mathrm{E}$ & destas y sondeos \\
\hline Escala 4 & $\begin{array}{l}\text { Implement } \\
\text { que fueron } \\
\text { anterior, p } \\
\text { mas de inf } \\
\text { los que irá }\end{array}$ & $\begin{array}{l}\text { ín de herramientas de información focalizada } \\
\text { iseñadas por parte de la ciudadanía en la escala } \\
\text { ejemplo, en la priorización de necesidades de te- } \\
\text { nación, de forma de disponibilizarla a públicos a } \\
\text { igida la información. }\end{array}$ \\
\hline & 1. & Open data (datos abiertos) \\
\hline Herramientas & 2 & Herramientas de visualización de datos \\
\hline & 3. & Civic Apps (aplicaciones para móviles ciudadanas) \\
\hline Escala 5 & $\begin{array}{l}\text { Promoción } \\
\text { vados, com } \\
\text { escuelas. }\end{array}$ & $\begin{array}{l}\text { fomento de prácticas de transparencia en pri- } \\
\text { or ejemplo organizaciones de sociedad civil, }\end{array}$ \\
\hline & 1. & Lenguaje claro \\
\hline & 2 & Plataformas cívicas \\
\hline & & Innovación abierta \\
\hline & 4 & Transparencia Presupuestaria \\
\hline
\end{tabular}




\section{Participación Ciudadana y Colaboración}

\begin{tabular}{|c|c|}
\hline DIMENSIÓN 2 & $\begin{array}{l}\text { PARTICIPACIÓN CIUDADANA Y COLABORACIÓN: SE DEBEN } \\
\text { GENERAR ESPACIOS PARA UNA PARTICIPACIÓN QUE SEA CON- } \\
\text { TINUA, PERMITA SEGUIMIENTO, DELIBERACIÓN DE PROYECTOS, } \\
\text { PROGRAMAS Y POLÍTICAS A NIVEL MUNICIPAL, ASÍ COMO ESPA- } \\
\text { CIOS DE COLABORACIÓN Y CO-CREACIÓN CON LA CIUDADANÍA. } \\
\text { JUNTO CON PROMOVER LA INCORPORACIÓN CONTINUA DE LOS } \\
\text { ACTORES SOCIALES DEL TERRITORIO A LA GESTIÓN MUNICIPAL. }\end{array}$ \\
\hline Escala 1 & $\begin{array}{l}\text { Implementación de los cuatro mecanismos de participación } \\
\text { ciudadana que exige la Ley 20.500: } \\
\text { - Consulta Ciudadana } \\
\text { - Consejos de la Sociedad Civil } \\
\text { - } \quad \text { Cuentas Públicas Participativas } \\
\text { - } \quad \text { Audiencias públicas }\end{array}$ \\
\hline Herramientas & $\begin{array}{l}\text { 1. Metodologías de Foro con público objeti- } \\
\text { vo } \\
\text { 2. Foros abiertos: Salas de exhibición y diálogo } \\
\text { 3. Comentarios del público - documentos comen- } \\
\text { tables } \\
\text { 4. Grupos focales (focus groups) } \\
\text { 5. Encuestas y sondeos } \\
\text { 6. Modelo Cuentas Públicas Participativas } \\
\text { 7. Modelo de Consulta Pública CPLT }\end{array}$ \\
\hline Escala 2 & $\begin{array}{l}\text { Utilización y/o implementación de, a lo menos, dos herramien- } \\
\text { tas de Gobierno Abierto que promuevan la participación ciu- } \\
\text { dadana desde el gobierno municipal o local. }\end{array}$ \\
\hline
\end{tabular}




\begin{tabular}{|c|c|}
\hline \multirow{5}{*}{ Herramientas } & $\begin{array}{l}\text { 1. Crowdsourcing y citizensourcing } \\
\text { 2. Comités ciudadanos y toma de decisiones par- } \\
\text { ticipativas }\end{array}$ \\
\hline & 3. Crowdfunding (Micromecenazgo) \\
\hline & $\begin{array}{l}\text { 4. E-peticiones, campañas y recolección de fir- } \\
\text { mas }\end{array}$ \\
\hline & 5. Innovación abierta \\
\hline & 6. Presupuestos participativos \\
\hline Escala 3 & $\begin{array}{l}\text { Elaboración y co-diseño de al menos dos politicas locales en } \\
\text { determinado tiempo, por ejemplo, una ordenanza ambiental } \\
\text { de manera participativa (proceso documentado desde el prin- } \\
\text { cipio hasta el final, con un documento aprobado por el Con- } \\
\text { cejo Comunal al final del periodo), o una ordenanza de parti- } \\
\text { cipación ciudadana. }\end{array}$ \\
\hline \multirow{3}{*}{ Herramientas } & $\begin{array}{l}\text { 1. Comités ciudadanos y toma de decisiones parti- } \\
\text { cipativas }\end{array}$ \\
\hline & 2. Co-creación y co-producción \\
\hline & $\begin{array}{l}\text { 3. Comentarios del público - documentos comen- } \\
\text { tables }\end{array}$ \\
\hline Escala 4 & $\begin{array}{l}\text { Toma de decisiones a nivel local en base a las herramientas de } \\
\text { participación ciudadana implementadas. }\end{array}$ \\
\hline \multirow{4}{*}{ Herramientas } & 1. Portales de transparencia \\
\hline & 2. Lenguaje claro \\
\hline & 3. Plataformas cívicas \\
\hline & 4. E-peticiones, campañas y recolección de firmas \\
\hline Escala 5 & $\begin{array}{l}\text { Evaluación de la satisfacción de la comunidad respecto a las } \\
\text { politicas de participación ciudadana del municipio y rediseño/ } \\
\text { retroalimentación de acciones en base a los resultados. }\end{array}$ \\
\hline \multirow{3}{*}{ Herramientas } & 1. Grupos focales (focus groups) \\
\hline & 2. Encuestas y sondeos \\
\hline & 3. Jurados de ciudadanos \\
\hline
\end{tabular}




\section{Rendición de Cuentas}

\begin{tabular}{|c|c|}
\hline Dimensión 3 & $\begin{array}{l}\text { RENDICIÓN DE CUENTAS: PROCESO A TRAVÉS DEL CUAL LAS } \\
\text { AUTORIDADES INFORMAN, RESPONDEN Y ARGUMENTAN SUS } \\
\text { DECISIONES Y ACCIONES A LA CIUDADANÍA, EN CUANTO EL } \\
\text { EJERCICIO DE SU RESPECTIVA FUNCIÓN PÚBLICA. }\end{array}$ \\
\hline Escala 1 & $\begin{array}{l}\text { Se debe realizar un proceso de consulta e información pública } \\
\text { de al menos una politica que se esté ejecutando en el Munici- } \\
\text { pio, se exigirá la realización de esta en base al Modelo de Con- } \\
\text { sulta Pública del Consejo para la Transparencia, que incluye } \\
\text { plazos y elementos estandarizados para su realización. }\end{array}$ \\
\hline Herramientas & $\begin{array}{l}\text { 1. Lenguaje claro } \\
\text { 2. Plataformas cívicas } \\
\text { 3. Modelo de Consulta Pública CPLT }\end{array}$ \\
\hline Escala 2 & $\begin{array}{l}\text { Realización de Cuenta Pública participativa en base al modelo } \\
\text { del CPLT. }\end{array}$ \\
\hline Herramientas & 1. Modelo Cuentas Públicas Participativas CPLT \\
\hline Escala 3 & $\begin{array}{l}\text { Implementación de Transparencia Presupuestaria por parte } \\
\text { del municipio. }\end{array}$ \\
\hline Herramientas & $\begin{array}{l}\text { 1. Transparencia Presupuestaria } \\
\text { 2. Open data (datos abiertos) } \\
\text { 3. Portales de transparencia }\end{array}$ \\
\hline Escala 4 & $\begin{array}{l}\text { Implementación de al menos } 2 \text { herramientas de rendición de } \\
\text { cuentas sectoriales (presupuestos, obras, compras, etc.) que } \\
\text { respondan ante intereses de la ciudadania y justifiquen el pro- } \\
\text { ceder de la administración o gobierno local a la ciudadanía. }\end{array}$ \\
\hline Herramientas & 1. Contraloría Ciudadana CPLT \\
\hline Escala 5 & $\begin{array}{l}\text { Implementación de herramientas de rendición de cuentas que } \\
\text { aseguren responsabilidad y sanciones en caso de incumpli- } \\
\text { miento por parte de la administración o gobierno local frente } \\
\text { a la ciudadanía. }\end{array}$ \\
\hline Herramientas & $\begin{array}{l}\text { 1. Contraloría Ciudadana CPLT } \\
\text { 2. Jurados de ciudadanos }\end{array}$ \\
\hline
\end{tabular}




\section{Elemento transversal: Innovación}

La innovación se definió como transversal, puesto que debería estar implicada en las tres dimensiones y en general en las actividades, programas y proyectos del municipio. Se definieron tres ámbitos de acción no escalables, sino que complementarios. Su aplicación dependerá del objetivo que se proponga cada municipio en las dimensiones del Modelo, así como del público o usuarios con los que se trabaje. A continuación, se presenta la definición de innovación y sus tres ámbitos de acción:

\begin{tabular}{|l|l|}
\hline \multirow{5}{*}{ ELEMENTO } & $\begin{array}{l}\text { INNOVACIÓN: SE DEBE PROMOVER LA MODERNIZACIÓN DE } \\
\text { TROCESOS INTERNOS Y SERVICIOS A LA CIUDADANÍA, PERMI- } \\
\text { TIENDO NO SOLO LA FACILIDAD EN TRÁMITES, SINO TAMBIÉN, } \\
\text { LA POSIBILIDAD DE QUE LA CIUDADANÍA CONSTRUYA HERRA- } \\
\text { MIENTAS QUE RESUELVAN PROBLEMÁTICAS COMUNITARIAS, ASÍ } \\
\text { COMO POTENCIAR ESPACIOS COLABORATIVOS Y CO-CREACIÓN. }\end{array}$ \\
\hline & $\begin{array}{l}\text { Implementación de acciones destinadas a ampliar los canales de co- } \\
\text { municación para que la ciudadanía pueda acceder a servicios públi- } \\
\text { cos, los que pueden ser presenciales (por ejemplo compromisos de } \\
\text { atención al público, implementación de procesos para aumentar la } \\
\text { rapidez y eficiencia en respuestas al público, mejora de señaléticas, } \\
\text { tótems de información, estándares de calidad de atención) o elec- } \\
\text { trónicos (como portales, sitios, blogs o páginas web, call centers, } \\
\text { entre otros), considerando la realidad local, niveles de alfabetización } \\
\text { digital de la ciudadanía y características propias de la población. }\end{array}$ \\
\cline { 2 - 3 } & $\begin{array}{l}\text { Se incorporan medidas o procedimientos que fomentan la in- } \\
\text { corporación de valor a procesos y actividades a través de tra- } \\
\text { bajo colaborativo y de co-construcción entre departamentos } \\
\text { municipales, funcionarios y sociedad civil, otros municipios o } \\
\text { gobiernos locales, y/o en conjunto con el sector privado. }\end{array}$ \\
\hline $\begin{array}{l}\text { Ámbitos de } \\
\text { Acción }\end{array}$ & $\begin{array}{l}\text { Adopción de iniciativas que contribuyan a la desburocratiza- } \\
\text { ción, tales como suprimir barreras institucionales que inhiban la } \\
\text { acción de la sociedad civil, simplificar trámites administrativos a } \\
\text { través de guías, instructivos y/o transacciones on-line y prestar } \\
\text { determinados servicios especializados; también pueden incluir el } \\
\text { diseño, testeo e implementación conjunta de e-servicios con sus } \\
\text { usuarios, previendo su diferenciación; la simplificación o supre- } \\
\text { sión de normas que hayan perdido vigencia o resulten contradic- } \\
\text { torias; la incorporación de mejoras en gestión documental. Tam- } \\
\text { bién se consideran relevantes iniciativas y esfuerzos por parte de } \\
\text { la Municipalidad para orientar a los usuarios en la «selva de la } \\
\text { burocracia». Implica una política de innovación. }\end{array}$ \\
\hline
\end{tabular}


Seguimiento, monitoreo y evaluación del Modelo

\section{i. Diagnóstico municipal:}

El Consejo para la Transparencia elaboró un instrumento de diagnóstico para medir el nivel en que se encontraban los Municipios respecto de cada una de las dimensiones del Modelo. La información recogida sirvió de base para hacer recomendaciones en el diseño de los planes municipales y para la priorización de actividades posibles de incorporar en sus planes de acción. Los resultados de este diagnóstico se revisaron con los respectivos municipios y las organizaciones de la sociedad civil que forman parte del compromiso OGP.

\section{ii. Compromiso de implementación: Plan de Acción}

Los Municipios que se suscribieron al Modelo presentaron un Plan de Acción al Consejo para la Transparencia y a las organizaciones de sociedad civil, en el que establecieron objetivos, plazos, responsables, así como la relevancia y ambición (tal como se realiza en los formularios para los compromisos nacionales de AGA), comprometiendo la implementación de actividades.

iii. Puesta en marcha del Modelo GaM:

El 11 de mayo de 2018, en la semana de Gobierno Abierto, se realizó la Jornada de Lanzamiento del Modelo de Gobierno Abierto Municipal, en dependencias del Consejo para la Transparencia y con la presencia de autoridades locales.

iv. Medición de Avance del Modelo GaM:

Para el cumplimiento del Compromiso, cada municipio responderá un Cuestionario de Autoevaluación Municipal, basado en el Mecanismo de Revisión Independiente de la AGA (IRM, por sus siglas en inglés) en el que se detallará el grado de cumplimiento en la implementación, puntualidad y verificadores asociados, así como la relevancia de las acciones en relación con cada una de las dimensiones 
del Modelo. Dentro de los tiempos asociados al Compromiso AGA, este instrumento será aplicado en una primera instancia el 30 de junio de 2018 y posteriormente el 31 de julio de 2018, a modo de actualización previa al cierre de las actividades del compromiso.

No obstando aquello, y considerando que la iniciativa de desarrollar un Modelo de Gobierno Abierto surge desde lo local, los municipios participantes serán requeridos de la aplicación del instrumento de autoevaluación con un corte temporal al 31 de diciembre de 2018 y, posteriormente, según los plazos definidos por los municipios en sus propios planes de acción.

\section{Implementación y desafíos del Modelo: próximos pasos}

Actualmente los municipios participantes se encuentran en la fase inicial de ejecución de sus planes locales de acción, desde una apuesta que sobrepasa temporalmente los límites del Modelo como un compromiso AGA. Si bien se aprecia variedad a nivel de los municipios participantes en cuanto a los planes que definieron -en términos de ambición y complejidad-, en todos los casos conversan con los resultados obtenidos tras la aplicación de instrumental de diagnóstico y las recomendaciones que el Consejo para la Transparencia remitió a cada municipio en cada dimensión del Modelo. De esta forma, y solo a modo de ilustración, en la medida que se presentaban brechas en las escalas iniciales de la dimensión transparencia, las recomendaciones fueron en la línea de avanzar en la adopción de buenas prácticas en transparencia activa y derecho de acceso a la información, así como en la formalización de una estrategia de focalización en materia de apertura de datos en formatos reutilizables. Por otra parte, en el caso de la dimensión Participación y Colaboración, las recomendaciones priorizaron -dentro de otras cosas- el desarrollo de presupuestos participativos y la integración de herramientas tipo crowdsourcing y/o citizensourcing que favorezcan el involucramiento ciudadano en la gestión del municipio, ya sea en el marco del diseño, evaluación y/o rediseño de iniciativas municipales, o de la ejecución de funciones propias del municipio orientadas a 
la provisión directa de algún servicio a la comunidad. Por último, en cuanto a la dimensión Rendición de Cuentas, el foco sugerido estuvo puesto en la realización de cuentas públicas participativas, según la propuesta del CPLT, así como integrar procesos de consulta pública que favorezcan que el municipio conozca la opinión de la comunidad, en relación con materias que sean de interés ciudadano a nivel local, como fase previa al diseño y/o implementación de programas, proyectos o políticas municipales.

Si bien se espera que los planes locales tengan su propio desarrollo e instancias de revisión y autoevaluación, el propio Modelo también debe consolidarse, por ello se han identificado desafíos relevantes para intentar resolver en las siguientes etapas del Modelo: a) liderazgo de las autoridades: es relevante que efectivamente puedan impregnar a la organización municipal respecto de lo que implica la gestión de Gobierno Abierto, lo que contribuiría al siguiente desafío; b) lograr un cambio en la gestión, es decir lograr una implementación de acuerdo al paradigma de GA y no solo a cumplimiento de indicadores y verificadores tipo check list; c) implementar planes de capacitación y difusión permanentes, tanto a la comunidad como a funcionarios municipales sobre GA, lo que resulta necesario ante el desconocimiento actual, que a su vez dificulta la concreción de planes y acciones acordes a las necesidades locales; d) colaboración y participación ciudadana en los territorios locales para la implementación de los compromisos municipales; e) innovación: resulta un desafío en general en las organizaciones sociales; aplicarla como elemento transversal a las dimensiones del modelo, con indicadores y verificadores, es sin duda una ambición y un reto importante en la gestión de los municipios; f) articulación de la gestión municipal de GA con niveles regional y central; g) medición, reto tanto por la heterogeneidad de los municipios, como por la flexibilidad del Modelo y el riesgo de estigmatización de quienes no lo cumplan. 


\section{BiBLIOGRAFÍA}

Colón de Carvajal, B. (2016). El paradigma del gobierno abierto provincial: fantasía o realidad, En El paradigma del gobierno abierto, Universidad Complutense de Madrid, p.78. Disponible en: https:// paradigmagobiernoabierto.org/2016/02/07/capitulos_autor/

CLAD, (2016). Carta Iberoamericana de Gobierno Abierto. Disponible en: http://54.207.3.16/sfp/archivos/documentos/CIGA_2016\%20 final_knawtdh9.pdf

Hernández, J. (2016). Índice institucional para el gobierno abierto Municipal, Instituto Chileno de Estudios Municipales (ICHEM), Facultad de Ciencias Sociales y Humanidades, Universidad Autónoma de Chile, Santiago, Chile. Disponible en: http://ichem.uautonoma.cl/ wp-content/uploads/2016/08/VB-IIGAM-2016-digital_FINAL-2.pdf

OEA (2014). Gobierno Municipal Abierto en América Latina. De la Proximidad Administrativa a la acción colaborativa, Disponible en https:// www.oas.org/es/sap/dgpe/pub/OEA-Gobierno_Municipal_Abierto.pdf

Ramírez-Alujas, Á., \& Dassen, N. (mayo 2016). Vientos de cambio II: Avances y desafíos de las políticas de gobierno abierto en América Latina y el Caribe, Inter-American Development Bank.

Ramírez-Alujas, Á., \& Hofmann, A. (2012). La Promesa del Gobierno Abierto. Disponible en: http://inicio.ifai.org.mx/Publicaciones/ La\%20promesa\%20del\%20Gobierno\%20Abierto.pdf

Villoria, M. (2014). La publicidad activa en la Ley de transparencia, acceso a la información y buen gobierno: posibilidades e insuficiencias, Govern Obert, Gencat.

Zurita, R.; \& Ascarrunz, J. (2015). Estrategias de Gobierno Abierto en clave comparada: Los casos de Quito y La Paz, Trabajo preparado para su presentación en el VIII Congreso Latinoamericano de Ciencia Política, organizado por la Asociación Latinoamericana de Ciencia Política (ALACIP). Pontificia Universidad Católica del Perú, Lima, 22 al 24 de julio de 2015. 


\section{SEgunda PARTE: \\ Mecanismos de Participación Ciudadana en Chile}





\title{
LOS PRESUPUESTOS PARTICIPATIVOS"
}

\author{
Bernardo Navarrete Yáñez \\ Universidad de Santiago de Chile
}

Las comunas son las unidades territoriales más desagregadas de la administración pública en Chile. En ese territorio habita una «comunidad» de vecinos que expresa una realidad socioeconómica «con un cierto grado de coherencia e interconexión interna» (Amorós, 1999: 183; Ferris, 1993: 5) y que eligen alcaldes y concejales para que administren un municipio (Borja, 1997) y gobiernen una comuna.

Los vecinos como ciudadanos probablemente participen más en elecciones para resolver lo anterior que para controlar la agenda de problemas de la comuna, lo que requeriría otras formas de participación política. Estas últimas están a su disposición, pero no son utilizadas con la misma frecuencia e intensidad (Torcal, Montero y Teorell, 2006) porque las unidades locales no son islas homogeneizadas, sino que responden a una realidad diversa y multicultural (Touraine, 1997), y varían sensiblemente de un país a otro (Hoffmann-Martinot, 1999).

Dentro del abanico de posibilidades de participación a nivel local sobresalen los presupuestos participativos, instrumento que será analizado en este capítulo dentro de la discusión sobre los gobiernos locales y la representación de desiguales, dado que el modelo de gobierno local y su diseño institucional definirá las reglas del juego de la participación.

Este capítulo es producto del proyecto DICYT Nº 031852 NY de la Dirección de Investigación Científica y Tecnológica de la Vicerrectoría de Investigación, Desarrollo e Innovación, Universidad de Santiago de Chile. 
Pero antes de continuar es importante señalar que participación ciudadana y democracia no son términos sinónimos. La primera no es suficiente para entender la dinámica de la democracia, pero sin participación la democracia no existiría. Por otra parte, no existe consenso sobre los efectos positivos-negativos de la participación desde el punto de vista de la eficiencia, pero sí parece haberlo desde la legitimidad democrática y más específicamente en la legitimidad por rendimientos, que pareciera importar más que la legitimidad electoral o de origen, ya que la globalización está generando cambios donde las administraciones municipales poco pueden influir (Andrew y Goldsmith, 1998), generando desapego con lo local y la comunidad (Stone, 2002), perjudicando de paso la «capacidad de los gobiernos locales para solucionar problemas cada vez más complejos, cargados de emotividad e incluso potencialmente divisorios» (Benest, 1999: 1). Ello porque en la actualidad, fácticamente no se ha logrado extender la participación a espacios que superen lo local, que a su vez no sean fácilmente cooptados por lógicas elitistas, representativas y excluyentes (Mora, 2015).

Por lo anterior, existen a lo menos tres argumentos sobre por qué los académicos deben estudiar el ámbito local. Primero, porque importa por la política y políticas; segundo, porque hay ventajas metodológicas que se reflejan en el estudio de caso que guía este capítulo; y, por último, porque el análisis de la política a nivel subnacional puede generar diferentes tipos de preguntas que van más a fondo que el nivel nacional (Trounstine, 2009). Todo esto en un contexto donde la investigación sobre la política local puede y debe contribuir a ampliar los debates en ciencia política y permitirnos entender cómo y por qué este nivel de política es único, y, en especial, porque se puede observar que la participación hoy es un «imperativo» de las políticas públicas (Sintomer, 2007). Para evitar los problemas de precisión en las definiciones, la entenderemos como el control ciudadano en la definición de la agenda de problemas locales y en la implementación de las decisiones y políticas que se generan (Torcal, Montero y Teorell, 2006). 
Con todo lo expuesto, este texto se estructura a partir de una discusión sobre la llamada «letra chica del contrato democrático", que aborda el problema de distribución asimétrica de recursos, tensionando dos legitimidades que están imbricadas: la de origen, donde el poder se genera a partir de las elecciones y que no aparecen cuestionadas como mecanismo de selección de representantes, y la legitimidad por rendimiento, que apunta a las políticas y programas que se implementan a nivel local y el grado de participación que tienen los vecinos en ellos. Esta discusión permite avanzar en el siguiente acápite, que aborda conceptualmente la relación entre participación y presupuestos participativos, en adelante PP, dada la amplia literatura que se ha producido en los últimos años y que ilustra sobre las luces y sombras de un proceso que ha sido definido como «una alternativa válida para transformar la inversión pública en derechos y no en favores» (Souza, 2004: 163). Seguidamente abordo el caso de los PP en Brasil, ya que es paradigmático y el más analizado a nivel de estudio de caso y comparado, cerrando con un check list como guía para evaluar los casos disponibles.

\section{Participación y Presupuestos Participativos}

La participación política como concepto no es más que «un cajón de sastre que acomoda formas muy diferentes de acción» (Huntington y Nelson, 1976: 14, citado por Torcal, Montero y Teorell, 2006), pero también el encuentro de distintos temores, ya sea a la «omnipotencia de la mayoría» de Tocqueville, o las «minorías siniestras» de Benthan, que saben usar el poder de la administración para sus propios beneficios y contra el interés general y de los que Mancur Olson llamó «los grupos olvidados», a quienes los buscadores de rentas terminarán perjudicando (Schwartz, 2018). En este doble escenario de indefiniciones y miedos, se ha reinstalado el debate sobre la importancia de la participación -ahora de la mano de la crisis de legitimidad del sistema político-, centrando la atención en los procesos a través de los cuales la democracia funciona (Sen, 2006), pero bajo la siguiente interrogante: ¿La demanda de participación 
es para trabajar junto con las instituciones, o se busca un proceso paralelo a la acción de las instituciones? (Sintomer, 2007). Asimismo, se olvidó que las innovaciones prácticas en participación supusieron que todas ellas, por definición, eran democráticas, ya que fomentarían la ciudadanía desde la base. La experiencia latinoamericana señala que ello no ha sido cierto (Avritzer, 2017), porque no se han podido excluir las «redes clientelares», que son parte de la política cotidiana en los barrios (Pagani y Arce, 2008).

Una innovación muy popular en estos días es la denominada Presupuestos Participativos (PP) (Orçamento Participativo - OP, en portugués). En una definición preliminar, es un instrumento de planificación anual que surge en un espacio de cogestión (Martínez y Villavicencio, 2005) y que «ponen en juego una metodología participativa que permite a los municipios incorporar la participación de los habitantes de la comuna mediante un proceso de información, deliberación, decisión y control, sobre una parte importante de los recursos municipales» (Subsecretaría de Desarrollo Regional - SUBDERE 2008: 14). Esta definición asume como propias dos criticas sustantivas a los PP, que son la inexistencia de un proceso secuencial donde los vecinos se informan, deliberan, deciden y controlan, y que se implementa sobre una "parte importante de los recursos municipales», cuando en verdad para algunos no es más que «dividir correctamente lo que sobra» (Cavalcanti y Maia, 2000).

No obstante, su popularidad va en aumento porque se entiende que profundiza la participación de los pobres, redistribuye los recursos (Su, 2017), y puede generar un cambio social, ya que los ciudadanos comunes apoyan los nuevos procesos democráticos si las instituciones producen cambios tangibles y positivos en sus vidas (Wampler, 2012).

Pero -siempre hay un pero-, la realidad de los PP no ha superado la arena de política local y cuando se establecen desde el nivel nacional

no han tenido un éxito generalizado que promueva la participación ciudadana a nivel local, la transparencia fiscal, ni gobiernos municipales eficientes. Este fracaso se debe, en 
parte, a que los diseñadores de las leyes nacionales tuvieron otros objetivos y, también, a los obstáculos locales, incluyendo alcaldes reacios, baja capacidad fiscal y administrativa de los gobiernos municipales, y sociedades civiles fragmentadas y conflictivas (Goldfrank, 2005, p. 1).

Incluso, algunos estudios insinúan que no hay ningún efecto de mayor participación en las preferencias de política elegidas por los votantes y los nuevos votantes; que no tienen preferencias sectoriales drásticamente diferentes (Peixoto, Sjoberg y Mellon, 2017).

Anticipándome al caso de estudio, y como ejemplo de parte de lo señalado anteriormente, en 1989 en Porto Alegre, Brasil, las autoridades comunales del Partido de los Trabajadores (PT) pusieron en práctica un plan que buscó integrar a la comunidad en la discusión del presupuesto y cómo gastarlo (Pedreros, 2007). Y si bien algunos han sostenido que desde los años 70 algunos gobiernos municipales controlados por el Partido del Movimiento Democrático Brasileño (PMDB) sometían sus presupuestos al debate público, la ciudadanía solo tenía voz -y no voto- dentro de estos procesos (Goldfrank, 2005).

Surgió aquí el problema llamado «dilema de gobernabilidad»: Si lo implemento en el gobierno local y funciona, cuando asciendo al gobierno nacional ¿cambian las relaciones con la sociedad civil? La respuesta es sí. El PT, con Lula Da Silva y Dilma Rousseff como presidentes, cedieron en el impulso a la agenda participativa que potenciaron a fines de los 80 (Gómez, 2016) y establecieron una «gobernabilidad social» a través de recompensas, como la distribución de empleos en el aparato estatal y la asignación de subsidios estatales masivos (Gómez 2015). En este nivel y por ausencia de mayoría parlamentaria, el equilibrio de intereses en conflicto fue mayor, exigiendo -de paso-, que los antiguos liderazgos de las organizaciones sociales a nivel local estuviesen más alineados con las políticas nacionales. Por tanto, el cambio en el nivel de gobierno terminó moderando el discurso ideológico (Goirand, 2014) y se integró dentro del régimen político y económico dominante; los movimientos sociales que dependían de los gobiernos del PT lograron alcanzar sus reclamaciones, aunque se hayan abandonado los objetivos de transformación social por programas sociales específicos (Levy, 2012). 


\section{El caso de Porto Alegre}

En los últimos treinta años Brasil se ha convertido en un «laboratorio de experiencias de participación» (Avritzer y Ramos, 2016: 1), donde Porto Alegre es al presupuesto participativo, como lo local a la democracia. Es el más antiguo y el más conocido (Sintomer, 2005). Ninguna otra ciudad ha sido más identificada con una política pública de participación a partir de la década de 1990, a tal punto que hoy «su modelo se ha extendido a lo largo de Brasil y el mundo, con más de 2.700 gobiernos implementando alguna versión de la misma» (Abers, Brandão, King, and Votto, 2018: 1). Más específicamente, desde 1989 se ha realizado en más de 45 países una auténtica innovación democrática (Cabannes, 2018), todo ello bajo el lema «democratizar radicalmente la democracia» (Cabannes y Lipietz, 2018).

En 1996, la Organización de Naciones Unidas (ONU) en la Cumbre sobre Asentamientos Humanos en Estambul, la definió como una «innovación urbana» ejemplar (De Sousa Santos, 1998). Es más, el Banco Mundial y la ONU recomiendan los PP como una buena práctica, con potencial para mejorar la salud y el bienestar (Campbell, Escobar, Fenton y Craig, 2018).

El «entusiasmo» generado alrededor del presupuesto participativo produjo algunas preguntas relevantes (Souza, 2004, pp. 161-162), las que responderé a partir de las reflexiones y cuestionamientos de varios autores que han sido observadores de estos procesos:

a) ¿Por qué algunos gobiernos municipales en Brasil optaron por implementar políticas que daban poder a los más pobres, en un país rotulado como clientelista, elitista y sin tradición de compromiso cívico? Aun cuando el PP impulsado por el Partido de los Trabajadores (PT) en Porto Alegre se implementó exitosamente, «una vez que llegaron al gobierno nacional, (...) descartaron los mecanismos participativos y el objetivo de construir una democracia profunda» (Goldfrank, 2007: 53). De hecho, más allá de que no se revigorizó la democracia ni dio voz a la mayoría pobre, la crítica apunta que al asumir la administración se abandonó una de las características del 
PT: sus formas creativas para empoderar a los más pobres a través de la participación popular (Baiocchi y Checa, 2007).

b) ¿Por qué esos gobiernos locales optaron por la participación popular cuando tenían ya una agenda congestionada, con problemas de difícil solución? Los funcionarios públicos electos y los administradores departamentales incorporaron nuevos mecanismos de participación, porque tienen y han tenido el control sobre gran parte del proceso participativo y, por lo tanto, influyen en el contenido y el resultado (Skoggard, 2018).

c) ¿Por qué en una era en que el individualismo y el consumo individual son enaltecidos como símbolos de libertad, algunos políticos adoptan y estimulan la cooperación en la búsqueda de bienes colectivos destinados a grupos sociales excluidos? Uno de los problemas que se detectó en la experiencia de presupuestos participativos de Nueva York fue que, en un contexto de austeridad fiscal, las instituciones participativas tenían problemas para retener participantes voluntarios ( $\mathrm{Su}, 2017)$.

d) ¿Por qué en una era de desilusión con los sistemas políticos y los políticos, las personas han respondido positivamente a las propuestas participativas que vienen, precisamente, de los políticos? No todos han respondido a los PP ya que como muestra Ganuza y Baiocchi (2012), existe desconfianza hacia ellos.

e) Por último, en un tiempo en que la literatura sobre acción colectiva enfatiza que los individuos se guían por el auto-interés, ¿Cuáles son los incentivos a la cooperación que han encontrado los distintos actores, tanto colectivos como individuales? A partir de la literatura disponible, se muestra que los individuos sí se mueven por el auto-interés, y los modelos de acción colectiva son robustos para explicar por qué un vecino participa en el PP de su barrio y no en el de al lado y por qué el número de participantes es mínimo respecto de quienes deberían hacerlo. Por otra parte, un PP es en sí mismo un incentivo a la cooperación, ya que implica ponerse de acuerdo en qué gastar, proceso que no se sostiene en los individuos sino en la burocracia municipal. Dicho de otro modo, el incentivo 
viene -como muestra buena parte de los casos disponibles- de la institucionalidad municipal y el alcalde que gobierne.

En Porto Alegre, el presupuesto participativo fue exitoso como un modelo para movilizar a las comunidades -incluidos los pobres-, mejorar el acceso a infraestructuras y servicios de pequeña escala, y transformar la ciudadanía. (Abers, Brandão, King y Votto, 2018, p. 1).

Sin embargo, en una segunda vista, con una tasa de participación por debajo del $3 \%$ de la población y la pérdida de interés de los grupos que desean ver cumplidos sus deseos, el éxito de Porto Alegre no es particularmente impresionante (Masser y Mory, 2018). Es más, el apoyo político para el presupuesto participativo en su lugar de nacimiento ha disminuido a través de los años, culminando con su suspensión en Porto Alegre en 2017 (Abers, Brandão, King y Votto, 2018, p. 1).

\section{Y POR Último, cómo eVAluar un Presupuesto Participativo. Un EJERCICIO DE CHECK LIST}

Más allá de las críticas, el PP es un mecanismo atractivo: es políticamente moldeable, se está simplificando hasta entenderse como un conjunto de procedimientos para la democratización de la demanda y con ello importa más para la presupuestación (Ganuza y Baiocchi, 2012) que para el fortalecimiento de la democracia.

Y aquí parece centrarse el aporte de los PP, democratizar la agenda de políticas públicas locales y poner en cuestión la inversión anual que realizan los municipios, lo que no es poco para incentivar el compromiso y accountability de los vecinos de una comuna ya que en tres pasos simples y siguiendo el cuadro $\mathrm{N}^{\circ} 1$, pueden evaluar su propia experiencia o la de comunas cercanas. 


\section{CuAdro N $^{\circ}$ I. Descripción del NiVEl De COMPRomiso}

Y ACCOUNTABILITY EN UN PRESUPUESTO PARTICIPATIVO

i. Antes del Presupuesto Participativo:

1.1. Proponer la puesta en marcha de los Presupuestos Participativos de carácter vinculante, autorreglamentado y universal.

1.2. Mostrar previamente el compromiso del municipio a gestionar, financiar y ejecutar las obras en el orden priorizado. Así como a realizar una supervisión compartida -con el grupo motor ciudadano y su grupo de seguimiento de obrasdel estado de ejecución de las propuestas, elaborando un calendario para ello.

1.3. Establecer la cuantía y procedencia del presupuesto destinado al Programa de Presupuestos Participativos.

1.4. Reconocer al Grupo Promotor como órgano de representación e interlocutor vecinal en dicho proceso.

1.5. Informar de posibles contrataciones relativas a Presupuestos Participativos, como por ejemplo, la contratación de un agente dinamizador.

2. Durante el Presupuesto Participativo:

2.1. Informar del comienzo de los Presupuestos Participativos con la celebración de Asambleas Informativas.

2.2. Informar del comienzo y finalización de las Asambleas Vecinales para el debate y elaboración de propuestas.

2.3. Informar cuándo se inicia el periodo de viabilidad técnica de las propuestas.

2.4. Informar de que los Presupuestos Participativos han entrado en la fase de votación de propuestas.

2.5. Informar de que ha concluido el proceso de votaciones de Presupuestos Participativos.

3. Finalizado el Presupuesto Participativo:

3.1. Agradecer la participación de manera expresa y proponer vincular la permanencia y estabilidad del proceso en la futura acción de gobierno, independientemente de cambios en la composición de la Corporación Local.

3.2. Presentación y balance del proceso de los Presupuestos Participativos.

3.3. Informar de los resultados y dar cuenta por parte del Grupo Promotor de las propuestas priorizadas en las votaciones.

3.4. Publicar en el acta de sesión la lista de propuestas con la siguiente información: zona, enunciado de la propuesta, votos recibidos y prioridad atribuida.

3.5. Informar de posibles limitaciones presupuestarias devenidas.

3.6. Informar de que los proyectos de Presupuestos Participativos se están redactando por la oficina técnica respectiva.

3.7. Informar del comienzo de los proyectos y obras, por ejemplo: «Se está trabajando en la mejora de la tubería de suministro de agua potable de la Plaza de la Constitución».

3.8. Informar del seguimiento de los proyectos y obras, por ejemplo: «Estando a punto de concluir la de abastecimiento de agua potable de la Plaza de la Constitución».

3.9. Informar de la finalización de los proyectos y obras de Presupuestos Participativos.

Fuente: Fernández, J. L. (2015). Instituciones de democracia participativa a nivel local: características e impacto de las propuestas participativas sobre políticas públicas. Anuario de Derecho Municipal, (9), 143-174. Con algunas adaptaciones. 
El cuadro anterior, tiene tres etapas sencillas. La primera plantea establecer un orden priorizado que responde tres preguntas importantes ¿por qué se eligieron ciertas alternativas para su consideración?, ¿por qué no se tuvieron en cuenta las demás?, y ¿qué problemas se pasaron por alto? y además permite reconocer al Grupo Promotor como órgano de representación e interlocutor vecinal en dicho proceso. Esto equivale a identificar qué problemas entrarán al PP y quienes serán la contraparte del municipio, resolviendo en la práctica la viabilidad política y quién será objeto de apoyo financiero externo en un tiempo específico conocido por todos, controlando un ambiente que cambia rápidamente generando conflictos en las prioridades (Plant, 2009). En este primer proceso, no da lo mismo si las decisiones se toman a nivel urbano o rural. En gobiernos urbanos las decisiones son tomadas dentro de una relativa estructura burocrática formal, en la cual puede haber una insignificante distancia entre los tomadores de decisiones y los ciudadanos. Lo mismo no puede ser dicho para las municipalidades rurales, donde el proceso de toma de decisión está mucho más atado a lazos personales y sociales (Jacob, 2008).

La segunda etapa es la implementación o «Durante el Presupuesto Participativo", donde las palabras necesariamente se convierten en hechos (Bardach, 2001) y el encadenamiento es directo entre decisión y acción, lo que rara vez se observa en otros procesos ya que al contrario, la interconexión se produce de manera multilineal y no unilineal (Pressman y Wildavsky, 1998). Esto es consistente con lo que informa la literatura disponible, que una mayor participación de la ciudadanía, en el proceso de implementación, es positivo en términos de efectividad en el resultado de una política local determinada (Scott y Macdonald, 1975; Gargan, 1981).

La tercera etapa y final es el equivalente a una evaluación informada y compartida entre el grupo promotor y la burocracia municipal. Este solo proceso muestra que la acción de un gobierno local consiste en producir bienes públicos locales que benefician sin exclusión al conjunto de los ciudadanos, y que para lograrlo más allá de que dispongan de presupuesto, esto se hace en periodos de 
corto plazo (Foucault y Francois, 2005, p.85), una demanda lógica dada la sobre demanda que siempre tensiona la legitimidad por rendimientos de los municipios.

\section{Conclusiones}

La participación y los presupuestos participativos no son conceptos equivalentes ni complementarios a nivel local ya que varían a esta escala de gobierno y entre barrios. Mientras el primero expresa los problemas propios de la definición de conceptos en ciencias sociales, los segundos se estructuran en la definición de gasto municipal. Ambos son deseables y existe extensa literatura que muestra la importancia de la participación para la democracia, pero un instrumento como los PP no define por si solo la calidad de una democracia a nivel local y menos nacional.

La identificación de los PP con la izquierda en América Latina tuvo por respuesta la desconfianza desde la derecha, en un viejo debate sobre la superioridad moral de la izquierda que lo planteó dentro de la búsqueda de una sociedad nueva «construida sobre bases más justas» (Sanchez-Cuenca, 2018: 3). Pero, en la práctica, terminó siendo usado por alcaldes de derecha e independientes, dejando los ideales en su eterna búsqueda de ser alcanzados.

Sin embargo, la relación de esos procedimientos con el liderazgo edilicio y la institucionalidad administrativa es, a lo menos, ambigua. No parece existir diferencias en la discusión sobre su contribución a las políticas públicas locales y barriales, sino a su dependencia del municipio en todo el proceso. En este sentido, los presupuestos participativos son un medio de legitimidad para las autoridades electas, especialmente para los alcaldes y en menor medida para los concejales, pero también para la burocracia municipal. Ambos niveles -el político y el administrativo- están tendiendo a controlar el proceso y lo pueden llevar a lógicas plebiscitarias sobre la legitimidad de quienes gobiernan.

Lo anterior nos lleva a un problema relacionado con la dependencia de los vecinos respecto al apoyo que brinda la burocracia 
municipal al proceso de PP y al presupuesto disponible para llevarlo a cabo. Tal como muestra el caso de Porto Alegre en 2018, sin financiamiento para el proceso y en ausencia de presupuestos sobre los que decidir, se acaba el PP.

Por último, la escala dónde implementar los PP importa y hace la diferencia. Administrar una comuna y administrar un Estado nacional es radicalmente distinto, y cuando se ha buscado generarlos desde arriba hacia abajo, los resultados no han sido alentadores. Del mismo modo, los proyectos político-ideológicos que se pueden implementar a nivel local no necesariamente lo son a nivel nacional y el caso del Partido de los Trabajadores es un buen ejemplo de esa distancia.

\section{BibLIOGRAFÍA}

Andrew, C. y Goldsmith, M. (1998) From Local Government to Local Governance: And beyond? International Political Science Review, 19 (2), pp. 101-117.

Avritzer, L., \& Ramos, A. (2016). Democracia, escala y participación. Reflexiones desde las instituciones participativas brasileñas. Revista Internacional de Sociología, 74(3), e040. doi:http://dx.doi. org/10.3989/ris.2016.74.3.040

Baiocchi, G., \& Checa, S. (2007). The brazilian workers'party: from local practices to national power. WorkingUSA, 10(4), pp. 411-430.

Bardach, E. (2001). Developmental dynamics: Interagency collaboration as an emergent phenomenon. Journal of Public Administration Research and Theory 11.2: 149-164.

Benest, F. (1999). La Función del Gobierno Local en el Restablecimiento de la Cohesión entre los Ciudadanos. Punto de Vista: Fundació Carles Pi I Sunyer D'estudis Autonòmics I Locals.

Borja, R. (1997). Enciclopedia de la política. México: Fondo de Cultura Económica FCE.

Brugué, J., Font, J. y Gomà, R. (2008). Participación y Democracia: Asociaciones y poder local. En: Funes y Adell (editores) Movimientos sociales: cambio social y participación. Madrid: UNED ediciones.

Cabannes Y. y Lipietz B. (2018) Revisiting the democratic promise of participatory budgeting in light of competing political, good governance and technocratic logics. Environment and Urbanization. 30, Issue 1, pp. 67-84 
Cabannes, Y. (2018). Another City is Possible with Participatory Budgeting. University of Chicago Press Economics Books. University of Chicago Press, (number 9781551646923), July.

Campbell, M., Escobar, O., Fenton, C., \& Craig, P. (2018). The impact of participatory budgeting on health and wellbeing: a scoping review of evaluations. BMC public health, 18(1), p. 822.

Cavalcanti, E. y Maia, R. (2000). Contradicciones en un proceso democrático: la práctica del presupuesto participativo en las ciudades brasileñas. En: Revista del CLAD, Reforma y democracia 18, Caracas, Venezuela.

De Sousa Santos, B. (1998). Participatory budgeting in Porto Alegre: toward a redistributive democracy. Politics \& Society, 26(4), pp. 461-510.

Fernández, J. L. (2015). Instituciones de democracia participativa a nivel local: características e impacto de las propuestas participativas sobre políticas públicas. Anuario de Derecho Municipal, 9, 143-174.

Ferris, J. (1993). Iniciativas del gobierno local para la prestación de servicios. Londres: SAGE Publications.

Foucault M. and Francois A. (2005) La politique, influence-t-elle les décisions publiques locales? Analyse empirique des budgets communeaux de 1977 à 2001 Politiques et management public, 23(3), Bordeaux.

Ganuza, E. y Baiocchi, G. (2012). The Power of Ambiguity: How Participatory Budgeting Travels the Globe. Journal of Public Deliberation 8: Iss. 2, Article 8.

Gargan, J. (1981). Consideration of local government capacity. Public Administration Review. 41(6), 649-658.

Goirand, C. (2014). The Worker's Party, from contention to public action: a case of institutionalization. Journal of Politics in Latin America, 6(3), 95-127.

Goldfrank, B. (2005). Los procesos del «Presupuesto Participativo» en América Latina: Éxito, fracaso y cambio. Revista de Ciencia Política, 26 (2). Nuevo México, USA.

Goldfrank, B. (2007). ¿De la ciudad a la nación? La democracia participativa y la izquierda latinoamericana. Revista Nueva Sociedad (212), noviembre-diciembre, pp. 53-66.

Gómez, H. (2015). Securing Social Governability: Party-Movement Relationships in Lula's Brazil. Journal of Latin American Studies, 47 (3), pp. 567-593.

Gómez, H. (2016). Lula, el Partido de los Trabajadores y el dilema de gobernabilidad en Brasil: Fondo de Cultura Económica.

Hill, D. (1980). Teoría democrática y régimen local. Madrid: Instituto de Estudios de Administración Local. 
Hoffmann-Martinot, V. (1999) ¿Hacia una convergencia europea de los modelos de gobierno local? Gestión y Análisis de Politicas Públicas GAPP, 16, pp. 3-16.

Informe GOLD (2007) La Descentralización y la Democracia Local en el mundo. Primer Informe Global. Síntesis del Resumen Ejecutivo. Barcelona: Gobiernos Locales Unidos.

Levy C. (2012). Social Movements and Political Parties in Brazil: Expanding Democracy, the 'Struggle for the Possible' and the Reproduction of Power Structures, Globalizations, 9:6, pp. 783-798.

Markku, K. (2001). Local empowerment: its contributions to decentralization and democracy. ECPR. Joint Sessions of Workshop. Workshop 21: Local Autonomy and Local Democracy. Grenoble, 6 - 11 April. Masser K., Mory L. (2018) Citizens' Participation-How Gamification Can Help Citizens' Participation to Flourish. In: The Gamification of Citizens' Participation in Policymaking: Palgrave Pivot, Cham.

Mora, A. P. (2015). ¿La democracia participativa: utopía o realidad? Criterios, 8(1), pp. 71-101.

Peixoto, T., Sjoberg, F., \& Mellon, J. (2017). A Get Out The Vote (GOTV) experiment on the world's largest participatory budgeting vote in Brazil. British Journal of Political Science.

Plant, T. (2009). Strategic planning for municipalities: ensuring progress and relevance. Performance Improvement, 48(5).

Pressman, J. \& Wildavsky, A. (1973). Implementación. Cómo grandes expectativas concebidas en Washington se frustran en Oakland. México: Colegio Nacional de Ciencias Políticas y Administración Pública, A.C.; Fondo de Cultura Económica.

Sanchez-Cuenca, I. (2018). La superioridad moral de la izquierda. Madrid: Editorial Lengua de Trapo.

Schwartz, P. (2018). ¿Es imposible la democracia liberal? Diario El Mundo. 16/07/, pp. 19-20.

Scott, P. and Macdonald, R. (1975). Local policy management needs: The federal response. Public Administration Review. Vol. 35: 786-794.

Sen, A. (2006). El valor de la democracia. Editorial El Viejo Topo.

Sintomer, Y. (2005). Los presupuestos participativos en Europa: retos y desafíos. Revista CLAD Reforma y Democracia 31, pp. 1-17.

Sintomer, Y. (2007). La participación ciudadana como tendencia política europea., en Arenilla Sáez Manuel (dir.) Villoria Mendieta, Manuel; Iglesias Alonso, Ángel; Delgado Godoy, Leticia (coords.) Los modelos, proyectos y políticas de participación en grandes y medianas ciudades. Madrid. Universidad Rey Juan Carlos, Servicio de Publicaciones: Dykinson. pp. 17- 34.

Skoggard, I. (2018). Albert, Victor 2016. The limits to citizen power: participatory democracy and the entanglements of the state. Chicago, 
IL: The University of Chicago Press. 224 pp. Social Anthropology, 26 (1), pp.130-131.

Souza, C. (2004). Algunas reflexiones sobre el presupuesto participativo. En Marcelo Escobar, Gustavo Badía, y Sabina Frederic (editores). Federalismo y Descentralización en grandes ciudades: Buenos Aires en perspectiva comparada. Buenos Aires: Prometeo Libros, pp 161-179.

Stone, C. (2002). Urban Regimes and Problems of Local Democracy. Paper prepared for Workshop 6 Institutional Innovations in Local Democracy. ECPR Joint Sessions Turin, Italy 22-27 March.

$\mathrm{Su}$, C. (2017). From Porto Alegre to New York City: Participatory Budgeting and Democracy. New Political Science (39) 1, pp. 67-75.

Touraine, A. (1997). El regreso del actor. Buenos Aires: Eudeba.

Trounstine, J. (2009). All Politics Is Local: The Reemergence of the Study of City Politics. Perspectives, 7(3), pp. 611-818

Wampler, B. (2012). Participatory Budgeting: Core principles and Key Impacts. Journal of Public Deliberation 8 (2), Article 12.

Abers, R., I. Brandão, R. King, and D. Votto. (2018). Porto Alegre: Participatory Budgeting and the Challenge of Sustaining Transformative Change. World Resources Report Case Study. Washington, DC: World Resources Institute. Available online at www.citiesforall.org Avritzer, L. (2017). Participatory budgeting as a democratic innovation: Origins, expansion and limits: Promises and Limits of Democratic Participation in Latin America. In The Two Faces of Institutional Innovation: Edward Elgar Publishing.

Pagani, M. y Arce, E. (2008). El presupuesto participativo como política pública de participación ciudadana: debilidades y fortalezas de la experiencia platense. V Jornadas de Sociología de la UNLP. Universidad Nacional de La Plata. Facultad de Humanidades y Ciencias de la Educación. Departamento de Sociología, La Plata.

Pedreros, C. (2007). Presupuestos Participativos: Al Rescate de la Voz Ciudadana Santiago, Chile. Diario El Ciudadano. 9 de septiembre de 2007. SUBDERE (2008). Los Presupuestos Participativos en el espacio local. Documento de trabajo (1). Santiago, Chile: División de Municipalidades.

Torcal M., Montero J. y Teorell J. (2006). La participación política en España: modos y niveles en perspectiva comparada. En Ciudadanos, asociaciones y participación en España (pp. 47-76). Centro de Investigaciones Sociológicas (CIS). 



\section{CONSEJO COMUNAL DE ORGANIZACIONES \\ DE LA SOCIEDAD CIVIL (COSOC)... ¿REAL PROMOTOR DE LA PARTICIPACIÓN CIUDADANA EN EL ESPACIO LOCAL?}

\section{Mila Ríos Lemus"}

De un pueblo a otro hay una prodigiosa diversidad de costumbres, temperamentos, caracteres. Solo hay una naturaleza

bumana, estoy de acuerdo; pero modificada por religiones, gobiernos, leyes, costumbres, prejuicios y climas, se hace tan

diversa que no podemos buscar entre nosotros lo que sería bueno para la generalidad de los hombres, sino lo bueno para ellos en un momento y país determinado.

Rousseau: «Discurso Sobre el Origen y Fundamentos de la Desigualdad Entre los Hombres»

Los objetivos que pretende abordar este trabajo se resumen, básicamente, en tres; el primer objetivo es desarrollar un marco conceptual que nos acerque al concepto de participación ciudadana en la gestión pública prevaleciente en nuestro país, desde allí explorar las intenciones ( «buenas») que motivaron la creación de la figura: COSOC, Consejos Comunales de Organizaciones de la Sociedad Civil, enfatizando aspectos tales como: atribuciones, marco normativo, tránsito histórico para derivar en la actual figura, comparación con su símil anterior, entre otras. Un segundo objetivo está dado por una suerte de evaluación respecto al desempeño que ha tenido la figura

Administradora Pública, UDEC. Magister en Gerencia y Políticas Públicas UAI, estudiante doctorado Ciencia Política, UC. 
COSOC luego de una relativa corta vida, si se considera una entrada en vigor posterior a la promulgación de la ley 20.500 en febrero del año 2011. Un tercer y último objetivo se refiere a los desafíos que debiesen movilizar, no solo a la institucionalidad COSOC, sino que también debiese motivar una nueva lógica de tratamiento hacia la sociedad civil y al desarrollo de los territorios.

\section{ORIGEN Y PROPÓSITO}

\section{Introducción: Antecedentes Generales, Principales Propósitos y Marco Normativo}

La participación ciudadana, expresada en los respectivos mecanismos y niveles, depende directamente de la normativa existente en cada país. En el caso de Chile, existen acuerdos internacionales y cuerpos legislativos que generan márgenes de acción en los cuales la participación ciudadana puede desarrollarse.

Existe un hecho declarativo en el cual se fundamenta la concepción de la participación ciudadana en la gestión pública en Chile; evaluar la efectividad de esta declaración motivaría un capítulo por sí mismo; dejaremos esta idea fija en la dimensión de lo declarativo, así pues, encontramos coherencia en ámbitos, tales como el internacional, ya que la normativa de Derechos Humanos reconoce como tal, la manifestación y asociación ciudadana, por lo que los Estados deben considerar y acoger la creación y extensión de estas instancias. Es en ese sentido que el Gobierno de Chile contempla a la participación ciudadana en la gestión pública como un lineamiento base para el desarrollo de la ciudadanía y la democracia, a través de la rendición de cuentas, el control ciudadano y la participación en diversos procesos de toma de decisiones en la gestión e implementación de políticas públicas.

Dichas apreciaciones se encuentran consagradas en la carta Iberoamericana de Participación en la Gestión Pública, aprobada en Lisboa el año 2009 y suscrita por nuestro país, en la cual se define 
a la participación como un proceso de construcción social de las políticas públicas, que conforme al interés general de la sociedad democrática, canaliza, analiza, da respuesta o amplía los derechos económicos, sociales, culturales, políticos y civiles de las personas y derechos de las organizaciones grupales en que se integran, así como de las comunidades, pueblos indígenas y afrodescendientes (CLAD, 2009).

Podemos decir entonces que, en consideración de lo anterior, se hace estrictamente necesario que los poderes públicos velen por la existencia de un marco normativo común y mínimo que actúe como marco legal para todas las organizaciones y que equilibre en primera instancia la libertad asociativa con el acceso y participación ciudadana, y, por otro lado, proteja las libertades y derechos fundamentales posiblemente afectados en el ejercicio de las actividades mencionadas. La importancia de esto radica en la innegable labor que realizan las asociaciones en la actividad social y política del país. Las organizaciones contribuyen en la construcción y expansión de la democracia y la ciudadanía, al aportar en el diseño y ejecución de políticas públicas, representar los intereses ciudadanos ante los poderes estatales y velar por la protección de la probidad y transparencia en las decisiones públicas (Historia de la Ley No 20.500,2011).

Así mismo la ley reconoce especialmente, la función fundamental que cumplen las organizaciones sin fines de lucro en el desarrollo de actividades que buscan alcanzar metas y propósitos colectivos; así la citada ley sobre asociaciones y participación ciudadana en la gestión pública pretende abordar aspectos relevantes de lo mencionado y que tiene en su eje fundacional, promover una participación ciudadana efectiva, que fortalezca el sistema democrático a través de la legitimidad de las acciones públicas (Ley N² 20.500, 2011)

La ley de participación ciudadana encuentra su fundamento jurídico central en la Constitución Política de la República, la cual en su artículo $1^{\circ}$ plantea el derecho de las personas a participar con igualdad de oportunidades en la vida nacional, como también, en el artículo $19^{\circ}$ inciso 15 respecto al derecho de asociarse sin permiso previo y gozar de personalidad jurídica. En el mencionado cuerpo 
legal se declara específicamente en el artículo $\mathrm{N}^{\circ} 69$ que «el Estado reconoce a las personas el derecho de participar en sus políticas, planes, programas y acciones». Para cumplir con tal reconocimiento, la ley modifica cinco cuerpos legales distintos. En consideración del objeto de estudio, destaca la modificación a la Ley Orgánica Constitucional de Bases de la Administración del Estado, explicitando en el título IV el derecho de los ciudadanos a participar en la gestión pública, y la modificación de la Ley N 18.695 Orgánica Constitucional de Municipalidades, reemplazando al Consejo Económico Social Comunal (CESCO) -impuesto en dictadura-, por el Consejo Comunal de Organizaciones de la Sociedad Civil (COSOC), lo que otorgó a las organizaciones representantes, facultades informativas y consultivas para incidir en el diseño, ejecución y evaluación de políticas públicas comunales. Además, plantea el rediseño de instancias de participación a nivel local, incluyendo, por ejemplo, nuevos mecanismos como lo son los presupuestos participativos (Marín \& Mlynarz, 2012).

En resumen, los aspectos centrales de la Ley 20.500 son:

1. Genera un nuevo marco jurídico para la Asociatividad. La Ley estipula la creación de "organizaciones de interés público", las cuales se conforman por personas jurídicas sin fines de lucro cuyo fin es la promoción del bien común. Para este cometido se crea el registro de organizaciones a cargo del Registro civil en estrecha dependencia de las actualizaciones que realicen los Municipios y otros órganos de la administración del Estado. La Ley crea además el Fondo de Fortalecimiento de las Organizaciones de Interés Público y un Consejo Nacional del Fondo. El Fondo se constituirá por donaciones y aportes realizados a título gratuito, recursos que provengan de otros órganos del Estado, aportes de cooperación internacional recibidos a cualquier título y aportes extraordinarios u ordinarios que la Ley de Presupuestos contemple anualmente. Respecto al Consejo, este deberá aprobar los requisitos y las bases generales para la postulación de programas y proyectos para ser financiados por 
el fondo en el país y deberá, además, adjudicar programas o proyectos de carácter nacional postulados anualmente.

2. Establece la participación como un derecho ciudadano.

3. Instaura una nueva institucionalidad denominada «Consejos de la Sociedad Civil».

4. A nivel municipal, instaura de manera obligatoria los «Consejos Comunales de Organizaciones de la Sociedad Civil» y estipula la creación de una Ordenanza de Participación Ciudadana, la cual debe contener la tipología de organizaciones que deberán ser informadas y consultadas, así como también las épocas o fechas en las cuales se llevará a cabo este proceso. Bajo la Ley 18.695, la Ordenanza Municipal deberá ser elaborada por el alcalde con acuerdo del Concejo Municipal y contener los medios e instrumentos que materializan la participación, como lo son por ejemplo, Fondos Concursables, Consultas Ciudadanas, Presupuestos Participativos, Consejos Comunales de la Sociedad Civil, entre otros.

\section{Breve reseña histórica: Del CODECO a los COSOC, un largo camino para el escenario actual}

Los procesos históricos ocurridos en Chile durante los años 70 y 80 , dieron paso al proceso de cambio desde un régimen dictatorial a uno democrático; este periodo se denominó «proceso de transición", concentrado durante los años 90. Es en este periodo donde se observan significativos esfuerzos para promover la participación social y establecer condiciones mínimas para participar. El énfasis estuvo puesto en promover una mayor descentralización, fortalecer los gobiernos locales y la participación ciudadana; así lo ratifica Montecinos (2006), la participación ciudadana fue el elemento distintivo en el desarrollo de la gestión pública, pasando a ser además componente principal de la descentralización y la modernización del Estado; los municipios fueron parte de este proceso (Montecinos, 2006). Hay que reconocer que entre estos dos grandes propósitos, descentralización y participación ciudadana, existe una relación 
directa y positiva. Sin embargo, la participación ciudadana se presentó en forma más bien instrumental al primer propósito.

Fue con el gobierno de Patricio Aylwin que se tomaron las primeras medidas de participación en un contexto complejo, esta fue devolverle el derecho a voto a la ciudadanía, a través de la elección de alcaldes y Concejales en cada comuna a partir del año 1992. Al respecto, los Concejos Municipales desplazaron a los CODECOS, así lo estipuló la Ley que modifica la Constitución Política de la República en materia de Gobiernos Regionales y Administración Comunal, la cual también instauró los Consejos Económico y Social Comunal (CESCO), los Plebiscitos Comunales y la autonomía financiera de las municipalidades (Ley 19.097, 1991).

Esta autonomía financiera fue apoyada por la Subsecretaría de Desarrollo Regional y Administrativo (SUBDERE) que a partir del año 1994 dio inicio al Programa de Fortalecimiento Institucional Municipal (PROFIM) (Montecinos, 2006). El propósito de este programa fue fortalecer las capacidades de los municipios en cuatro áreas: Finanzas y administración presupuestaria; Generación de proyectos de inversión y ordenamiento territorial; Recursos humanos y desarrollo de organizaciones; y Prestación de servicios a la comunidad. Esto permitiría a las municipalidades resolver sus problemas y así aumentar su autonomía, alcanzando mayores niveles de eficiencia y eficacia en la prestación de servicios municipales (DIPRES, 1999).

Además de avances en materia financiera, se dieron importantes avances en otros ámbitos -considerando el bajo nivel de inicio- como es la elección directa de alcaldes y concejales, la incorporación del CESCO, disposiciones para la creación de ordenanzas municipales, y modificaciones a la ley 19.418 sobre juntas de vecinos y demás organizaciones. Aún con lo anterior, no fue hasta iniciando los años 2000, que se retoma los temas de participación ciudadana para su profundización (Valdivieso, 2009).

Los esfuerzos se centraron en generar espacios de participación, sin embargo, la ciudadanía no se presentó de forma activa para utilizar estos mecanismos de la forma esperada. Las críticas apuntaron a la incapacidad de los CESCO de lograr sus objetivos, lo que motivó 
actualizar el marco normativo, ingresando así al Congreso Nacional en el año 2004 la propuesta de Ley 20.500 sobre «Asociaciones y Participación Ciudadana en la Gestión Pública» (Loyola, 2016). A fin de observar las principales diferencias entre el antiguo CESCO y el actual COSOC, se presenta el siguiente cuadro:

\begin{tabular}{|c|c|c|}
\hline \multicolumn{3}{|c|}{ CANTIDAD DE MIEMBROS QUE LO CONFORMAN } \\
\hline & POR LEY & OBSERVACIONES \\
\hline CESCO & $\begin{array}{l}\text { Cantidad de miembros en rela- } \\
\text { ción con el tamaño de población. }\end{array}$ & $\begin{array}{l}\text { En la práctica este criterio no estaba } \\
\text { relacionado con la cantidad de organi- } \\
\text { zaciones activas, en tanto a veces pare- } \\
\text { cía un número excesivo u otras veces } \\
\text { insuficiente. }\end{array}$ \\
\hline COSOC & $\begin{array}{l}\text { Cantidad de miembros en rela- } \\
\text { ción a la cantidad de concejales. } \\
\text { No será un número menor al } \\
\text { doble ni superior al triple de los } \\
\text { concejales en ejercicio. }\end{array}$ & $\begin{array}{l}\text { Al estar en un rango, permite cierta fle- } \\
\text { xibilidad de atender el caso concreto y } \\
\text { observar la cantidad de organizaciones } \\
\text { activas. }\end{array}$ \\
\hline \multicolumn{3}{|c|}{ CANTIDAD DE MIEMBROS POR ESTAMENTO } \\
\hline & POR LEY & OBSERVACIONES \\
\hline CESCO & $\begin{array}{l}\text { Cantidad de miembros por esta- } \\
\text { mento: } 40 \% \text { de juntas de vecinos, } \\
30 \% \text { de organizaciones funciona- } \\
\text { les y } 30 \% \text { de organizaciones re- } \\
\text { presentativas. }\end{array}$ & $\begin{array}{l}\text { Porcentajes establecidos que restaron } \\
\text { flexibilidad a la forma en que se expre- } \\
\text { saba la participación de las organiza- } \\
\text { ciones. }\end{array}$ \\
\hline COSOC & $\begin{array}{l}\text { Cantidad de miembros por esta- } \\
\text { mentos determinado por el regla- } \\
\text { mento de cada consejo }\end{array}$ & $\begin{array}{l}\text { Permite cierta flexibilidad de atender el } \\
\text { caso concreto y observar la cantidad de } \\
\text { organizaciones activas. }\end{array}$ \\
\hline \multicolumn{3}{|c|}{ Presidencia } \\
\hline & POR LEY & OBSERVACIONES \\
\hline CESCO & El alcalde es quien preside. & $\begin{array}{l}\text { El hecho de que sea la autoridad quien } \\
\text { preside esta instancia que por defini- } \\
\text { ción es una instancia de participación, } \\
\text { impuso restricciones al despliegue del } \\
\text { CESCO. }\end{array}$ \\
\hline COSOC & El alcalde es quien preside. & $\begin{array}{l}\text { El hecho de que sea la autoridad quien } \\
\text { preside esta instancia que por defini- } \\
\text { ción es una instancia de participación, } \\
\text { impone restricciones al despliegue del } \\
\text { COSOC. (Por tanto, en este momento } \\
\text { es uno de los puntos centrales para mo- } \\
\text { dificar la ley 20.500) }\end{array}$ \\
\hline
\end{tabular}




\begin{tabular}{|c|c|c|}
\hline \multicolumn{3}{|c|}{ CANTIDAd de Sesiones AnUales } \\
\hline & POR LEY & OBSERVACIONES \\
\hline CESCO & Sesionar al menos cada tres meses. & $\begin{array}{l}\text { Imponía cierta frecuencia que restaba } \\
\text { flexibilidad. cuatro sesiones al año. }\end{array}$ \\
\hline COSOC & Cuatro sesiones anuales mínimas. & $\begin{array}{l}\text { Cuatro sesiones al año que pueden fi- } \\
\text { jarse con flexibilidad, sin embargo, se } \\
\text { ha puesto poco énfasis a que las cuatro } \\
\text { sesiones son las "mínimas». (Este pun- } \\
\text { to igual genera flexibilidad porque se } \\
\text { sabe que hay comunas donde su CO- } \\
\text { SOC sesiona todos los meses) }\end{array}$ \\
\hline \multicolumn{3}{|c|}{ QUORUM PARA SESIONAR } \\
\hline & POR LEY & OBSERVACIONES \\
\hline CESCO & $\begin{array}{l}\text { Quorum para sesionar la mayo- } \\
\text { ría de los consejeros en ejercicio. }\end{array}$ & $\begin{array}{l}\text { Imponía un alto quorum que no facili- } \\
\text { taba sesionar. }\end{array}$ \\
\hline COSOC & Quorum para sesionar de 1/3. & $\begin{array}{l}\text { Se baja el quorum para facilitar sesio- } \\
\text { nar. }\end{array}$ \\
\hline \multicolumn{3}{|c|}{ ROL QUE CUMPLE DENTRO DEL MUNICIPIO } \\
\hline & POR LEY & OBSERVACIONES \\
\hline CESCO & $\begin{array}{l}\text { De asesoría, no contempla fun- } \\
\text { ciones vinculantes. }\end{array}$ & $\begin{array}{l}\text { Una de las principales limitaciones a la } \\
\text { actuación del organismo. }\end{array}$ \\
\hline COSOC & $\begin{array}{l}\text { De asesoría, no contempla fun- } \\
\text { ciones vinculantes. }\end{array}$ & $\begin{array}{l}\text { Una de las principales limitaciones a la } \\
\text { actuación del organismo. }\end{array}$ \\
\hline \multicolumn{3}{|c|}{ MATERIAS EN LAS CUALES PARTICIPA } \\
\hline & POR LEY & OBSERVACIONES \\
\hline CESCO & $\begin{array}{l}\text { Dar su opinión respecto de: } \\
\text { - Plan de Desarrollo Comunal } \\
\text { (PLADECO) } \\
\text { - La política de servicio y progra- } \\
\text { ma anual de acción e inversión } \\
\text { - Cuenta anual del alcalde } \\
\text { - Cuenta anual del Concejo } \\
\text { - Sobre las materias que el alcal- } \\
\text { de y el Concejo sometan a consi- } \\
\text { deración } \\
\text { - Plan regulador comunal (PRC) } \\
\text { - Interponer recursos de reclama- } \\
\text { ción (monitoreo Ley } 20.500 \text { ) }\end{array}$ & $\begin{array}{l}\text { Materias muy delimitadas y con carác- } \\
\text { ter no vinculante. }\end{array}$ \\
\hline
\end{tabular}




\begin{tabular}{|c|c|c|}
\hline COSOC & $\begin{array}{l}\text { - Pronunciarse sobre: cuenta } \\
\text { pública del alcalde; cobertura y } \\
\text { eficiencia de los servicios muni- } \\
\text { cipales; materias que hayan sido } \\
\text { establecidas por el Concejo. } \\
\text { - Formular observaciones a los } \\
\text { informes que el alcalde presen- } \\
\text { tará sobre: presupuesto de inver- } \\
\text { sión, PLADECO, plan regulador. } \\
\text { - Opinar sobre asignación o de- } \\
\text { nominación de los bienes munici- } \\
\text { pales y nacionales de uso público } \\
\text { que se encuentren bajo la admi- } \\
\text { nistración de la Municipalidad. } \\
\text { - Consultar al alcalde respecto a las } \\
\text { materias sobre las cuales debe pro- } \\
\text { nunciarse el Concejo Municipal. } \\
\text { - Solicitar al Concejo Municipal } \\
\text { sobre las materias de relevancia } \\
\text { local que deben ser consultadas a } \\
\text { la comunidad por intermedio del } \\
\text { Consejo. }\end{array}$ & $\begin{array}{l}\text { Materias menos delimitadas y con ca- } \\
\text { rácter no vinculante. }\end{array}$ \\
\hline
\end{tabular}

Fuente: elaboración propia, con base en la ley y reglamento tipo SUBDERE (2011). 


\section{Atribuciones de los COSOC Comunales}

Con la intención de representar la pluralidad social que existe en nuestro país y abrir espacios de carácter consultivo en el ámbito local, se establece de manera obligatoria el Consejo Comunal de Organizaciones de la Sociedad Civil en todos los municipios del país. El COSOC reemplaza al Consejo Económico y Social Comunal (CESCO) y su principal objetivo es apoyar la gestión realizada por el municipio a través de la participación en el diseño, planificación, ejecución y evaluación de políticas públicas municipales. Tanto organizaciones comunitarias funcionales y territoriales, como organizaciones de interés público, organizaciones sindicales, asociaciones de comunidades indígenas, asociaciones gremiales y organizaciones de otras actividades catalogadas como «relevantes» para el desarrollo de la comuna pueden participar e integrar el COSOC.

Los consejeros permanecen cuatro años en el cargo, y deben reunirse al menos cuatro veces al año con la presencia del alcalde, quien ejerce el cargo de presidente del consejo. Entre las principales funciones a desempeñar destaca: pronunciarse en el mes de marzo sobre la cuenta pública que el alcalde emita respecto de su gestión y funcionamiento municipal; manifestar su opinión sobre la eficiencia y cobertura de los servicios municipales; formular propuestas al presupuesto, plan de inversiones, plan comunal de desarrollo y plan regulador; informar al alcalde su opinión acerca de las propuestas de modificación a la denominación o asignación de bienes municipales y solicitar previo acuerdo con el Concejo Comunal ( $2 / 3$ de los concejales en ejercicio) la realización de un plebiscito comunal. Para el desarrollo de lo mencionado, los consejeros deben informar previamente lo acontecido a sus respectivas organizaciones y recibir opiniones y consultas sobre los temas tratados.

Los consejeros son elegidos a través de elecciones periódicas realizadas cada cuatro años. Al respecto la municipalidad publicará un listado con las organizaciones que posean personalidad jurídica y que estén en condiciones de participar (padrón). Para postular al cargo de consejero, el candidato debe ser chileno o extranjero avecindado en el país, tener 18 años de edad (con excepción de los representantes señalados en la Ley 19.418 sobre Juntas de Vecinos y demás Organizaciones Comunitarias), 
tener como mínimo un año de afiliación en la organización a la que representa y no haber sido condenado a pena aflictiva. No podrán participar de la elección los ministros de estado, subsecretarios, miembros del consejo del banco central, gobernadores, secretarios regionales ministeriales, consejeros regionales, contralor general de la república, alcaldes, concejales, miembros y funcionarios del poder judicial, de tribunales electorales regionales, del tribunal calificador de elecciones y de las Fuerzas Armadas, Investigaciones y Carabineros. Pueden votar los representantes legales de cada organización que estén inscritos en el padrón o cualquier otro individuo habilitado por la organización. Serán elegidas las primeras mayorías hasta completar el número de consejeros estipulados en cada categoría, en consideración de que la composición del consejo no puede ser inferior al doble ni superior al triple de los concejales en ejercicio.

Entre las causales de cesación del cargo se encuentra: renuncia aceptada por la mayoría de los consejeros, inhabilidad sobreviniente, extinción de personalidad jurídica de la organización a la que representa, inasistencia injustificada a más del 30\% de las sesiones e incurrir en alguna de las incompatibilidades que consagra la Ley 18.695 Orgánica Constitucional de Municipalidades.

\section{Diferencias entre el Consejo de la Sociedad Civil Comunal y COSOC de Servicios Centralizados}

Dado el desarrollo precedente de la figura COSOC Comunal, a continuación, nos centraremos en los Consejos de la Sociedad Civil de Servicios Centralizados de Cobertura Nacional. Al respecto, la ley señala que son un mecanismo de participación ciudadana en que se vincula a los órganos de la administración del Estado, con representantes de la sociedad civil organizada.

Entre sus objetivos se encuentra acompañar a la máxima autoridad de cada ministerio o servicio público en los procesos de toma de decisiones en políticas públicas. El artículo 74 de la Ley N²0.500 Sobre Asociaciones y Participación Ciudadana en la Gestión Pública establece: 
Los órganos de la Administración del Estado deberán establecer consejos de la sociedad civil, de carácter consultivo, que estarán conformados de manera diversa, representativa y pluralista por integrantes de asociaciones sin fines de lucro que tengan relación con la competencia del órgano respectivo.

Si bien en esencia, ambas figuras cumplen el mismo propósito y en ambos casos sus resoluciones no son vinculantes, no hay que desconocer principalmente dos aspectos:

- Vinculación con las bases sociales: aun cuando ambos se vinculan con las bases sociales, el COSOC comunal se vincula con bases sociales mayormente territoriales, mientras que el Consejo de la Sociedad Civil de un ministerio o servicio público no lo hará necesariamente bajo ese criterio y se vinculará más bien por área temática relacionada a la misión institucional.

- Atribuciones/funciones: la ley 20.500 es mucho más específica y taxativa en el caso de los COSOC comunales, mientras que en el caso de los Consejo de la Sociedad Civil de un ministerio o servicio público es más genérico y los pormenores de su funcionamiento son materia de reglamentación interna de cada entidad.

\section{Aproximación a UNA EVALUACiÓN DE LA FIGURA DE LOS CONSEJOS COMUNALES DE ORGANIZACIONES DE LA SOCIEDAD CIVIL COSOC}

Es necesario considerar que en ningún caso estamos presentando una evaluación que se ajuste a una metodología de evaluación, sino que más bien nos aproximamos a emitir ciertas conjeturas respecto al desempeño de la figura COSOC durante el periodo de vigencia de la ley 20.500, con datos muy básicos. 
CONSEJO COMUNAL DE ORgANIZACIONES DE LA SOCIEDAD CIVIL (COSOC)...

CONFORMACIÓN A NIVEL NACIONAL: PORCENTAJE DE CONFORMACIÓN Y FUNCIONAMIENTO A NIVEL NACIONAL

\section{CONFORMACIÓN COSOC}

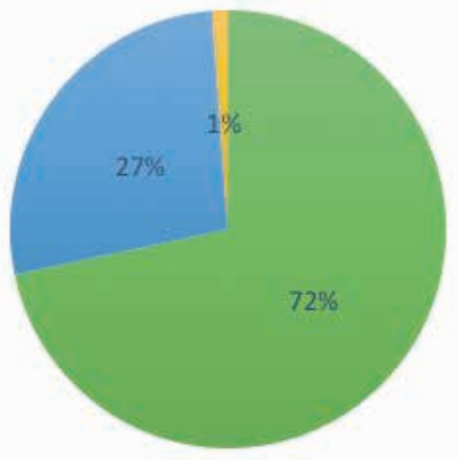

$=\mathrm{Si}=$ No ${ }^{-}$Blanco

Fuente: SUBDERE año 2015

\section{VIGENCIA COSOC}

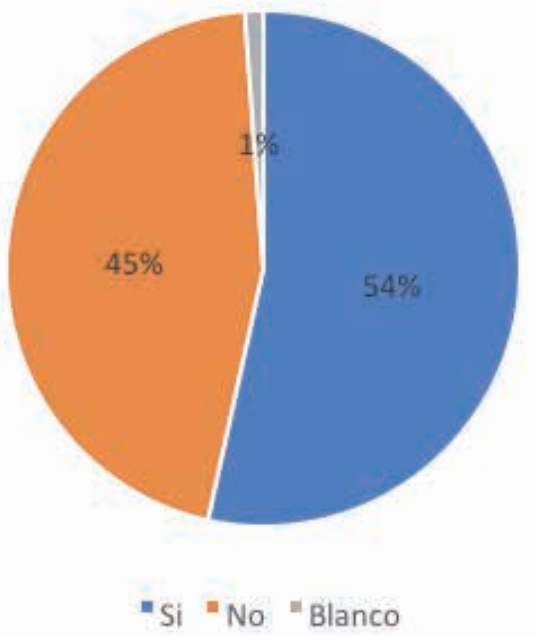

Fuente: SUBDERE año 2018. 
Lo anterior, a pesar de ser un dato muy básico, es significativo en cuanto deja al descubierto ciertas cosas:

1. El número de COSOC, en términos generales decreció con el tiempo. Desde el año 2015 al año 2018.

2. El número de COSOC conformados, no necesariamente importa un COSOC vigente y funcionando.

3. La caída es significativa, de $72 \%$ a $54 \%$.

¿Cómo se explica que las municipalidades no estén dando cumplimiento a lo mandatado por ley?

Aventuramos algunas explicaciones:

La Ley 20.500 carece de mecanismos de fiscalización y sanción que aseguren cumplimiento dejando este a criterio y voluntad del directivo, en este caso del alcalde.

Los incentivos para quienes participan como consejeros no están diseñados con un criterio de sostenibilidad.

La promulgación de una ley, cualquiera sea esta, genera un primer impulso para el cumplimiento. Si los incentivos no están bien diseñados, el cumplimiento decae.

El COSOC en algunos casos recoge y se ajusta al tipo de participación que se realiza en los territorios locales; estos casos se han mantenido, pero en otros, esta figura no se ajusta al tipo de participación que exhiben los territorios. La participación pasa por otras instancias, no se logra canalizar ni promover una participación que converse con este tipo de institucionalidad, en definitiva, no logra hacer sentido con aquello que ocurre en la comuna.

El Consejo Nacional de Participación Ciudadana y Fortalecimiento de la Sociedad Civil, conformado el 14 de enero de 2016, entregó un informe de evaluación de la ley 20.500, con la idea de poder discutir modificaciones a este cuerpo legal, habiendo recogido este informe antecedentes de fuentes primarias, como dirigentes de organizaciones sociales, funcionarios municipales y expertos en estas materias. Respecto al COSOC comunal, el Informe señala las siguientes: 
Participación ciudadana en las municipalidades

El Consejo de la Sociedad Civil (COSOC comunal) es un órgano de participación de la sociedad civil en la gestión municipal y forma parte de su estructura interna.

El COSOC comunal tendrá funciones de control social, participación en todo el proceso de construcción de la política pública municipal e incorporación de observaciones al PLADECO, Plan Regulador, PADEM, Plan de Salud y Presupuesto, propondrá mecanismos y modalidades de consulta y participación, entre otras.

El Concejo Municipal deberá, cuando corresponda, considerar los informes del COSOC y justificar sus decisiones en los casos que no sigan sus recomendaciones. El COSOC rendirá cuenta pública anual ante la ciudadanía.

El presidente del COSOC será elegido entre sus propios consejeros y tendrá derecho a participar en el Concejo $\mathrm{Mu}-$ nicipal con derecho a voz.

El alcalde formará parte del COSOC, con derecho a voz. Deberán asistir a sus sesiones ordinarias y extraordinarias el administrador municipal, el contralor municipal, el SECPLA y el asesor jurídico, en calidad de asesores.

Las municipalidades deberán considerar en su presupuesto los ítems necesarios para el financiamiento de los mecanismos de participación, incluido el COSOC, la asistencia técnica necesaria para ejercer adecuadamente sus funciones y la rendición de cuentas de los consejeros hacia sus organizaciones de base. Entre los ítems necesarios deberán considerarse los gastos necesarios en que incurran los consejeros para cumplir con su función.

El incumplimiento de las obligaciones señaladas en título IV de la Ley de Municipalidades, será sancionado como grave falta administrativa.

Será requisito para postular a ser elegido como integrante del COSOC ser miembro de una organización cuya directiva haya sido calificada por el Tribunal Electoral Regional, esté inscrita en el registro nacional de personas jurídicas sin fines de lucro y hacer entrega de la última memoria y balance de la organización.

Cabe indicar que la División de Organizaciones Sociales DOS, de la Secretaría General de Gobierno SEGEGOB, también elaboró un Informe orientado a presentar propuestas de modificación a la 
Ley 20.500, para lo cual levantaron información de fuentes directas en todas las regiones del país, a través de dirigentes sociales de organizaciones territoriales y funcionales, funcionarios públicos, académicos, expertos en el tema de participación ciudadana y además incorporaron la opinión de residentes chilenos en el extranjero.

\section{ASPECTOS A CONSIDERAR PARA EL FUTURO DE LOS CONSEJOS COMUNALES DE ORGANIZACIONES DE LA SOCIEDAD CIVIL COSOC, EN CHILE}

\section{Principales debilidades de la figura de los COSOC}

De acuerdo con lo planteado precedentemente, en función de los informes señalados, cabe indicar que se ha generado información suficiente para dar cuenta de las debilidades que la Ley 20.500 ha presentado al momento de ponerse en marcha, a partir del año 2011. Existen observaciones e indicaciones de reforma a la ley, a partir de lo planteado por diversos actores sociales de todo el país, para mejorar el acercamiento entre sociedad civil y la gestión pública de los distintos servicios que componen el aparato público.

Específicamente en la gestión de los municipios del país afectos a la implementación de la Ley 20.500, existen claras deficiencias respecto del funcionamiento de los Consejos Comunales de Organizaciones de la Sociedad Civil, toda vez que este organismo, en la pretensión de involucrar la opinión ciudadana en la toma de decisiones de la gestión municipal, es de carácter consultivo y no vinculante, lo cual implica que solo tiene la opción de opinar sin derecho a exigir a la autoridad que sus sugerencias, observaciones o propuestas tengan carácter de obligatoriedad, pues de acuerdo a la ley es solo un órgano de consulta.

Por otra parte, existe consenso en la mirada de dirigentes y funcionarios municipales, en el sentido de que este órgano de representación de organizaciones sociales y de interés público, sea presidido por la primera autoridad local (alcalde), lo cual deviene en un 
contrasentido con el espíritu de la ley, que pretende fortalecer a las organizaciones de la sociedad civil, por tanto debiera ser presidido por miembros de las propias organizaciones que lo componen. En la actualidad solo se puede elegir un vicepresidente en ausencia del alcalde.

Finalmente, otro de los temas sensibles y que ha sido objeto de discusión en todas las instancias de levantamiento de información respecto al funcionamiento de la Ley, se refiere a la certificación de las elecciones de organizaciones funcionales y territoriales, por parte de los Tribunales Electorales Regionales TER, lo que genera una dificultad evidente para los dirigentes de organizaciones sociales, sobre todo en comunas alejadas de las capitales regionales, para quienes este requisito constituye una limitante a la participación fluida que se espera; más bien, lejos de acercarlos a la gestión del municipio respectivo, es un agente desmotivador que no alienta a las organizaciones y a quienes las representan a hacerse parte de estos procesos.

\section{Principales fortalezas}

Dentro de las fortalezas posibles de observar, sin duda que se encuentra la posibilidad de que estos órganos de representación organizacional, a diferencia de los anteriores CESCOS, hayan podido ampliar su ámbito de representación a otro tipo de organizaciones aparte de las convencionales, funcionales y territoriales amparadas en la Ley 19.418 de juntas de vecinos, pues también se amplía y considera la inclusión de sindicatos, asociaciones gremiales, comunidades indígenas y otras que según la ley sean consideradas como de interés público o de actividades relevantes para el desarrollo de cada comuna.

Por otra parte y pese a ser un órgano de carácter consultivo, de todas formas, se han ampliado sus atribuciones, acercando la posibilidad de las organizaciones de influir en aspectos relevantes de la acción del municipio, a través de la implementación de sus servicios, planes, programas y proyectos de desarrollo comunal, frente a los cuales se encuentran convocados a dar opinión sugerir y proponer, 
además de pedir información de la gestión de las autoridades locales, y participar activamente de la cuenta pública anual.

Cabe mencionar en este punto, que en la actualidad existe un convenio de colaboración entre la SUBDERE y el Consejo para la Transparencia, orientado a promover y difundir el desarrollo de Cuentas Públicas Participativas a nivel local, proceso en el cual los COSOC cumplirán un rol fundamental para el mejor desarrollo de esta iniciativa.

\section{Recomendaciones}

Una de las cuestiones fundamentales, observables al momento de analizar el desarrollo de la gestión local participativa en diversos municipios del país, dice relación con la figura de la primera autoridad local, como un actor clave para el impulso y desarrollo de una gestión «implicativa» que considere a los ciudadanos, no solo desde la mirada de la democracia representativa para la elección de representantes y autoridades, sino también más allá: considerar la opinión e influencia de los ciudadanos, a través de diversos mecanismos de democracia directa, lo cual permite una mayor legitimidad democrática para el desarrollo de su acción política.

De hecho, el aspecto a considerar se refiere precisamente a reforzar el compromiso de las autoridades locales con este tipo de gestión de cara a los ciudadanos, pues se ha demostrado que es un elemento sine qua non para la implementación de mecanismos de participación ciudadana en el espacio local, la «voluntad política» de alcaldes y concejales electos, para que estos procesos sean posibles y además se sostengan en el tiempo, como una manera innovadora de involucrar a los vecinos en la acción pública de los municipios.

Otro tema pertinente a considerar se refiere a los espacios de formación ciudadana y cívica para los dirigentes de organizaciones sociales. Este esfuerzo debe ser permanente y sistemático, para lo cual toda la institucionalidad pública pertinente debiera trabajar coordinadamente para sostener estos procesos, necesarios y requeridos por la diversidad de representantes de organizaciones, que no siempre 
cuentan con las voluntades, los recursos y las instancias adecuadas para mantenerse informados y actualizados en su rol dirigencial. Desde esta perspectiva, el trabajo coordinado de instituciones afines al tema, con los municipios, debiera abrir nuevos canales de comunicación con las «bases sociales» y su dirigencia, toda vez que, en el actual escenario jurídico vigente, estos roles fundamentales para el fortalecimiento de un sólido «entramado social», no poseen los debidos y adecuados alicientes o reconocimientos que motiven su acción.

Finalmente, será un rol de los municipios, de sus autoridades y funcionarios respectivos, el utilizar de la mejor manera posible este espacio de participación que la ley permite, reconociendo que, en muchos municipios del país, este órgano ha propiciado efectivamente un diálogo virtuoso entre la autoridad y los ciudadanos, para un desarrollo comunitario más armónico y pertinente a las necesidades y requerimientos de la ciudadanía.

\section{Conclusiones}

Con todo y tal como se señaló en un inicio, durante las últimas décadas, en Chile, la promoción de la participación ciudadana ha estado vinculada con los objetivos de promoción de la descentralización; en tanto ambos objetivos no son un fin en sí mismo, ambos instrumentalmente persiguen bienes públicos tales como: un desarrollo territorial más armónico, una sociedad más participativa que facilite la cohesión social, procesos de desarrollo más sustentables, contribuir al fortalecimiento de la democracia, entre muchos otros; por tanto, dadas las características de los objetivos finales que persiguen, resultan ser procesos y herramientas de desarrollo que además de ser compatibles, son absolutamente complementarios.

La historia reciente parece mostrarnos una creciente preocupación e incorporación de la participación ciudadana en la gestión pública. Aun cuando existen legítimas dudas por las motivaciones reales de esta incorporación, es necesario reconocer avances en este sentido. Los avances son aún limitados y en lo que refiere al tema 
en cuestión, podemos señalar y fundamentar las siguientes consideraciones:

El CESCO y el COSOC si bien no son el mismo instrumento de involucramiento ciudadano, las modificaciones y mejoras en la versión actual (COSOC) no dejan de ser eso, una versión mejorada de los anteriores CESCOS y mantiene las mismas deficiencias del origen: no es una entidad movilizadora de la participación local, no tiene una incidencia real en la gestión local y los énfasis están puestos más en la forma que en el fondo, es decir, podemos decir que a nivel nacional hay un porcentaje de COSOC constituidos, pero no sabremos si aquellos COSOC están efectivamente generando participación ciudadana en la gestión local o instalando temas propios de las organizaciones sociales en la agenda municipal.

Tal como se mencionó precedentemente, existen antecedentes críticos fundados, tanto del diseño como de la implementación de la Ley 20.500, esto desarrollado por instancias como el Consejo Nacional de Participación Ciudadana y la División de Organizaciones Sociales del Ministerio Secretaria General de Gobierno, principalmente. Aun cuando todo lo expuesto por estas instancias resulta atendible y razonable, cabe cuestionar si a la luz de los antecedentes conocidos es necesario persistir en este tipo de figura de representación ciudadana, que no ha ofrecido resultados similares en las comunas donde se ha implementado.

Esa última idea, se refuerza al observar la gestión de diversos municipios del país, ya que los resultados obtenidos en la implementación y funcionamiento de los COSOC comunales, muestran una estrecha relación con la capacidad de gestión y la voluntad política de sus autoridades locales (alcaldes, concejales) y la capacidad técnica de sus equipos profesionales, pues existen experiencias demostrables de municipios donde los COSOC constituyen una instancia oportuna de vinculación de las organizaciones sociales y la sociedad civil, con la gestión de sus municipios, generando vínculos virtuosos de cooperación y comunicación (Victoria, San Antonio, Peñalolén, La Serena). 
De tal forma, las entidades que han presentado sus propuestas de modificación de la ley 20.500, en lo referido a la gestión local, y del COSOC específicamente, se remiten a proponer mejoras que potencien los atributos que se encuentran en la base de su diseño original, no poniendo en tela de juicio la relevancia de mantener este tipo de institucionalidad.

Los antecedentes expuestos respecto a la evaluación de la puesta en marcha de la conformación COSOC nos muestra una figura que no ha sido eficaz en la consecución de su objetivo fundamental, cual es generar un acercamiento de colaboración y cooperación entre los requerimientos ciudadanos y la gestión de los municipios. Es más, se trata de una figura que se ha replegado con el tiempo.

Reconociendo que existen casos en los cuales los COSOC han cumplido el mandato para el cual fueron creados, también se hace necesario reconocer que la figura es ineficaz en muchos casos, la mayoría, y que dado lo simple y contundente de la evidencia, es necesario abrir la posibilidad a otro tipo de fórmulas que canalicen la participación de la sociedad organizada en la gestión local.

¿Qué se puede hacer en aquellos casos en que la figura COSOC ha dado resultados positivos?, pues bien, en aquellos casos, se sugeriría adoptar las propuestas de mejoras de la figura COSOC, que van de la mano de las sugerencias tanto del Consejo Nacional de Participación Ciudadana como de la DOS.

¿Qué se puede hacer en aquellos casos en que la figura COSOC no ha dado resultados positivos?, pues bien, se sugiere eliminar la pretensión de aplicar reglas generales a la totalidad territorial, de este modo, se propondría otorgar autonomía a los territorios, a objeto de que sean los propios municipios, en conjunto con sus organizaciones sociales y tejido asociativo, quienes puedan diseñar y declarar el tipo de institucionalidad participativa que quieren poner en marcha, formalizar esa declaración y otorgar flexibilidad en cuanto a composición, atribuciones y otras para la implementación. De este modo se estaría atendiendo la diversidad territorial y cultural de cada territorio comunal, reconociendo la capacidad de las entidades locales para asumir los desafíos que la participación 
ciudadana demanda de las estructuras institucionales, tanto nacionales, como, sobre todo, subnacionales.

\section{BibliOgRAFÍA}

Cerdá Díaz J. y Rodríguez Barredo J. M. (1999). En busca de la calidad. Las Cartas de Servicio como fórmula de compromiso con los ciudadanos. Boletín de la ANABAD, 1999, 3-4, pp. 223-236. Disponible en : http://eprints.rclis.org/15220/1/CERDA_DIAZ_Julio_En_busca_de_la_calidad.pdf

CLAD (2009). Carta Iberoamericana de Participación Ciudadana en la Gestión Pública. [online] Lisboa: CLAD, pp.2-7. Recuperado a partir de https://goo.gl/pd6kNi [Acceso 3 Dic. 2017].

Consejo Nacional de Participación Ciudadana (2017) Disponible en http:// participemos.gob.cl/wp-content/uploads/2017/06/informe-final-1. pdf

Historia de la Ley No 20.500 Sobre asociaciones y participación ciudadana en la gestión pública. (2011). In: Congreso Nacional. [online] Valparaíso: Biblioteca del Congreso Nacional de Chile, p.5 Recuperado a partir de https://goo.gl/YBvcxX [Acceso 8 Oct. 2011].

Marín, T. \& Mlynarz, D. (2012). Monitoreo a la Normativa de Participación Ciudadana y Transparencia Municipal en Chile. [online] p.13 Recuperado a partir de https://goo.gl/rCbKYm [Acceso 9 Oct. 2017].

Montecinos, E. (2006). Descentralización y Democracia en Chile: Análisis sobre la Participación Ciudadana en el Presupuesto Participativo y el Plan de Desarrollo Comunal. Revista de Ciencia Política, [online] 26(2), p.191-208. Recuperado a partir de https://goo.gl/YjmYoK [Acceso 6 Oct. 2017].

Valdivieso, P. (2008). Propuesta para el progreso de la administración pública y de la gestión local con participación ciudadana, desde la perspectiva del caso de Chile. Documentos y Aportes en Administración Pública y Gestión Estatal, Santa Fe, s/v., n. 11, p. 89-123, jul.dez. 2008 https://seer.ufrgs.br/debates/article/viewFile/26117/16875 


\section{CARTAS DE SERVICIO. UNA HERRAMIENTA DE PARTICIPACION CIUDADANA PARA LA MEJORA DE LOS SERVICIOS MUNICIPALES EN CHILE. EXPERIENCIA DE LA SUbDERE*}

\section{Marcelo Rojas Belmar"*}

Subsecretaría de Desarrollo Regional

\section{I.- GESTIÓN LOCAL PARTICIPATIVA: EL MUNICIPIO AL SERVICIO DE LOS CIUDADANOS}

La Gestión Local Participativa es el eje articulador de este artículo, y se enmarca en el contexto de impulsar y estimular la implementación de diversos mecanismos de participación ciudadana en la gestión de los municipios de Chile, a objeto de involucrar progresivamente a los ciudadanos, en los procesos de implementación de políticas públicas en el espacio local. Lo anterior, en el entendido de que los largos procesos de modernización del Estado en nuestro país arrastran aún variadas tareas pendientes con el rol de la ciudadanía en la gestión de los asuntos públicos. Lo anterior, demanda una renovada concepción de la participación ciudadana en la gestión pública en general, de la gestión municipal en particular, permitiendo nuevas formulaciones conceptuales y modos de operación en la práctica, que generarían círculos virtuosos entre la acción

\footnotetext{
Subsecretaría de Desarrollo Regional y Administrativo del Ministerio del Interior y Seguridad Pública.

** Licenciado en Trabajo Social de la U. de la Frontera, Magister en Investigación Gestión y Desarrollo Local de la U. Complutense de Madrid. Asesor del Departamento de Desarrollo Municipal de la SUBDERE.
} 
del Estado y los requerimientos cada vez más exigentes, informados y expectantes por parte de los ciudadanos.

Durante los últimos años es posible observar en esta línea, diversos mecanismos y herramientas que han permitido una mayor apertura de la acción de la política pública, de cara a los ciudadanos, por ejemplo en las formas de ejercicio de una modalidad en la asignación participativa de recursos de inversión, a través de una herramienta como los Presupuestos Participativos, que permite a los ciudadanos involucrarse en el proceso de toma de decisiones respecto a una pequeña parte del presupuesto municipal para la elección de proyectos de desarrollo comunitario; el desarrollo de cuentas públicas participativas en la gestión de distintos servicios y reparticiones públicas centralizadas o regionales como los GORE, de los cuales existen interesantes experiencias que revisar; en la instalación de nuevos organismos de Estado mediante procesos de diálogos ciudadanos que buscan no solo dar a conocer el sentido y trascendencia de una política pública, sino que además recogiendo la incidencia ciudadana en dichos procesos, como ha venido siendo la creación de nuevas comunas y de nuevas regiones que ponen de relieve el rol de la ciudadanía en los procesos de descentralización; la puesta en marcha de la ley de acceso a la información pública o la aplicación de instrumentos de participación ciudadana a escala local, como las Consultas Ciudadanas o las Cartas de Servicio o Cartas Ciudadanas.

Es en ese marco, donde la Subsecretaría de Desarrollo Regional y Administrativo busca aportar a la gestión municipal con instrumentos de participación que permitan una acción proactiva de los ciudadanos hacia los municipios, tal como se ha podido observar en estas prácticas de implementación de Cartas de Servicios Municipales. 


\section{II.- CARTAS DE SERVICIOS MUNICIPALES EN LA GESTION DE LA Subdere}

En los últimos años desde la SUBDERE se ha venido desplegando una importante cantidad de iniciativas orientadas a fortalecer los procesos de descentralización del país, en todas las áreas que estas materias implican. Ello ha permitido generar importantes avances, para poner a los ciudadanos de cada territorio subnacional, en el centro de la atención y del quehacer de las políticas públicas.

Es por ello que la iniciativa de generar e implementar la herramienta participativa de las Cartas de Servicios Municipales, se enmarca directamente en esta dirección, contribuyendo a fortalecer el proceso de descentralización y modernización del Estado, orientado a promover y proporcionar instrumentos de gestión pública que permitan un mayor acercamiento y vinculación ciudadana con la gestión pública en general y la gestión municipal en particular, en correspondencia con las necesidades e intereses ciudadanos de cada espacio local, y los actuales lineamientos del Programa de Gobierno del presidente Sebastián Piñera, bajo cuya primera administración se promulgó la Ley 20.500 Sobre Asociaciones y Participación Ciudadana en la Gestión Pública.

En este contexto, el mecanismo participativo de las Cartas de Servicios Municipales, permite al gobierno local generar una instancia de mejora continua respecto de los programas y servicios que este ofrece a la ciudadanía, comprometiendo públicamente la mejora en procesos de trámites, información y estándares de calidad en la provisión de servicios municipales, haciendo de la gestión local un proceso de mejoramiento continuo, en el contexto de los procesos de gestión de calidad de los servicios municipales, incorporando la variable de participación ciudadana.

Por otra parte, las Cartas de Servicios Municipales, introducen un elemento de control social en el ámbito de la gestión municipal, en la medida que a partir de este instrumento, los ciudadanos asumen un rol más protagónico en ámbitos que atañen por una parte a la gestión pública local, y por otra, a la mejora de la calidad de vida de los propios vecinos que habitan el territorio comunal. 
De tal forma, el presente artículo pretende dar a conocer los principales contenidos técnicos y metodológicos del mecanismo participativo de las Cartas de Servicios, con la idea de poder replicar buenas prácticas de esta herramienta de gestión local participativa, rescatando experiencias concretas de implementación de este mecanismo, en diversas comunas del país.

\section{III.- CARTAS DE SERVICIO Y GESTIÓN DE CALIDAD DE LOS SERVICIOS MUNICIPALES: EXPERIENCIA DE LA SUBDERE}

Las Cartas de Servicios son instrumentos de mejora de la calidad de los servicios públicos mediante las cuales, los distintos órganos de la Administración Pública, ya sea en el nivel central o específicamente en el espacio de la gestión municipal, explicitan y difunden los servicios que se prestan, los derechos y deberes de los ciudadanos y usuarios en relación con los mismos, los compromisos de calidad asumidos por la institucionalidad pública en su prestación, haciéndose partícipes a los ciudadanos de cada espacio territorial, de los procesos de mejora y transparencia en la gestión de los municipios.

En este contexto, la Subsecretaría de Desarrollo Regional y Administrativo SUBDERE, en el marco de las políticas de descentralización llevadas a cabo en nuestro país, aspira aportar al desarrollo de un municipio al servicio de los ciudadanos, para que actúe como el principal motor del desarrollo económico, social y cultural de los habitantes de cada comuna del país. Lo anterior, puesto que para nosotros, el municipio es la puerta de entrada del ciudadano al aparato público, para el ejercicio de sus derechos, y uno de los principales gestores del desarrollo comunal.

En su afán por establecer estándares de calidad en la provisión de servicios municipales, esta Subsecretaría a través de su Departamento de Desarrollo Municipal, ha generado diversas estrategias orientadas a procurar mejoras en la entrega de servicios y programas municipales, de cara a las necesidades de la comunidad. En el entendido que el ciudadano, hoy, busca encontrar en el municipio una primera instancia para la satisfacción de sus demandas y para 
la obtención de determinados bienes y servicios públicos de calidad de parte del mismo.

De tal forma, a los municipios les corresponde un papel esencial en este desafío, por cuanto son las instituciones con mayor cercanía a los ciudadanos, como se mencionó anteriormente. El objetivo estratégico es que los municipios se constituyan en verdaderos Gobiernos Locales, ampliando las actuales funciones que desarrollan y entregándoles un mayor grado de autonomía en la gestión.

Es en este escenario, donde cabe la mención al impulso que se otorgó en su momento a la implementación de una primera generación de servicios municipales estandarizados, integrada por los servicios que reiteradamente se mencionan en diversos estudios y en la misma experiencia de la SUBDERE, como básicos para el desempeño de las funciones municipales y que son cuantitativamente los más demandados por la población. Dichos servicios son:

\section{A.- Servicios a la Comunidad}

- Servicio de construcción y áreas verdes y jardines

- Servicio de recolección, transporte y disposición de residuos sólidos domiciliarios

- Servicio de instalación y mantención de alumbrado público

B.- Servicios de Protección Social

- Servicio de actualización y nuevos ingresos al Registro Social de Hogares

\section{C.- Servicio Trámites Municipales}

- Servicio de otorgamiento y renovación de patentes comerciales

- Servicio de otorgamiento y renovación de permisos de circulación

- Servicio de otorgamiento y renovación de licencias de conducir 
En este sentido cobra relevancia la existencia de la metodología de Cartas de Servicios, en función de las cuales se despliega un mecanismo de participación ciudadana que permite vincular la gestión municipal, con las demandas de los vecinos por servicios municipales de calidad ${ }^{1}$. Se trata del desarrollo de "diálogos ciudadanos», que permiten establecer compromisos por parte de los actores involucrados (autoridad local, funcionarios municipales, miembros de la comunidad) respecto de un determinado programa o servicio municipal, con la finalidad de recibir opinión de la ciudadanía y contribuir con ello a la mejora del respectivo servicio, lo cual queda registrado en afiches de pública difusión en cada comuna.

Cabe indicar que, los servicios que se han considerado para el desarrollo de una nueva versión de esta metodología se desprenden del trabajo desplegado en el país por el Programa de Mejoramiento de la Gestión de los Servicios Municipales, de la SUBDERE. Por tanto, los servicios mencionados previamente, constituyen el marco específico a partir del cual los municipios, sometieron a opinión ciudadana algunos de ellos, con la idea de establecer compromisos compartidos de mejora de estos.

El proceso desarrollado para esta metodología durante el año 2017, implicó además de la implementación del mecanismo, la ejecución de módulos de capacitación y formación de funcionarios municipales de cada municipio focalizado, lo que permitió recoger aprendizajes sustantivos, considerando la realidad diversa de cada comuna, para actualizar conocimientos y ponerlos a disposición de todos los municipios de Chile.

«Estudio de Identificación de los Estándares Básicos de Calidad de Servicios Municipales Garantizados». Centro de Políticas Públicas, Pontificia Universidad Católica de Chile. Link: http://calidadmunicipal.subdere.gov.cl 


\section{IV.- Metodología PARA LA IMPLEMENTACión DE CARTAS DE SERVICIOS MUNICIPALES}

\section{1. ¿Qué es y cómo se elabora una Carta de Servicio?}

Si bien las Cartas de Servicios Municipales o Cartas Ciudadanas, surgen en el Reino Unido, con el objetivo inicial de contribuir a la eficiencia del gasto de los recursos municipales, las Cartas de Servicios han sido ampliamente definidas en bibliografía sobre gestión de calidad, con un importante desarrollo en España. En Cerdá y Rodríguez (1999) se plantea que estas constituyen un compromiso con los ciudadanos, creando servicios que respondan a sus demandas no solo en cantidad, sino también en calidad:

(...) documento por el cual se informa al ciudadano de los objetivos y compromisos de una determinada área de actividad (...) incluye un sistema de medición de rendimiento, a través de indicadores que permiten comprobar el grado de cumplimiento de los objetivos, determinando la calidad del servicio que se presta a los ciudadanos (Cerdá y Rodríguez, 1999, p. 225).

La normativa española define la Carta de Servicio como «un documento escrito por medio del cual las organizaciones informan públicamente a los usuarios sobre los servicios que gestionan y acerca de los compromisos de calidad en su prestación y los derechos y obligaciones que les asisten.» (Gobierno de España, 2010:9; en Manual Para la Implementación de Cartas de Servicios Municipales, SUBDERE, Departamento de Desarrollo Municipal, 2018).

En la gestión pública nacional se le define como un instrumento a partir del cual, una institución, en este caso el municipio, se compromete a difundir y prestar servicios y/o programas con determinados estándares de calidad, fijando mecanismos para la presentación de opiniones, aportes, reclamos y sugerencias de parte de los vecinos y estableciendo las formas de corrección cuando no puede cumplir con los compromisos asumidos (SUBDERE, 2010²).

2 Manual para la implementación de Cartas Ciudadanas Municipales, División de Municipalidades, SUBDERE 2010. 
En este contexto, la Carta de Servicio se entiende como un instrumento de comunicación entre el municipio y los ciudadanos, es decir, implica generación de información en dos sentidos: desde el municipio hacia la ciudadanía y desde esta hacia el municipio. La retroalimentación que se produce entre ambos es la esencia de dicho instrumento.

Es importante indicar que quien informa es el municipio, es quien decide abrir sus puertas a la comunidad en un gesto de transparencia para dar cuenta de diversas actividades institucionales que tienen o tendrán un impacto en la ciudadanía. De esta manera, parte de la información entregada se transmite como compromisos hacia la comunidad, sin embargo, el municipio puede, a través de la misma vía, considerar una serie de «responsabilidades» de los ciudadanos, las cuales pueden tener relación con el trato hacia los funcionarios municipales, la necesidad de informar al municipio sobre actos que afecten la calidad del servicio prestado, entre otros ${ }^{3}$. Al informar, el municipio asume implícitamente que lo comunicado debe cumplirse y que, de no poder llevarse a cabo, deberá adoptar los mecanismos correctivos que el mismo se imponga.

De lo anterior, se deriva la importancia de definir los componentes de la información entregada y sus verificadores con el correspondiente sistema de monitoreo y evaluación.

\subsection{Objetivos de la Carta de Servicio}

En Cerdá y Rodríguez (1999) se plantea que las Cartas de Servicios se desarrollan con base en los siguientes objetivos:

- Garantizar el derecho de los ciudadanos a la información.

- Comunicar su compromiso de servicio y calidad.

- Estimular toda iniciativa de mejora del servicio.

- Responder y anticiparse a las demandas ciudadanas. ${ }^{4}$

3 Manual Para la Implementación de Cartas de Servicios Municipales, SUBDERE, División de Municipalidades, Departamento de Desarrollo Municipal, 2018

4 Ibidem. 
A modo de síntesis, como instrumento en la gestión municipal pueden orientarse a dos objetivos generales: de información y control (SUBDERE, 2010). Estos dos objetivos obligan a los municipios a desarrollar dos tipos de flujos de trabajo, a nivel interno y externo:

La gestión interna obliga al servicio a revisar los procesos para asegurar los estándares que se reflejarán en la Carta de Servicios. Ello implica la definición de los estándares de una manera objetiva y medible, así como el monitoreo y seguimiento del grado de cumplimiento de los compromisos desplegando las acciones de mejora necesarias para conseguirlos.

La gestión externa corresponde a las acciones para comunicar a los ciudadanos los compromisos asumidos por el municipio con respecto a sus servicios.

\section{3. ¿Cómo es una Carta de Servicio?}

Es importante tener en cuenta que la Carta de Servicio debe ser redactada con un lenguaje claro y sencillo, recordando que es un instrumento dirigido a usuarios de un servicio, no un reglamento de funcionamiento, por lo que no debiese incluir tecnicismos ni fórmulas legales que dificulten el objetivo principal de información.

El contenido de la Carta de Servicio puede ser estructurado considerando los siguientes apartados:

\section{Introducción}

Constituye la presentación de la Carta, puede incluir algún saludo inicial, aunque lo fundamental es la presentación y descripción del servicio, a través de la definición que se ha establecido en los estándares de calidad de los servicios municipales. A su vez puede contener información asociada a la dependencia administrativa del servicio, su objetivo y/o prestaciones. 


\section{Compromisos municipales}

Una parte fundamental en el diseño de las Cartas de Servicio es el establecimiento de las obligaciones del municipio, las cuales dicen relación con la forma en que el municipio se compromete a entregar el servicio a la comunidad, considerando por ejemplo aspectos como: trato a los usuarios, modo de acceso al servicio, frecuencias y tiempos en la entrega de determinadas prestaciones, entre otros.

A través de los compromisos municipales se expresan los estándares de calidad, como por ejemplo: establecer plazos para la realización de trámites administrativos, plazos de respuestas a consultas, frecuencia de la prestación, entre otros.

Es importante que el equipo municipal a cargo del diseño de la Carta de Servicio realice la distinción entre las aspiraciones de la comunidad, en términos del trato y prestaciones que recibe de la municipalidad asociados al servicio (recogiendo información de la oficina de información y reclamos, o realizando reuniones participativas), y el tipo de trato y prestaciones hacia la comunidad que el municipio puede efectivamente entregar, considerando los más altos estándares de calidad que logre alcanzar. Del análisis de ambos, se podrán establecer los compromisos que puedan satisfacer efectivamente a la ciudadanía y que puedan ser cumplidos por el municipio eficientemente.

\section{Compromisos ciudadanos}

Es necesario establecer las responsabilidades que se propondrán a los ciudadanos respecto al servicio, que pueden incluir, entre otros, los aspectos relativos al trato esperado por parte de la comunidad hacia los funcionarios del municipio. En este apartado es donde se señalan también las responsabilidades respecto a las prestaciones recibidas; a modo de ejemplo, puede incluirse el compromiso ciudadano de solicitar observaciones o correcciones al servicio, respetando los canales de comunicación, plazos y horarios definidos en la Carta de Servicio. 
Lo ideal es trabajar en conjunto con la comunidad para definir cuáles son las responsabilidades de esta; así se fortalece aún más lo establecido en la Carta. Por lo anterior, la definición de los compromisos ciudadanos, debe ser elaborado por representantes de la sociedad civil comunal.

\section{Mecanismos de reclamos y sugerencias}

La esencia de un sistema de gestión de calidad es poder recibir la retroalimentación de los usuarios con respecto al servicio prestado, es por esto que la Carta de Servicio debiera indicar un texto que comunique a los ciudadanos sobre cómo entregar sus sugerencias, consultas o reclamos sobre el servicio, observaciones que a su vez deben ser atendidas en un plazo determinado.

Para poder realizar una adecuada evaluación continua de la puesta en marcha de la Carta de Servicio y monitorear su impacto, es necesario establecer mecanismos de reclamos y sugerencias para ser utilizados por los ciudadanos en caso de que lo informado respecto del servicio no sea cumplido según lo explicitado en la Carta.

Los mecanismos de reclamos que pueden ser elaborados, van desde diseñar una ficha de reclamo en donde se identifique fecha, reclamo o sugerencia, nombre de persona que lo efectúa y sus datos de contacto, hasta un sistema computacional interno que básicamente contenga la misma información, pero que además añada despachos electrónicos de los reclamos y sugerencias al departamento o persona que deba hacerse cargo y su correspondiente registro en un banco de datos.

\section{4. ¿Cómo se elabora una Carta de Servicio?}

Definición de lo que se informará: elección del servicio

Una posibilidad que presenta la Carta de Servicio es la de constituirse como mecanismo de difusión de la labor municipal. El municipio cumple innumerables tareas que pueden encontrar en la Carta de Servicio el mejor medio para ser difundidas, por ejemplo, la entrega de algún nuevo servicio, o el cambio en la forma de entregar determinadas prestaciones. 
Otra posibilidad es la de observar la realidad comunal y evaluar a través de un diagnóstico de carácter participativo con actores locales, los ámbitos estratégicos en donde se expresan las mayores necesidades de acceso a información y demanda de control ciudadano por parte de la comunidad con respecto a un servicio determinado.

En la decisión sobre lo que finalmente se informará o será sometido a control ciudadano, a través de la Carta de Servicio, se deben definir los objetivos y alcances de este instrumento. La Carta de Servicio se enfocó, para el caso de la experiencia realizada por SUBDERE, en diez comunas del país (Coquimbo, Combarbalá, Los Andes, Recoleta, Malloa, Codegua, Traiguén, Temuco, Osorno y Purranque).

Los servicios que los municipios pusieron a disposición de la opinión ciudadana para su mejora y/o proceso de control ciudadano, estableciendo compromisos de las partes, deberes y derechos para tales fines, fueron los siguientes:

\begin{tabular}{|l|l|}
\hline \multicolumn{1}{|c|}{ Comuna } & \multicolumn{1}{c|}{ Servicio definido } \\
\hline 1.- Coquimbo & Servicio de otorgamiento y renovación de licencias de conducir \\
\hline 2.- Combarbalá & Patentes comerciales / Permisos de circulación \\
\hline 3.- Los Andes & Servicio de construcción y áreas verdes y jardines \\
\hline 4.- Recoleta & Programa Escuela Abierta / Permisos de circulación \\
\hline 5.- Malloa & Servicio de construcción y áreas verdes y jardines \\
\hline 6.- Codegua & Servicio recolección de residuos sólidos y domiciliarios \\
\hline 7.- Traiguén & Servicio de alumbrado público \\
\hline 8.- Temuco & Servicio de otorgamiento y renovación de patentes comerciales \\
\hline 9.- Osorno & Servicio de alumbrado público \\
\hline 10.- Purranque & $\begin{array}{l}\text { Servicio de otorgamiento y renovación de permisos de circu- } \\
\text { lación }\end{array}$ \\
\hline
\end{tabular}

Tal como se observa, lo ideal es que, en la selección del servicio, se consideren ámbitos de alto impacto comunal, aunque en comunas grandes se ofreció la posibilidad de considerar un servicio general pero definido en un territorio específico de la comuna. Se pueden estimar también criterios que evalúen la factibilidad de cumplir de 
manera óptima los estándares definidos y considerar, a su vez, la demanda ciudadana en torno a las prestaciones ofrecidas.

V.- DESCRIPCIÓN DE UNA EXPERIENCIA DE BUENA PRÁCTICA EN LA IMPLEMENTACIÓN DE CARTAS DE SERVICIOS MUNICIPALES

\section{1.- Implementando una Carta de Servicio: el caso de Codegua}

Antes de referirse al caso puntual de una de las diez comunas que fueron parte de este proceso, cabe indicar que los municipios participantes, fueron focalizados considerando representación de la diversidad geográfica, indicadores de calidad de acuerdo con línea base municipal del programa de mejoramiento de la gestión municipal de la SUBDERE y disposición de las autoridades locales para trabajar los instrumentos.

\subsection{Antecedentes}

La comuna de Codegua fue considerada una buena práctica en este proceso de implementación de Cartas de Servicio, toda vez que representa diversos factores que permitieron realizar el proceso de generación de este instrumento de manera óptima.

Codegua se ubica geográficamente en la Provincia de Cachapoal, Región del Libertador Bernardo O’Higgins. Limita al norte con la comuna de Mostazal, al sur con las comunas de Machalí y Rancagua, al oeste con la comuna de Graneros y, al este, con la Región Metropolitana.

De acuerdo con datos del Censo de Población y Vivienda (INE, 2017), la comuna de Codegua tiene una población de 12.988 habitantes y registra 4.402 viviendas. El 51\% de la población habita en zonas rurales. 


\subsection{Facilitadores en la implementación de la Carta de Servicio en Codegua}

Los factores que se presentan a continuación constituyen elementos que facilitaron el éxito del proceso en el caso de la comuna de Codegua en el trabajo que implicó el desarrollo de la Carta de Servicio Municipal para el caso de las prestaciones asociadas a la recolección de residuos sólidos domiciliarios. Y se presentan con la idea de compartir y permitir modelar futuros procesos que algún municipio se proponga llevar adelante.

\section{a) Adecuada elección del servicio}

La primera reunión de trabajo en el contexto de la Asistencia Técnica en la comuna permitió definir el servicio a trabajar para la implementación de la Carta. En aquella reunión, denominada Mesa de Trabajo con funcionarios municipales, participaron un grupo de funcionarios municipales que conformaban el equipo definido por la autoridad comunal para estos fines.

El equipo se constituyó con la idea predefinida de abordar el servicio de recolección de residuos sólidos domiciliarios. La decisión se justifica, por parte de los funcionarios, considerando el impacto comunal del servicio (afecta a toda la población comunal) y los resultados de la encuesta de satisfacción usuaria desarrollada en esta comuna por la SUBDERE, a través del Programa calidad de la Gestión Municipal.

\section{b) Alto compromiso del equipo municipal}

La conformación del equipo municipal a cargo del proceso consideraba originalmente al Administrador Municipal, el Director de Desarrollo Comunitario (DIDECO), la encargada de organizaciones comunitarias, un administrativo de la Secretaría Municipal, la jefa del Departamento de Aseo y Ornato, la encargada de Medio Ambiente y el Director de Obras Municipales (DOM), de quien dependía el

5 Manual para la Implementación de Cartas de Servicios Municipales, SUBDERE, Departamento de Desarrollo Municipal 2018 
Departamento de Aseo y Ornato, del cual, a su vez, dependía el servicio de recolección de residuos.

Fue fundamental contar con un equipo que dominaba a cabalidad el servicio abordado, pues permitió definir objetivos posibles de cumplir por el municipio, con la posibilidad implícita de poder responder a los vecinos con información pertinente, en las instancias de participación.

\section{c) Amplia convocatoria ciudadana}

En el trabajo de identificación de actores, los participantes del municipio expresaron la importancia de convocar a las juntas de vecinos de la comuna, organizaciones de adultos mayores y organizaciones funcionales relacionadas, como el comité ambiental comunal. También consideraron importante que estuvieran presentes las asociaciones de «canalistas» de la comuna por la pertinencia del tema, así como empresas agrícolas que operan en la comuna, todas las cuales participaron en la jornada de diálogo ciudadano.

d) Comunidad local comprometida con mejorar la gestión del servicio

Debido a que el foco del trabajo se centró en motivar la participación ciudadana, los representantes de las organizaciones ciudadanas que participaron percibieron el espacio como una oportunidad para aportar en los procesos de mejora del servicio. Ello hizo posible superar una relación basada solo en demandas al municipio sin involucrarse en la solución de los problemas detectados.

De esta manera, para el caso de Codegua, las observaciones presentadas por parte de los grupos de trabajo se sistematizaron en dos temas, i) las observaciones que los dirigentes realizaron a los compromisos municipales presentados y, ii) los compromisos ciudadanos que se mencionaron por parte de los actores sociales convocados. 
e) Valoración de instancias de participación por municipio y comunidad

En la actividad de evaluación del proceso los funcionarios municipales de Codegua expresaron su valoración hacia la Asistencia Técnica y metodología de la Carta de Servicio, pues permitió dar formalidad a los compromisos que podrían haberse asumido de igual manera, y comunicado a partir de otras instancias, tal vez sin el mismo efecto.

Destacaron, además, cómo la Carta de Servicio les permitió efectivamente mejorar la comunicación con la comunidad en el tema específico de la recolección de residuos sólidos domiciliarios, a través de las instancias de participación y la generación del Comité de Seguimiento, lo que obliga a volver a reunirse periódicamente con los representes de las organizaciones comunales para dar cuenta de los compromisos asumidos.

f) Preocupación por mejorar los canales de participación entre municipio y comunidad

Atendiendo a las dificultades de diálogo efectivo entre municipio y comunidad, en la Mesa de Diseño, Difusión y Evaluación de la Carta de Servicio, donde participaron funcionarios municipales y dirigentes de las organizaciones de mayor representación de la comuna (v.gr. uniones comunales, comité ambiental), se estableció como compromiso municipal adicional el disponer de buzones en áreas rurales, que serían administrados por las Juntas de Vecinos y que operarían como una forma de ampliación de la OIRS municipal, para uso de los vecinos.

De este modo, los compromisos municipales inicialmente expuestos en el Diálogo Participativo fueron modificados considerando esta inquietud manifestada por los dirigentes, quedando tanto los compromisos municipales como ciudadanos de la siguiente manera. 
g) Formalización de instancia de seguimiento de los compromisos de la Carta de Servicio

La propuesta de conformar un Comité de Seguimiento para el monitoreo de los compromisos de la Carta de Servicio fue bien recibida en Codegua tanto por dirigentes sociales como por funcionarios municipales participantes del proceso. Por ambas partes, se valoró la responsabilidad que brinda a los compromisos establecidos, la creación del Comité de Seguimiento, pues permite evaluar el cumplimiento de los compromisos asumidos por las partes involucradas en este proceso. 


\section{VI.- Afiche CARTA DE SERVicio de LA COMUnA DE CODEgUA}

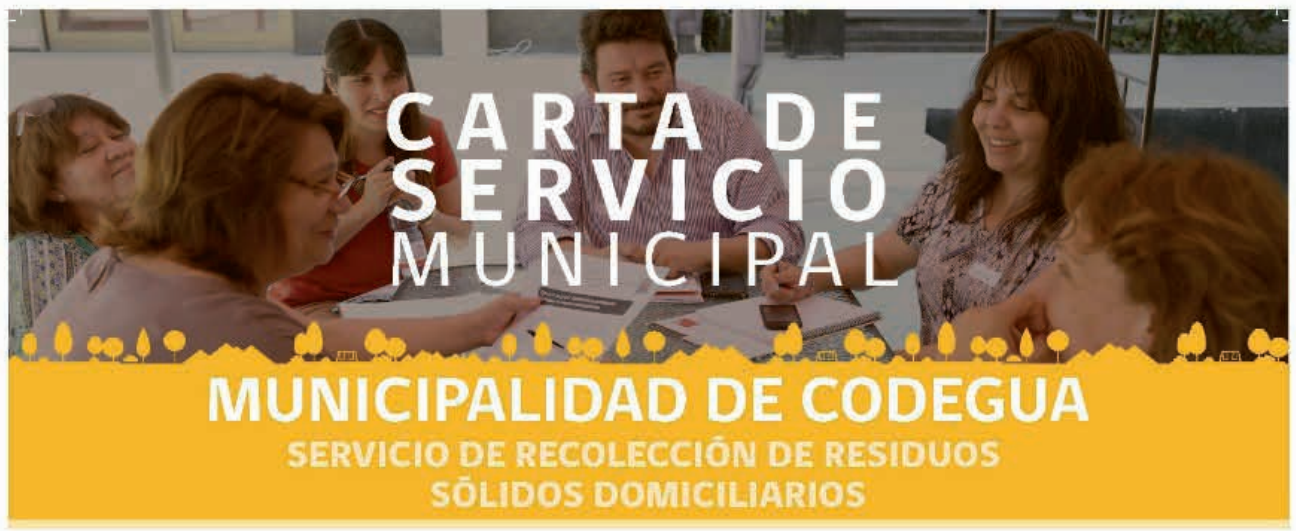

\section{DESCRIPCIÓN DE SERVICIOS}

El servicio de Recolección de Residuos Solicios Domiciliarios (RSD) proporcionado por la Muniçipalidad de Codegua a sus habitantes y usuarios, consiste en recoger y retirar este tipo de residuos desde la puerta de sus casas o propiedades, trarsportando los residuos mediante camiones recolectores al Relleno Sanitario La Yesca.

\section{COMPROMISOS MUNICIPALES}

1. Cumplir con la recolección de residuos sóltidos comicitlarios: dọs veces a ta semana en áree urbana y una vez a ta semana en zonas rurates.

2. Informar sobre recorridos y cambios en el servicio a través de sitio web. afiches en tugares estratégicos de la comura y reuniones con dirigentes de las organizaciones comunitarias.

3. Realizar 4 operativos anuales de recolección de residuos voluminosos y escombros domicitiarios.

4. Informar y sensibitizar a la comunicad a través de 6 charlas anuales sobre temas de interes sobre el servicio.

5. Limpieza de micro basurales en espacios públicos una vez at mes.

6. Realizar una jornada anual de acopio de envases de plaguicidas.

7. Establecer un canal de comunicacion correspondiente a un buzôn en juntas de vecinos en zonas rurales para sugerenclas, reclamos e información sobre el servicic. En zonas urbanas a traveàs de la ORS.

8. Establecer un telëfono de contacto para denuncias canalizadas a través de los dirigentes sociales.

\section{COMPROMISOS CIUDADANOS}

1. Patticipar activamente en las actividades que convoque la municipalidad sobre el servicio de recolección de residuos sólidos comiciliarios.

2. Informar a los vecinos sobre mod ficaciones, charlas u operativos del servicio de recolecciōn de resicuos sólidos domiciliarios, en las reuniones de las organizaciones en que se participe.

3. Informar incumplimientos o sugerencias en torno a la prestación del servicio, a través de los buzones en las juntas de vecinos en zonas rurales $y$ to OIRS en área urbana.

4. Entregar los envases de plaguicidas a una entidad autorizada.

5. Informarse sobre puntos de reciclaje en la comuna y hacer uso de estos.

6. Disponer la basura corriciliaria en contenedores o recipientes adecuados, para que esta sea retirada por el camion recolecto cuidando peso y volumen excesivos.

\section{Contacto para informaciones, reclamos y sugerenclas: \\ - Mesa Central Municipalidad de Codepraa 72-2973500. \\ - Direcciôn de Obras Muricipales 72-2973526 \\ - Departamento de Aseci y Ornato 72-2973575. \\ ink: https/municipalidaddecodoguaclireclamos htmi}

Esperando que los compromisos expresacos en esta Carta contribuyan a fortatecer el vinculo entre el Municipio y la comunidad

Ana Maria Silva Gutiêrrez

Alcaldesa I. Municipalidad de Codegua
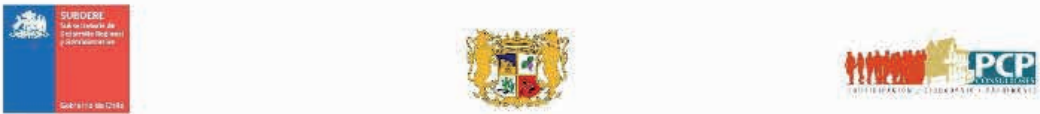


\section{VII.- BIBLIOGRAFÍA}

Cerdá Díaz J. y Rodríguez Barredo J. M. (1999). En busca de la calidad. Las Cartas de Servicio como fórmula de compromiso con los ciudadanos. Boletín de la ANABAD, 3-4, pp. 223-236. Disponible en: http://eprints.rclis.org/15220/1/CERDA_DIAZ_Julio_En_busca_de_la_calidad.pdf

Gobierno de Chile, SUBDERE; Corporación Libertades Ciudadanas: $M a$ nual Para La Implementación de Cartas Ciudadanas Municipales. (Santiago de Chile 2010). División de Municipalidades. Departamento Desarrollo Municipal SUBDERE. Serie Documentos de Trabajo. Disponible en: http://www.subdere.gov.cl/sites/default/files/ documentos/articles-80383_recurso_4.pdf

Gobierno de España, Ministerio de la Presidencia: Guía para el desarrollo de Cartas de Servicio. Agencia Estatal de Evaluación de las Políticas Públicas y la Calidad de los Servicios (Madrid, 2010). Colección Guías. Disponible en: http://www.aeval.es/export/sites/aeval/comun/ pdf/calidad/guias/Guia_CARTAS_2009.pdf

Gobierno de Chile, SUBDERE: Manual Para La Implementación de Cartas de Servicios Municipales. (Santiago de Chile 2018). División de Municipalidades. Departamento Desarrollo Municipal SUBDERE.

Ayuntamiento de Málaga (s/f). Proyecto de implementación de un sistema de Cartas de Servicio. Disponible en: http://calidad.malaga.eu/export/ sites/default/formacion/calidad/portal/menu/portada/documentos/ metodologia_CS_Malaga_v7_-_final.pdf 



\title{
AVANCES Y DESAFÍOS DE LOS FONDOS \\ DE DESARROLLO VECINAL (FONDEVE)
}

\author{
Margarita Fuentes \\ Instituto Chileno de Estudios Municipales \\ Universidad Autónoma de Chile
}

\section{INTRODUCCIÓN}

El principal objetivo de este texto es entregar una revisión de lo que ha sido el Fondo de Desarrollo Vecinal (FONDEVE), comenzando por describir su origen y funcionamiento, para luego explicitar cuáles han sido reconocidas como sus fortalezas y qué elementos constituyen desafíos para este mecanismo de participación ciudadana.

Este trabajo se ha realizado con base en revisión documental y con información obtenida a través de la ejecución, por parte del Instituto Chileno de Estudios Municipales (ICHEM) y SUBDERE, de capacitaciones y asistencias técnicas realizadas entre la Región Metropolitana y de Magallanes sobre gestión local participativa ${ }^{1}$.

La mayor limitación encontrada ha sido la falta de información, producto tanto de la escasa producción académica sobre el FONDEVE, como de la falta de evaluación por parte de las Municipalidades.

Dentro de los principales resultados, se encuentra que el foco de atención no ha estado centrado en la ejecución de los proyectos que obtienen financiamiento, sino en el proceso de selección que se da en

1 En la etapa de formación (capacitaciones) participaron alrededor de 200 funcionarios municipales de 130 comunas. En la etapa de asistencia técnica, participaron alrededor de 400 funcionarios municipales de 54 comunas. 
cada comuna. Aunque es cierto que el funcionamiento del proceso depende de cada comuna, ha habido un sentir compartido en relación a las fortalezas y desafíos, que son trabajados a lo largo del texto.

En cuanto a las fortalezas, se distingue principalmente: 1) la valoración del FONDEVE como instrumento participativo, reconociendo su temprano origen y contexto; 2) que permite el fortalecimiento de la gestión de los dirigentes sociales y, 3) que promueve la vinculación de distintos actores de la municipalidad con dirigentes sociales.

En la otra cara, en relación a los desafíos, se ha identificado: 1) que provoca una sobrecarga ocasional de trabajo para los funcionarios municipales, especialmente en la época de postulación; 2) el poco estudio y producción de conocimiento que existe en relación a este mecanismo; 3) la forma de financiamiento, en relación a la falta de un aporte fiscal que contribuya a disminuir las desigualdades territoriales; y 4) la principal crítica ha estado dirigida al proceso de selección y su falta de transparencia, lo que ha provocado la prevalencia de relaciones clientelares entre concejales y dirigentes de juntas de vecinos.

Finalmente, se reflexiona si los puntos débiles encontrados logran mermar o no la contribución del FONDEVE a los principios que le dieron origen, relacionados con la participación ciudadana y fortalecimiento de la democracia.

\section{ORIGEN}

El Fondo de Desarrollo Vecinal (FONDEVE) se oficializa con la ley ${ }^{\circ} 19.418$ de 1995 , que establece normas sobre juntas de vecinos y demás organizaciones comunitarias. En dicha ley, se explicita la creación de un fondo en cada Municipalidad que tendrá por propósito «apoyar proyectos específicos de desarrollo comunitario presentados por las juntas de vecinos» (Ley n¹9.418, 1995).

Dentro de los principios que guían la ley $\mathrm{n}^{\circ} 19.418$ y, por lo tanto, el FONDEVE, se encuentra la «solidaridad organizada, la participación y la autoayuda» (Congreso Nacional de Chile, 1990, 
pág. 5), que permita que los habitantes de un territorio se sientan identificados y contribuyan con el desarrollo local.

Así, el FONDEVE surge como un instrumento participativo, ya que permite la detección de necesidades y levantamiento de proyectos, de equipamiento e infraestructura, basados en el punto de vista de los propios vecinos. Además, debido al contexto de reciente retorno a la democracia ${ }^{2}$, fue una herramienta altamente valorada.

Según la Subsecretaría de Desarrollo Regional y Administrativo (SUBDERE) y la División de Organizaciones Sociales (DOS), los objetivos de este fondo son:

Promover la participación de las organizaciones sociales, con la finalidad de que estas se organicen, prioricen sus necesidades y formulen proyectos en base a sus intereses.

Desarrollar proyectos que tengan impacto local y logren satisfacer necesidades sentidas de la comunidad, que mejoren la calidad de vida de los vecinos y constituyan un aporte al desarrollo y fortalecimiento de la vida comunitaria de las distintas localidades.

Contribuir e incentivar el desarrollo cultural, deportivo, social y educativo a nivel territorial (SUBDERE y DOS, 2016, pág. 43).

En cada comuna, será el Concejo Municipal el encargado de elaborar el reglamento para el funcionamiento específico del fondo en dicho territorio. Cabe señalar que será el mismo Concejo el que reciba las postulaciones cada año y decida qué proyectos obtendrán financiamiento y cuáles no.

De todas formas, a lo largo de los años, las comunas han ido construyendo sus propios procedimientos para la ejecución de estos fondos. Así, el nivel de estructura y transparencia del proceso de postulación y selección de los proyectos depende de cada comuna.

2 Aunque la ley fue aprobada en 1995, el mensaje presidencial fue ingresado al Congreso en 1990. 
FORTALEZAS

Valoración del FONDEVE como instrumento participativo

Dentro de sus fortalezas, se destaca que el FONDEVE fue uno de los primeros instrumentos participativos implementados en las municipalidades. Se valora su existencia, como se señaló anteriormente, considerando también el contexto post dictadura en el que fue creado, donde se observan esfuerzos por promover e institucionalizar la participación. Aunque los resultados de dicha institucionalización de la participación ciudadana son dignos de reflexión y crítica, como se puede observar en otros capítulos de este libro, se considera importante la intención de otorgar mayor control a los habitantes de un territorio y de reconocer la importancia de la organización social como «raíz y expresión de una democracia verdadera» (Congreso Nacional de Chile, 1990, pág. 5).

En ese sentido, se fomenta la organización de los vecinos, así como la reflexión y creación de propuestas sobre su propio entorno. Este fondo apunta a validar los conocimientos de los habitantes de un territorio y darles cierto control para solucionar problemas específicos, principalmente sobre equipamiento e infraestructura.

Fortalecimiento de la gestión de los dirigentes sociales

Durante su desarrollo, se ha reconocido que este instrumento ha permitido a los dirigentes sociales mejorar su gestión, ya que permite concretar, a través del financiamiento otorgado por la municipalidad, ciertos proyectos de interés para su junta de vecinos. Paralelamente, esto contribuye a la validación de dichos dirigentes frente a su comunidad. 
Vinculación de distintos actores de la municipalidad con dirigentes sociales

También, el FONDEVE permite a los funcionarios municipales acercarse a los vecinos y dirigentes, por el apoyo que les otorgan durante el proceso de postulación. Así mismo, vecinos y dirigentes generan experiencia en formulación de proyectos, abriendo posibilidades de obtención de financiamiento a través de participación en fondos concursables externos a la municipalidad.

Por último, las autoridades comunales también se ven implicadas en el proceso, ya que es el Concejo Municipal el encargado de decidir qué proyectos y qué juntas de vecinos obtendrán apoyo. Esto también provoca una relación entre las juntas de vecinos, a través de sus dirigentes, con los concejales, pero esta relación será profundizada más adelante.

Así, el FONDEVE es un mecanismo que se encuentra altamente arraigado en la gestión municipal participativa, ya que, por un lado, involucra en su funcionamiento a los distintos actores de una comuna y, por otro lado, tales actores perciben recibir, de algún otro modo, beneficios a lo largo de este proceso.

\section{Desafíos}

\section{Sobrecarga ocasional de trabajo para funcionarios municipales}

Por otro lado, aunque los funcionarios municipales valoran que el fondo promueva la participación ciudadana, hay varios que perciben también una sobrecarga de trabajo durante el periodo de postulación. Esto depende, en primer lugar, del tamaño de los equipos y, por lo tanto, de su capacidad de respuesta frente al aumento de solicitudes por parte de dirigentes sociales y, en segundo lugar, de la preparación previa que tengan los vecinos en materia de formulación de proyectos. 
Como se señaló anteriormente, una gran debilidad del Fondo de Desarrollo Vecinal es el poco estudio que existe al respecto. Por ejemplo, la investigación sobre su impacto en cada comuna es más bien desigual. En la mayoría de las comunas es bastante poco el conocimiento que se ha generado al respecto, por lo que es muy difícil conocer los efectos específicos de los proyectos financiados.

En esa misma línea, este instrumento no ha sido foco de atención de la academia, la cual se ha centrado en otro tipo de mecanismos como los Consejos Comunales de Organizaciones de la Sociedad Civil (COSOC) o los presupuestos participativos. Por esto, lo que se encuentra escrito sobre el FONDEVE desde la academia es bastante escueto, ya que no hay estudios específicos sobre este instrumento, sino que son algunos apartados dentro de artículos sobre temas más amplios, y la mayoría, escritos hace algunos años.

Como se señalará luego, existen críticas sobre el proceso de selección de este mecanismo lo que pondría en duda su coherencia con los principios de la ley que lo creó, y, por lo tanto, si está contribuyendo de forma positiva al fortalecimiento de la democracia.

En ese sentido, es necesario que las municipalidades realicen mayores esfuerzos en este aspecto y no solo en relación al avance mismo de los proyectos, sino la evaluación de si este mecanismo está promoviendo la participación o no.

\section{Falta de aporte fiscal}

Otro elemento que ha sido blanco de críticas desde el principio tiene relación con la forma de financiamiento del FONDEVE, ya que se compone de recursos propios del Municipio fijados anualmente y un aporte de las mismas organizaciones. Ya en la historia de la ley 19.418 (1995) se observa que la principal discusión en torno a este fondo tenía relación con si debería haber o no contribución estatal. Inicialmente, el nombre era Fondo Nacional de Desarrollo Vecinal, con cargo al presupuesto de la nación y distribuido de la 
misma forma que el fondo común municipal (Congreso Nacional de Chile, 1995).

Finalmente, la ley aprobada contempló que el financiamiento estaría a cargo de cada Municipalidad. Considerando la desigualdad territorial y el disímil funcionamiento de las 345 municipalidades, el FONDEVE (así como muchos otros mecanismos y programas) dependerá de la capacidad de cada municipio.

Son varios actores los que consideran necesario el que exista un aporte fiscal para apoyar a las municipalidades. El Consejo Nacional de Participación Ciudadana y Fortalecimiento de la Sociedad Civil, planteó en el apartado de propuestas para las Municipalidades, que se debe «hacer efectivo el aporte fiscal al FONDEVE de las Municipalidades y hacer obligatorio su uso por parte de estas» (Consejo Nacional de Participación Ciudadana, 2017, p. 48). En este marco se propone que el poder central efectúe esta ayuda económica para fortalecer los FONDEVE de forma paulatina en todos los Municipios del país, priorizando las localidades rurales y extremas.

\section{Proceso de selección y clientelismo}

La mayor crítica a los Fondos de Desarrollo Vecinal está relacionada con que durante los procesos de postulación, puede ser utilizado como instrumento de clientelismo entre dirigentes sociales y concejales. Esto, porque «los proyectos aprobados mediante el fondo de desarrollo vecinal, muchas veces se entendían como favores o premios a la 'abnegada labor' de muchos dirigentes sociales» (Montecinos, 2007, p. 345).

Así, los concejales dan respaldo a los proyectos y juntas de vecinos que les otorguen reconocimiento público o apoyo electoral (Luján, 2017), por lo que ambas partes perciben salir beneficiadas en este proceso.

Como señala Egon Montecinos: «muchos concejos municipales en Chile utilizan este fondo con un criterio clientelar, ya que los concejales pueden influir en la decisión respecto a qué organización apoyan con recursos municipales» (2011, p. 68). Esto es algo sabido por la comunidad en general, tanto vecinos como funcionarios 
municipales, por lo que la percepción que muchas veces se tiene del FONDEVE es que es un proceso muy poco transparente y frustrante, ya que las juntas de vecinos que no tienen vínculos directos con algún miembro del concejo municipal no tienen incentivos suficientes para participar.

Así, se pone en duda la contribución del Fondo de Desarrollo Vecinal con los principios y objetivos de la ley con la que fue creado. Dichos principios y objetivos están directamente relacionados con el fortalecimiento de la democracia, a través del fomento de la participación y la «organización solidaria». Los obstáculos que presenta el proceso de postulación y selección apuntarían a que el camino se ha ido desviando.

En ese contexto, surge la duda de por qué, existiendo ese análisis ampliamente reconocido, no se han modificado las condiciones del FONDEVE. Según la literatura y la información obtenida mediante trabajo en terreno, las posibles soluciones para que este instrumento asegure un proceso transparente son:

- Arreglos a nivel central: Exigir a las municipalidades, y facilitar instrumentos, para poder garantizar la transparencia del proceso de selección.

- Arreglos a nivel municipal: Que cada municipalidad, de acuerdo con sus capacidades, trabaje en la elaboración de instrumentos de evaluación y garantía de transparencia.

- Eliminación del FONDEVE: Considerando que los recursos municipales son escasos y por lo tanto, deben ser optimizados, ha surgido la idea de que los recursos del Fondo de Desarrollo Vecinal se destinen a los presupuestos participativos, donde la selección también se lleva a cabo de forma participativa. Este también tendría que ser un cambio a nivel central, ya que el FONDEVE es exigido por ley.

Como a nivel central no ha habido cambios al respecto, lo que ha ocurrido en la práctica es más cercano al segundo punto, donde cada municipalidad ha realizado cambios (o no) en la medida de 
sus posibilidades y especialmente de sus prioridades. Los municipios que han mostrado un mayor compromiso con la transparencia han tendido a dejar el FONDEVE como herramienta para proyectos muy específicos de equipamiento e infraestructura de las juntas de vecinos, pero el mecanismo que más se fomenta como herramienta de transformación social a nivel comunal, es el de los presupuestos participativos.

Por otro lado, independiente del marco legal nacional, es decir, si tener FONDEVE o no fuera una opción para las municipalidades, lo más probable es que seguiría existiendo, al menos en la mayoría de las municipalidades. Esto se debe a que es un mecanismo altamente arraigado, tanto entre vecinos, funcionarios y autoridades, donde todos los actores perciben que de una u otra forma existen beneficios para todas las partes.

Frente a lo anterior, es necesaria la creación de protocolos e instrumentos para que la evaluación de los proyectos sea lo más transparente posible, de forma de asegurar la real posibilidad de obtener recursos a todas las juntas de vecinos presentes en la comuna.

\section{CONCLUSIONES}

Luego de considerar las fortalezas y debilidades que se identificaron a través de la revisión documental y de la información obtenida a través de las capacitaciones y asistencias técnicas realizadas, se observa que el FONDEVE fue percibido como un mecanismo altamente participativo durante la década de los noventa. Considerando que por la dictadura la participación ciudadana era nula, fue muy bien recibido por parte de los municipios y habitantes de la comuna, entregar cierto control a las juntas de vecinos para poder solucionar problemas de su entorno.

Ahora bien, han pasado los años y el contexto en relación con la participación ciudadana ha cambiado. Actualmente, esta se asume como eje transversal a la gestión pública y se ha complejizado enormemente su comprensión. 
Aún no hay absoluto consenso en cómo se debe operacionalizar, pero en todos los niveles se asume como importante, y esto se refleja en los esfuerzos que se han realizado, como la ley 20.500 sobre asociaciones y participación ciudadana en la gestión pública. Se han creado nuevos mecanismos, como los presupuestos participativos y los COSOC, que han implicado elementos y formas más profundas de participación ciudadana.

En este nuevo escenario, los Fondos de Desarrollo Vecinal evidencian debilidades en torno a la participación ciudadana debido a los obstáculos que presentan en su desarrollo, especialmente en la etapa de selección. En ese sentido, se pone en duda su aporte, siendo considerado como mecanismo participativo, en el fortalecimiento de la participación ciudadana y de la democracia a nivel local.

Ahora bien, sí existen medidas que se pueden adoptar para mejorar esta situación. En primer lugar, urge generar más información en relación al impacto que tienen los FONDEVE como mecanismos de participación ciudadana. En segundo lugar, se debe ordenar y crear los instrumentos y procesos necesarios para garantizar la transparencia de los procesos de postulación y selección. Por último, desde el nivel central se debería flexibilizar los instrumentos de participación ciudadana obligatorios, dejando a decisión de cada municipalidad, según sus capacidades, el seguir ejecutando el FONDEVE o traspasar los recursos a instrumentos que avancen a la democratización de forma más profunda, como los presupuestos participativos.

\section{BibLIOGRAFÍA}

Castillo, A., \& Villavicencio, H. (2005). Del Fondo de Desarrollo Vecinal (FONDEVE) al presupuesto participativo. En Hacia una democracia deliberativa: La experiencia del presupuesto participativo (págs. 39-49). Chile: Ediciones el Tercer Actor. Corporación Libertades Ciudadanas.

Congreso Nacional de Chile. (1990). Primer trámite constitucional: Mensaje. Historia de la Ley ${ }^{\circ} 19.418$ : Ley sobre juntas de vecinos y organizaciones comunitarias funcionales. Valparaíso, Chile: Biblioteca del Congreso Nacional (BCN). 
Congreso Nacional de Chile. (1995). Primer trámite constitucional: Cámara de Diputados. Historia de la Ley $n^{\circ} 19.418$ sobre juntas de vecinos y organizaciones comunitarias funcionales. Valparaíso, Chile: Biblitoeca del Congreso Nacional (BCN).

Consejo Nacional de Participación Ciudadana. (2017). Informe Final: Estado de la participación ciudadana en Chile y propuestas de reforma a la ley 20.500 sobre asociaciones y participación ciudadana en la gestión pública. Chile.

Ley n¹9.418. (10 de octubre de 1995). Diario Oficial de la República de Chile. Chile.

Luján, D. (2017). Entre la autonomía y la dependencia. Lobby, clientelismo político e idea de estado en los contextos locales chilenos. Polis, 133-154.

Montecinos, E. (2007). Los límites de la modernización municipal para profundizar la particiáción ciudadana en Chile ¿Es la gobernanza de proximidad una alternativa? Gestión y Política Pública, 319-351.

Montecinos, E. (2011). Democracia participativa y presupuesto participativo en Chile: ¿Complemento o subordinación a las instituciones representativas locales? Revista de Ciencia Política, 63-89.

SUBDERE y DOS. (2016). Guía Participación Ciudadana en la Gestión Municipal. 



\section{TERCERA PARTE: \\ Buenas PRÁCticas de Gestión Participativa Municipal}





\title{
Municipalidad de NACimiento. EXPERIENCIA PRESUPUESTOS PARTICIPATIVOS 2OI7-20I8
}

\author{
Mariela Muñoz \\ Municipalidad de Nacimiento
}

\section{Antecedentes}

La Ilustre Municipalidad de Nacimiento, desde el año 2011, ha desarrollado formalmente iniciativas de participación ciudadana en distintos ámbitos de su gestión local, primero y según los requerimientos que establece la normativa legal chilena, y en segundo lugar, como iniciativa autónoma del municipio, para dar solución a demandas de la comunidad que han involucrado participación ciudadana activa de sus habitantes.

Desde el año 2016 a la fecha, la decisión del alcalde, Sr. Hugo Inostroza Ramírez y del Concejo Municipal, ha sido de fortalecer y apoyar las iniciativas de ejecución de los presupuestos participativos comunales, y los ha situado como un instrumento importante de planificación y de priorización de las necesidades de la comuna, a través de un diálogo permanente con las organizaciones territoriales, y que se inicia con la participación de estas, desde el diagnóstico de las necesidades en sus respectivos territorios, priorización de sus demandas, formulación de ideas de proyectos para abordar sus problemáticas, hasta el proceso de votación y ejecución, en donde también asumen una participación activa, según corresponda en cada caso. 
Situación inicial. Desarrollo de estrategias para LLEGAR AL MECANISMO DE PRESUPUESTOS PARTICIPATIVOS

\section{FONDEVE}

Desde el año 1999, y en virtud de lo que mandata la Ley 19.418; Sobre juntas de vecinos y demás organizaciones sociales, se atendió las necesidades y demandas de la comunidad a través del Fondo de Desarrollo Vecinal (FONDEVE), una de las primeras e incipientes herramientas de participación ciudadana, que consistía en la transferencia de recursos en dinero para las organizaciones territoriales de la comuna, que presentaran proyectos al municipio en dos líneas de concursabilidad: equipamiento e infraestructura. Actualmente, esta línea de proyectos se encuentra vigente para las organizaciones -Juntas de Vecinos urbanas y rurales-, con un presupuesto anual de 23 millones de pesos y con la publicación de bases y llamado a concurso, en el mes de marzo de cada año.

\section{Plan de equipamiento comunitario}

Así mismo, desde el año 2015 comenzó también a gestarse una nueva iniciativa, que sería denominada Plan de Equipamiento Comunitario, y que consistió en establecer una metodología que permitiera ordenar y priorizar la necesidad de proyectos de infraestructura de la comunidad, y cuyos montos estaban entre los 20 a 120 millones de pesos. La gestión y ejecución de dichos proyectos, se estableció en un horizonte de 4 años, y en su mayoría, serían ejecutados por la Municipalidad de Nacimiento con financiamiento de fondos externos. Este ejercicio de participación ciudadana fue dirigido a las organizaciones territoriales y funcionales de la comuna, en donde agrupadas, según su distribución territorial, llevaron a cabo un proceso que permitió elaborar el diagnóstico de sus necesidades a través de reuniones con el municipio, entrevistas individuales y grupales de las organizaciones. El municipio, posteriormente, recogió estas 
propuestas, realizó jornadas de socialización en donde se expuso el trabajo de cada uno de los grupos de organizaciones conformados para tal efecto, se priorizaron sus demandas, y se sometieron a un proceso de votación en donde los proyectos más votados fueron seleccionados para financiarse. Actualmente, y según lo indicado anteriormente, el Plan de Equipamiento Comunitario, se encuentra vigente y en proceso de ejecución; es una herramienta de participación ciudadana creada en la comuna, sin precedente de que dicha experiencia se ejecute en otras y con un horizonte de tiempo más amplio que el del mecanismo de presupuestos participativos, que como se verá a continuación, es de un año y medio aproximadamente.

PRIMERA VERSIÓN DE PRESUPUESTOS PARTICIPATIVOS 20 I 6

Para el año 2016, ante la necesidad de generar mayor compromiso y participación de las organizaciones, y ante la experiencia comparada de otros municipios, se decidió incorporar progresivamente el mecanismo de Presupuestos Participativos, en su primera versión, dirigida exclusivamente a organizaciones territoriales -juntas de vecinos- de la comuna. Se crearon las bases que regularían el proceso, con características locales pertinentes, se estableció un presupuesto asignado, y se determinó que las Juntas de Vecinos del sector urbano y rural de la comuna, participarían agrupadas en dos sectores y cuyos montos presupuestarios asignados para cada sector, serían de 40 y 20 millones, respectivamente. Cada Junta de Vecinos, tendría derecho a postular una iniciativa simple de proyecto, según las necesidades que esta misma detectara en su comunidad, por un monto comprendido entre 3 y 10 millones. Posteriormente, y según el cumplimiento de las etapas de admisibilidad como factibilidad técnica establecidas en las Bases que regulan el proceso, las iniciativas de proyectos pasarían a una instancia de votación, en donde serían seleccionadas aquellas con mayor votación. 
En el año 2018, se realizó la segunda versión de Presupuestos Participativos 2017-2018, bajo el mismo espíritu de fortalecer el compromiso de las organizaciones en la resolución de sus problemáticas y así también comprometer la participación de la comunidad a través de un acto democrático de votación. Se actualizaron las bases del proceso y se recogieron las sugerencias de mejoras advertidas en la primera versión.

Se convocó nuevamente a las organizaciones territoriales de la comuna, sectores urbano y rural. Se dispuso de un presupuesto municipal, aprobado por el Concejo Municipal, de 60 millones de pesos, desglosado en 40 millones para financiar ideas de proyectos de las organizaciones urbanas y 20 millones para financiar las ideas de proyectos ganadores de las organizaciones del sector rural de la comuna.

Cada Junta de Vecinos, ya fuera urbana o rural, tuvo derecho a postular una idea de proyecto por un monto de entre 3 y 10 millones de pesos, que atendiera a una necesidad manifestada por su comunidad. Dichas iniciativas se presentaron al municipio para, posteriormente, ser evaluadas en dos etapas, admisibilidad y factibilidad técnica, a cargo de un grupo de profesionales expertos de la unidad de SECPLAN del municipio, en donde se establecieron los ajustes necesarios que no hubiesen sido considerados por las organizaciones participantes. Cabe agregar, que las etapas de evaluación también consideraron la participación activa de representantes de las organizaciones urbanas y rurales, quienes, en mesas de trabajo, desarrolladas conjuntamente con las unidades municipales que participan desde el municipio, SECPLAN y Departamento de Organizaciones Comunitarias, sancionaron el proceso, antes de llevar a efecto la votación. En dicha versión del proceso, de las 12 ideas de proyectos presentadas por las organizaciones urbanas (9) y rurales (3), todas pasaron a la etapa de votación.

El proceso de votación permitía la participación mediante el voto, de todos los socios de las organizaciones territoriales de la comuna, hubiera o no presentado ideas de proyectos. El único 
requisito exigido previamente, era estar inscrito en el denominado Padrón de Votación de cada organización. Este documento consistía en un listado de hasta 50 socios, realizado por cada Junta de Vecinos, que los habilitaba para votar y que fue solicitado por el municipio, con anterioridad a llevarse a efecto el proceso de votación. Se requirió este documento para garantizar la transparencia y orden del proceso; al estar el socio de la organización inscrito previamente en un Padrón, se evitaba que votara dos veces, o que alguien que no correspondiera a la organización y/o incluso a la comuna, se presentara a votar. Favoreció a su vez, que las organizaciones que habían presentado ideas de proyecto realizaran estrategias de asociatividad con aquellas organizaciones que, si bien no habían presentado ideas de proyectos, podían habilitar a sus socios, previa inscripción en el Padrón de Votación, para participar del proceso como votantes.

La votación se desarrolló en un día único, tanto en el sector urbano como rural. En el caso del sector urbano, se estableció como sede de votación la Escuela El Saber de la comuna. Participaron de la votación 500 personas aproximadamente, quienes desde las 09.00 h. hasta las $18.00 \mathrm{~h}$. se presentaron con gran entusiasmo para ser parte del proceso. Los resultados de este se publicaron el mismo día, al momento del cierre y escrutinio de las mesas. Contó con un gran despliegue y colaboración de las unidades municipales. En el caso del sector rural, las votaciones se efectuaron de forma simultánea en los tres sectores de la comuna: La Esperanza, San Francisco de Monterrey y San Francisco de Millapoa, correspondientes a los sectores de las organizaciones que habían presentado las ideas de proyectos del sector rural. Participaron del proceso, en total, 130 socios, durante una jornada que se desarrolló entre las $09.00 \mathrm{~h}$. y las 16.00 h. Los resultados del proceso de votación, también se dieron a conocer en el mismo día, una vez finalizado este y cerradas las mesas de votación.

Todas las etapas del proceso se socializaron debidamente con la comunidad. Se dispuso de manera activa, a dos unidades del municipio, SECPLAN y Depto. de Organizaciones Comunitarias, para atender y resolver consultas y solicitudes de parte de las 
organizaciones, durante todas las etapas del proceso. El aspecto logístico se financió con recursos del municipio y prescindió del apoyo externo para llevarlo a cabo, a diferencia de la primera versión, en donde se contrató los servicios de una consultora externa.

\section{AprendizAJES}

El mecanismo de Presupuestos Participativos en la comuna se ha implementado desde el año 2016 y se han ejecutado dos versiones, bajo la gestión del alcalde, Sr. Hugo Inostroza Ramírez. Ha sido una experiencia desafiante pero muy satisfactoria, que por una parte, supone entender y aplicar una metodología que debe adaptarse a las condiciones propias de la comuna, y supone también un aprendizaje y preparación institucional constante de parte las unidades municipales involucradas en la ejecución de las etapas del proceso.

Por otra parte, la comunidad organizada formalmente a través de las Juntas de Vecinos también ha experimentado un desafío importante al que ha debido ir adaptándose, puesto que la metodología, supone un ejercicio de traspaso de responsabilidad sobre la decisión de la asignación de recursos para la comunidad, por lo que esta debe ser adecuadamente informada del proceso, incentivada y altamente involucrada en cuanto a su participación.

Para el municipio ha sido una experiencia positiva, llena de aprendizajes, reconfortante, aun cuando implica un alto despliegue logístico y de recurso humano, que afronta diversas etapas de coordinación y altas horas de trabajo, pero tiene a su vez, un fuerte valor agregado, que recoge y legitima el esfuerzo tanto del municipio como de la comunidad que participa hasta el acto democrático de la votación.

Finalmente, al existir estas formas innovadoras de participación ciudadana, baja la presión sobre la demanda espontánea del municipio, ya que se convierte en una herramienta validada, reconocida y legitimada para atender los problemas comunitarios; se transparentan, además, los procesos de gestión local y se favorece el control ciudadano sobre el gobierno local.

(Ilustre Municipalidad de Nacimiento, 2017) 
Municipalidad de Nacimiento. Experiencia presupuestos participativos

\section{BIBLIOGRAFÍA}

Ilustre Municipalidad de Nacimiento. (2017). Bases Proceso Presupuestos Participativos 2017-2018. Nacimiento: Municipalidad de Nacimiento. 



\title{
Directorio URBANO DE COYHAIQUE: HACIA UNA PARTICIPACIÓN EFICIENTE
}

\author{
Juan Carmona \\ Municipalidad de Coyhaique
}

\section{RESUMEN}

El Directorio Urbano de Coyhaique, es una iniciativa de participación, que surge desde la Municipalidad del lugar, procurando constituir con un grupo de actores de la sociedad civil, autoridades y representantes de organismos privados, una instancia de gobernanza de la ciudad en lo relativo a su práctica y proyección urbana. Se ha tenido como meta preparar una visión de ciudad y actuar para concretar programas de intervención y proyectos con un enfoque de gobernanza. La ciudad enfrenta actualmente diversos desafíos que no se han logrado solucionar, entre ellos el cierre de las herramientas de planificación urbana, instrumentos en los que intervienen fundamentalmente actores públicos en su fase formal, pero que han sido materia de consultas ciudadanas en su preparación. El ejercicio de diálogo ha sido una tarea compleja en la que se han enfrentado interrogantes sobre la normativa mínima interna que debe regir al Directorio, hasta la definición de los grandes temas. Se ha puesto especial atención en algunos elementos que pueden ayudar a su comprensión, para efectos de derivar posteriormente en un análisis crítico sobre los logros y retos que quedan por alcanzar. 


\section{Elementos De CONTEXTO}

La comuna de Coyhaique tiene una población de 57.818 habitantes y en la ciudad vive el $86.4 \%$ de ellos. Los actores sociales se encuentran organizados en diversos cuerpos intermedios y se agrupan en entidades de segundo grado, tales como uniones comunales o federaciones. Si bien separadas en la distancia del resto de Chile, las organizaciones siguen causas de cohesión semejantes a las de otras ciudades a nivel nacional. Por tanto, representan los intereses de las más diversas expectativas y buscan con su quehacer y gestión influir en distintos grados en la toma de decisiones. Sin embargo, hay especificidades que guardan relación con corporaciones que se orientan, por ejemplo, a la defensa del medio ambiente y de los pueblos originarios, representando realidades propias de Aysén. Por una parte, se enfatiza la belleza paisajística y el volumen de agua dulce en los cuerpos de agua, proporcionalmente mucho mayor que aquel disponible en otras regiones del país, y por otra, la presencia de habitantes que reconocen formar parte del pueblo Mapuche Tehuelche.

Hay trabajos sistemáticos que se han llevado adelante con Programas de intervención comunitaria, que obedecen a políticas públicas destinadas a mejorar la calidad de vida de los habitantes, por ejemplo el denominado Programa Barrios, el cual sigue una metodología participativa, creando diversos cuerpos intermedios informales, o dicho de otro modo sin personalidad jurídica, pero que han demostrado ser eficientes como medio de cohesión social en contextos territoriales específicos y con fines muy concretos.

Coyhaique, es la capital de la región de Aysén y su población constituye cerca del $60 \%$ de ella. Por tanto, la construcción de ciudad es un desafío para que esta resulte habitable en un entorno complejo, teniendo presente la multitud de factores que influyen en el hecho de que una ciudad funcione bien. Siendo la región un territorio con paisajes valorados internacionalmente por agencias especializadas en destinos y por estudiosos de los ecosistemas, la ciudad capital, la más poblada de Aysén, pero de tamaño pequeño, sin discutir ni profundizar sobre la clasificación, en el corazón de la Patagonia, ha 
sido por largo tiempo, hasta la actualidad y durante las épocas invernales, la ciudad más contaminada de América, fundamentalmente por el uso de leña en las temporadas frías, para calefacción. Distinta de otras realidades, el contaminante principal no es la emisión que proviene del transporte.

\section{El Directorio Urbano de Coyhaique, INSTANCIA DE REFLEXIÓN Y DIÁLOGO}

El Directorio Urbano nace como una iniciativa que busca mirar el futuro desde un espacio de encuentro que reúna a actores, que bajo otras modalidades actúan en paralelo, para tratar temas similares o complementarios, pero que han desarrollado agencias que son suficientes para sí mismas, mas no para el conjunto del territorio. Lo señalado, ocurre con mayor frecuencia a nivel público, en particular con el trabajo de los ministerios, y que se agrava por el centralismo que aún caracteriza el sistema público en Chile.

El Directorio Urbano de Coyhaique declaró constituirse como: «una instancia que facilitará la Participación Ciudadana y de los sectores involucrados en la Gestión Urbana, con el objeto de contribuir e impulsar el desarrollo armónico de la ciudad en sus aspectos económicos, sociales, ambientales, estructurales, funcionales y espaciales» (Convenio Marco Trabajo Colaborativo para la Constitución del Directorio Urbano de Coyhaique). El trabajo se planteó en orden a crear un Plan Centenario, dado que en el año 2029 se celebrará el primer siglo de vida de la ciudad, por tanto, el hito se propuso como una meta para consolidar la visión de ciudad construida en conjunto y la ejecución de proyectos estratégicos asociados.

Las circunstancias que en su momento se plantearon, para efectos de proponer el Directorio Urbano como una forma participativa de atender el desarrollo de la ciudad fueron, por una parte, la constatación de que la ciudad necesitaba una instancia de cooperación eficiente entre los actores que intervienen en las decisiones que la afectan e implican al conjunto de los habitantes del territorio, y por otro lado, se consideró la oportunidad de futuro que la ciudad tiene, en la medida que se alcancen acuerdos entre los actores, tanto 
para los diagnósticos como para la planificación y ejecución de las acciones propias de ellos.

La iniciativa, no tiene el carácter de entidad pública, sino más bien es una conjunción de actores y sujetos que se proponen la búsqueda de un sistema de gobernanza cuyo efecto sea verificable en los factores de construcción de ciudad.

\section{SOBRE LOS ACTORES}

La estrategia se diseñó en su base institucional considerando experiencias en otra comuna a nivel nacional, específicamente Concepción, la cual inició su propio proceso hace varios años. La selección de actores considerados en el directorio se planteó orientada a la búsqueda de líderes representativos de sus organismos. Se invitó a dirigentes de la sociedad civil, del sector privado, del sector público y a las Universidades con presencia en la Región de Aysén, para conformar el directorio, el cual comenzó a reunirse bajo las premisas antes señaladas.

Los miembros del directorio son dirigentes representativos y autoridades, pero además la composición ha considerado instituciones cuyo aporte esperado guarda relación con la profundidad de su especialidad en la definición urbana, dada la pertinencia de las actividades que desarrollan.

Un elemento adicional en el proceso de conformación del directorio es que, a la motivación para darle vida, se sumó una propuesta técnica de la unidad de asesoría urbana de la propia municipalidad de Coyhaique, por tanto, la formación del directorio conllevó el aporte profesional para la interpretación del territorio y acciones que pudieran desarrollarse. Se constata que, si bien el cargo de asesor urbanista se contempla en la principal norma municipal, dicha función queda supeditada a los recursos que se le designen, para su funcionamiento. Por ello, el liderazgo que se ejerce desde dicha unidad municipal debe reconocerse como un aporte que supera lo administrativo. 


\section{SOBRE LOS ALCANCES DE LA REFLEXIÓN Y LA TOMA DE DECISIONES}

Uno de los aspectos complejos en los sistemas de participación, y el Directorio Urbano no escapa a ello, son las reglas de funcionamiento, las normas que lo rigen, que en este caso, si bien se aprueban por el Concejo Municipal, estas son dinámicas en tanto los temas atendidos incumben de forma diversa a los componentes y solo se plantean interrogantes en la medida que surgen asuntos relativos a conflictos de intereses, propuestas opuestas o situaciones jurídicas que limiten la generación de consenso.

La dinámica local demuestra que es complejo para quienes ejercen autoridad en sus diversos ámbitos, tener la disposición a ceder parte de su poder o al menos generar un ambiente propicio para la búsqueda de acuerdos que impliquen adoptar decisiones en conjunto, lo que demostraría, más que una debilidad, una necesidad de profundizar precisamente en las formas cómo se hace más eficiente la toma de decisiones, situación que implicaría profundizar en transparencia, para compartir información.

La práctica del directorio demuestra que se requiere una definición de la cronología o al menos de una planificación de la participación en su proceso, ya sea para definir sugerencias de lineamientos futuros, o bien, adoptar acuerdos para llevar adelante iniciativas que requieren el concurso de los actores. La incorporación de las prácticas de participación ha ido lentamente interpelando a los actores involucrados respecto de: a) qué esperar de la participación, b) explicar por qué se propicia y c) para qué se inician los procesos. El conjunto de preguntas y otras no definidas son esperadas por quienes son convocados a formar parte de las instancias; su falta de respuesta o respuestas parciales derivan en expectativas no cumplidas, o bien, generan nuevas situaciones, como por ejemplo, exigir acciones vinculantes a contrapartes no preparadas para dialogar sobre soluciones consensuadas. El Directorio ha iniciado su propio recorrido en la solución de dichas preguntas, sobre las que en general se demuestra falta de un sistema de actuaciones que involucran los liderazgos y habilidades para el diálogo de los participantes. 
El Directorio Urbano es una modalidad de encuentro de actores que han sido invitados a reflexionar, pensar en conjunto el desarrollo de Coyhaique. Es una construcción institucional voluntaria y solo obliga la meta de alcanzar productos que modelen y propongan elementos del desarrollo urbano en un horizonte de tiempo, cuyo límite está definido por el hito del centenario de la ciudad, de corto y mediano plazo.

Las actas del directorio demuestran el interés por los grandes temas de la ciudad capital regional y su devenir; por otra parte, el proceso da cuenta de las debilidades de los actores actuando en forma separada. A modo de ejemplo el Plan Regulador de Coyhaique inició su proceso de aprobación hace más de dos años, sin que durante ese periodo de tiempo haya alcanzado el cierre de su ciclo o aprobación, sino más bien, se haya puesto en duda su sometimiento y se esté considerando actualmente optar por enfatizar la aprobación del Plan Intercomunal Coyhaique-Aysén, hecho que lleva a concluir que cuando los actores, es decir los servicios públicos involucrados, no logran avanzar en sus especificidades de las cuales están dotados por ley, un sistema de gobernanza puede ser una herramienta que mejore la eficiencia de los procesos.

La situación señalada a modo de ejemplo da lugar a una nueva reflexión, la cual guarda relación con la suma de nuevos actores, entre los que se cuenta al menos uno, el que la ley define como organismo fiscalizador: se trata de la Contraloría General de la República, entidad a la que corresponde la revisión de los procedimientos, pero que no ha participado de estos. Dada la relevancia que importa su rol en el cierre de procesos definidos por el sistema normativo, eventualmente su actuación podría ser revisada, incorporándola no para ser parte interesada o decisora, sino para hacer seguimiento desde el inicio a las actuaciones públicas, especialmente aquellas que por su alcance y magnitud resultan ser altamente complejas.

El directorio ha conocido, además, la situación de discrepancia sobre un tema específico de ciudad, relativo a una acción de consulta y participación. La presentación de la situación ha sido motivada a iniciativa del Colegio de Arquitectos y está referida al 
emplazamiento de una estructura arquitectónica significativa para la ciudad. Su anteproyecto o idea original, dio lugar a un ejercicio participativo, el que posteriormente habría sido abortado, en tanto ejercicio participativo, por el organismo propulsor de tal infraestructura. En opinión del colegio, el proceso de participación debió haber culminado con decisiones que dieran cuenta de cómo se respetaría la imagen de ciudad, que se gesta en conjunto, por parte de quienes conocen sobre urbanismo, además de otras afirmaciones que surgieron de falta de elementos técnicos para definir la estructura, la cual se orienta a convertirse en edifico institucional. Dicha situación está en progreso y no se ha cerrado, sin embargo, es una oportunidad de ejercicio sobre la gobernanza urbana en Coyhaique.

Adicionalmente, otro elemento de aporte, que preliminarmente se puede anticipar como beneficio del Directorio Urbano de Coyhaique, es que las prácticas y propuestas son materia de reflexiones institucionales e individuales específicas, sin embargo, las soluciones que se vislumbren y se califiquen de exitosas pueden llegar a ser de aplicación general, a modo de metodologías, para otras experiencias que en términos comparativos sean susceptibles de ser replicables.

\section{Conclusiones}

El Directorio Urbano de Coyhaique es una iniciativa orientada a la gobernanza de la ciudad, aún en fase de consolidación, y se plantea como una instancia innovadora para reflexionar sobre los procesos que pudieran conducir a Coyhaique, para llegar a ser una ciudad exitosa.

En la actualidad resulta un imperativo contar con la discusión crítica de los actores involucrados, para avanzar en la conformación de un territorio, que por una parte sea capaz de responder a las aspiraciones de sus habitantes y por otra que supere por sí mismo sus limitaciones.

Los pasos dados por el Directorio Urbano de Coyhaique enfrentan los interrogantes propios del crecimiento; hay en su dinámica elementos que apuntan al sentido de la gobernanza como opción 
metodológica, orientada a construir procesos eficientes. Se tiene por una parte el impulso de la acción colectiva y por otra, la realidad de la institucionalidad versus la búsqueda de la participación vinculante. El contexto de la participación se da en un marco de institucionalidad, que por sí misma presenta carencias y elementos que son perfectibles, es decir, la práctica del Directorio Urbano de Coyhaique es también una posibilidad para preguntarse por la calidad de la democracia local. 


\section{ESCUELA ABIERTA: \\ UNA HERRAMIENTA TRANSFORMADORA}

\section{Gianinna Repetti Lara}

Administradora Municipal de Recoleta

\section{Alejandra Placencia Cabello}

Profesora de Estado en Filosofía

«Escuela Abierta» es un programa creado para que los centros educativos municipales de Recoleta se conviertan en un polo de desarrollo social para toda la comunidad, es decir, estudiantes, organizaciones sociales, culturales y territoriales. El concepto que direcciona el programa se sustenta en la premisa de que abrir la escuela a la comunidad es, al mismo tiempo, contribuir a democratizar la escuela. El diagnóstico inicial, realizado a partir de la administración municipal encabezada por el alcalde Daniel Jadue, arrojó que la comuna carecía de espacios gratuitos para el encuentro vecinal y que la infraestructura disponible en sedes sociales era insuficiente. Asimismo, los espacios para la juventud y la realización de actividades culturales y deportivas eran muy escasos o prácticamente inexistentes.

Hoy día, Escuela Abierta no solo es un programa emblemático, sino que además es exitoso, porque logró cubrir una necesidad real de la comunidad, que fue, en primer término, facilitar espacios para las organizaciones sociales, sin tener que invertir en infraestructura. El programa comenzó su desarrollo en seis establecimientos educativos hasta llegar a las 19 escuelas de administración municipal. En su concepción, Escuela Abierta tiene el sello de una gestión municipal 
innovadora, participativa y enfocada en mejorar la calidad de vida de la población recoletana, lo que progresivamente se ha demostrado con el crecimiento de iniciativas y participación, pero también con el compromiso que los beneficiarios del programa han adquirido con las escuelas, colaborando en la mantención, el adecuado funcionamiento, respetando los espacios y las dinámicas propias de las actividades que se realizan en Escuela Abierta.

\begin{tabular}{|c|c|c|c|c|c|}
\hline \multicolumn{7}{|c|}{ GESTIÓN DE ESPACIOS PARA LA COMUNIDAD $^{1}$} \\
\hline & 2013 & 2014 & 2015 & 2016 & 2017 \\
\hline $\begin{array}{c}\text { Cantidad total de solicitu- } \\
\text { des de espacio atendidas }\end{array}$ & 208 & 401 & 432 & 419 & 469 \\
\hline $\begin{array}{c}\text { Núm. de participantes } \\
\text { aproximados }\end{array}$ & 18.530 & 28.266 & 34.141 & 26.778 & 28.562 \\
\hline
\end{tabular}

Antes de la implementación del programa, las escuelas municipales eran entidades cerradas al barrio, como ocurre en la mayoría de los lugares de Chile, sin embargo, abrirlas a la comunidad, para que la infraestructura estuviera disponible a las más diversas organizaciones territoriales, contribuyó a suplir una carencia concreta y posibilitó el desarrollo, regularidad y fortalecimiento de las organizaciones. A eso se sumó la oferta de talleres del municipio, a partir de la generación de vínculos con otros organismos como fundaciones, y el trabajo intersectorial con otras direcciones del municipio como Medio Ambiente, Salud, Cultura, Deportes y DIDECO, aportando al proyecto con actividades y talleres de las más diversas áreas. La comunidad escolar debió abrir las escuelas, eliminando progresivamente la resistencia cultural de ser o existir solo para sí y comprender que se debe educar para la inclusión social y la formación ciudadana, que es una de las consecuencias más inmediatas de esta apertura al ampliar el contexto educativo incorporando al entorno natural, social y cultural. La comunidad escolar debió hacer una transformación

1 Fuente: DAEM Municipalidad de Recoleta, Programa “Escuela Abierta”, año 2018. 
de sí misma e incorporar en sus proyectos educativos institucionales esta nueva relación con la comunidad.

Para que la escuela sea genuinamente un lugar abierto a la comunidad, se han generado instancias de trabajo permanente que se han ido perfeccionando en virtud de la experiencia. Lo fundamental es que la escuela dejó de funcionar solo en base a una estructura organizacional tradicional y de un modo unidireccional en la toma de decisiones; es decir, adquirió una dinámica de comunidad como 'cuerpo colegiado', que discute lo que ocurre en su escuela, define y se compromete, actuando en base al diálogo, la responsabilidad y el respeto de todos los miembros que la componen.

El vínculo escuela-comunidad se da en un marco que impulsa el cambio cultural y dinámicas de la escuela, lo que debe darse en diversos planos como son: las relaciones de convivencia entre las personas, con los espacios físicos, actitudinales y pedagógicos, entre otros. Para ello se definieron las siguientes reuniones como instancias de participación, las que se suman a las que han sido tradicionales en las escuelas: Coordinación de Escuela Abierta con los encargados de escuela y miembros del equipo para monitorear avances y funcionamiento; reuniones de Directorio Colegiado, constituido como 'Consejo Escolar', con los representantes de la comunidad, pero de carácter resolutivo; actividades de intercambio permanente entre las organizaciones sociales usuarias/beneficiarias de Escuela Abierta, como Juntas de Vecinos y organizaciones sociales; trabajo intersectorial, entre distintas direcciones municipales y corporaciones para el trabajo coordinado y definición de iniciativas conjuntas.

Al cabo de cinco años de implementación, se ha avanzado en dinámicas participativas en que la comunidad se ha apropiado del programa, ha colaborado en su mejor funcionamiento y se han establecido compromisos recíprocos entre la Municipalidad y las organizaciones que son parte de Escuela Abierta.

Una de las últimas iniciativas implementadas fueron las «Cartas de Servicio Municipal», propuesta piloto de la SUBDERE a una cantidad acotada de municipios en Chile. Recoleta se incorporó a participar con el programa, permitiéndole trabajar una metodología de 
participación que constituye un avance en la línea de afianzar buenas prácticas municipales en los servicios y/o programas que benefician a la comunidad recoletana. Se realizaron reuniones preparatorias con apoyo de la consultora PCP, designada por la SUBDERE, y el equipo compuesto por la Administración Municipal y encargados del Programa Escuela Abierta y DAEM. Se realizaron jornadas de participación ciudadana con representantes de la comunidad escolar y organizaciones sociales que son usuarios/beneficiarios de Escuela Abierta. En tres jornadas se determinaron los compromisos de la comunidad con el programa y se recibieron opiniones para mejorar los compromisos que la municipalidad podría establecer con la comunidad. En la última reunión se determinó un Comité de Seguimiento de los compromisos y se firmó un acta en que los miembros del comité se hicieron responsables de evaluar el cumplimiento de la Carta de Servicio al cabo de un año. Una vez definidos los compromisos, se trabajó un diseño de afiche con la Consultora y equipo de comunicaciones de la Municipalidad para exponerlo en todas las reparticiones municipales y escuelas.

De esta experiencia se pueden identificar aprendizajes importantes para la mejora constante del programa. Algunas fortalezas son:

- La Carta de Servicio permitió identificar que el programa Escuela Abierta es altamente valorado por la comunidad.

- La comunidad está dispuesta a colaborar para mejorar las dinámicas de funcionamiento que se dan entre los beneficiarios/usuarios con el municipio y entre las mismas organizaciones.

- El equipo del programa Escuela Abierta respondió rápida y favorablemente a los requerimientos solicitados para la elaboración de la Carta de Servicio.

Algunas dificultades del mecanismo de participación, resueltos a tiempo para que la iniciativa pudiera concretarse, fueron: 
- Lograr reunir a la misma gente para las jornadas de participación en las que se requirió ir ratificando los puntos señalados como acuerdo. Se realizaron esfuerzos adicionales para lograr el objetivo.

- Los tiempos administrativos retrasaron un poco el cumplimiento del calendario inicial, ya que se comenzó con el trabajo con plazos muy limitados y se tuvieron que hacer adecuaciones de acuerdo con la realidad.

El mecanismo de participación utilizado para la realización de la «Carta de Servicio Municipal del Programa Escuela Abierta» posee varias ventajas:

- Permite escuchar a la comunidad y dialogar para mejorar el trabajo que se realiza en el Programa, lo que se vuelve relevante al considerar que es un servicio de alta valoración social.

- Permitió comprometer a la comunidad y al municipio en una relación de reciprocidad con Escuela Abierta.

- Establecer un comité de seguimiento posibilita evaluar la implementación de los compromisos que, al ser elaborados participativamente y ser conocidos por todos, fortalecen el trabajo del municipio y su vínculo con la comunidad.

Una vez terminado el proceso de elaboración, se evaluó que la iniciativa realizada es una buena práctica municipal porque se cumple con un objetivo fundamental: incorporar a la comunidad recoletana en la mejora de los servicios que se ofrecen y que tienen el foco puesto en la participación ciudadana para que estos puedan crecer, ser más convocantes y robustecerse como política permanente y actualizada en beneficio de los vecinos de la comuna. 


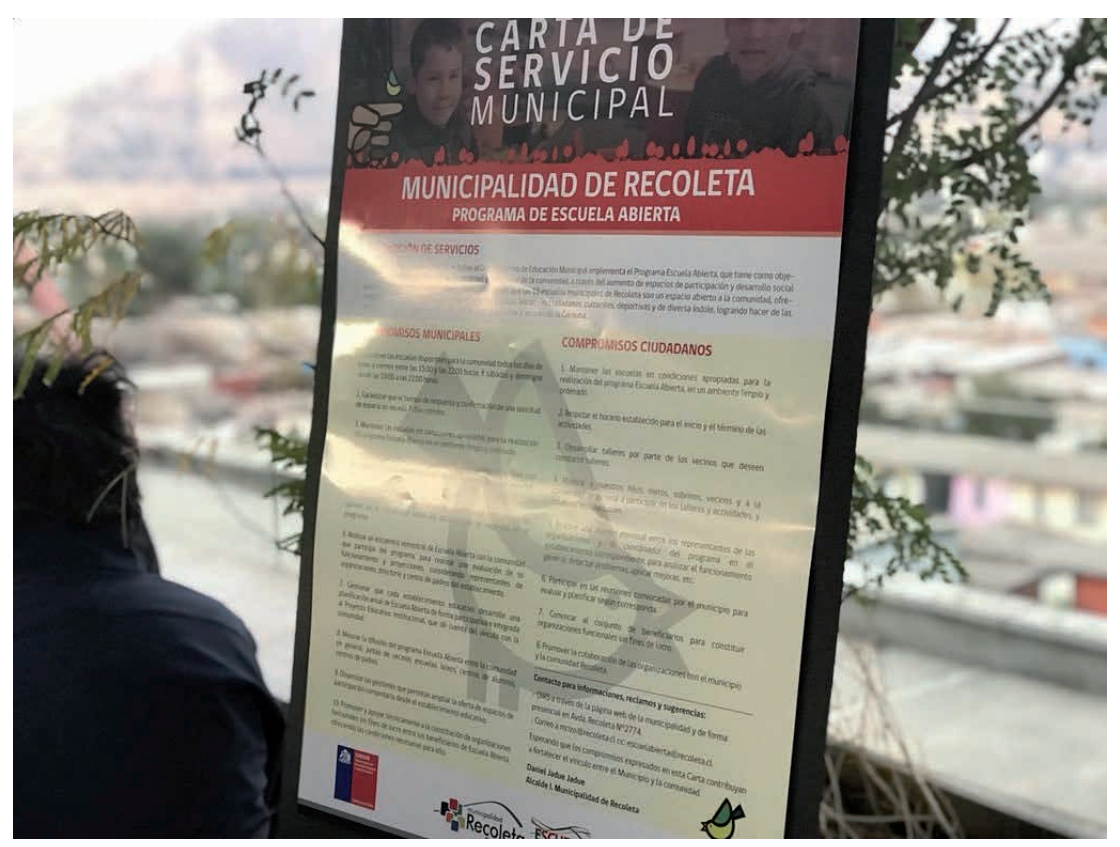

El equipo encargado de Escuela Abierta realiza una permanente reflexión a partir de la experiencia del programa. Se pueden destacar el respeto y valor que se le da a la educación pública, ya que la escuela es de toda la comunidad. Se ha logrado integrar positivamente la política de Escuela Abierta a las actividades permanentes y cotidianas de la escuela, en una relación democrática entre los participantes y la comunidad. Se ha puesto en valor la identidad, cultura y talentos locales, entre otros.

Desde el año 2013 a la fecha el desarrollo del programa ha crecido permitiendo una serie de iniciativas que se han instalado como política pública a nivel local, pero con proyección nacional. Actualmente, las actividades de la comunidad se han complementado con algunas innovaciones impulsadas por la Municipalidad, por ejemplo: becas, cursos de conducción, curso lengua de señas, escuela popular de teatro, muralismo, desarrollo de proyectos socioeducativos, entre otros.

Como política nacional, aplicable a la diversidad de municipios que existen en Chile, en abril de 2017 el MINEDUC publica a través 
de la División de Educación General, el documento «Orientaciones para la implementación de Escuela Abierta a la Comunidad», en el marco del lanzamiento de la nueva política de Familia y Comunidad. Por otra parte, en mayo del mismo año, se entrega el reconocimiento «Buenas prácticas en materia de seguridad pública y la prevención del delito», de la Subsecretaría de Prevención del Delito y el Centro de Estudios en Seguridad Ciudadana del Instituto de Asuntos Públicos de la Universidad de Chile. Estos ejemplos, son una muestra de que el concepto de Escuela Abierta, desarrollado en Recoleta, posee un valor que trasciende la realidad local y tiene perspectivas amplias, con implicancias positivas para la comunidad escolar y el entorno social en los más diversos temas. 



\title{
Programa Congreso Infantil. Municipalidad de Temuco
}

\author{
Departamento Comunitario y Vecinal* \\ Dirección de Desarrollo Comunitario \\ Municipalidad de Temuco
}

\section{1.- INTRODUCCIÓN}

Para la Municipalidad de Temuco, el programa Congreso de Niños es una instancia de participación ciudadana propuesta a todos los establecimientos educacionales de la comuna, municipales, subvencionados y particulares. En la práctica el Congreso de Niños es una instancia donde las niñas y niños asumen un papel activo en sus comunidades escolares, donde tienen la libertad de expresar opiniones, hablar sobre los asuntos que les afectan e intercambiar experiencias con sus pares en busca de una solución en común.

Por consiguiente, la Municipalidad de Temuco a través del programa Congreso de Niños, busca fomentar en los niños y niñas una cultura de participación ciudadana, donde dialoguen, analicen y reflexionen sobre las problemáticas existentes en su entorno y con estos antecedentes crear iniciativas y proyecto construidos en alianza, considerando la opinión de sus pares.

La participación infantil es reconocida como un derecho según se indica en la «Declaración de las Naciones Unidas sobre los Derechos de la Infancia» (1989), de acuerdo con Susan Fountain, citada en Confancia: con voz, del Consejo de la juventud de España (2004,

Equipo Técnico: Valeria Constanzo S., Rodrigo Pinto M., Tomás Contreras, Miguel Gamonal Paredes. 
p. 12), que en su libro «¡Nada más Justo!», divide los artículos de la convención en cuatro amplias categorías:

- Derechos a la Supervivencia.

- Derechos al Desarrollo.

- Derechos a la Protección.

- Derechos a la Participación.

\section{2.- ConteXtualización}

La comuna de Temuco posee una población de 36.712 jóvenes que se encuentran en el rango de los cinco a los 14 años (CENSO 2017), esto corresponde a cerca del $13 \%$ de la población total de la comuna. Dado el rango etario en el que se encuentran, no pueden representar legalmente a ninguna organización funcional o territorial, como tampoco participar en los distintos procesos eleccionarios de autoridades locales, regionales y presidenciales.

La Municipalidad de Temuco, en su tarea de formar una ciudadanía responsable, comprometida e informada, durante el año 2016 crea el «Congreso de Niños», instancia que permitió realizar un diagnóstico respecto a las problemáticas y necesidades de la comuna desde el punto de vista de los niños y niñas; en dicho momento se invitó a todos los establecimientos educacionales, convocándose a 12 establecimientos, con un total de 60 niños, quienes pudieron enterarse de cuáles eran las funciones y responsabilidades del municipio, para posteriormente trabajar en el análisis de esta información y así proponer ideas de mejoramiento de la comuna.

En la segunda Versión del Congreso de Niños, se utilizó una nueva metodología de trabajo, donde los participantes tenían la posibilidad de desarrollar una temática y convertirla en una iniciativa que fuera en beneficio de su macrosector y comunidad en general, propiciando buscar temáticas que fueran orientadas a las mismas trabajadas en el año anterior. 


\section{3.- Desarrollo del programa Congreso infantil}

\section{1.-Metodología de trabajo}

a) Objetivos del programa

\section{Objetivo general}

Generar y co-construir instancias de participación ciudadana, discusión y toma de decisiones, de los habitantes de la comuna en temas de interés barrial y comunal, entendiendo la participación ciudadana como un indicador del mejoramiento de sus condiciones sociales.

\section{Objetivos especificos}

1. Contribuir en la construcción responsable y consciente de ciudadanía en los niños y niñas de Temuco, a través de la incorporación de la opinión ciudadana en las iniciativas propuestas en su territorio, fortaleciendo las nociones de democracia y participación, lo que permite que los resultados proyectados sean más efectivos y cercanos a las necesidades de las comunidades.

2. Propiciar instancias de diálogo, reflexión y debate para niñas y niños de Temuco, donde puedan expresar opiniones, respetando puntos de vista y formulando preguntas relacionadas con el tema propuesto al macrosector.

3. Potenciar el levantamiento de líderes naturales presentes en las reuniones, de manera que estos puedan expresar de forma oral y visual el tema abordado, en una exposición organizada y estructurada de manera adecuada, incorporando el material de apoyo pertinente, dirigida a las autoridades comunales representando a los establecimientos de cada macrosector. 


\section{b) Fase convocatoria}

Se realizó la invitación a 100 directores y sostenedores de establecimientos educacionales municipales, subvencionados y Privados de la comuna de Temuco. Cada establecimiento registró cinco alumnos, preferentemente un niño y/o niña por curso, con la intención de promover la equidad de género. La convocatoria fue contestada por 22 establecimientos educacionales urbanos y rurales de la comuna, traducido a 110 niños y niñas de cuarto a sexto básico y 22 profesores tutores, es decir 132 participantes activos.

\section{2.-Desarrollo de las asambleas por macrosector}

\section{a) Asamblea}

Durante la primero asamblea se dio a conocer a los participantes los resultados obtenidos en la jornada diagnóstica del año 2016, permitiendo un espacio de consultas, reflexión y análisis. Con estos antecedentes expuestos se inició la jornada donde se formaron mesas de trabajo, que contaban de cinco a siete estudiantes de distintos establecimientos.

Cada grupo debía elegir una temática en específico para elaborar un anteproyecto, donde los integrantes estuviesen de acuerdo. Para esto, se dispuso de moderadores, quienes debieron apoyar y aclarar dudas de la realización del anteproyecto, además de entregar los materiales necesarios para la creación de un papelógrafo o collage que reflejara y explicara su iniciativa. En el desarrollo de la actividad, la temática más abordada fue la de medio ambiente en los establecimientos urbanos y la conectividad digital en los establecimientos rurales.

Al finalizar la jornada, cada grupo eligió a dos representantes, quienes expusieron su idea, contemplando objetivos, cobertura, población objetivo y alcances, con el fin de que todos, niñas y niños, pudieran pasar al primer proceso de deliberación del programa, el cual consistía en informarse, decidir y votar por el proyecto que mejor representara sus ideas y al macrosector, siendo la idea seleccionada expuesta en la jornada final del Congreso de Niños. 


\section{b) Congreso}

En la jornada final del Congreso Comunal, ocho proyectos, uno de cada macrosector, fueron expuestos a todas las niñas y niños participantes de las jornadas y a las autoridades, esto con el fin de que los niños participaran de la segunda etapa deliberativa que contempla este programa, la cual comprende que los participantes se informen, decidan y voten por el proyecto que les parece más viable de realizar a nivel comunal.

En dicho proceso se vivenciaron las distintas fases antes descritas y en cuatro horas de trabajo se procedió a realizar la votación, donde las niñas y niños eligieron el proyecto representante del macrosector Santa Rosa, denominado «Eco-parque camino hacia el futuro» el que cuenta con un presupuesto de diez millones de pesos para ser ejecutado en el periodo 2017-2018.

\section{c) Ejecución proyecto ganador}

El proyecto «Eco-parque camino hacia el futuro», tiene por objetivo fomentar e incentivar en los niños y niñas una cultura medioambiental, basándose en la realización de talleres educativos teórico-prácticos en torno a las temáticas de compostaje, la regla de las tres $\mathrm{R}$ (reciclar, reutilizar y reducir) y jardines urbanos, el cual será ejecutado en el Parque Langdon del macrosector Santa Rosa.

Esto con el fin de que las niñas y niños involucrados clase a clase conozcan el resultado de su trabajo y que las intervenciones que se hagan sean parte del hermoseamiento del mismo parque.

La ejecución de la iniciativa considera la participación de 100 niños pertenecientes a establecimientos educacionales y juntas de vecinos del macrosector Santa Rosa y tendrá una duración de tres meses desde septiembre a noviembre de 2018. 



\section{Cuarta PARTE: \\ EXPERIENCIAS DESDE la Sociedad Civil para la Participación Ciudadana}





\title{
PROMOCIÓN DE LA PARTICIPACIÓN CIUDADANA A NIVEL LOCAL DESDE \\ LAS BIBLIOTECAS PÚBLICAS EN CHILE: \\ APRENDIZAJES DEL PROGRAMA \\ BibLIOACCIÓN CIUDADANA"
}

\author{
Juan Fernández Labbé** \\ RIMISP
}

\section{INTRODUCCIÓN}

Este artículo se basa en el proceso de sistematización y evaluación del programa Biblioacción Ciudadana, que se propuso explorar durante tres años nuevas prácticas en el fortalecimiento del vínculo entre las bibliotecas públicas (en adelante BP), los gobiernos locales y la ciudadanía en Chile, a través del desarrollo de proyectos de interés de la comunidad. Fue ejecutado por la Fundación Democracia y Desarrollo (FDD), en conjunto con 14 municipios y sus BP, y contó con el financiamiento de la Fundación Bill \& Melinda Gates.

\footnotetext{
Este artículo es una síntesis de dos documentos preparados en el marco del programa Biblioacción Ciudadana, los cuales fueron en su momento comentados por Clara Budnik, Francisca Navarro, Paz Zavala, Fernando Pardo y Luis Santana. El autor agradece sinceramente sus comentarios. También agradece al conjunto de profesionales que colaboraron en el trabajo de campo durante tres años y a los equipos locales de las bibliotecas y municipios integrantes de esta experiencia.

** Investigador en Rimisp-Centro Latinoamericano para el Desarrollo Rural. Doctor en Sociología. Coordinador de la evaluación y sistematización del proyecto Biblioacción Ciudadana. <jfernandez@rimisp.org>
} 
El programa se focalizó en el diseño e implementación de formas innovadoras para promover la participación ciudadana (presencial y virtual) a través de las BP e involucrar a las personas y organizaciones sociales en la toma de decisiones de los gobiernos locales. Se orientó a que las BP estimularan el aumento del compromiso ciudadano con los temas locales, los municipios mejoraran los procesos de toma de decisiones en torno a los desafíos presentes y futuros de la comunidad, y la ciudadanía contribuyera al dinamismo económico, la inclusión social y el desarrollo local.

Su modelo de acción consideraba tres características relevantes: (i) la firma de un convenio conjunto entre biblioteca-municipio y la FDD, y el consiguiente compromiso de formar un equipo con un funcionario de la biblioteca y uno del municipio para la ejecución del proyecto; (ii) la promoción de la articulación biblioteca-municipiocomunidad; y (iii) las TICs al servicio de la incidencia y dinamización social (uso de redes sociales y plataformas digitales para el fomento de la participación ciudadana y el desarrollo local).

Participaron 14 municipios y 17 bibliotecas de ocho regiones del país, abarcando una gran diversidad de realidades geográficas, culturales y socioeconómicas. Las comunas involucradas fueron: San Pedro de Atacama (Región de Antofagasta), Río Hurtado (Región de Coquimbo), Santiago, Recoleta, Providencia, Huechuraba, Melipilla (Región Metropolitana), Doñihue (Región de O’Higgins), Perquenco, Renaico (Región de la Araucanía), Futrono, Los Lagos (Región de Los Ríos), Quemchi (Región de Los Lagos) y Coyhaique (Región de Aysén).

El rol de Rimisp fue acompañar la ejecución sistematizando los procesos y reflexionando sobre sus resultados a partir de tres preguntas guía: a) ¿Qué cambió en las comunas del programa en torno a las bibliotecas y la participación ciudadana?; b) ¿Qué explica los cambios ocurridos?; y c) ¿Qué lecciones y aprendizajes se extraen de lo realizado? Para ello, entre los años 2014 y 2016, se realizaron sucesivas visitas en terreno a las 14 comunas, llevando a cabo aproximadamente 300 entrevistas y 42 reuniones con actores involucrados a nivel comunal, así como media docena de reuniones 
con el equipo de coordinación nacional del programa, entrevistas con un representante de la Dirección de Bibliotecas, Archivos y Museos (DIBAM), y la aplicación de un cuestionario online a bibliotecas no-participantes.

El presente documento se organiza en cinco secciones: la primera sitúa al programa en cuanto a su propuesta y premisas principales; la segunda presenta a los proyectos comunales, su situación inicial y evolución en el tiempo; la tercera analiza la existencia de cambios en torno a las BP municipales; la cuarta identifica factores facilitadores y nudos críticos; y finalmente la quinta presenta una reflexión acerca de las condiciones que desafían la promoción de la participación ciudadana desde las bibliotecas y enuncia un conjunto de orientaciones para llevarla a cabo.

\section{El programa BiblioaCCión CiUdADANA Y SU PROPUESTA DE CAMBIO}

El programa se sitúa en la discusión teórico-práctica relativa al rol y función social de las BP, ante contextos sociales dinámicos. Recoge el espíritu de los manifiestos de la UNESCO y de la Federación Internacional de Asociaciones de Bibliotecarios y Bibliotecas (IFLA) en el sentido de considerar a la BP como fuerza viva de educación, cultura e información, aspectos fundamentales para la participación ciudadana y la consolidación democrática, así como de la tradición fundacional de la BP chilena ilustrada y republicana, que relevaba la formación de ciudadanos para el progreso y desarrollo de la sociedad. Además, considera la historia reciente del país, tanto en materia de institucionalidad bibliotecaria (esfuerzos de la década de los noventa por abrir la biblioteca a la comunidad), como de dinámicas sociales más recientes (movilizaciones sociales, ciudadanía demandante e insuficientes o ineficaces canales de participación ciudadana, y la necesidad de políticas públicas participativas).

En Chile, desde 1997, con el manual Gestión participativa en bibliotecas públicas, se ponía en la agenda de las bibliotecas la necesidad de vincularse activamente con sus comunidades, estableciendo «una relación dinámica, permanente y fluida (...) que transforme a 
la jefa o jefe de la biblioteca en un gestor cultural, reconocido por su comunidad» (DIBAM, 1997: 13). Era un paso importante, donde se hablaba de autodiagnósticos comunitarios y de planes anuales de acción cultural.

Casi veinte años después, el programa promovía la idea de que las bibliotecas podían -y debían- ir más allá, constituyéndose en un articulador de la comunidad y el municipio en ámbitos de desarrollo local.

El programa Biblioacción tenía como punto de partida tres premisas: (1) la participación ciudadana debe incorporarse a las bibliotecas, porque es un derecho y contribuye a superar las inequidades y formas de discriminación que afectan a la población; hace más eficiente y pertinente el trabajo de la biblioteca al considerar la mirada y los recursos de la población local; y es un compromiso del Estado, a incluir en sus políticas y acciones; (2) la convicción de que las BP pueden jugar un papel importante en el fortalecimiento de la participación ciudadana, ya que son centros comunitarios que suelen mantener distancia con las dinámicas políticas de los gobiernos de turno y tienen activos relevantes: un espacio físico gratuito y abierto al público, recursos tecnológicos, personal capacitado y vínculos con los gobiernos locales y grupos organizados de la comunidad, que les permitirían canalizar la voluntad de participación y creatividad de la ciudadanía y ser un puente con las autoridades locales; (3) por último, que un acompañamiento a equipos comunales conformados por la biblioteca y el municipio, contribuiría a desplegar y potenciar iniciativas locales que redundarían en cambios en los roles de los actores involucrados y en las relaciones entre ellos.

La teoría de cambio del programa (para transitar de la situación actual a la deseada) puede resumirse así:

- El propósito es fomentar la participación ciudadana y el compromiso cívico a través de las BP, facilitando el involucramiento de los ciudadanos en el proceso de toma de decisiones de los municipios. 
- Se espera que las bibliotecas sean articuladores locales que hagan de puente entre la ciudadanía y el gobierno local; que los municipios sean facilitadores, que escuchen, canalicen y den respuestas responsables a las demandas/propuestas ciudadanas; y que las organizaciones sociales sean movilizadoras de la ciudadanía, representándola e involucrándola en la identificación de problemas, generación de soluciones y desarrollo de acciones en torno a las decisiones municipales.

- Para lograr el propósito, el programa se planteó una estrategia de acción con cuatro ejes: (i) seleccionar a las bibliotecas participantes, constituir una comunidad de aprendizaje con ellas y que se formularan planes de acción en cada una (para ello realizó encuentros nacionales de intercambio, y facilitó plataformas tecnológicas como www.biblioaccionciudadana.cl y www.elquintopoder.cl); (ii) capacitar a los equipos locales para la elaboración de estrategias de participación ciudadana (cursos e-learning y talleres presenciales); (iii) estimular el compromiso cívico de las comunidades mediante las bibliotecas (visitas de apoyo y seguimiento, financiamientos puntuales y contratación de movilizadores locales); y (iv) generar un conjunto de orientaciones para estimular la participación ciudadana y el compromiso cívico desde las bibliotecas (proceso de sistematización y evaluación, que incluyó talleres, visitas de campo y la elaboración de informes sucesivos y una Guía para promover la participación ciudadana desde las bibliotecas públicas (Fernández e Ivusic, 2017). Por último, para la sostenibilidad y consolidación de los resultados del programa, se incluyó la externalización de una línea de desarrollo de capacidades y formación de formadores y un plan de divulgación y promoción desde herramientas digitales, que incluye un sitio web con la información, los recursos y herramientas generadas y recopiladas durante el programa ${ }^{1}$.

La Guía se encuentra disponible en español e inglés en www.biblioaccionciudadana.cl 
En términos conceptuales, el programa se basó en un modelo de participación ciudadana de cinco niveles, el que asocia grados de comunicación entre la institucionalidad pública y la ciudadanía, con grados de participación. En el eje de la comunicación, desde la más básica o pasiva hasta la más avanzada o activa define: información, consulta, deliberación, concertación y corresponsabilidad; y en el eje de la participación define: acceso a los datos, solicitud de opinión, intercambio de argumentos, acuerdos entre intereses y compromisos para la acción (Ochoa y Valdés, 2014).

Gráfico $\mathrm{N}^{\circ} \mathrm{I}$ : MODELO DE PARTICIPACIÓN

CIUDADANA PROPUESTO POR EL PROGRAMA

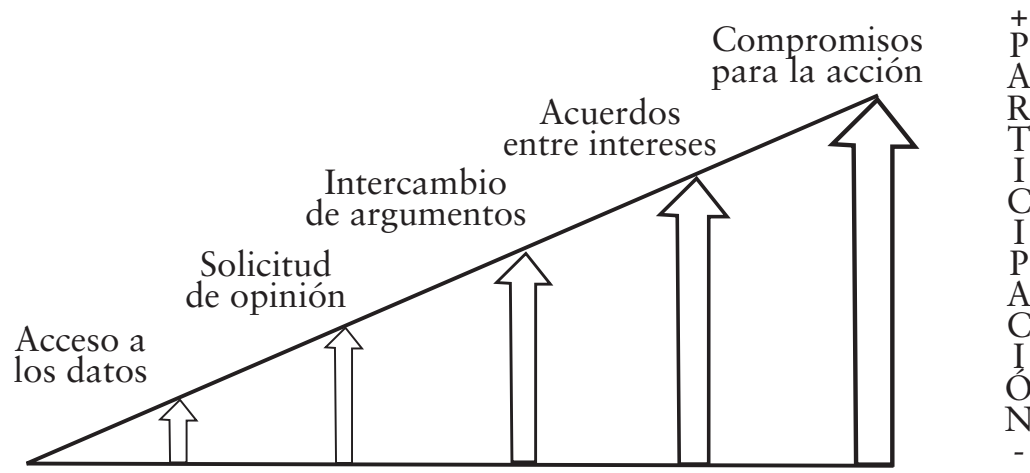

Información Consulta Deliberación Concertación Responsabilidad - COMUNICACIÓN +

Se podrán utilizar distintos instrumentos y herramientas, de acuerdo a los objetivos que nos tracemos y a los resultados que queremos alcanzar.

Fuente: presentación de Ochoa y Valdés (2014).

\section{LOS PROYECTOS COMUNALES, SU PUNTO INICIAL Y EVOLUCIÓN}

En Chile, de acuerdo con datos de DIBAM (2017), en el año 2016 existe un total de 457 BP registradas. De ellas, la gran mayoría se encuentra bajo la administración de sus municipios y la asesoría técnica de la DIBAM, mientras que un grupo reducido depende directamente de esta última en ambos aspectos. 
Una característica de las bibliotecas es su gran heterogeneidad en términos de tamaño y capacidad de gestión: desde bibliotecas unipersonales hasta otras con más de diez profesionales en su staff; algunas con instalaciones tecnológicas y acceso pleno a internet, y otras con conectividad limitada. Esa diversidad se refleja en las 17 bibliotecas que formaron parte del programa ${ }^{2}$.

De hecho, la experiencia recoge una gran diversidad no solo en cuanto al tipo de bibliotecas, sino que también al tipo de territorioscomunas (tamaño, ruralidad, etc.), al tipo de municipios (grado de autonomía financiera) y al tipo de sociedad local (proporción de población indígena, migrante, etc.), sumado a la ubicación geográfica (desde San Pedro de Atacama en el norte hasta Coyhaique en el sur).

Una primera pista respecto al estado inicial de las BP chilenas se observó al momento del concurso para la selección de las participantes en el programa. La convocatoria fue intensiva y multicanal, sin embargo, del universo potencial de participantes, solo el $6,4 \%$ postuló. La baja participación tuvo relación con dos aspectos fundamentales (Rimisp, 2016): i) la exigencia de conformación de una dupla entre la biblioteca y el municipio (se postulaba en conjunto y se comprometía trabajar la iniciativa de la misma manera) y ii) su foco en participación ciudadana y desarrollo local con una oferta de apoyo y acompañamiento, donde lo central no era un financiamiento directo o recursos de inversión. Ambos elementos hicieron que una parte importante de las bibliotecas desistiera de postular y, como se evidenciaría más adelante, que las postulantes seleccionadas se enfrentaran a diversos desafíos ${ }^{3}$.

Las bibliotecas participantes y su contexto comunal. Las comunas participantes presentan distintos tamaños poblacionales,

2 Son 14 comunas, pero una de ellas (Coyhaique) involucra a cuatro bibliotecas, por lo que el total de bibliotecas asciende a 17.

3 De las 15 comunas seleccionadas inicialmente, dos se retiraron en la primera etapa (Molina y Paillaco, reemplazadas por Melipilla y Huechuraba) y una en la segunda etapa (San Vicente de Tagua-Tagua, que no fue sustituida). Adicionalmente, Río Hurtado, si bien se mantuvo hasta la fecha formal del convenio firmado, en la práctica no completó el proceso. 
niveles de pobreza, escolaridad de su población, así como también sus municipios cuentan con condiciones de gestión diferenciadas.

Cuadro $\mathrm{N}^{\circ}$ I: CARACTERIZACión de las COMUNAS PARTICIPANTES

\begin{tabular}{|c|c|c|c|c|}
\hline Dimensión & \multicolumn{4}{|c|}{$\begin{array}{c}\text { Ubicación de las comunas } \\
\left(\mathrm{n}^{\circ} \text { de comunas según característica) }\right.\end{array}$} \\
\hline \multirow{2}{*}{$\begin{array}{l}\text { Población } \\
\text { (INE, 2016) }\end{array}$} & $\begin{aligned}< & 10.000 \\
& \text { hab. }\end{aligned}$ & $\begin{array}{l}10.000- \\
50.000 \\
\text { hab. }\end{array}$ & $\begin{array}{c}50.001- \\
100.000 \\
\text { hab. }\end{array}$ & $\begin{array}{l}>100.000 \\
\text { hab. }\end{array}$ \\
\hline & 4 & 4 & 2 & 4 \\
\hline \multirow{2}{*}{$\begin{array}{l}\text { Pobreza monetaria } \\
\text { (CASEN, 2011) }\end{array}$} & $>14,4 \%$ & $\begin{array}{l}10 \%- \\
14 \%\end{array}$ & $1 \%-9 \%$ & $<1 \%$ \\
\hline & 4 & 5 & 4 & 1 \\
\hline \multirow{2}{*}{$\begin{array}{c}\text { Índice de Desarrollo } \\
\text { Humano-IDH }\end{array}$} & Top 10 & $11-99$ & $100-200$ & 201-341 \\
\hline & 2 & 3 & 3 & 6 \\
\hline \multirow{2}{*}{$\begin{array}{l}\text { Años de escolaridad prome- } \\
\quad \text { dio (CASEN, 2011) }\end{array}$} & $>10,5$ años & $\begin{array}{l}8-10,5 \\
\text { años }\end{array}$ & \multicolumn{2}{|c|}{$<8$ años } \\
\hline & 2 & 11 & \multicolumn{2}{|c|}{1} \\
\hline \multirow{2}{*}{$\begin{array}{l}\text { Condiciones de gestión mu- } \\
\text { nicipal (SINIM, 2011) }\end{array}$} & \multicolumn{2}{|c|}{$\begin{array}{c}\text { Dependencia FCM } \\
>50 \%\end{array}$} & \multicolumn{2}{|c|}{$\begin{array}{c}\text { Dependencia FCM } \\
<50 \%\end{array}$} \\
\hline & \multicolumn{2}{|c|}{9} & \multicolumn{2}{|c|}{ 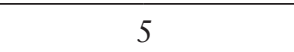 } \\
\hline \multirow[t]{2}{*}{$\begin{array}{l}\text { Tipo de territorio funcional } \\
\text { (Rimisp, 2011) }\end{array}$} & $\begin{array}{l}\text { Rural-urb } \\
\text { peq. }\end{array}$ & $\begin{array}{l}\text { Rural- } \\
\text { urb } \\
\text { med. }\end{array}$ & $\begin{array}{l}\text { Rural- } \\
\text { urb } \\
\text { grande }\end{array}$ & $\begin{array}{l}\text { Metropo- } \\
\text { litano }\end{array}$ \\
\hline & 2 & 4 & 3 & 5 \\
\hline
\end{tabular}

Las bibliotecas también son muy diversas en capacidades físicas y humanas. Sus instalaciones, presupuesto, equipamiento tecnológico, personal y capacidades las sitúan en distintas posiciones frente al desafío de ser articuladoras locales para la participación ciudadana. 


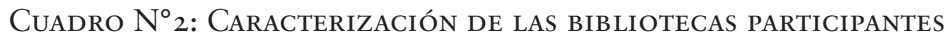

\begin{tabular}{|c|c|c|c|}
\hline Dimensión & \multicolumn{3}{|c|}{ Ubicación de las bibliotecas } \\
\hline \multirow[t]{2}{*}{ Antigüedad } & $\begin{array}{c}\text { Menos de } 17 \\
\text { años (después del } \\
2000)\end{array}$ & \multicolumn{2}{|c|}{$\begin{array}{c}\text { Más de } 17 \text { años } \\
\text { (antes del año 2000) }\end{array}$} \\
\hline & 6 & & \\
\hline \multirow{2}{*}{$\begin{array}{l}\text { Presupuesto anual* } \\
(* 4 \sin \text { información })\end{array}$} & $>20$ millones & $\begin{array}{c}\text { Entre } 8 \text { y } 20 \\
\text { millones }\end{array}$ & $<7$ millones \\
\hline & 4 & 2 & 8 \\
\hline \multirow{2}{*}{ Instalaciones } & $>200 \mathrm{mt} 2$ & 100 y $200 \mathrm{mt} 2$ & $<100 \mathrm{mt} 2$ \\
\hline & 5 & 5 & 7 \\
\hline \multirow[t]{2}{*}{ Tecnología } & $\begin{array}{l}>10 \text { pc con } \\
\text { internet }\end{array}$ & $\begin{array}{l}\text { 5-10 pc con } \\
\text { internet }\end{array}$ & $\begin{array}{l}<5 \text { pc con } \\
\text { internet }\end{array}$ \\
\hline & 7 & 4 & 6 \\
\hline \multirow{2}{*}{ Personal } & 3 o más personas & \multicolumn{2}{|c|}{1 o 2 personas } \\
\hline & 9 & \multicolumn{2}{|c|}{8} \\
\hline
\end{tabular}

Los proyectos locales: sus diversas temáticas. La diversidad temática caracteriza a los proyectos desarrollados por las bibliotecas participantes. Desde la revalorización de la cultura local, hasta el desarrollo económico local, pasando por lo medioambiental, la seguridad ciudadana, el turismo y la sexualidad responsable, entre otras, las bibliotecas abordaron ámbitos de preocupación de sus comunidades locales que traspasaban la esfera de «lo cultural» en su sentido tradicional.

Cuadro $\mathrm{N}^{\circ}{ }_{3}$ : Tema y ObJetivo de los PROYectos Comunales

\begin{tabular}{|c|c|c|}
\hline Biblioteca-comuna & Tema & Título proyecto \\
\hline San Pedro de Atacama & Rescate cultural & Voces de mi pueblo \\
\hline Río Hurtado & Liderazgo social & Escuela de líderes locales \\
\hline Santiago & Memoria barrial & Encuentro de diálogo creativo \\
\hline Huechuraba & $\begin{array}{c}\text { Seguridad comuni- } \\
\text { taria }\end{array}$ & $\begin{array}{c}\text { Diálogos participativos en } \\
\text { seguridad comunitaria }\end{array}$ \\
\hline Recoleta & Migrantes & Vecino migrante \\
\hline Providencia & Huertos urbanos & Bibliohuerto Bellavista \\
\hline Melipilla & $\begin{array}{c}\text { Desarrollo econó- } \\
\text { mico (tejido) }\end{array}$ & Tejiendo El Bollenar \\
\hline
\end{tabular}




\begin{tabular}{|c|c|c|}
\hline Biblioteca-comuna & Tema & Título proyecto \\
\hline Doñihue & Medioambiente & Eco Doñihue \\
\hline Renaico & Sexualidad & Sexualidad responsable \\
\hline Perquenco & Juventud & Consejo juvenil (COJ) \\
\hline Los Lagos & $\begin{array}{c}\text { Desarrollo econó- } \\
\text { mico (artesanía) }\end{array}$ & $\begin{array}{c}\text { Taller de emprendedores- } \\
\text { Antilhue }\end{array}$ \\
\hline Futrono & Capacitación & Te escucho, te enseño \\
\hline Quemchi & $\begin{array}{c}\text { Desarrollo econó- } \\
\text { mico (turismo) }\end{array}$ & Turismo rural comunitario \\
\hline Coyhaique & $\begin{array}{c}\text { Integración sectores } \\
\text { aislados }\end{array}$ & $\begin{array}{c}\text { Infoteca Coyhaique } \\
\text { (4 bibliotecas) }\end{array}$ \\
\hline
\end{tabular}

Si bien una hipótesis inicial podía ser que las bibliotecas con más recursos y en contextos urbanos tuvieran más facilidad para impulsar procesos participativos, uno de los hallazgos es que estos pueden desplegarse en cualquier territorio. Un límite cierto está en el caso de las bibliotecas unipersonales, donde hay una barrera de personal y de recursos para la realización de acciones que tengan mayor alcance.

\section{RESULTADOS: LOS CAMBIOS OCURRIDOS}

Cuando hablamos de bibliotecas, de municipios o de organizaciones, hablamos de sus equipos humanos, de las personas que lideran o colaboran en sus procesos. Los equipos de las bibliotecas que han avanzado en el camino de ser promotoras/articuladoras de la participación ciudadana se caracterizan por haber desarrollado algunas prácticas respecto de las cuales, en términos globales, podemos extraer los siguientes cinco cambios:

\subsection{Un nuevo enfoque para ser las bibliotecas del futuro}

Las encargadas de las bibliotecas han internalizado un enfoque que ha ampliado su horizonte de acción, es decir, han potenciado su conexión con el territorio, han incorporado la necesidad y relevancia de la participación y el rol que pueden ejercer. Se ha ampliado el 
abanico de posibilidades de este espacio, que siempre ha sido considerado un lugar de encuentro, pero que de serlo para la gestión cultural, el fomento lector y la capacitación, lo es ahora también para una diversidad de temas de desarrollo e inclusión desde el enfoque participativo.

Las bibliotecas le han agregado un componente participativo a sus viejos y nuevos temas. En la mayoría de los casos, es primera vez que abordan aspectos como la migración, la sexualidad, la seguridad ciudadana o la participación de los jóvenes en el desarrollo local. Aunque otros como el desarrollo económico local o el medioambiente eran usuales, ahora se potencia su aspecto participativo.

Por otro lado, en algunos casos han llegado a nuevos sectores de la población e incorporado a nuevos usuarios que no solían acudir a la biblioteca (por ejemplo, mujeres adultas que comenzaron a hacerlo a propósito de la asistencia a talleres).

RECUADRO $\mathrm{N}^{\circ} \mathrm{I}$

¿Cómo SE Ven a sí mismas las bibliotecas?: LUGAR DE ENCUENTRO Y CON POTENCIAL ARTICULADOR

A un año y medio de iniciado el programa, se llevaron a cabo dos talleres con los equipos de los proyectos comunales. Una de las actividades consistió en pedir a cada equipo que dibujaran su biblioteca y luego presentaran su dibujo. Predominaron las visiones de la biblioteca como espacio de encuentro, que gestiona y facilita procesos locales. La mayoría de los dibujos se sitúan en un territorio con personas, con música, con patrimonio, rodeados de entorno natural, de instituciones y de actividades realizadas por ellos mismos, situación que refleja la superación de la imagen estereotipada de una biblioteca pública quieta y silenciosa, y grafica una biblioteca dinámica y conectada con su territorio. 


\subsection{Prácticas participativas en las que la biblioteca cumple un rol destacado}

Un cambio claro es que las bibliotecas han realizado actividades nuevas, que no formaban parte de su práctica tradicional, innovando en torno a la participación.

Lo más común fue la realización de diagnósticos participativos, reuniones informativas o de identificación de demandas. Se aplicaron encuestas, se hicieron talleres y asambleas. En algunos casos los mecanismos de consulta tuvieron efecto en decisiones de pequeña escala (por ejemplo, elección de talleres a realizar) o se enmarcaron en procesos potenciales (insumo para un plan ambiental y para el Consejo ambiental comunal, o para un Consejo comunitario de seguridad). En un grupo reducido de casos se avanzó más hacia la constitución de instancias de concertación y/o toma de decisión, como una Mesa público-privada de turismo (elaboración de la ordenanza de turismo); una Mesa Migrante (derechos de los colectivos migrantes); y un Consejo Comunal de Jóvenes (decisión de presupuesto sobre becas de enseñanza superior, de deporte y cultura).

Hacia el término del programa, un resultado claro es que la participación ciudadana se ha incorporado «al radar» de las bibliotecas como algo que es relevante y que no es ajeno a su acción, los equipos lo asimilan como un proceso en el cual la biblioteca puede jugar un rol destacado.

RECUADRO $\mathrm{N}^{\circ} 2$

«Primero se hicieron reuniones con diferentes organizaciones, con el presidente de los adultos mayores, de la junta de vecinos, y después ya se hizo una asamblea con toda la localidad de Antilhue, ellos ahí vieron sus debilidades, sus recursos naturales disponibles, todo lo que tenían en su localidad y con ello decidieron que lo que faltaba era trabajar la artesanía con identidad local y de eso se hizo el proyecto» (Biblioteca, Los Lagos). 
Uso de TICs para la participación ciudadana. Si bien las TICs son parte de la realidad de las bibliotecas hace años, su uso orientado hacia la incidencia y dinamización social era algo menos común. En el marco del programa, algunas bibliotecas innovaron con el uso de Facebook, una realizó una transmisión vía streaming y en otros casos se observó la utilización de Whatsapp para coordinarse. Aquí el aprendizaje fue, más allá de la expansión de su uso concreto, por un lado la comprensión de las potencialidades que tiene el uso de plataformas digitales, y por otro, los espacios de pertinencia o adaptación a las realidades locales, pues en algunos contextos rurales destacó la utilización de medios comunales con mayor capacidad de difusión y convocatoria, como las radios y los diarios locales. De este modo, se abrió el abanico de opciones considerando las características de los territorios.

\section{RECUADRO $\mathrm{N}^{\circ} 3$}

\section{EXPERIENCIAS DESTACADAS DE USO DE PLATAFORMAS TECNOLÓGICAS Y OTROS MEDIOS}

Facebook y streaming

El equipo de Futrono, en conjunto con el diario local y con el apoyo de la Fundación Democracia y Desarrollo, organizó un debate ciudadano entre los dos candidatos a alcalde, aprovechando el contexto electoral local. El debate se realizó en la biblioteca, con alta asistencia de dirigentes sociales y comunidad en general. Fue grabado en video, transmitido en directo por streaming y subido luego a YouTube y Facebook.

Grupo de Whatsapp de la Mesa de Turismo

El equipo de Quemchi, involucrado en el proceso de elaboración de una ordenanza municipal de turismo, promovió la puesta en funcionamiento de una Mesa público-privada de turismo, cuyos participantes decidieron crear un grupo de Whatsapp para estar conectados y poder organizarse. El grupo ha funcionado de manera efectiva para la coordinación de reuniones y además ha favorecido la autonomía y horizontalidad, pues cualquiera puede plantear una inquietud o propuesta.

Programa radial

El equipo de Renaico participa en la programación de la Radio Vacilona, con un programa semanal dedicado a vida saludable, en el que incorporaron el tema de sexualidad responsable. De este modo, difunden la iniciativa, amplían su ámbito de acción y públicos, e interactúan con la comunidad en un medio ampliamente usado por la población. 


\subsection{Articulación de redes a nivel local}

\section{Articulación y colaboración entre biblioteca y municipio}

En parte importante de los casos, se produjo un trabajo colaborativo entre la biblioteca y algún departamento o unidad municipal en torno del proyecto (Programa migrantes, Unidad de medioambiente, Departamento de cultura, Departamento de turismo, Casa de la mujer, Dirección de Desarrollo Comunitario, OPD). En algunos casos los municipios comprometieron un presupuesto adicional para las actividades de las bibliotecas y, en otros, incluso se propuso cambiar el estatuto de las encargadas de biblioteca, ubicadas en localidades aisladas, para que fueran delegadas municipales, e hicieran de puente de información entre la comunidad de dichas localidades y el municipio.

Por otro lado, en cuatro comunas el trabajo de la biblioteca con el municipio se reflejó en el establecimiento de alianzas con profesionales del programa Servicio País de la Fundación Superación de la Pobreza, radicados en el municipio, y que colaboraron con los proyectos.

El cambio que se aprecia, en términos generales, tiene que ver con un avance desde una situación en la que la biblioteca respondía a solicitudes del municipio (comúnmente para utilizar sus instalaciones en actividades comunales), hacia una situación en la que se trabaja en conjunto en torno a un objetivo común.

\section{Vinculación entre biblioteca y organizaciones sociales-comunidad}

Fue extendida la exploración de formas diversas para convocar, informar y consultar a la comunidad local. En un caso hubo vinculación a una instancia que reúne a más de 25 organizaciones de colectivos migrantes, siendo un espacio permanente de interlocución entre las organizaciones y el municipio. En otro caso, la biblioteca participa de la Red de Infancia y familia, y además tiene un programa radial semanal en el que invitaron a diversos actores locales. Otra experiencia formó una mesa pública-privada que integra a 12 
emprendedores turísticos. Por último, otra biblioteca destaca por su rol en la creación de una JJVV y de una bandera local, como símbolo de identidad colectiva.

Un proceso importante fue la realización de «talleres de oportunidades de participación ciudadana» impulsados por FDD, realizados en 12 bibliotecas, con una asistencia promedio de 16 personas. En esta actividad se convocó de modo más amplio a los actores comunitarios, se les dio a conocer la iniciativa y se invitó a generar propuestas para su localidad.

\subsection{Expansión de capacidades y empoderamiento}

Las bibliotecas que avanzan hacia un rol articulador expanden sus capacidades en distintos ámbitos. En primer lugar, crecen en liderazgo y empoderamiento. La práctica de encontrarse con otros que están en procesos similares y de mirar a sus comunas con otro enfoque, constituye un espacio de aprendizaje y desarrollo que en algunos casos impulsa el despliegue de habilidades personales para hablar en público y liderar iniciativas que implican vincularse con otros. Estos equipos humanos son portadores de procesos de largo plazo que han ido sumando y acumulando durante el programa.

Si bien algunos de los encargados de bibliotecas contaban con experiencia en trabajo comunitario, al inicio del programa las capacidades en materia de participación ciudadana eran en su mayoría limitadas, tanto en términos conceptuales como de herramientas metodológicas para su puesta en práctica. También se evidenció, como un aspecto deficitario al comienzo del programa, las bajas capacidades de formulación de proyectos de los equipos, observándose dificultades para estructurar objetivos-actividades-plazos y elaborar planes de acción. Durante el proceso se hacen conscientes de sus fortalezas y debilidades, y ante temas que no manejan, deciden perfeccionarse o buscar aliados que puedan complementar los vacíos. 


\subsection{Visibilidad y aporte a la gestión local: la biblioteca y cambios en municipio y comunidad}

Las bibliotecas que promueven la participación son bibliotecas que se hacen más visibles para el municipio, y son valoradas en otros términos, como aporte a la gestión local, como un actor con el que hacer cosas en conjunto y no solo como un espacio físico donde realizar actividades.

Esto implica un cambio en los municipios (alcaldía o departamentos municipales específicos) en el que han visualizado a las bibliotecas como actores que pueden colaborar en el ámbito local, más allá de la gestión cultural. En ese escenario, en algunos casos han apoyado a la biblioteca con recursos adicionales e incluso le han otorgado un nuevo rol y estatuto (como el caso en que las encargadas de las bibliotecas de localidades rurales han sido propuestas como delegadas municipales para la intermediación entre comunidad y municipio).

RECUADRO $\mathrm{N}^{\circ} 4$

«Las bibliotecas comenzaron a visibilizarse, las que somos antiguas vemos que la Municipalidad valora y visibiliza el trabajo hoy y ese punto es clave, hay más respaldo (...) estamos empoderadas igual, porque ahora no estamos solas, nos sentimos acompañadas» (Biblioteca Nirehuao, Coyhaique).

«... Lo más relevante considero ha sido el espíritu de sentir que estamos en un puesto acá que es relevante porque es transversal a la comunidad y nos permite colaborar en acciones que son necesidades, somos como agentes de cambio...» (Biblioteca, Renaico).

Por su parte, en algunos casos la comunidad ha pasado a observar a la biblioteca como un aliado para abordar agendas locales concretas (Mesa de turismo, Red de infancia y familia, Mesa migrante, Consejos comunales). Es decir, más allá de la valoración del «lugar de encuentro» que siempre ha sido, es también un facilitador en relación a preocupaciones locales que deben ser trabajadas en el entorno municipal. 


\section{Aprendizajes Sobre factores FACILITADORES Y NUDOS CRÍTICOS}

Las bibliotecas que han empujado un avance hacia el rol de articuladores locales, lo han hecho en un marco en el que se puede identificar algunos elementos facilitadores, algunos externos y otros internos. Entre los primeros, se reconoce la existencia de un apoyo externo, generador de espacios de encuentro, de seguimiento y de soportes puntuales, correspondiente al programa Biblioacción Ciudadana; también un contexto político que cuando está marcado por una impronta de lo participativo, facilita los procesos, tanto por el apoyo que pueda existir desde el municipio como por la cultura participativa que puede estar más desarrollada en la población.

En cuanto a los internos, destacan la capacidad para la construcción de confianzas y el trabajo en torno a una iniciativa común; también la sintonía del tema abordado con la agenda de interés local; el liderazgo y la trayectoria de las personas que impulsan la iniciativa; la motivación y el trabajo articulado del equipo y, por último, las características de las instalaciones de las bibliotecas y la disposición de sus funcionarios.

La experiencia del programa arroja también aprendizajes sobre nudos críticos que hacen difícil el logro de los cambios deseados y que aquí se plantean como desafíos a abordar:

Contexto institucional y falta de directrices en materia de participación ciudadana. La institucionalidad pública chilena, si bien cuenta con una normativa en materia de participación ciudadana (Ley 20.500), presenta deficiencias y limitaciones en cuanto a incorporarla efectiva y sustantivamente en la gestión pública. Actualmente ni DIBAM ni los municipios les dan directrices a las bibliotecas para que incorporen la participación ciudadana en su gestión cotidiana, ni tampoco son evaluadas en este ámbito. Que lo hagan es un esfuerzo extra, que no tiene incentivos institucionales, ni tampoco orientaciones técnicas sobre cómo hacerlo.

Desconfianza de la ciudadanía. El marco general de desprestigio de los políticos y la desconfianza creciente en las instituciones, junto con la existencia de experiencias frustradas de participación (por 
instrumentales o poco sustantivas), establecen barreras al impulso de procesos participativos, al menos a través de canales formales. Esto es una dificultad que requiere un esfuerzo para re-encantar a la ciudadanía y para modificar prácticas institucionales fuertemente arraigadas.

Cultura clientelar municipal. La instalación de prácticas clientelares y asistencialistas en algunos gobiernos locales (donde la administración ofrece bienes y servicios en el corto plazo a usuarios que solo se involucran con la institución en tanto obtengan un beneficio material concreto), ha permeado culturalmente los mecanismos por los que se hacen operativas las políticas y por las que median las relaciones entre institución y ciudadanía. Esa dinámica entiende la participación desde una óptica limitada y obstaculiza la generación de procesos en los que se busca un rol activo, de mayor involucramiento y con compromisos mutuos.

Propuesta innovadora de difícil apropiación por los equipos locales. El compromiso cívico, la participación ciudadana y la articulación de actores para el desarrollo local aparecían como deseables, pero difíciles de asimilar como labor concreta de la biblioteca. Ello se observó tanto al momento del concurso como durante el inicio de la implementación, donde en varios casos las actividades del proyecto «competían» con las otras acciones de la biblioteca, es decir, eran vistas como algo adicional y no como algo que sumara a un objetivo común perseguido por la biblioteca.

Comprensión teórica y práctica sobre la participación de distintos actores. En general, existió confusión en los actores respecto del significado y alcance de la participación ciudadana en el marco del programa. FDD, biblioteca, municipio y organizaciones podían tener nociones diversas, además de expectativas y compromisos distintos a la hora de llevarla a cabo. En el caso de los equipos biblioteca-municipio, su experiencia y conocimiento previo en temas comunitarios o participativos eran muy variables, lo que requería esfuerzos significativos a nivel de conceptos y metodologías. 
Rotación de equipos. Los cambios en los equipos (tanto de biblioteca como de municipio) tienen una doble lectura, pues cuando los hubo como parte de una decisión consciente para favorecer los proyectos, fueron positivos, sin embargo, cuando se produjeron por otras razones, y cuando incluso significaron un reemplazo por ambas partes (biblioteca y municipio), representaron un serio obstáculo que derivó en reformulación de los proyectos y desconexión con los procesos acumulativos desarrollados en los encuentros y talleres nacionales. La sostenibilidad de los equipos y de los procesos depende también de las decisiones del alcalde, por lo que adicionalmente cambios de autoridad suelen poner en riesgo la continuidad de los procesos.

Pertinencia de las herramientas digitales. En general, las plataformas web y los cursos e-learning puestos a disposición de los proyectos fueron poco utilizados. En algunos casos había limitaciones objetivas (falta de conectividad, centralización institucional de las comunicaciones), mientras que en otros eran vistos como algo sin utilidad práctica. En las comunas más rurales la baja penetración tecnológica en la población explicaba la situación, realzándose otros medios como las radios comunitarias o comunales. Si bien el potencial de las TICs para la participación es amplio, no en todos los territorios es igual de pertinente.

Limitación de personal y recursos. En algunos casos, el carácter unipersonal de las bibliotecas representa una restricción significativa para su vinculación con la comunidad, así como en otros lo es la falta de recursos para trasladarse a zonas aisladas de la comuna. En la mayoría de los casos, el tiempo de dedicación al proyecto se evidenció como un nudo crítico, pues se consideraba una carga laboral extra a las labores propias ya asumidas. 


\section{CONDICIONES Y ORIENTACIONES PARA LA PROMOCIÓN DE LA PARTICIPACIÓN DESDE LAS BIBLIOTECAS}

Los aprendizajes de este proyecto podemos ubicarlos en dos niveles. En un primer nivel, hemos aprendido que los procesos participativos promovidos desde las BP son, no solo posibles, sino que deseables por cuanto generan una dinámica de trabajo colaborativo y la articulación de redes comunales desde un lugar propicio para el diálogo. En un segundo nivel, que hay distintos factores que juegan a favor y en contra de que dichos procesos se desplieguen y potencien (a nivel macro y local).

En primer lugar, respecto de la gestión participativa de las bibliotecas y sus vínculos con la comunidad bajo el supuesto de que las políticas impulsadas en la década de los noventa habían dejado huella, se observó que si bien las bibliotecas tenían experiencia de trabajo comunitario y en algunos casos mantenían relación con organizaciones sociales, esto era acotado y se daba casi exclusivamente en torno a actividades culturales en las que la comunidad era más bien un asistente que un partícipe activo. En cuanto a los vínculos con los gobiernos locales, en muchos casos las bibliotecas estaban invisibilizadas para los alcaldes y principales departamentos municipales y, cuando eran consideradas, lo eran más para la facilitación de sus instalaciones físicas que para la realización de iniciativas conjuntas. De hecho, el requisito del programa de conformación de un equipo con contrapartes de la biblioteca y el municipio para participar, es señalado como un elemento disuasivo por parte de las bibliotecas que no postularon, y como un gran desafío para los que sí lo hicieron.

En cuanto a los recursos tecnológicos y la capacitación del personal, se constató en el grupo de bibliotecas participantes que ni la conectividad era plena (en las bibliotecas de comunas rurales o en las auxiliares en zonas aisladas ello no estaba garantizado), ni todo el personal contaba con experiencia y formación cercana a los temas de participación ciudadana y en formulación de proyectos.

Por otro lado, respecto a la voluntad de participación y creatividad de la ciudadanía, lo cierto es que a nivel macro existe una gran 
desconfianza y desilusión ciudadana respecto de las autoridades, además de un contexto de efervescencia social que no busca precisamente ser canalizada bajo marcos institucionales formales, sino que se despliega en diversas esferas y prácticas no institucionales. Ello representa un desafío de mayor calado para cualquier iniciativa que se centre en el fomento de la participación ciudadana, donde se debe reencantar a la comunidad y resguardar que los procesos participativos se cristalicen en acciones concretas.

Finalmente, ante el reconocimiento de que la participación ciudadana es un compromiso del Estado y por ello este debe promoverla y facilitarla, la realidad indica que, en Chile, todos los mecanismos de participación ciudadana, exceptuando los plebiscitos, son de carácter informativo o consultivo, representando para algunos solo una «participación simbólica» y que el marco normativo que rige la materia (Ley 20.500) presenta deficiencias y no se constituye precisamente en un promotor cabal del compromiso cívico, requiriendo ser perfeccionado (Consejo de Participación, 2017).

ReCUADRo N 5

«La sociedad chilena reclama cambios en el ejercicio democrático y una parte importante de esos cambios se relaciona con la demanda por mayor y mejor participación, por un involucramiento más directo en los asuntos públicos, aquellos que nos competen a todos y en los que, normalmente sin embargo, no podemos influir» (presidente del Consejo Nacional de Participación Ciudadana y Fortalecimiento de la Sociedad Civil, 17 de enero de 2017, en ceremonia de entrega a la Presidenta de la República del informe final del estado de la participación ciudadana en Chile).

Por otro lado, para DIBAM, la apuesta del programa y el fomento de la participación ciudadana desde las bibliotecas es un aspecto de interés y se valora positivamente el potencial que tendría, por ejemplo, desarrollar desde las bibliotecas planes comunales participativos de cultura. Ello, reconociendo que algunas condiciones de base en las bibliotecas (rotación de equipos), en la institucionalidad local 
(participación instrumental) y en la comunidad (baja alfabetización digital) pueden limitar su alcance.

A nivel institucional no existen los incentivos adecuados para que entidades como las BP lleven a cabo un rol en materia de participación ciudadana, pero que en ese contexto, la experiencia del programa da cuenta de que algunas han iniciado ya un camino, que podría ser más profundo y de mayor alcance en un marco institucional que le entregue orientaciones o incentivos.

Como telón de fondo de los procesos de fomento de la participación ciudadana hay un modelo institucional y un modelo de gobernanza que la participación ciudadana desafía, que exige ajustes, flexibilidad, confianza, y eso pasa por abrir la puerta a la ciudadanía, pero también por fortalecer sus capacidades para trabajar en conjunto, o sea, ceder poder, pero fortalecer a los actores que pueden compartir y hacerse cargo de ese poder.

Orientaciones para el fomento de la participación ciudadana desde las bibliotecas

El llamado a la participación requiere de temas que interesen a las personas, que sean significativos para su vida, y de procesos que se traduzcan en decisiones concretas y efectivamente compartidas, pero por sobre todo, requiere de procesos de re-significación de la política, de la preocupación por los temas comunes, los desafíos colectivos y el encuentro con el otro para construir un futuro. Para eso, las bibliotecas son espacios propicios, por sus instalaciones, cercanía a la comunidad y capacidad de formación. Los siguientes diez pasos resumen los aprendizajes obtenidos para promover dicho proceso: 


\section{RECUADRO N 6}

DiEZ PASOS PARA PROMOVER LA PARTICIPACIÓN CIUDADANA DESDE LAS BIBLIOTECAS PÚBLICAS:

Paso 1. Conociéndonos y reconociéndonos: autodiagnóstico del equipo

Lo primero es que el equipo encargado de impulsar la iniciativa conozca sus capacidades y necesidades para llevar a cabo un proyecto que busca situar a la biblioteca como un articulador local y promotor de la participación ciudadana. Para ello un autodiagnóstico que identifique las fortalezas y debilidades, y explore las posibilidades de suplir estas últimas, es un importante punto de partida.

Paso 2. Los temas que importan en el territorio: identificando la agenda local

Que la iniciativa entronque temáticamente con la agenda local se evidencia como un facilitador de los procesos, por lo que es deseable identificar los temas que son de interés en el territorio, delinear los marcos de la agenda local y explorar ámbitos en los cuales la biblioteca podría involucrarse.

Paso 3. Conociendo a los actores del territorio: mapeo de actores y situación de la biblioteca en su entorno

Un punto esencial para impulsar procesos de articulación y participación es identificar a los actores de la comuna. Por ello, se sugiere llevar a cabo un trabajo para conocer a los actores relevantes en el territorio para la construcción de redes, generación de alianzas y elaboración de estrategias para promover la articulación local y la participación ciudadana.

Paso 4. Dinámicas municipales y oportunidades de colaboración: identificando a los posibles aliados

La recomendación fundamental para procesos de articulación local es ¡busque aliados! Por ello, es indispensable identificar a los actores concretos en los espacios de gestión municipal con los cuales la biblioteca puede tejer redes de aliados y establecer ámbitos de colaboración.

Paso 5. Planificando un sueño: elaboración participativa del proyecto

El desarrollo de la iniciativa requiere de una planificación y que además esta sea participativa, dado el énfasis que caracteriza al proyecto. Para esto, se deben plasmar las ideas del equipo local y de los actores involucrados participativamente en la iniciativa, en un conjunto ordenado y racional de actividades a desarrollar en un tiempo determinado, mediante la formulación de un proyecto.

Paso 6. Cambiando las dinámicas al interior del municipio: visibilidad y trabajo colaborativo

Una vez formulado un proyecto que tiene como base haber identificado las capacidades del equipo ejecutor, las temáticas relevantes en la agenda local, el mapa de actores de la comuna y los potenciales aliados en el municipio, hay que llevar a cabo acciones concretas para estrechar vínculos entre la biblioteca y el gobierno local, sus autoridades y estructura de gestión, y generar una relación de trabajo colaborativo en torno al proyecto. 
Paso 7. Cambiando los vínculos con la comunidad: nuevos públicos, nuevas redes y nuevos temas

Lo propio hay que hacer con la población comunal, a objeto de estrechar los vínculos entre la biblioteca y la comunidad, interactuando con organizaciones sociales y ejerciendo un rol de articulador y puente entre la ciudadanía y el gobierno local. Ello, involucrándose en nuevos temas, con nuevos actores y llegando a audiencias nuevas.

Paso 8. Innovando: información y dinamización social a través de plataformas tecnológicas y otros medios

La articulación en el nivel local requiere de herramientas que faciliten la circulación de información y los procesos de consulta y deliberación. En ese marco, se debe aprovechar el potencial de las TICs para ejercer un rol de articulador y de promotor de la participación ciudadana, y fomentar su uso por parte de la comunidad. En contextos específicos, usar otros medios ad-hoc (por ejemplo, diarios y radios locales).

Paso 9. Aprendiendo de lo realizado: la sistematización y la evaluación de la experiencia

El desarrollo de la iniciativa enfrenta al equipo a diversas contingencias que pueden facilitar u obstaculizar las actividades y el avance hacia el logro de los objetivos, de las cuales hay que aprender y generar ajustes y reorientaciones si es necesario. Para ello se debe conocer e internalizar la práctica de la sistematización y la evaluación como algo útil para lograr un mejoramiento permanente de las iniciativas y generar aprendizajes que contribuyan a mejores procesos ciudadanos y de desarrollo local.

Paso 10. Consolidando lo logrado: facilitando la instalación de capacidades

Es importante que los logros se proyecten en el tiempo, por lo que es bueno tener en cuenta algunas claves para lograr la sostenibilidad de las iniciativas. La instalación de capacidades y prácticas es clave para que los procesos perduren, ampliándose el horizonte de posibilidades para la consolidación de dinámicas más participativas y democráticas en las que aporte la biblioteca. 


\section{REFERENCIAS BIBLIOGRÁFICAS}

Consejo Nacional de Participación Ciudadana y Fortalecimiento de la Sociedad Civil (2017). Informe final del estado de la participación ciudadana en Chile.

DIBAM (1997). Gestión Participativa en las Bibliotecas Públicas: los desafíos de trabajar en Comunidad.

Fernández, J. e Ivusic, J. (2017). Guía para promover la participación ciudadana desde las bibliotecas públicas. FDD-Rimisp.

Ochoa, G. y Valdés, M. (2014). Curso e-learning Biblioacción ciudadana: Presentación Módulo 2 «Participación y gestión».

Rimisp (2016). Informe Final de Evaluación del Programa Biblioacción Ciudadana. 



\title{
ABRE: LA COLABORACIÓN EN EL CENTRO DE LA GESTIÓN MUNICIPAL
}

\author{
Manuel Barros Riveros" \\ Fundación Ciudadano Inteligente
}

En este artículo se describe el proceso de diseño e implementación del proyecto Abre, una iniciativa de Fundación Ciudadano Inteligente que busca incorporar a vecinas y vecinos en la creación, diseño, implementación y seguimiento de políticas municipales a través de metodologías participativas presenciales y digitales. Se ofrece un breve repaso del contexto nacional e internacional que gatilló la creación de este proyecto y luego se profundiza en el proceso de diseño, su implementación y principales resultados.

América Latina atraviesa hoy uno de sus momentos políticos más complejos de las últimas décadas. El destape de una serie de casos de corrupción y escándalos relacionados con el financiamiento irregular de la política, así como la inercia de décadas de gestión gubernamental a espaldas de la ciudadanía -a nivel nacional y subnacional- han propiciado un clima de desafección política y desconfianza no solo interpersonal, sino también entre y hacia las autoridades e instituciones públicas en toda la región. No por nada asistimos en los últimos años a un escenario político confuso, en el cual se presentan, por un lado, bajísimos índices de participación electoral y asociatividad y, por el otro, altos niveles de efervescencia política, en donde los movimientos sociales han tomado un protagonismo especial y el debate público apunta recurrentemente a la

Coordinador de proyectos en Fundación Ciudadano Inteligente, organización chilena sin fines de lucro que tiene como misión el fortalecimiento de las democracias en América Latina. 
urgencia de refrescar las formas de representación, la composición de la clase política y, sobre todo, los mecanismos y procesos de toma de decisiones.

En Latinoamérica existen más de 16 mil gobiernos locales (ciudades, municipios, distritos, cantones, etc.) en donde habitan aproximadamente 612 millones de personas. Lamentablemente, estos gobiernos han estado fallando sistemáticamente en el cumplimiento del mandato popular de administrar los recursos públicos y tomar decisiones para preservar o mejorar la calidad de vida de sus habitantes. Según estudios, el 61\% de los latinoamericanos dice confiar «poco» $\mathrm{o}$ «nada» en sus municipios, contra solo un $6 \%$ que reconoce confiar «mucho» (Latinobarómetro, 2013). Además, los gobiernos locales de la región promedian un 40,5 en la escala de percepción de la corrupción, donde 0 es muy corrupto y 100 nada corrupto (Transparency International CPI, 2015).

La Fundación Ciudadano Inteligente (FCI), una organización chilena sin fines de lucro dedicada al fortalecimiento de las democracias en toda América Latina es consciente de este contexto de desafección y desconfianza hace ya tiempo. Es por esto que hace algunos años esta organización inició un proceso de reflexión para abordarlo, con el objetivo de desarrollar soluciones innovadoras para disminuir estas brechas entre gobiernos y ciudadanía, potenciar el trabajo de los gobiernos locales y fomentar la implementación de iniciativas de Gobierno Abierto a nivel subnacional.

En un comienzo la idea fue crear una suerte de Toolkit Municipal, un paquete de soluciones que combinara las herramientas y metodologías que FCI ya había desarrollado y probado en distintos contextos (plataformas de información para procesos electorales, metodologías de fiscalización al poder, sitios de transparencia, herramientas de crowdsourcing, etc.) y ofrecerlo a municipios a modo de servicio. Sin embargo, el acercamiento de la fundación a la realidad municipal de Chile y otros países del continente arrojó una verdad incómoda pero desafiante: las herramientas utilizadas a la fecha no eran suficientes a la hora de abordar los problemas que enfrenta la administración subnacional; hoy se requieren procesos reflexivos 
y dinámicos de diseño que permitan crear soluciones innovadoras, flexibles y realmente eficaces para combatir la corrupción, la desconfianza y la lejanía con la que han estado operando los municipios en la región, que es, dicho sea de paso, un ámbito de administración muy diferente al del nivel nacional. Si de verdad se busca abrir gobiernos locales, hay que sumergirse en estos y desarrollar colaborativamente soluciones orgánicas e integrales que hagan sentido tanto a la administración como a la comunidad y que, según ha demostrado la experiencia, trasciendan al mero desarrollo de tecnología.

Finalmente, el proyecto -que adoptó el nombre 'Abre'- derivó en un modelo de participación ciudadana vinculante que involucra a la ciudadanía en cuatro etapas del ciclo de políticas públicas municipales. Un proyecto que combina lo tecnológico con lo presencial y que asegura su sostenibilidad en el tiempo mediante capacitaciones e instalación de capacidades en equipos municipales.

¿Por qué enfocarse en el nivel subnacional? La razón se ha esgrimido hasta el cansancio en la ciencia política y los estudios municipales: los gobiernos locales son para la ciudadanía la puerta de entrada al Estado y la gestión pública y, si se quiere, el territorio en el que se diseñan (en cierta medida) e implementan las políticas que moldean directamente sus condiciones y calidad de vida. Además de coincidir con esta idea, el equipo de FCI llegó a la convicción de complementar sus esfuerzos de alcance nacional con iniciativas dirigidas a espacios acotados, suponiendo que a nivel local resultaría más accesible instalar capacidades y comenzar a pavimentar de a poco un camino de largo aliento. Aunque la práctica demostró que esta premisa no siempre se cumple, el proyecto ya ha arrojado resultados que nos hacen creer que sería importante realizar esfuerzos de replicación.

\section{El proceso de diseño de Abre}

Como se mencionó anteriormente, FCI llevaba años pensando en posibles formas de llevar sus herramientas al plano local. En 2016, cuando la fundación decidió realizar este esfuerzo, hubo que sentarse 
a reflexionar profundamente al respecto, ya que desde un comienzo se constató que trasladar la experiencia y aprendizajes acumulados en ocho años de existencia no sería suficiente ni aseguraría, en ningún contexto, su utilidad y pertinencia si es que se reimplementaran softwares y/o metodologías con solo algunos ajustes coyunturales. En otras palabras, el equipo entendió que el esfuerzo sería más que una mera adaptación al espacio local.

Fue así como FCI se planteó el desafío de «diseñar el Spotify de la participación», es decir, una herramienta lo suficientemente «sexy» como para asegurar su uso, masividad y sostenibilidad en el tiempo. Había que construir un proyecto capaz de convencer sobre su utilidad e importancia no solo a los municipios, sino también a la ciudadanía. Por complicado que sonara, el equipo de la fundación decidió contribuir a romper las barreras que existen entre las comunidades y sus gobiernos, combatir la desconfianza y la apatía con una iniciativa que, a diferencia de las miles que han quedado en el tacho del olvido, sirviese para transformar culturas organizacionales al interior de los gobiernos subnacionales y, además, reconquistar el interés de la ciudadanía transfiriéndole poder efectivo, que es, desde la perspectiva organizacional de FCI, el verdadero significado de "abrir un gobierno".

Para enfrentar este complejo desafío fue necesario aproximarse a la realidad municipal, sumergirse en el estado del arte en materia de participación ciudadana y mapear soluciones similares que hayan arrojado éxitos y aprendizajes. Hasta ese momento, FCI nunca había trabajado desarrollando servicios de ningún tipo para gobiernos y pretender diseñar algo funcional sin una cuota de realidad y pragmatismo, sin duda, hubiese resultado en un esfuerzo fallido. Para esto, luego de algunas entrevistas a expertos y visitas a diversos municipios de la Región Metropolitana de Chile, FCI estableció una alianza y convenio de colaboración con uno de los municipios vanguardistas en temas de apertura e innovación gubernamental en el país: la Ilustre Municipalidad de Peñalolén, comuna del sector oriente de la capital con más de 240 mil habitantes. 
Afortunadamente FCI ya había establecido contacto con Peñalolén en el marco del desarrollo del Modelo de Gobierno Abierto $\mathrm{Mu}-$ nicipal $^{1}$ en Chile. Pero las principales razones por la que se escogió a Peñalolén como institución aliada para el diseño e implementación de este proyecto fueron varias, todas condiciones excluyentes para el desarrollo de una iniciativa de estas características:

- Voluntad política: Durante la última década ha existido en la alcaldía de Peñalolén el interés por innovar e invertir tiempo y recursos en la búsqueda de soluciones creativas a los desafíos que enfrenta la municipalidad. Además, se han implementado iniciativas de gobierno digital y rendición de cuentas que han allanado el camino para nuevos y venideros proyectos de innovación.

- Sensibilidad en funcionarios: Lo anterior también ha derivado en un conocimiento, aunque todavía no distribuido extensivamente en el equipo municipal, bastante amplio sobre el estado del arte en materia de gobierno abierto y la importancia de la temática.

- Presupuesto: La municipalidad se atrevió a diseñar un proyecto que desde un comienzo se planteó como una metodología para abrir espacios de incidencia vinculante a la ciudadanía. Para esto se acordó que el proyecto sería implementado en algún área que contase con el presupuesto necesario para tomarse el tiempo que requiere hacer participación, lo que permitió trabajar con la certeza de que el resultado al menos no provocaría frustraciones en la comunidad.

Luego de establecido el convenio de colaboración se aplicó un proceso de diseño bajo los principios y recursos ofrecidos por el enfoque Human Centered Design (HCD) o diseño centrado en el usuario. Este enfoque se basa en principios de campos del conocimiento como

1 Compromiso N¹5 del 3er Plan de Acción de Chile en la Alianza para el Gobierno Abierto, a cargo del Consejo para la Transparencia, desarrollado en conjunto con siete municipalidades de Chile y la colaboración de Chile Transparente y Fundación Ciudadano Inteligente. 
la ergonomía, la ciencia computacional y el desarrollo de inteligencia artificial con el objeto de aplicar, ya sea en políticas públicas o estrategias de marketing, procesos inteligentes y flexibles capaces de solucionar desafíos de diseño de forma efectiva, facilitando la construcción de "productos mínimamente viables» y las iteraciones ágiles para el aprendizaje por error (Giacomin, 2012).

En el marco de la aplicación del HCD, los equipos de Ciudadano Inteligente y Peñalolén implementaron y utilizaron las siguientes etapas y herramientas:

\section{Fase de inspiración}

1. Encuadre del desafío de diseño:

a) Sesiones creativas de identificación de problemas: Reuniones periódicas entre los dos equipos institucionales y primeras lluvias de ideas en torno al problema;

b) Entrevistas a usuarios extremos y promedios: Se definieron perfiles variados de vecinos y usuarios de servicios públicos para conocer apreciaciones y disposiciones en torno al municipio, la vida en vecindarios y experiencias de colaboración o participación;

c) Definición de desafío y audiencias.

2. Inmersión en contexto: Visitas intensivas a terreno para observación de dinámicas, lenguajes y prácticas en espacios como:

a) Centro de Atención al Vecino (CAV);

b) Barrio Lo Hermida (de alta articulación comunitaria);

c) Iniciativa «Recuperación de Espacios Públicos»;

d) Mesa barrial (espacio de coordinación municipio-vecinos).

3. Entrevistas a expertos: Conversaciones con responsables de experiencias exitosas de participación y apertura gubernamental en Chile y el mundo. 
4. Instancias de inspiración análoga: Inmersiones y entrevistas en contextos ajenos a la administración municipal, pero con capacidad de arrojar luces sobre dinámicas de colaboración y cesión de poder en distintos niveles y realidades.

\section{Fase de ideación}

5. Descarga de aprendizajes: En matrices se volcó todo lo extraído en la fase anterior con el objetivo de simplificar y visualizar los avances. Así comenzó a fraguarse el concepto de una iniciativa simple, amigable, atractiva y eficaz que se hiciera cargo de cuestiones como la apatía, la frustración y la aversión a la cesión de poder.

6. «Cómo podríamos»: Se identificaron las grandes categorías de necesidades y fueron traducidas a desafíos de diseño en preguntas en formato «¿Cómo podríamos...?». Así surgieron interrogantes como: ¿Cómo podríamos llegar a los vecinos de formas cómodas y versátiles? o ¿Cómo generamos más instancias de encuentro cara-a-cara entre vecinos y funcionarios?

7. Brainstorming: Luego de definidos los desafíos se llevaron a cabo sesiones de ideación en las que la regla fue soñar sin límites, sin temor a equivocarse. No hay malas ideas. Pensar en soluciones ideales y luego aterrizar, ese fue el objetivo.

8. Combinación de ideas: Muchas de las «posibles ideas» surgidas en la fase de ideación fueron agrupadas en clusters y luego aterrizadas a conceptos específicos, lo que simplificó el abanico de opciones y facilitó la última etapa de esta fase.

9. Creación de concepto: Con las ideas agrupadas en la actividad anterior se redactó un primer concepto para el proyecto, muy alineado con lo que se diseñó a la postre.

Concepto original: «Una metodología para la participación ciudadana vinculante en la elaboración de políticas, programas o acciones municipales, acompañada de herramientas y actividades de 
soporte que faciliten la labor y exijan responsabilidades en ambos sentidos (gobierno y vecinos)».

Cuadro i. Breve Resumen de APrendizajes, FASE DE INSPiración ${ }^{2}$

\begin{tabular}{|c|c|c|}
\hline Desafíos / Obstáculos & OPORTUNIDADES & Posibles SOLUCIONES \\
\hline $\begin{array}{l}\text { Comunidad: Descono- } \\
\text { cimiento sobre mecanis- } \\
\text { mos y espacios de par- } \\
\text { ticipación ofrecidos por } \\
\text { municipio }\end{array}$ & $\begin{array}{l}\text { Aumento en niveles de em- } \\
\text { poderamiento ciudadano }\end{array}$ & $\begin{array}{l}\text { Crear Decide Peña / } \\
\text { Facilitar y simplificar } \\
\text { acceso a incidencia e } \\
\text { involucramiento }\end{array}$ \\
\hline $\begin{array}{l}\text { Comunidad: Deterioro } \\
\text { de vínculos en vecinda- } \\
\text { rios, necesidad de en- } \\
\text { cuentro y colaboración }\end{array}$ & $\begin{array}{l}\text { Algunas experiencias pre- } \\
\text { vias positivas y existencia } \\
\text { de canales de comunica- } \\
\text { ción y coordinación }\end{array}$ & $\begin{array}{l}\text { Programa de talleres } \\
\text { y actividades barria- } \\
\text { les basadas en con- } \\
\text { cepto de co-responsa- } \\
\text { bilidad (participatory } \\
\text { city) }\end{array}$ \\
\hline $\begin{array}{l}\text { Municipio: Temor a la } \\
\text { cesión de poder / a la } \\
\text { participación vinculante }\end{array}$ & $\begin{array}{l}\text { Existencia de voluntad po- } \\
\text { lítica a nivel de la máxima } \\
\text { autoridad }\end{array}$ & $\begin{array}{l}\text { Creación de la uni- } \\
\text { dad de gobierno } \\
\text { abierto + perfeccio- } \\
\text { namiento división de } \\
\text { innovación }\end{array}$ \\
\hline $\begin{array}{l}\text { Municipio: Escasa inte- } \\
\text { roperabilidad e inexis- } \\
\text { tencia de experiencias } \\
\text { exitosas de innovación } \\
\text { y colaboración inter-de- } \\
\text { partamentos }\end{array}$ & $\begin{array}{l}\text { Presencia de funcionarios } \\
\text { con "perfil innovador» y } \\
\text { mayor sensibilización so- } \\
\text { bre Gobierno Abierto a } \\
\text { nivel institucional }\end{array}$ & $\begin{array}{l}\text { Implementación de } \\
\text { plataforma de pro- } \\
\text { puestas apadrinadas } \\
\text { por unidades muni- } \\
\text { cipales (open innova- } \\
\text { tion) }\end{array}$ \\
\hline $\begin{array}{l}\text { Comunidad: Creciente } \\
\text { despolitización y descon- } \\
\text { fianza / desgaste de la de- } \\
\text { mocracia representativa }\end{array}$ & $\begin{array}{l}\text { Exigencias ciudadanas por } \\
\text { mayor participación e inci- } \\
\text { dencia en toma de decisio- } \\
\text { nes (por desconfianza) }\end{array}$ & $\begin{array}{l}\text { Creación de un Parla- } \\
\text { mento Comunal para } \\
\text { deliberación y toma } \\
\text { de decisiones }\end{array}$ \\
\hline
\end{tabular}

2 Se realizó una selección arbitraria de los elementos a exponer en este artículo. El listado de elementos identificados, tanto problemáticas como posibles soluciones, es muy extenso. 
Todo el proceso descrito permitió ingresar a la fase de prototipado con evidencia suficiente para diseñar eficientemente. El objetivo de FCI fue desde un comienzo desarrollar un proyecto que facilitase la aplicación de un enfoque bottom-up en el diseño de políticas públicas a nivel municipal, poniendo la colaboración y la confianza en el centro de la toma de decisiones. De esta forma -centrándose en los usuarios- se facilita la acomodación permanente de la administración a las necesidades locales complejas y cambiantes, lo que produce mayor equidad y distribuye de mejor manera las posibilidades de incidencia en la elaboración de políticas (Peters, 1995).

\section{El Resultado: ¿EN QUÉ CONSISTE Abre?}

Luego de todo el proceso descrito, Abre tomó forma y se consolidó como un programa/servicio para municipios que facilita la incorporación de la comunidad del territorio en la creación, diseño, implementación y seguimiento de políticas municipales a través de metodologías participativas presenciales y digitales. Es decir, una plataforma digital -que facilita la comunicación y seguimientoacompañada de instancias offline para el encuentro cara-a-cara y la co-creación de soluciones, orientada a la cesión de poder en las distintas fases del ciclo de políticas públicas a través de la participación ciudadana vinculante. ¿El objetivo? transformar la manera en que se toman las decisiones y avanzar hacia formas de gobierno subnacional abierto y participativo.

Para esto se pensó en aplicaciones móviles, en chats y ventanillas de recepción automatizadas; en algo que estuviera en el bolsillo de los vecinos y vecinas. Algo simple, rápido, tecnológico, moderno. Pero no. El contacto con la realidad municipal nos mostró que, a diferencia de lo que sucede en gobiernos europeos, donde iniciativas como estas se han estado implementando hace ya algunos años, en Chile y América Latina no existen ni los recursos apropiados en municipios para el desarrollo tecnológico, ni la penetración necesaria de internet y la telefonía móvil, lo que forzó la búsqueda de una 
manera creativa y eficaz de combinar tecnología con metodologías presenciales.

Entre las etapa de inspiración, ideación y diseño se mantuvieron los siguientes conceptos pilares que dieron forma al proyecto: a) el crowdsourcing como un mecanismo para abrir discusiones públicas y procesos de toma de decisiones; b) el uso de la tecnología como elemento complementario al trabajo en terreno para simplificar la comunicación, el levantamiento de información y la rendición de cuentas; c) la exigencia a autoridades de implementar el programa en proyectos con presupuesto y que los resultados de la participación sean vinculantes; d) la asignación de tareas a las vecinas y vecinos, fomentar la co-responsabilidad; e) el uso de un lenguaje simple y cercano en todo momento; f) la presencia en terreno, fomentar la interacción cara-a-cara; g) la aplicación de metodologías de trabajo ágiles en instancias de co-diseño; y h) la transferencia e instalación de capacidades en el equipo municipal, asegurar la sostenibilidad del proyecto en el tiempo.

\section{LA REIMPlementación DE CONSUl}

Comprenderá el lector que Abre es mucho más que una herramienta tecnológica. No obstante, esta juega un rol clave, ya que, además de facilitar comunicación y el accountability entre vecinos y funcionarios, funciona como espacio para la centralización y sistematización de todo el proceso. En este sentido el equipo de Fundación Ciudadano Inteligente comprendió que no era necesario «reinventar la rueda» y que, fiel al espíritu open source, se podía reimplementar una iniciativa que ya estaba mostrando resultados interesantes en España y otras partes del globo: Consul.

Consul es un software abierto y gratuito para la participación ciudadana, que puede ser utilizado por cualquier persona y permite la customización para su ajuste a cualquier requerimiento. Consul puede integrarse con registros existentes que posea el municipio y permite el resguardo de la seguridad de los datos de sus usuarios. Además, tanto los equipos técnicos y de desarrollo del proyecto, 
como otras instituciones que están utilizándolo, ofrecen apoyo y retroalimentación para facilitar su uso.

A la fecha Consul permite a los municipios y sus comunidades: 1) abrir debates sobre temas de interés público para la deliberación colectiva; 2) levantar y priorizar de manera vinculante propuestas ciudadanas para proyectos y políticas públicas municipales; 3 ) disponibilización de procesos de participación en asignación de presupuestos (presupuestos participativos); 4) votaciones de proyectos municipales; y 5) instancias de legislación colaborativa. Sin duda, una herramienta muy potente que está cambiando la forma de gobernar las ciudades del mundo.

Con la existencia, vigencia y disponibilidad de una herramienta como Consul no fue necesario desarrollar todo desde cero, bastó con que el equipo de desarrollo in-house de FCI reimplementara el código. Sin embargo, dado que Abre combina los aspectos antes mencionados del software con instancias presenciales -y dado que se había constatado la necesidad de buscar soluciones distintas a las implementadas en gobiernos ricos y desarrollados (como Madrid)se hizo necesario realizar una serie de modificaciones al software:

- Se quitó la recepción abierta y permanente de propuestas. En Abre las propuestas ciudadanas deben realizarse en el marco de un desafío abierto por la municipalidad;

- Se eliminó la posibilidad de abrir presupuestos participativos. Si un municipio desea utilizar Abre para esos propósitos, puede abrir un desafío y funciona de igual manera;

- Se agregó un feature de seguimiento al ciclo de vida de los desafíos, desde que se abren hasta que son evaluados tras el co-diseño y la implementación;

- En Abre, dado que existen instancias en terreno donde los vecinos pueden crear propuestas asesorados por funcionarios, los usuarios «admin» (funcionarios) pueden apoyar y crear propuestas en nombre de otra persona (cuando esta no cuenta con correo electrónico de contacto o las capacidades para gestionar un computador). 


\section{LAS CUATRo ETAPAS DE AbRE}

Antes de iniciar el trabajo conjunto entre FCI y los municipios, se le exige a estos una serie de requisitos excluyentes para la implementación. Estos son:

- Las decisiones tomadas en conjunto con la ciudadanía deben ser vinculantes;

- Se debe asignar presupuesto para la implementación de la metodología y los proyectos resultantes o contemplar de antemano las posibilidades de postulación a fondos externos para su implementación;

- Debe existir comunicación permanente con la comunidad;

- El municipio debe dar respuesta siempre a las inquietudes de la ciudadanía, de manera de no romper las expectativas generadas en el proceso;

- La autoridad alcaldicia deberá manifestar la voluntad de realizar el proyecto al resto de la estructura municipal, ordenando la conformación de los dos equipos necesarios (de Soporte y Territorial). De esta forma se asegura la disposición de los funcionarios para su correcto funcionamiento.

\section{Etapa 0: Construcción del desafio}

Los desafíos son un llamado a vecinos y vecinas a proponer soluciones para un problema puntual que el municipio quiere resolver, por ejemplo: mejorar un parque, implementar un sistema de reciclaje barrial, facilitar el acceso a los servicios municipales a personas con capacidades diferentes, diseñar políticas para áreas específicas, etc. Una vez publicado el desafío en el sitio de Abre, la comunidad es convocada para proponer sus soluciones a través de la misma plataforma. 


\section{Etapa 1: Recepción y priorización de propuestas}

En la primera etapa de Abre se le ofrece a la comunidad la posibilidad de crear, a través de la plataforma web, ideas y propuestas concretas para resolver el desafío que ha planteado el municipio. Para posibilitar la creación de propuestas, el municipio debe publicar en el sitio de Abre las restricciones del desafío. Dentro de los límites que implican tales restricciones, la comunidad debe ser libre de proponer las soluciones que consideren que responden mejor a su realidad local y necesidades.

La inteligencia y la creatividad están distribuidas equitativamente en la población. El espíritu detrás del crowdsourcing plantea que «todos podemos pensar en soluciones creativas, cualquier ciudadano podría crear la mejor solución a un problema público». ¡Ese es el objetivo de la etapa de levantamiento y priorización de propuestas en Abre! Aprovechar el conocimiento de las y los vecinos del territorio y hacerlos parte del proceso.

Además, junto con crear propuestas, los usuarios del sitio pueden entregar su apoyo a las propuestas de sus vecinos y vecinas que les interese potenciar. Así, en paralelo a la ideación se va desarrollando el proceso de priorización mediante la lógica de 'likes'.

\section{Etapa 2: Talleres de co-diseño}

Una vez finalizada la primera etapa del proceso, la o las propuesta(s) más apoyadas por la comunidad son publicadas y llevadas a dos instancias de co-diseño, dos espacios presenciales en el que tanto el equipo municipal como los vecinos y vecinas interesados trabajan codo a codo en la definición específica y técnica del proyecto a implementar, así como su cronograma de implementación y distribución de responsabilidades.

En el Taller de Co-Diseño $\mathrm{N}^{\circ} 1$ el objetivo es construir de manera corresponsable e informada el proyecto a desarrollar. Es decir, se toma la o las ideas ganadoras y se presentan al público para afinar sus detalles y crear un prototipo consensuado. En el Taller $\mathrm{N}^{\circ} 2$ el 
municipio presenta una adaptación viable y financiable del prototipo creado en la primera sesión, con lo cual se discuten algunos nudos críticos y se valida con toda la comunidad. Finalmente se deben acordar pasos y plazos para su implementación, como también los mecanismos de rendición de cuenta y monitoreo, además de las tareas que serán responsabilidad de los vecinos y vecinas. Este último punto es clave, ya que Abre propone no solo abrir los espacios de toma de decisiones, sino también recuperar las confianzas a través de la idea de co-responsabilidad: que la comunidad sea parte de los proyectos.

Cuadro 2. Esquema de etapas y flujo de actividades, proyecto Abre

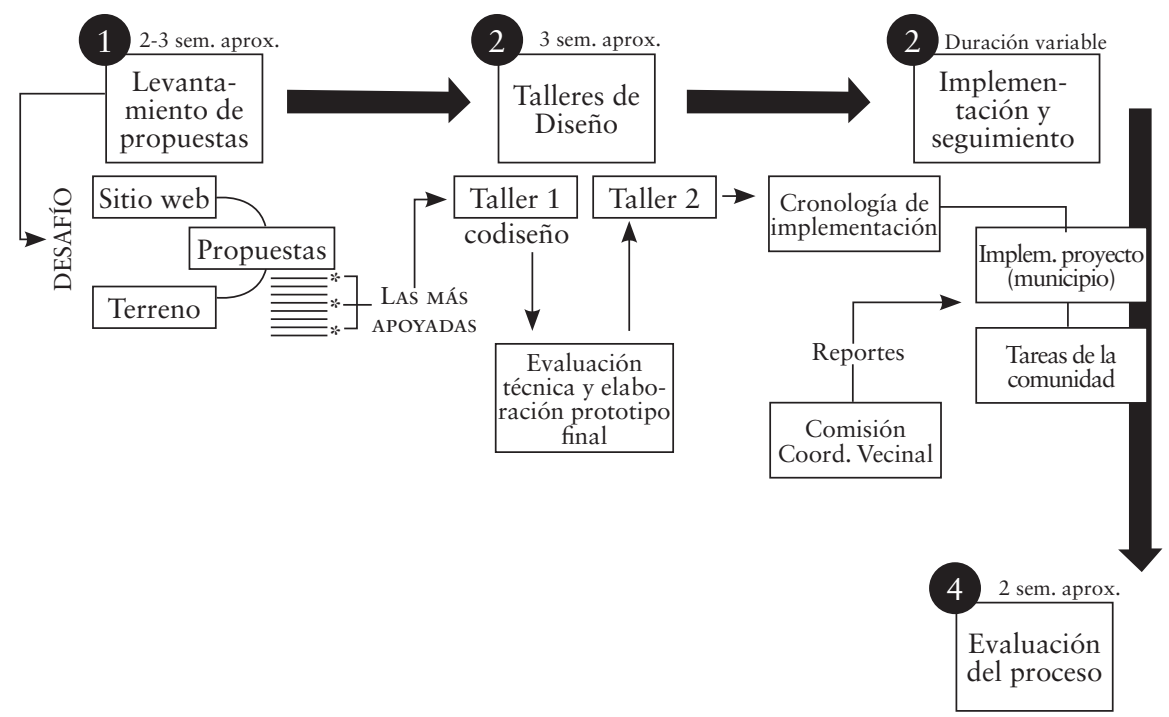




\section{Etapa 3: Implementación}

Esta etapa consiste en la ejecución del proyecto acordado. Por la amplia diversidad de proyectos posibles, esta etapa no cuenta con una estructura rígida y su extensión en el tiempo va a depender de la naturaleza del desafío (no es lo mismo la construcción de una carretera que la definición de prioridades en materia de seguridad ciudadana).

En esta etapa Abre establece un canal de comunicación amigable para que tanto autoridades, funcionarios y vecinos puedan entregar reportes y rendir cuenta de las labores realizadas. En una sección de la plataforma digital, el gobierno deberá colgar reportes y fotografías de los avances, los cuales podrán ser comentados u objetados por la comunidad. La periodicidad de estos reportes es definida en el segundo taller de diseño, en la etapa anterior.

\section{Etapa 4: Evaluación del proceso}

Esta última etapa permite a los vecinos involucrados en el proceso evaluar la experiencia, entregando valoraciones cualitativas y cuantitativas sobre cada una de las etapas y elementos del proceso. Este ejercicio final permite al municipio recabar datos valiosos para mejorar la implementación de Abre en proyectos futuros.

\section{¿CuÁl es el producto?}

Una vez finalizado el ciclo completo de Abre, el municipio cuenta con una política o proyecto local creado $100 \%$ de manera colaborativa con los vecinos de la comuna. Esto, cree Fundación Ciudadano Inteligente, aumenta la confianza de la ciudadanía en la gestión local y también brinda al municipio un mejor conocimiento de las necesidades de sus vecinos. Además, al elaborarse desde la propia comunidad, la política asegura sostenibilidad en el tiempo y, así, optimización en el uso de los recursos públicos. 
Cabe destacar que las capacidades y el sitio web específico para la comuna quedan instalados en el Municipio, por lo que se puede volver a repetir el proceso cuantas veces la municipalidad estime conveniente, contando con toda la preparación y apoyo logístico para ello.

\section{IMPLEMENTACIÓN Y PRIMEROS RESULTADOS}

Abre fue implementado por primera vez en la comuna de Peñalolén, en el primer piloteo del proyecto. En la ocasión, la municipalidad aprovechó el programa "40 nuevas áreas verdes» -ya anunciado en el programa de la alcaldesa Carolina Leitao- para desarrollar uno de estos cuarenta proyectos de manera colaborativa probando la metodología y la plataforma Abre.

En Abre Peñalolén vecinos y vecinas fueron convocados a colaborar con propuestas para mejorar el parque de su barrio en el barrio San Luis de Macul. Tal como lo establece la metodología y secuencia del proceso, luego del levantamiento y priorización de propuestas (fase que contó con una considerable participación, registrando 44 propuestas y más de 230 apoyos) se realizaron dos talleres de diseño en el mismo parque, a los que asistieron más de 50 personas para, en primera instancia, construir maquetas con una aplicación concreta de las ideas propuestas en la primera etapa y, en segunda instancia, acordar las tareas tanto del municipio como de la comunidad.

Al término del proceso, tanto la comunidad como funcionarios y autoridades del municipio valoraron positivamente la iniciativa, destacando la facilidad en su aplicación y la efectividad de sus resultados.

Durante 2018 Abre se estará implementando en la Municipalidad de Renca en dos proyectos puntuales: 1) la priorización de un conjunto de proyecto municipales en cartera; y 2) la reactivación comunitaria de siete espacios públicos en cada una de las macrozonas de la comuna. 
El programa Abre hoy se encuentra abierto a quien quiera implementarlo en su municipalidad. Si bien Ciudadano Inteligente ofrece una primera implementación acompañada como una contraprestación remunerada (con capacitaciones y asesoría técnica), también es posible que municipios que cuenten con las capacidades implementen esta plataforma que es de código abierto y soliciten ayuda de manera informal a la organización.

\section{BiBLIOGRAFÍA}

Giacomin, J. (2012). What is Human Centred Design?. Human Centred Design Institute, Brunel University Uxbridge. Middlesex, Reino Unido.

Latinobarómetro (2013). Latinobarómetro 2013. Corporación Latinobarómetro. Santiago, Chile.

Peters, G. (1995). Modelos alternativos del proceso de la política pública: de abajo hacia arriba o de arriba hacia abajo. University of Pittsburgh, Dept. Political Sciences. Pittsburgh, Estados Unidos.

Transparency International (2015). Corruption perceptions index 2015. Transparency International. 
Manuel Barros Riveros

Anexos

Anexo i. Vista de plataforma Abre

(REIMPLEMENTACión CONSUl), SECCión DESAFío

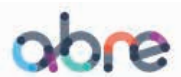

PEÑALOLEN

Sobre Abre Desafios $\mathbf{v}$

\section{Hi PEITALOLÉn \\ CRECE PARATODOS}

Entrar Registrarse

$<$ Volver

\section{- DESAFIO PARA UNIDAD VECINAL 23}

\section{SOÑEMOS EL PAROUE SAN LUIS}

El nuevo Parque San Luis lo re-diseñaremos en conjunto. A través de esta plataforma recogeremos propuestas ciudadanas para abordar este proyecto y mejorar entre todos este importante espacio comunitario. ¡Lo que decidamos será realizado por la Municipalidad!

\section{Anexo 2. Vista de plataforma Abre (reimplementación Consul),} SECCIÓN LISTADO DE PROPUESTAS

¡Ingresa tu idea para el proyecto de renovación del Parque San Luis, construyamos un espacio de comunidad para nuestras familias!. Ha finalizado el tiempo de recepción de propuestas, pero te invitamos a participar de los Talleres de Diseño

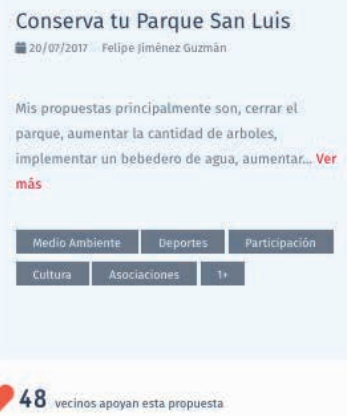

Parque entretenido para niños M. 19/00/2017. Alexander Gallardo Nraya

Un parque entretenido para que nuestros niños se diviertan Ver más

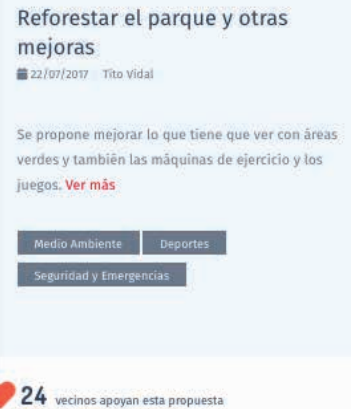

Mejor iluminación en el sector de la cancha

in 2707 izon carlos pradenas seguel

Mejorar la iluminación del parque, principalmente sumar iluminaciōn por el pasaje abedul (entre palmera y teja) y agregar un ja... Ver màs

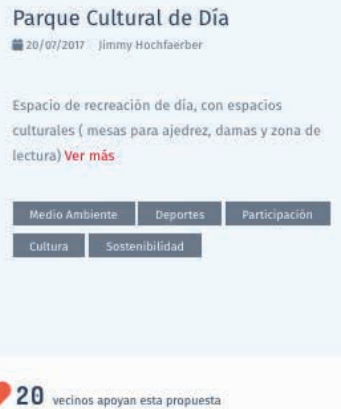

Parque Autosustentable de San Luis

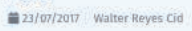

Aumentar número de árboles e incluir especies. nativas, añadir un punto limpio $y$ un sector de compostaje. Mejorar pavimentos, ci... Ver màs 



\title{
GESTIÓN MUNICIPAL Y EMPRESAS: HACIA UN NUEVO MODELO DE GOBERNANZA
}

\author{
Rodrigo Soto Cuevas \\ Jefe de Desarrollo Huella Local \\ Gonzalo Vial Luarte \\ Director Ejecutivo Huella Local
}

\section{INTRODUCCIÓN}

Fundación Huella Local (FHL) es una organización sin fines de lucro constituida por un equipo multidisciplinario que cree en el desarrollo socioeconómico local, basado en el apoyo a la gestión pública municipal, principalmente en la elaboración de proyectos de inversión, articulando a la comunidad, el sector público y privado.

De forma específica, el apoyo de FHL a la gestión municipal se realiza de manera estratégica en los gobiernos locales de las comunas más vulnerables del país, focalizando su trabajo en el desarrollo de proyectos de equipamiento e infraestructura, de modo de aumentar la inversión pública y su impacto en el territorio, junto con generar cohesión social a través de la integración de los actores presentes en él.

Lo anterior se basa en la necesidad de FHL, de responder al diagnóstico y problemática existente en los territorios que resultan prioritarios para sus actores. 


\section{Diagnóstico}

El diagnóstico del cual da cuenta la misión de FHL, se compone de tres dimensiones principales: gobierno local, empresa privada y ciudadanía. Estas dimensiones hacen referencia a los actores clave en el territorio, cuya interrelación virtuosa puede traer beneficios a este si se articulan de forma estratégica.

\section{Gobierno local}

Desde los gobiernos locales de comunas vulnerables, se observan grandes necesidades de infraestructura y equipamiento; a su vez una baja capacidad profesional en los municipios para hacerse cargo de esta realidad.

Según los datos de la AMUCH (2016) hay un 29,36\% de profesionalización en el sector municipal, levemente mayor que el 29,1\% del año 2014, confirmando una tendencia al alza en los últimos seis años, aunque de muy lento avance. Además, el $80 \%$ de los municipios chilenos tiene menos de 250 trabajadores promedio. Sin embargo, hay municipalidades que tienen más de tres mil funcionarios, lo que revela la alta heterogeneidad del sistema municipal en cuanto a sus trabajadores. De esta forma, se da la contradicción de que quienes más necesitan recursos para hacer frente a las carencias territoriales, menos capacidades tienen para captarlos.

Según Contreras et al. (2011), la disponibilidad de profesionales en las unidades encargadas de la formulación de proyectos se destaca en todos los trabajos revisados como el principal problema que enfrentan los municipios para elaborar sus iniciativas de inversión. Esto se debe a varias razones, pero sobresalen las bajas remuneraciones que reciben estos profesionales, lo que llevaría a una alta rotación de los equipos y, en consecuencia, a una escasa acumulación de experiencia en la formulación de iniciativas de inversión, afectando la calidad técnica de dichas iniciativas (Pontificia Universidad Católica de Chile, 2016). 
Además, se observa que existe un grupo selecto de comunas que concentran las mayores riquezas del universo municipal. El caso más extremo es el de Las Condes con un presupuesto 214 veces el de Timaukel. Pero esto no solo ocurre en Las Condes. Las 10 comunas con mayores ingresos tienen en conjunto el mismo presupuesto que las 256 comunas con menores presupuestos. Estas grandes asimetrías ejemplifican las diferencias en la capacidad de gestión municipal; los municipios dependen de los recursos que puedan recaudar para poder materializar sus objetivos como institución pública (Alarcón, 2015).

En Chile, la inversión pública local se ha desarrollado principalmente a través de la transferencia de recursos desde el gobierno central hacia los gobiernos regionales, o directamente hacia los gobiernos locales. En el caso de los municipios, dadas las limitaciones presupuestarias ya citadas, que presentan en muchos casos, son pocos los que pueden financiar iniciativas de inversión con recursos propios, representando solo el 6\% de la inversión pública (Pontificia Universidad Católica de Chile, 2016).

Gráfico I. COMposición DE LA INVERSIón PÚblica 20 I 2 (MM USD)

15000

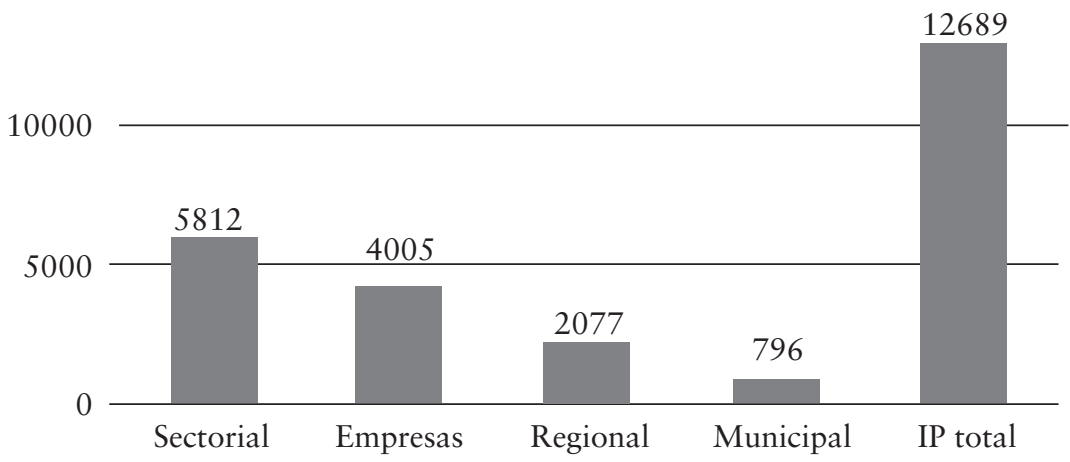

Fuente: Ministerio de Desarrollo Social (2013), Informe Anual de Inversión Pública 2012. 

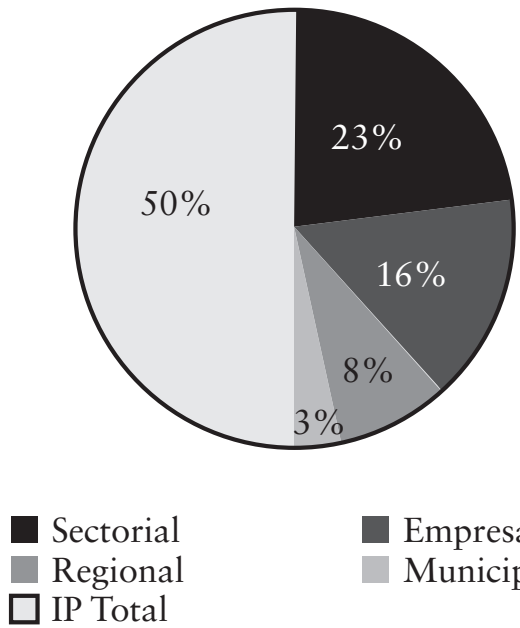

Empresas públicas

Municipal

Fuente: Pontificia Universidad Católica de Chile, 2016.

Respecto a la gestión deficiente que muestran los municipios al momento de postular a los fondos públicos existentes (FNDR, FRIL, PMU, PMB, FSPR, entre otros) y adjudicárselos, existen dos dimensiones del problema, documentadas por distintos estudios (Avendaño, 2009; Acuña, 2009; Contreras et al., 2011; Pontificia Universidad Católica de Chile, 2016). Estas son: capacidad para obtener la rentabilidad social (RS) del proyecto y adecuación de las iniciativas formuladas.

Los problemas que presentan los municipios en cuanto a su capacidad de formular proyectos que obtengan una recomendación favorable repercuten directamente en el número de proyectos que pueden optar a financiamiento externo, lo que finalmente deteriora las opciones de un municipio para ejecutar sus proyectos de inversión. Según Avendaño, si bien la medida RS no es un indicador que abarque toda la complejidad del proceso de formulación de proyectos, sí permite tener una idea general sobre la calidad técnica de las iniciativas formuladas (Pontificia Universidad Católica de Chile, 2016).

Por otro lado, dentro del proceso de inversión pública existen criterios políticos que influyen en que un determinado proyecto obtenga finalmente el financiamiento necesario para su ejecución. Si 
bien el criterio técnico corresponde a un primer filtro en el proceso, los criterios políticos aplicados con posterioridad son los que determinan el número de proyectos que finalmente obtienen recursos para su ejecución. A pesar de esto, la relación entre la cantidad de proyectos con recomendación favorable y la cantidad de proyectos efectivamente realizados sigue siendo alta. Al calcular la correlación entre ambas variables a nivel municipal para todos los proyectos ingresados al Sistema Nacional de Inversiones en el período 2009-2012 encontramos una correlación superior a 0,78 entre los proyectos con recomendación favorable y los proyectos que obtuvieron finalmente financiamiento (Pontificia Universidad Católica de Chile, 2016).

Ambas dimensiones del problema descrito, afectan de sobremanera a los municipios pequeños y sus consecuencias dan cuenta de la grave asimetría que existe en la distribución de los recursos públicos y la capacidad de los municipios para captarlos, todas estas características propias de un modelo político-administrativo centralizado.

\section{Empresa privada}

Como parte del diagnóstico, es muy relevante lo que ocurre con el sector privado y las inversiones a la hora de mirar el territorio donde aún en algunos casos persiste una visión que podría catalogarse como más tradicional, donde no se percibe una mirada de territorio ni la necesidad de adoptar un enfoque de este tipo, sino únicamente la de mantener relaciones con ciertos actores presentes en el entorno inmediato de la empresa (Centro de Políticas Públicas UC, 2016). Esto deriva en acciones efectistas y muchas veces clientelares, puesto que los objetivos dicen relación con la viabilidad social para iniciar actividades en un territorio, no el desarrollo de este.

Por otra parte, si bien las empresas ven en la acción municipal un actor relevante en el buen desarrollo de sus iniciativas, estas afirman que

la predominancia de una lógica transaccional instalada en la relación que se entabla muchas veces entre empresas y municipios, donde se privilegia la obtención de beneficios de 
corto plazo en detrimento de acciones que pueden apalancar el desarrollo sustentable de los territorios (Centro de Políticas Públicas UC, 2016. p. 12).

Este tipo de relaciones requiere de un actor experto confiable que permita entregar garantías e imparcialidades en el desarrollo de estrategias de desarrollo territorial, saliendo así de la transacción permanente.

Otro aspecto que se identifica en las empresas es el escaso involucramiento de los niveles corporativos de la empresa. En este sentido las propias empresas visualizan como desafío de que a nivel corporativo se cuente con una estrategia que incorpore objetivos concretos de sustentabilidad y colaboración, así como con una primera línea gerencial comprometida con alinear los intereses entre las distintas áreas (Centro de Políticas Públicas UC, 2016. p. 116).

Con todo, se aprecia que las empresas no generan vínculos de mediano y largo plazo con las comunidades y gobiernos locales, estableciéndose acciones de carácter transaccional que no aportan al desarrollo integral y sostenible de los territorios donde se emplazan. El impacto económico que en general bordea el 1\% de la inversión no está diseñado para apalancar otros fondos disponibles en el Estado para los territorios más rezagados, perdiéndose así la posibilidad de ampliar el universo de beneficiarios y aumentar la inversión pública y transferencia de recursos por parte del gobierno central, los gobiernos locales y sus comunidades.

\section{Comunidad}

Desde la comunidad se observa desconfianza, respecto a la labor realizada por el municipio y su capacidad técnica. Ejemplo de ello son los resultados de la encuesta nacional de percepciones ciudadanas sobre municipios (Centro de Políticas Públicas UC, 2016), cuyos resultados muestran un bajo nivel de conocimiento de la labor del municipio, pobre evaluación de los servicios municipales y el cumplimiento de promesas solo es calificado con nota 4,0. 
En una escala de 1 a 7, ¿cómo evaluaría a su municipio en los siguientes atributos?

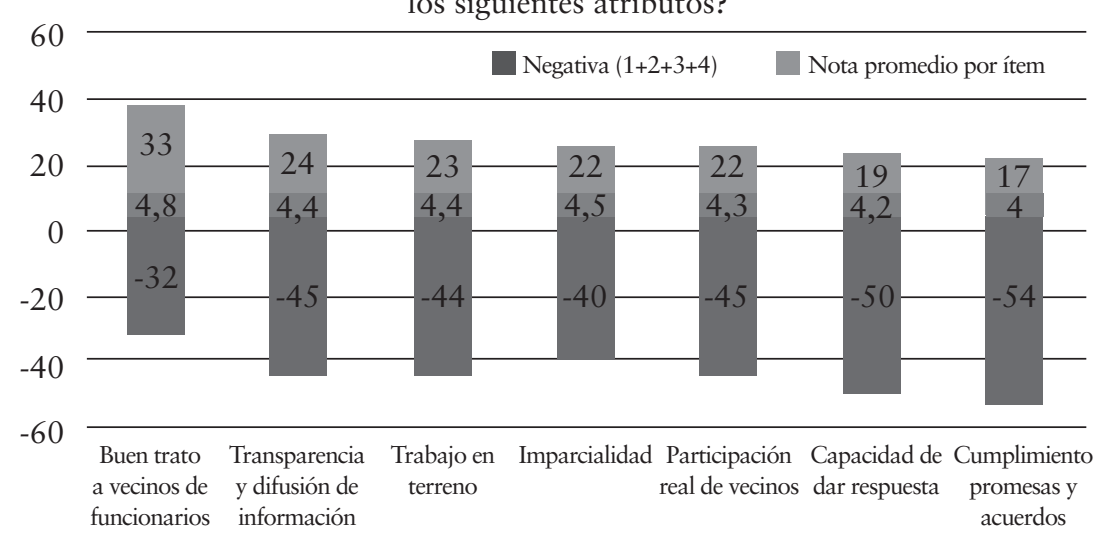

Fuente: elaboración propia. Centro Políticas Públicas UC, 2016.

Por otra parte, todos los segmentos creen que los dos principales problemas del municipio son: demasiada burocracia y poca preparación de los funcionarios, como se aprecia en el gráfico 3.

\section{Gráfico 3. Principal problema trabajo municipal}

¿Cuál cree usted que es el principal problema que afecta al trabajo de su minicipalidad?

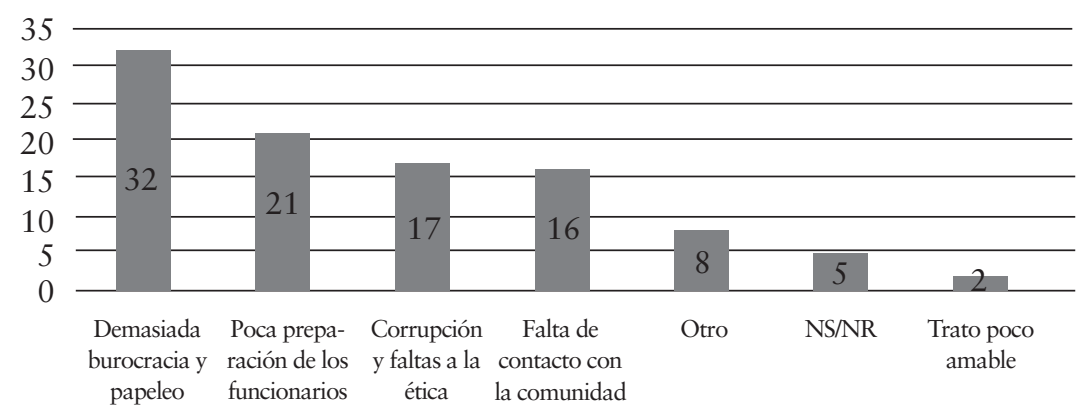

Fuente: elaboración propia. Centro Políticas Públicas UC, 2016. 
Respecto a los procesos de participación ciudadana existentes, estos también generan desconfianza, al establecerse mecanismos que despiertan expectativas, pero como tales instrumentos no son vinculantes, la fiesta democrática termina en una constante desilusión. Un ejemplo reciente de participación no vinculante lo encontramos en el proceso para discutir las bases de la nueva Constitución, el Sistema de Evaluación de Impacto Ambiental (SEIA) y la consulta de pueblos indígenas (Fuentes, 2018), donde la relación de confianza entre los actores: comunidad, estado y empresa privada, se ve ampliamente mermada por los resultados de estos procesos.

\section{Objetivos}

Para guiar nuestra labor nos hemos trazado los siguientes objetivos:

1. Objetivo general

- Realizar un apoyo estratégico en la gestión de los gobiernos locales de las comunas más vulnerables, a través del desarrollo de la cartera de proyectos municipal de equipamiento e infraestructura.

2. Objetivos específicos

- Mejorar la gestión municipal a través del desarrollo de la cartera de proyectos de infraestructura de comunas vulnerables.

- Desarrollo de proyectos de equipamiento e infraestructura de comunas vulnerables.

- Aumentar la inversión pública y privada en las comunas vulnerables.

\section{Metodología}

Para la consecución de los objetivos trazados, se ha implementado un modelo de apoyo estratégico y participativo a la gestión municipal, el cual se describe a continuación. 


\section{Modelo Fundación Huella Local}

FHL busca ser un articulador confiable en el ámbito social y técnico. Generando un proceso de articulación en el territorio, que vincula al sector privado, municipio y comunidad en el desarrollo de proyectos, con el fin de multiplicar el impacto de los esfuerzos privados y con ello aumentar la inversión pública en las comunas vulnerables del país.

\section{Figura i. Modelo FHL}

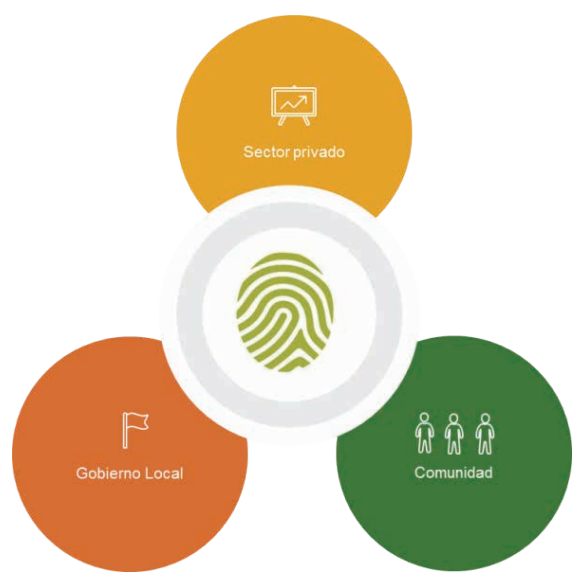

Fuente: Fundación Huella Local.

\section{Focalizamos nuestra acción en territorios prioritarios}

Esto a través de un ranking de priorización comunal, desarrollado para cada región del país, el cual se basa en el Índice Huella Local y cuya medición va de cero a uno, siendo los territorios con valores cercanos a cero, los más prioritarios.

Este índice se compone de tres variables que sustentan nuestra acción: Ingreso Municipal Total, la Capacidad Profesional del municipio (basada en el porcentaje de profesionales existentes como planta y contrata), y finalmente, el Índice de Pobreza Económica de la encuesta CASEN. Estas variables fueron ponderadas según su 
importancia mediante un panel de expertos y finalmente agregadas para dar lugar al indicador buscado.

De esta forma se obtiene un ranking como el que se muestra en la Tabla 1, que da lugar a un mapa de priorización territorial, tal como se observa en la Figura $\mathrm{N}^{\circ} 2$. En este caso, se presenta la Región de Coquimbo como ejemplo.

Tabla i. Ranking Región de Coquimbo.

\begin{tabular}{|l|l|l|}
\hline Ranking & \multicolumn{1}{|c|}{ Comuna } & \multicolumn{1}{|c|}{ Ihl $(0,4+0,2+0,4)$} \\
\hline 1 & Canela & 0,08 \\
\hline 2 & Río Hurtado & 0,21 \\
\hline 3 & Combarbalá & 0,25 \\
\hline 4 & Punitaqui & 0,28 \\
\hline 5 & La Higuera & 0,34 \\
\hline 6 & Los Vilos & 0,35 \\
\hline 7 & Monte Patria & 0,37 \\
\hline 8 & Vicuña & 0,38 \\
\hline 9 & Paiguano & 0,41 \\
\hline 10 & Andacollo & 0,42 \\
\hline 11 & Illapel & 0,48 \\
\hline 12 & Salamanca & 0,55 \\
\hline 13 & Ovalle & 0,59 \\
\hline 14 & Coquimbo & 0,73 \\
\hline 15 & La Serena & 0,77 \\
\hline
\end{tabular}

Fuente: Fundación Huella Local, SUBDERE. 
Figura 2. Mapa de priorización Región de Coquimbo.

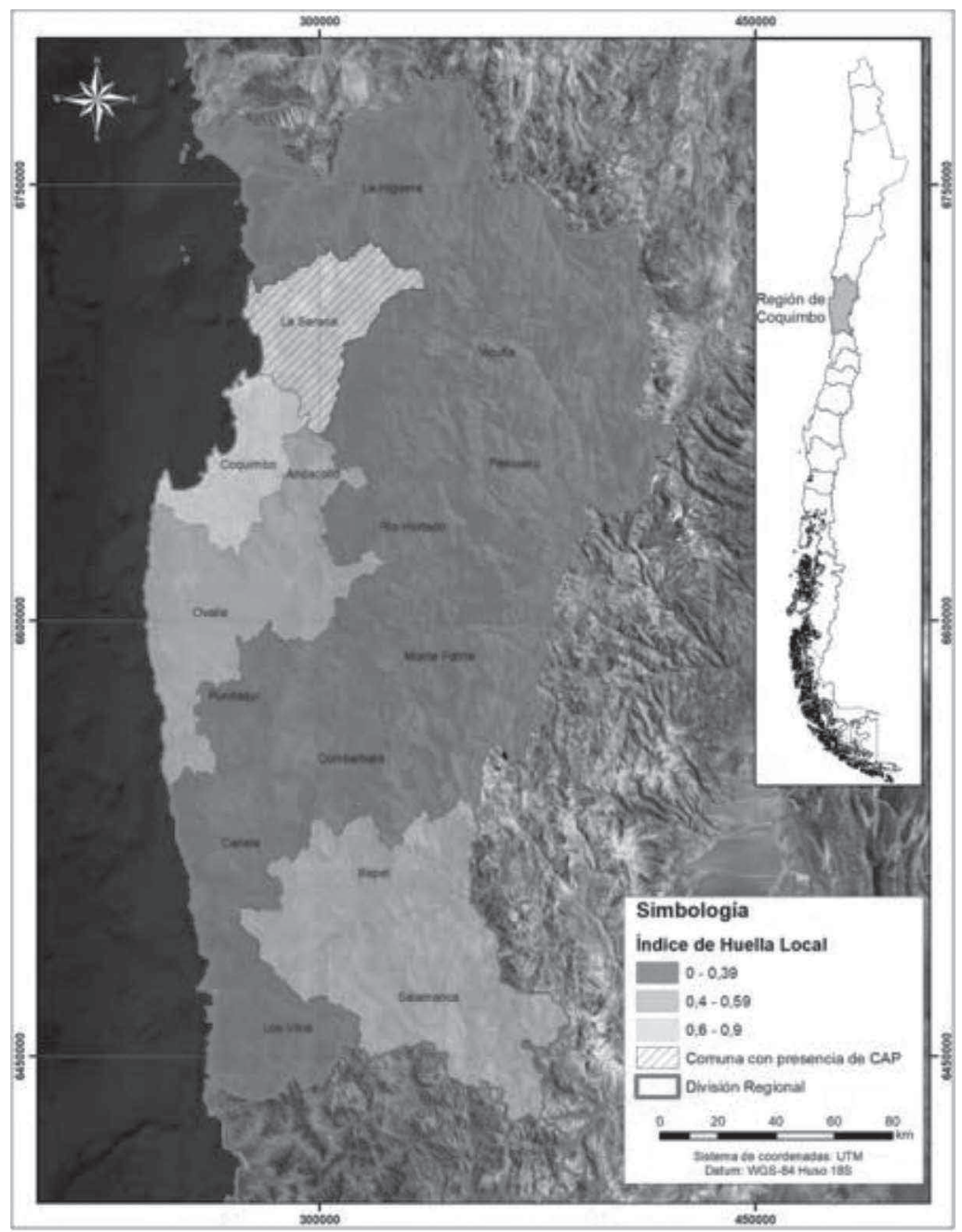

Fuente: Fundación Huella Local.

Apoyo estratégico a la gestión municipal

En esta etapa se efectúa un apoyo a los equipos municipales en el desarrollo de proyectos prioritarios para la comunidad, sumando esfuerzos privados y públicos, para el desarrollo de un proyecto de inversión social, el cual presenta las siguientes fases (Figura 3):

- Diagnóstico Participativo en el territorio. 
- Definición de una cartera de proyectos y una priorización de iniciativas con el Municipio - Las Comunidades - Empresas.

- Formulación de Proyectos para la obtención de recursos desde el estado (Huella Local - Equipo Municipal).

- Obtención de Recursos para Ejecución.

- Evaluación del Impacto.

Figura 3. FASES DE PRIORIZACIÓN DE CARTERA DE INICIATIVAS E HITOS DE UN PROYECTO DE INVERSIÓN SOCIAL

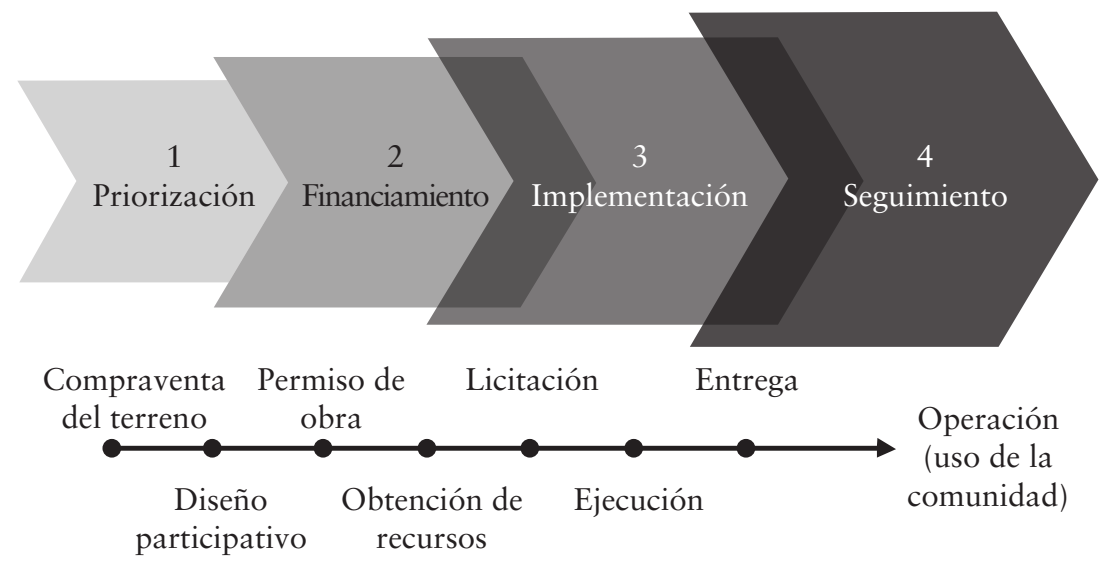

Fuente: Fundación Huella Local.

\section{MultipliCACión DEL IMPACTO}

El proceso descrito para cada uno de los proyectos contiene hitos que permiten generar una relación de pertenencia e impacto de mediano y largo plazo en las comunidades beneficiadas. Así también, este proceso genera un aumento de los beneficios sobre los territorios intervenidos, en los siguientes aspectos:

- El impacto del aporte económico de las empresas

- Los montos de inversión pública

- El relacionamiento comunitario 
¿Cómo se logra esto? A continuación, se entrega un ejemplo práctico donde se describe el modelo tradicional y el modelo de la FHL.

En el modelo tradicional el sector privado invierte 50 millones de pesos para la ejecución de un solo proyecto, sin consulta ciudadana ni priorización con equipo municipal (Figura 4).

FiguRA 4. INVERSIÓN PRIVADA MODELO TRADICIONAL

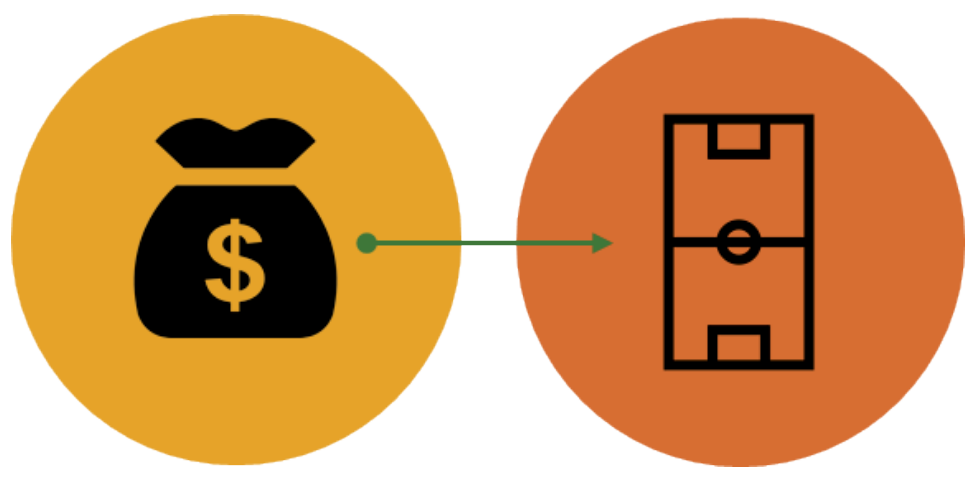

Fuente: Fundación Huella Local.

En cambio, en el Modelo Huella Local, el sector privado invierte \$50 millones para diseñar cinco proyectos, priorizados y consensuados con la comunidad y el equipo municipal. Estos proyectos serán ejecutados con fondos públicos disponibles. Pudiendo llegar a levantarse \$500 millones (Figura 5). 


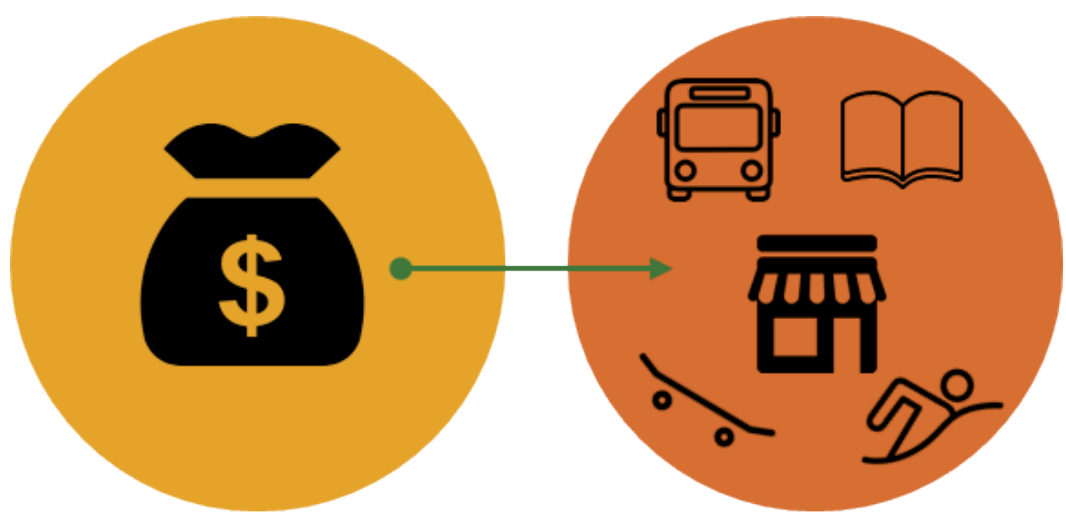

Fuente: Fundación Huella Local.

Con el Modelo Huella Local la inversión privada se ve multiplicada, al focalizarse solo en el diseño y formulación de los proyectos, lo cual a través de su postulación a fondos públicos permitirá detonar la inversión estatal para su ejecución, aumentando el impacto en el territorio.

\section{Indicadores de desempeño}

Los indicadores de desempeño de la FHL, se encuentran íntimamente relacionados con los objetivos trazados y constituyen un mecanismo de rendición de cuentas para con nuestros beneficiarios y colaboradores. 
TAbla 2. Indicadores de Desempeño.

\begin{tabular}{|c|c|c|}
\hline Objetivo General & $\begin{array}{c}\text { Indicador principal } \\
\text { de Gestión }\end{array}$ & Resultado \\
\hline $\begin{array}{l}\text { Realizar un apoyo estra- } \\
\text { tégico en la gestión de los } \\
\text { gobiernos locales de las } \\
\text { comunas más vulnerables, } \\
\text { a través del desarrollo de } \\
\text { la cartera de proyectos mu- } \\
\text { nicipal de equipamiento e } \\
\text { infraestructura. }\end{array}$ & $\begin{array}{l}\mathrm{N}^{\circ} \text { de comunas vulnerables } \\
\text { con convenio Huella Local } \\
\text { vigente por año v/s año an- } \\
\text { terior y metas fijadas. }\end{array}$ & $\begin{array}{l}\mathrm{N}^{\circ} \text { de convenios } \\
\text { firmados entre mu- } \\
\text { nicipios y Funda- } \\
\text { ción Huella Local, } \\
\text { respecto al año } \\
\text { anterior y a metas } \\
\text { fijadas por la fun- } \\
\text { dación al comienzo } \\
\text { de cada año. }\end{array}$ \\
\hline Objetivo Específico & Indicador & Resultado \\
\hline $\begin{array}{l}\text { Mejorar la gestión munici- } \\
\text { pal a través del desarrollo } \\
\text { de la cartera de proyectos } \\
\text { de infraestructura de co- } \\
\text { munas vulnerables }\end{array}$ & $\begin{array}{l}\text { X: N Comunas vulnerables } \\
\text { con convenio Huella Local } \\
\text { con Proyectos en desarrollo. } \\
\text { Y: No Total de Comunas } \\
\text { vulnerables con convenio } \\
\text { Huella Local. } \\
\text { (X/Y)x100/año }\end{array}$ & $\begin{array}{l}\text { Porcentaje de efi- } \\
\text { ciencia de la ges- } \\
\text { tión de Huella Lo- } \\
\text { cal por año. } \\
(X / Y) \times 100 / a n ̃ o\end{array}$ \\
\hline $\begin{array}{l}\text { Desarrollo de proyectos } \\
\text { de equipamiento e infraes- } \\
\text { tructura de comunas vul- } \\
\text { nerables }\end{array}$ & $\begin{array}{l}\mathrm{N}^{\circ} \text { de proyectos postulados } \\
(\mathrm{X}) \mathrm{v} / \mathrm{s} \mathrm{N}^{\circ} \text { de proyectos eje- } \\
\text { cutados (Y).Por comuna y } \\
\text { por región. } \\
(\mathrm{Y} / \mathrm{X}) \mathrm{x} 100 / \mathrm{año}\end{array}$ & $\begin{array}{l}\text { Porcentaje de efi- } \\
\text { cacia de la gestión } \\
\text { de Huella Local en } \\
\text { cada comuna y en } \\
\text { cada región donde } \\
\text { opera. }\end{array}$ \\
\hline $\begin{array}{l}\text { Aumentar la inversión pú- } \\
\text { blica y privada en las co- } \\
\text { munas vulnerables }\end{array}$ & $\begin{array}{l}\text { X: Inversión pública/privada } \\
\text { con presencia de Huella local } \\
\text { Y: Inversión pública/priva- } \\
\text { da sin presencia de Huella } \\
\text { Local } \\
(\mathrm{X}-\mathrm{Y} / \mathrm{Y}) \mathrm{x} 100\end{array}$ & $\begin{array}{l}\text { Tasa de crecimien- } \\
\text { to anual de la in- } \\
\text { versión pública y } \\
\text { privada en MM \$ } \\
\text { por municipio. }\end{array}$ \\
\hline
\end{tabular}

Fuente: Fundación Huella Local.

Es importante destacar que estos indicadores se encuentran en plena concordancia con cada uno de los objetivos y misión de la Fundación Huella Local, cuyos resultados buscan responder a la problemática detectada en los territorios vulnerables objeto de su acción. 


\section{EXPERIENCIAS EXITOSAS}

En la actualidad nuestra presencia territorial abarca de forma efectiva 10 comunas, en cinco regiones. Así también FHL cuenta con convenios con seis Municipios desde la región de Coquimbo hasta la región de Los Lagos. Desarrollando a la fecha un total de 41 iniciativas de inversión por un monto de \$ 4.352.705.696. Nuestra meta al año 2020, es llegar a estar presentes en 60 comunas del país.

A continuación, pasamos a describir algunas de nuestras experiencias exitosas, donde se podrá apreciar claramente nuestra metodología de trabajo.

\section{Región de Coquimbo}

\begin{tabular}{|c|c|}
\hline Nombre del proyecto & $\begin{array}{c}\text { Construcción Sede Social Club Adulto Mayor Nuevo } \\
\text { Amanecer, Chungungo. }\end{array}$ \\
\hline $\begin{array}{l}\text { Público objetivo / } \\
\text { Usuarios }\end{array}$ & Adultos mayores de Chungungo. \\
\hline Objetivos del proyecto & $\begin{array}{l}\text { Aumento del desarrollo local en la comuna. } \\
\text { Mejoramiento de los espacios públicos y comunitarios } \\
\text { en la comuna. } \\
\text { Fortalecimiento de la cohesión social de la comuna. }\end{array}$ \\
\hline $\begin{array}{l}\text { Número de usuarios } \\
\text { directos alcanzados }\end{array}$ & Alrededor de 40 usuarios. \\
\hline Resultados obtenidos & $\begin{array}{l}\text { Fortalecimiento del Club de Adulto Mayor. } \\
\text { Diseño participativo de la sede social. } \\
\text { Mejoramiento de espacios de reunión social. } \\
\text { Apoyo en la gestión municipal. } \\
\begin{array}{l}\text { Aumento de los fondos públicos ingresados al muni- } \\
\text { cipio. }\end{array}\end{array}$ \\
\hline
\end{tabular}




\begin{tabular}{|c|c|}
\hline Actividades realizadas & $\begin{array}{l}\text { Reunión con el equipo municipal para priorizar una } \\
\text { cartera de proyectos rezagados a desarrollar en la co- } \\
\text { muna de La Higuera. } \\
\text { El proyecto priorizado fue la Construcción Sede Social } \\
\text { Club Adulto Mayor Nuevo Amanecer, Chungungo. } \\
\text { Se realizó una primera reunión con el Club del Adulto } \\
\text { Mayor para contarles acerca del proyecto y escuchar } \\
\text { sus opiniones al respecto. En esta oportunidad mani- } \\
\text { festaron su alegría por la renovación de su sede social } \\
\text { y pidieron que se pudiera incorporar a la obra una } \\
\text { cancha de rayuela. } \\
\text { Se generó un diseño de arquitectura final en conjun- } \\
\text { to con el equipo municipal, que recogió las observa- } \\
\text { ciones y opiniones de la comunidad. Este diseño fue } \\
\text { presentado a los socios del club y se les comunicó que } \\
\text { sería postulado a fondos públicos en el mes de Julio } \\
\text { de } 2018 \text {. }\end{array}$ \\
\hline $\begin{array}{l}\text { Fuente Financiamiento } \\
\text { Obras }\end{array}$ & PMU \\
\hline $\begin{array}{l}\text { Lugar geográfico de } \\
\text { ejecución }\end{array}$ & Región de Coquimbo, comuna de La Higuera. \\
\hline
\end{tabular}

\section{Región de Valparaíso}

\begin{tabular}{|l|l|}
\hline \multicolumn{1}{|c|}{ Nombre del proyecto } & \multicolumn{1}{|c|}{$\begin{array}{c}\text { Plan de Relacionamiento Comunitario - Alianza } \\
\text { Chilquinta Energía S.A }\end{array}$} \\
\hline $\begin{array}{l}\text { Público objetivo } \\
\text { / Usuarios }\end{array}$ & $\begin{array}{l}\text { Población de los sectores de Los Morrillos, el Cón- } \\
\text { dor (el Chaparral), conjunto habitacional El Alba } \\
\text { de la comuna de Quillota y San Jorge y San Felipe } \\
\text { de la Comuna de la Cruz. }\end{array}$ \\
\hline Objetivos del proyecto & $\begin{array}{l}\text { Generar una instancia de participación comunita- } \\
\text { ria, a través del diálogo e interacción de los diversos } \\
\text { actores en donde se construirá el Proyecto Línea de } \\
\text { Transmisión Eléctrica Mayacay; con esto diseñar } \\
\text { de manera conjunta un proyecto de infraestructura } \\
\text { comunitaria que contribuya a mejorar las condicio- } \\
\text { nes de vida de la comunidad. }\end{array}$ \\
\hline $\begin{array}{l}\text { Número de usuarios di- } \\
\text { rectos alcanzados }\end{array}$ & Alrededor de 200 personas. \\
\hline
\end{tabular}




\begin{tabular}{|c|c|}
\hline Resultados obtenidos & $\begin{array}{l}\text { Instalación y ejecución de mesas de trabajo con las } \\
\text { comunidades identificadas en los sectores de Los } \\
\text { Morrillos. } \\
\text { La mesa de trabajo tiene tres objetivos: } \\
\text { - Informar a la comunidad de los avances del } \\
\text { proyecto. } \\
\text { - Capacitar a la comunidad en la postulación } \\
\text { a fondos públicos y privados. } \\
\text { - Diseñar de manera participativa un proyecto } \\
\text { de infraestructura comunitaria. } \\
\text { En estos momentos se está llevando a cabo el le- } \\
\text { vantamiento de necesidades con la comunidad de } \\
\text { Los Morrillos para luego realizar la priorización y } \\
\text { seleccionar el proyecto a ser ejecutado. } \\
\text { Con este trabajo se ha logrado empoderar y cohe- } \\
\text { sionar a la comunidad en torno a la construcción } \\
\text { de un proyecto que en un principio era visto como } \\
\text { nocivo. }\end{array}$ \\
\hline Actividades realizadas & $\begin{array}{l}\text { Reuniones de coordinación y definición del plan de } \\
\text { relacionamiento con la empresa Chilquinta Energía } \\
\text { S.A. } \\
\text { Reuniones de acercamiento con las comunidades. } \\
\text { Ejecución de mesas de trabajo participativas con } \\
\text { cada sector identificado. } \\
\text { Realización de talleres de capacitación para la for- } \\
\text { mulación y elaboración de proyectos de infraes- } \\
\text { tructura para los sectores. } \\
\text { Elaboración y puesta en marcha de Sistema de In- } \\
\text { formación Reclamos y Sugerencias (SIRS). }\end{array}$ \\
\hline $\begin{array}{l}\text { Lugar geográfico de eje- } \\
\text { cución }\end{array}$ & $\begin{array}{l}\text { Región de Valparaíso: } \\
\text { Comuna de Quillota: Sectores de Morrillos, el Cón- } \\
\text { dor (el Chaparral), conjunto habitacional El Alba } \\
\text { de la y comuna de la Cruz: sector de San Jorge y } \\
\text { San Felipe. }\end{array}$ \\
\hline
\end{tabular}




\section{Región Metropolitana}

\begin{tabular}{|c|c|}
\hline Nombre del proyecto & $\begin{array}{l}\text { Diseño para el desarrollo de una plaza de juegos en } \\
\text { Lipangue, comuna de Lampa. Convenio SIBELCO }\end{array}$ \\
\hline $\begin{array}{l}\text { Público objetivo / } \\
\text { Usuarios }\end{array}$ & Niños y jóvenes del sector de Lipangue. \\
\hline Objetivos del proyecto & $\begin{array}{l}\text { Diseñar y construir de forma participativa una pla- } \\
\text { za de juegos para los niños y jóvenes de Lipangue. }\end{array}$ \\
\hline $\begin{array}{l}\text { Número de usuarios di- } \\
\text { rectos alcanzados }\end{array}$ & 400 personas. \\
\hline Resultados obtenidos & $\begin{array}{l}\text { Diseño imagen objetivo de la plaza, planos de ar- } \\
\text { quitectura, financiamiento y terreno para la cons- } \\
\text { trucción de la misma. }\end{array}$ \\
\hline Actividades realizadas & $\begin{array}{l}\text { Selección y búsqueda de terreno: Reunión con la } \\
\text { comunidad de Lipangue y municipio de Lampa } \\
\text { para coordinar, la búsqueda de terrenos elegibles } \\
\text { para desarrollar este proyecto. } \\
\text { Análisis de prefactibilidad de terrenos: Una vez } \\
\text { encontrados los terrenos, se procedió a realizar su } \\
\text { análisis de prefactibilidad técnica y legal de los mis- } \\
\text { mos. } \\
\text { En paralelo se trabajó de forma colaborativa, un } \\
\text { diseño que cumpliera con la visión de la comunidad } \\
\text { respecto a la plaza a ejecutar. } \\
\text { Consecución de terreno: Una vez obtenido el terre- } \\
\text { no y su factibilidad legal, se procedió al diseño ar- } \\
\text { quitectónico y cálculo de costos del proyecto. } \\
\text { Obtención de financiamiento a través de fondos } \\
\text { privados. } \\
\text { Actualmente la plaza se encuentra construida y dis- } \\
\text { ponible para el uso de la comunidad. Lo anterior } \\
\text { da cuenta de la alianza virtuosa generada a través } \\
\text { de la construcción participativa de la plaza entre la } \\
\text { comunidad, el municipio, el equipo Huella Local } \\
\text { y trabajadores de la empresa que financia el pro- } \\
\text { yecto. }\end{array}$ \\
\hline $\begin{array}{l}\text { Fuente Financiamiento } \\
\text { Obras }\end{array}$ & Privado: Empresa SIBELCO. \\
\hline $\begin{array}{l}\text { Lugar geográfico } \\
\text { de ejecución }\end{array}$ & $\begin{array}{l}\text { Sector Lipangue, comuna de Lampa, región Metro- } \\
\text { politana. }\end{array}$ \\
\hline
\end{tabular}




\section{Región del Biobío}

\begin{tabular}{|l|l|}
\hline Nombre del proyecto & \multicolumn{1}{|c|}{$\begin{array}{c}\text { Desarrollo de Infraestructura Pública-Comunitaria- } \\
\text { Alianza Colbún S.A. }\end{array}$} \\
\hline $\begin{array}{l}\text { Público Objetivo / } \\
\text { Usuarios }\end{array}$ & $\begin{array}{l}\text { Habitantes en situación de pobreza de las comunas de } \\
\text { Santa Bárbara y Quilaco. }\end{array}$ \\
\hline $\begin{array}{l}\text { Objetivos del } \\
\text { proyecto }\end{array}$ & $\begin{array}{l}\text { Aumentar la inversión pública, focalizando los esfuer- } \\
\text { zos en la población vulnerable localizada en las comu- } \\
\text { nas de Santa Bárbara y Quilaco. }\end{array}$ \\
\hline $\begin{array}{l}\text { Número de usuarios } \\
\text { directos alcanzados }\end{array}$ & $\begin{array}{l}\text { En esta cartera de proyectos se espera que cerca de } \\
\text { e indirecta. }\end{array}$ \\
\hline Resultados obtenidos & $\begin{array}{l}\text { Reposición de aceras de calles Las Heras y Carrera. } \\
\text { Construcción de sede vecinal sector Los Junquillos. } \\
\text { Construcción graderías Liceo Cardenal Antonio Samoré. } \\
\text { Construcción camarín Los Boldos. } \\
\text { Construcción pozo con estanque sector Los Lirios. } \\
\text { Construcción habilitación sala de espera CECOSF. } \\
\text { Construcción patio cubierto escuela Mañil. } \\
\text { Construcción sede vecinal La Peña. } \\
\text { Construcción circuito Calistenia. }\end{array}$ \\
\hline
\end{tabular}




\begin{tabular}{|l|l|}
\hline Priorización de proyectos y definición de carteras: En \\
esta etapa se analizó en conjunto con el municipio y los \\
profesionales del equipo territorial la cartera de proyec- \\
tos de inversión en los distintos ámbitos de financia- \\
miento público para determinar la factibilidad técnico- \\
económica de cada uno, así como sus posibles plazos, \\
con la intención de priorizar su desarrollo. \\
Desarrollo y seguimiento de cartera priorizada: Esta \\
etapa dice relación con la elaboración de la cartera di- \\
vidida en tres fases: \\
Actividades \\
realizadas
\end{tabular}


Fotografía i. Construcción Sede Vecinal Los Junquillos.

Comuna Santa Bárbara.

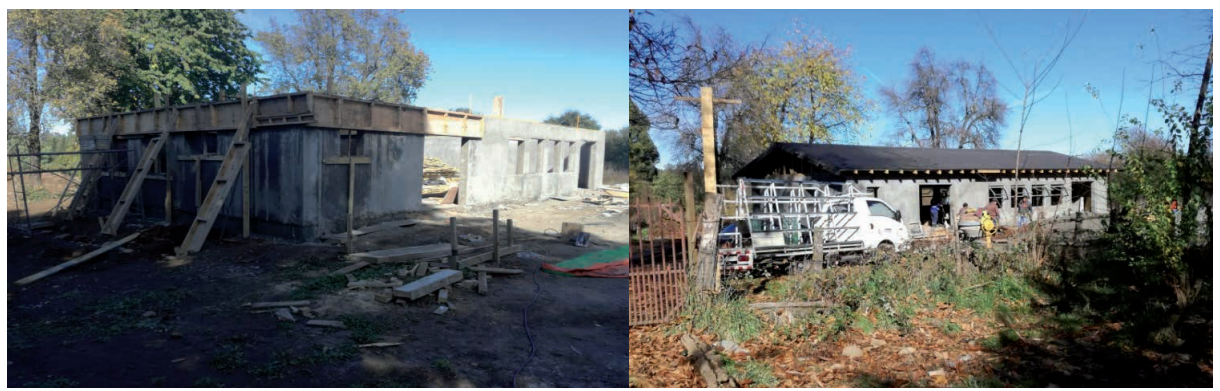

Fotografía 2. Pavimentación de aceras. Quilaco

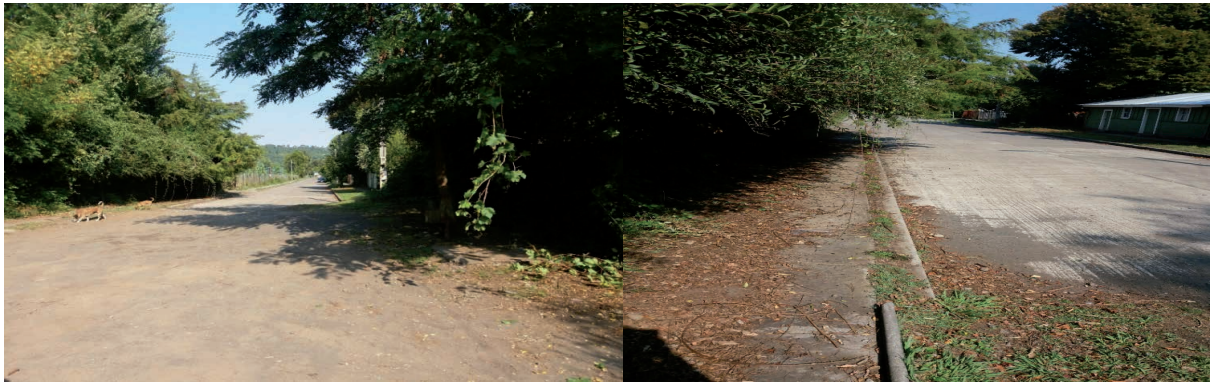

Fotografía 3. Plaza Lipangue. Lampa

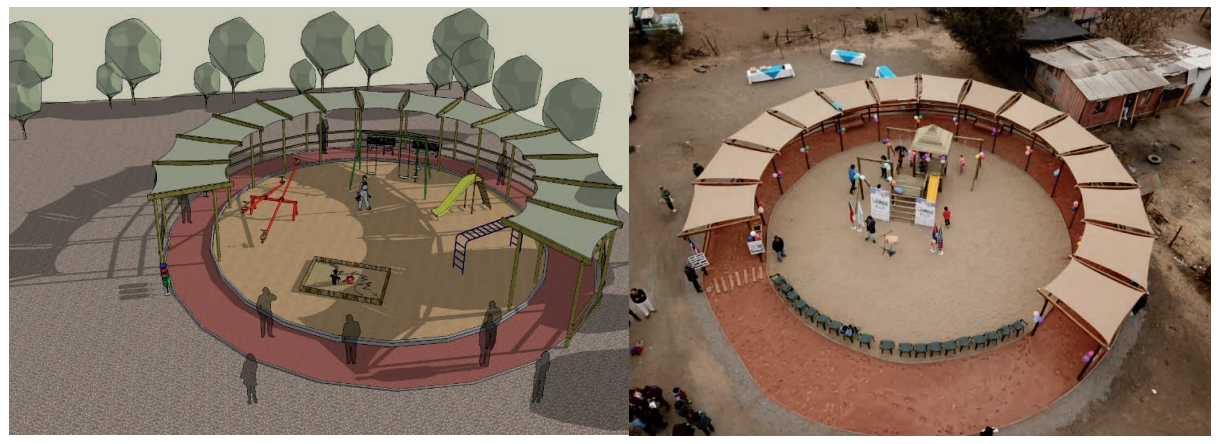




\section{Conclusiones}

A modo de conclusión podemos decir que el modelo propuesto por la fundación permite generar impactos en los ámbitos deseados:

a) A través de una nueva gobernanza en los territorios comunales donde comparecen empresa, comunidad y municipios, y con el apoyo técnico y social experto en temas de inversión y relacionamiento comunitario se logra aumentar la capacidad de los gobiernos locales para atender las necesidades de la comunidad.

b) Con lo anterior, aumenta la inversión pública en los territorios logrando el apalancamiento de fondos estatales. Con ello, se multiplica el impacto del esfuerzo privado en acciones RSE en términos económicos y en el universo de beneficiarios.

c) El desarrollo de estrategias consensuadas para el desarrollo de proyectos, la experiencia de los equipos técnicos y el constante perfeccionamiento de los equipos que se ponen a disposición comienzan a potenciar las capacidades de los actores locales; con ello se pretende dejar capacidad instalada en los territorios. La FHL trabaja hoy en convenios con universidades y centros de pensamiento para incorporar el entrenamiento y capacitaciones en los programas de relacionamiento que se proponen a las empresas.

Con todo, se espera ir testeando el modelo de gobernanza que aquí se propone de modo de perfeccionar y ampliar su impacto en los años venideros, y con ello poder debatir con argumentos sólidos sobre la necesidad de una reforma que permita a los municipios pasar de la administración al gobierno local, capaz de generar políticas públicas locales para atender las necesidades de la diversidad territorial de Chile. 


\section{Bibliografía}

Acuña, E., (2009). Propuestas de mejora al diseño y gestión del Fondo Nacional de Desarrollo Regional. Memoria para optar al título de ingeniero civil industrial. Universidad de Chile.

Alarcón, P. (Noviembre 3, 2015). La desigual distribución de recursos municipales. Julio 17, 2018. Instituto de Ciencias Alejandro Lipschutz. Sitio web: https://www.ical.cl/2015/11/la-desigual-distribucion-derecursos-muniipales/

Asociación de Municipalidades de Chile (2016). Informe Nacional de Capital Humano Municipal. Funcionarios, profesionalización y capacitación en los municipios de Chile (pp.4).

Avendaño, C., (2009). Estudio exploratorio de los elementos que afectan la formulación de proyectos a nivel municipal. Memoria para optar al título de ingeniero civil industrial. Universidad de Chile.

Centro de Políticas Públicas UC. (2016). Asociatividad Municipal: herramienta para la inversión local. Estudio en el marco de la Incubadora de Gestión Municipal UC-BCI (pp.21).

Centro de Políticas Públicas UC. (2016). Empresa y Territorio: Reflexiones en torno a la construcción de una mirada común sobre el territorio. UC-Consejo Minero-Acción Empresas. (pp. 10, 12, 116).

Centro de Políticas Públicas UC. (2016). Encuesta Nacional de Percepciones Ciudadanas sobre Municipios. Santiago de Chile, 2016.

Contreras, E., Barros, A., González, N. \&Fuenzalida, J., (2011). Gestión del Conocimiento y Transparencia: Desafíos para la Inversión Pública a Nivel Local, en Revista Trend Management, 13(4), Mayo 2011, pp. 44-52.

Fuentes, C. 2018). Participación ciudadana: la eterna desconfianza. Julio 17, 2018, de CIPER Chile Sitio web: https://ciperchile.cl/2018/06/14/ participacion-ciudadana-la-eterna-desconfianzal 


\section{SOBRE LOS EDITORES:}

José Hernández Bonivento

Director del Instituto Chileno de Estudios Municipales (ICHEM) de la Universidad Autónoma de Chile. Cientista político y licenciado en Literatura, Universidad de Los Andes, Bogotá (Colombia). Máster en Estudios Latinoamericanos con énfasis en Economía. Instituto de Iberoamérica, Universidad de Salamanca y doctor en Ciencias Políticas y de la Administración, Universidad Complutense de Madrid (España).

\section{Margarita Fuentes Romero}

Coordinadora de proyectos del Instituto Chileno de Estudios Municipales (ICHEM). Magíster en Ciencia Política, mención Políticas Públicas, P. Universidad Católica de Chile. Trabajadora Social, Universidad Alberto Hurtado (UAH). Diplomada en Desarrollo, Pobreza y Territorio, UAH.

\section{Mila Ríos Lemus}

Estudió Ciencias Políticas y Administrativas en la Universidad de Concepción, con título de administrador público. Magíster en Gerencia y Políticas Públicas de la Universidad Adolfo Ibáñez, actualmente doctorando en Ciencia Política Universidad Católica. Diplomado en: Evaluación de Políticas Públicas, Universidad de Chile; Gestión de Innovación, Universidad Alberto Hurtado; Gerencia Pública, Universidad de Chile. Se ha desempeñado como profesional asesora en diversas instituciones públicas, entre ellas SUBDERE y Ministerio de Desarrollo Social. 



\section{SOBRE LOS AUTORES}

Manuel Barros

Periodista y sociólogo. Actualmente trabaja como coordinador de proyectos en Fundación Ciudadano Inteligente, liderando iniciativas relacionadas con gobierno abierto, transparencia y participación ciudadana.

\section{Juan Francisco Carmona Flores}

Sociólogo. Es secretario municipal de Coyhaique y se ha especializado en Participación Ciudadana colaborando con las organizaciones intermedias y promoviendo la asociatividad entre municipalidades. Es magister en Gobierno y Gerencia Pública, obteniendo además diplomados en el área de la Ciencia Política.

\section{Valeria Angélica Constanzo Salazar}

Diseñadora licenciada en Diseño de la Universidad Católica de Temuco, diplomada en Diseño y Gestión de Paisaje Sustentable, Diplomada en Participación Ciudadana y Gobernanza. Actualmente se desempeña como Profesional Coordinador de programas Proyectos Participativos, Congreso de Niños y Lidera Joven del Departamento Comunitario y Vecinal de la Dirección de Desarrollo Comunitario de la Municipalidad de Temuco.

\section{Juan Fernández Labbé}

Doctor en Sociología y máster en Metodología de la Investigación en Ciencias Sociales por la Universidad Complutense de Madrid; egresado de magíster en Urbanismo de la Universidad de Chile y sociólogo por la Pontificia Universidad Católica de Chile. Investigador en RIMISP-Centro Latinoamericano para el Desarrollo Rural; consultor para Organismos de Naciones Unidas (FAO, FIDA, UN/DESA) y 
ONGs (OXFAM), y docente en la Universidad Diego Portales y en la Universidad Alberto Hurtado. Correo: jfernandez@rimisp.org

\section{Diego González Labarca}

Jefe (s) del Programa Municipal del Consejo para la Transparencia, sociólogo y magíster en Sociología de la Universidad Alberto Hurtado.

\section{Eduardo González Yáñez}

Consultor en Transparencia y Acceso a la Información, Gobierno Abierto y Transformación Digital, y exdirector de Desarrollos y Procesos del Consejo para la Transparencia. Ingeniero civil industrial de la Universidad de Santiago de Chile y Magíster en Gestión Pública en la Fundació Bosch i Gimpera de la Universidad de Barcelona, Diplomado en Gobiernos Corporativos y Dirección de Empresas de la Universidad de Chile.

\section{Francisca Gutiérrez Vielma}

Analista de Inteligencia de Negocio de la Dirección de Estudios del Consejo para la Transparencia, socióloga de la Universidad de Concepción, magíster en Trabajo Social y Políticas Sociales de la Universidad de Concepción.

\section{Hugo Inostroza Ramírez}

Alcalde comuna de Nacimiento. Ingeniero (E) en Administración de Empresas (Universidad del Bio- Bío). Diplomado en Alta Gerencia Pública. Funcionario municipal hace más de 22 años, concejal de la comuna de Nacimiento por dos períodos, actualmente, en su segundo período de alcalde.

\section{Egon Montecinos Montecinos}

Académico de la Universidad Austral de Chile. Trabajador Social, magíster en Ciencias Sociales, doctor en Investigación en 
Ciencias Sociales mención Ciencia Política. Director del Centro de Estudios Regionales de la Universidad Austral de Chile.

\section{Daniela Moreno Tacchi}

Directora de Fiscalización (s) del Consejo para la Transparencia, cientista político y magíster en Ciencia Política con mención en Instituciones y Procesos Políticos de la Pontificia Universidad Católica de Chile; diplomada en Comunicación Pública de la Universidad Alberto Hurtado y en Comunicación Empresarial, de la Universidad Diego Portales.

\section{Mariela Muñoz Erices}

Encargada Depto. Organizaciones Comunitarias. I. Municipalidad de Nacimiento. Magíster en Política y Gobierno UDEC, Trabajadora Social UDEC, diplomada en Gestión de Políticas Sociales UDEC.

\section{Bernardo Navarrete Yánez}

Profesor asociado en la Universidad de Santiago de Chile. Ha sido Visiting Scholar in Political Science en el Center For Latin American Studies de la Universidad de Stanford. Es doctor en Gobierno y Administración Pública por el Instituto Universitario de Investigación Ortega y Gasset-Universidad Complutense y tiene un magíster en Ciencia Política por el Instituto de Ciencia Política de la Pontificia Universidad Católica de Chile.

\section{Javier Órdenes Rodríguez}

Secretario Comunal de Planificación (SECPLAN), I. Municipalidad de Nacimiento. Ingeniero (E) en Administración de Empresas (Universidad del Bio- Bío). Diplomado en Gestión Municipal para el Desarrollo Humano Territorial (UFRO). d iplomado de Especialización en Desarrollo Local en Gestión Integral del Riesgo (UDEC). veintitres años de experiencia en la función municipal. 


\section{Daniel Pefaur Dendal}

Director de Estudios (s) del Consejo para la Transparencia, sociólogo de la Universidad de Arte y Ciencias Sociales ARCIS y magíster en Gobierno y Sociedad de la Universidad Alberto Hurtado.

\section{Alejandra Placencia Cabello}

Profesora de Estado en Filosofía USACH. magíster (c) Currículum y Evaluación USACH. Ha realizado diversos diplomados para la innovación en aula y el trabajo de temáticas como educación sexual, apreciación cinematográfica, orientación vocacional, entre otras. Actualmente encabeza las labores de apoyo para la evaluación del Programa Escuela Abierta de la Comuna de Recoleta. Madre de Aynara Matilde.

\section{Rodrigo Tomás Pinto Manosalva}

Trabajador Social Universidad Santo Tomás, diplomado en Participación Ciudadana y Gobernanza Universidad Autónoma de Chile, actualmente se desempeña como coordinador del Programa de desarrollo local de la Municipalidad de Temuco.

\section{Gianinna Repetti Lara}

Arquitecta USACH. Magister (c) en Políticas Sociales y Gestión Local ARCIS. Entre otros cursos y capacitaciones, es diplomada en Descentralización y Desarrollo Regional de la Universidad Alberto Hurtado. Trabajó en la Dirección de Obras Municipales de Estación Central como Jefa del Departamento de Ejecución de Obras. Directora SECPLA en la Municipalidad de Recoleta y actualmente Administradora Municipal del mismo municipio. Madre de Haydeé y Simón.

\section{Luis Marcelo Rojas Belmar}

Trabajador Social Universidad de La Frontera, magíster en Investigación Gestión y Desarrollo Local, Universidad Complutense de Madrid. Actualmente se desempeña como profesional asesor de 
la Unidad de Participación Ciudadana y Transparencia Municipal de la División de Municipalidades SUBDERE.

\section{Rodrigo Soto Cuevas}

Geógrafo, (C) magíster en Políticas Públicas. Jefe de Desarrollo Huella Local.

\section{Francis Valverde}

Magíster en Ciencias Sociales con mención en Sociología de la Modernidad, Universidad de Chile. Título en Pedagogía en Ciencias Naturales y Biología, Pontificia Universidad Católica de Chile. Tiene una experiencia de más de 43 años en derechos humanos y trabaja en la sociedad civil, con particular énfasis en los derechos de niñas, niños y jóvenes. Actualmente vocera del Bloque por la Infancia, secretaria de la Liga Iberoamericana de Organizaciones de la sociedad civil y directora ejecutiva de la Asociación Chilena Pro Naciones Unidas.

Gonzalo Vial Luarte

Geógrafo, magíster en Política y Gobierno. Director ejecutivo Huella Local. 


Este libro se terminó de imprimir en Santiago de Chile,

mayo de 2019

Teléfono: 222238100 / ril@ rileditores.com

Se utilizó tecnología de última generación que reduce el impacto medioambiental, pues ocupa estrictamente el papel necesario para su producción, y se aplicaron altos estándares para la gestión y reciclaje de desechos en toda la cadena de producción. 


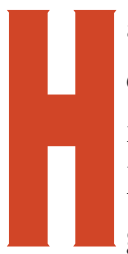
an pasado décadas desde que la idea de un gobierno más centrado en la ciudadanía tomara vuelo en la región, transformando instituciones y generando marcos legales. Esto ha afectado también el nivel local y, aunque ha habido grandes avances, el proceso no ha estado libre de problemas: las expectativas creadas han sido muy altas -generando no poca frustración en las personas- y hay un excesivo formalismo y poca incidencia de los participantes en la toma de decisiones.

El caso chileno nos es explicativo tanto del ascenso de la idea participativa como de la frustración originada por las falsas expectativas. Un reflejo de esto es la creación de la Ley 20.500, de Asociaciones y Participación Ciudadana en la Gestión Pública, que sin haber cumplido una década de existencia, ya está expuesta a discusiones para ser cambiada y mejorada.

Con el ánimo de aportar en esta discusión, cada vez más importante para Chile en un contexto de desafección política e institucional, se presenta en este libro los resultados de un arduo trabajo colectivo entre académicos, funcionarios públicos y actores de la sociedad civil, que busca analizar y dar cuenta tanto de vacíos como de avances en materia de participación ciudadana en la gestión pública local.

Todos estos capítulos buscan plantear puntos de vista que parten de la experiencia real, y que intentan dejar de lado tanto las altas expectativas como el excesivo optimismo que rodea la participación ciudadana, para centrarse en los avances y desafíos tanto del marco institucional como de la implementación de estrategias de involucramiento ciudadano.

\section{$\square$ \\ RiL editores}

